Carine Cavalcante Chamon

\title{
Revisão taxonômica e relações filogenéticas do grupo Acanthicus (Siluriformes, Loricariidae)
}

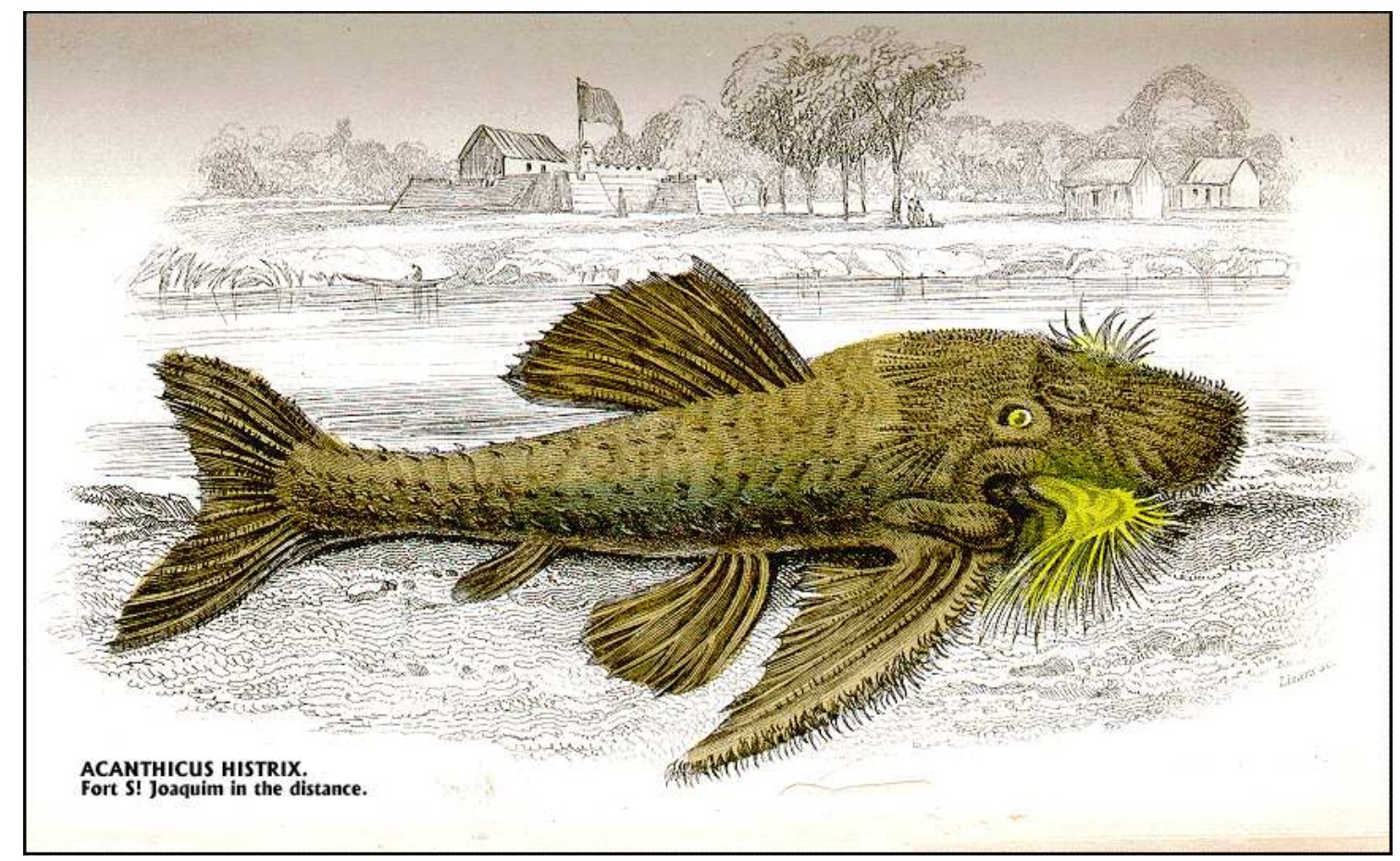

Tese de doutorado

São Paulo

2011 


\section{Carine Cavalcante Chamon}

Revisão taxonômica e relações filogenéticas do grupo Acanthicus (Siluriformes, Loricariidae)

Tese apresentada ao Instituto de Biociências da Universidade de São Paulo, para a obtenção do grau de Doutora em Ciências, na Área de Zoologia.

Orientador: Mário César Cardoso de Pinna

São Paulo

2011 
Chamon, Carine Cavalcante

Revisão taxonômica e relações filogenéticas do grupo Acanthicus (Siluriformes, Loricariidae)

Tese (Doutorado)-Instituto de Biociências da Universidade de São Paulo. Departamento de Zoologia.

1.Loricariidae 2.Ancistrini 3.Taxonomia 4.Sistemática

Comissão Julgadora:

Prof(a). Dr (a).

Prof(a). Dr (a).

Prof(a). Dr (a).

Prof(a). Dr (a).

Prof. Dr. Mário César Cardoso de Pinna

(Orientador) 


\begin{abstract}
AVISO
A presente tese é parte dos requisitos necessários para a obtenção do título de Doutor na área de Zoologia, e como tal, não deve ser vista como uma publicação no senso do Código Internacional de Nomenclatura Zoológica (apesar de disponível publicamente sem restrições). Dessa forma, quaisquer hipóteses, assim como novos nomes, não estão disponíveis na literatura zoológica. Pessoas interessadas devem estar cientes de que referências públicas ao conteúdo deste estudo, na sua presente forma, devem somente ser feitas com aprovação prévia do autor.
\end{abstract}

\title{
NOTICE
}

This thesis is a partial requirement for the PH.D. degree in Zoology and, as such, should not be considered as a publication in the sense of the International Code of Zoological Nomenclature (although it is available without restrictions). Therefore, any new information, opinions and hypothesis, as well as new names, are not available in the zoological literature. Interested people are advised that any public references to this study, in its current form, should only be done after previous acceptance of the author. 
"Nenhum problema tem solução. Nenhum de nós desata o nó górdio; todos nós ou desistimos ou o cortamos. Resolvemos bruscamente, com o sentimento, os problemas da inteligência, e fazemo-lo ou por cansaço de pensar, ou por timidez de tirar conclusões, ou pela necessidade absurda de encontrar um apoio, ou pelo impulso gregário de regressar aos outros e à vida.

Como nunca podemos conhecer todos os elementos de uma questão, nunca a podemos resolver. Para atingir a verdade faltam-nos dados que bastem, e processos intelectuais que esgotem a interpretação desses dados."

Fernando Pessoa, 1888-1935

Livro do Desassossego: composto por Bernardo Soares, ajudante de guarda-livros na cidade de Lisboa Organização: Richard Zenith

Companhia das Letras, 2006 
O caminho percorrido para a realização deste trabalho foi, muitas vezes, solitário. Porém, não poderia ter finalizado esta etapa sem o apoio de diversas pessoas ao longo desses quatro anos. Se por ventura alguém for esquecido, desconsidere, pois minha memória não tem ajudado muito ultimamente.

Primeiramente, gostaria de agradecer ao meu orientador, Mário César Cardoso de Pinna, pelo incentivo e pela orientação, sempre descontraída e com bom humor (mesmo rosnando). Pelos diversos bate-papos e discussões, alguns destes bastante importantes para o meu amadurecimento profissional e pessoal. Durante todo o tempo de nossa convivência, Mário mostrou sempre ser um exemplo de integridade, simplicidade e genialidade.

Agradeço ao Conselho Nacional de Desenvolvimento à Pesquisa $(\mathrm{CNPq})$, pelos primeiros seis meses de bolsa (processo 142697/2007-9) e à Fundação de Amparo à Pesquisa do Estado de São Paulo (FAPESP) pela bolsa concedida desde Maio de 2008 até Outubro de 2011 (processo 2007/07770-5).

Aos professores da Seção de Peixes do MZUSP, Heraldo A. Britski, Naercio A. Menezes e José Lima Figueiredo, que sempre cultivaram um ambiente de trabalho saudável e cooperativo, onde a harmonia sempre predominou. Ao Osvaldo T. Oyakawa, agradeço pelo apoio durante a realização deste e de outros trabalhos; pela amizade, pelos diversos bate-papos e esclarecimentos taxonômicos ou de outra natureza.

Aos meus colegas e amigos da Seção de Peixes, aos que ainda estão e aos que por lá passaram: Alberto Akama, André Netto-Ferreira (Tinho), Angela Zanata (Serr), Cristiano Moreira (Cris), Eduardo Baena (Duzão), Fábio Di Dario, Flávio Lima, Henrique Varella (Cabelinho), Ilana Fichberg, Isabel Landin, Janice Muriel-Cunha, José Luis Birindelli (Zé), Leandro Sousa (Gabiru), Manoela Marinho, Marina Loeb, Michel Gianeti (Miguelito) Pedro Carvalho (Pedrinho), Rodrigo Caires, Túlio Teixeira e Vera; agradeço pela convivência agradável, pelas discussões (algumas sérias outras nem tanto e outras nem um pouco), pelas brincadeiras e pela ajuda em várias etapas deste trabalho.

Agradeço ainda ao Duzão, pelas excelentes fotografias que compõem a maioria das ilustrações desta tese e pela paciência em me ajudar com a desvendar (ao menos um pouquinho) os mistérios do Photoshop. O cara é o "solution provider" da seção! Ao André, sou grata pela grande ajuda em "quase todos" (segundo ele) os programas de filogenia, edição, mapas e etc. Agradeço ainda ao André e também ao Zé pelas idéias e sugestões 
valiosas que contribuíram muito para a finalização deste trabalho. Ao Cris agradeço pela ajuda com o Bremer (mais uma vez!).

Agradeço a todos os funcionários do MZUSP, em especial a Dione e a Marta da biblioteca, que sempre solícitas e super eficientes nas minhas buscas por referências. À Marta da administração sempre muito prestativa para resolver os problemas burocráticos. À Dona Estela que era a responsável pelo importantíssimo cafezinho depois do almoço, sempre oferecido com carinho. Aos guardiões da portaria do MZ: Luis, Paulo, Claudio, Wanderlei, Elizeu e os mais novos agregados, pelo bom humor e solicitude. Aos responsáveis pela limpeza do nosso ambiente de trabalho, visto que é muito difícil manter limpo um porão!

Pelo empréstimo de material e/ou pela hospitalidade em me receber nas diversas instituições que eu visitei durante o projeto: Paulo A. Buckup e Marcelo Britto (MNRJ); Lúcia Rapp Py-Daniel e Jansen Zuanon (INPA); Roberto Reis (MCP); Wolmar Wosiak (MPEG); Jonathan Armbruster e Shobnom Ferdous (AUM); Mark Sabaj e John Lundberg (ANSP); Scott Schaefer e Mary Anne Rogers (AMNH); Sonia Fisch-Müller (MHNG); Helmut Wellendorf (NMW); Peter Bartsch (ZMB); Patrick Campbell (BMNH); Ronald de Ruiter (RMNH); Hielk Praagman (ZMA) e Roman Causse (MNHN).

Aos meus amigos queridos (alguns de longa data, outros recentemente agregados) agradeço pelo carinho, pelas conversas e discussões, por me aturarem de mau humor, pelo apoio nos momentos difíceis, pela companhia num bar... Enfim, por vocês fazerem parte da minha vida! De alguns eu já sinto muita saudades e de outros vou sentir...

À minha mãe, Maria A. C. Chamon (mais que querida) e ao meu pai, José Chamon (sempre em memória) pela imensa parcela de responsabilidade na formação do meu caráter, da minha personalidade, enfim, do que eu sou. Pelo amor incondicional a mim dedicado, sempre vou agradecer. Aos meus irmãos queridos, Catia e Alexandre, que apesar de nossas diferenças de personalidade, sempre foram muito amigos e companheiros, tornando nossa convivência em família harmoniosa. Aos meus sobrinhos prediletos (hehehe), Thiago e Rafael, pelo carinho, pela diversão, pelos sorrisos. Amo muito vocês!

Ao Fabio agradeço pelo carinho, pela paciência nas horas difíceis (não foram poucas), pelo otimismo em pensar que a vida é bela e que as pessoas são boas, pelos momentos divertidos, por compartilhar os mesmos propósitos, por olhar na mesma direção, por tornar meu mundo mais colorido, por me fazer ainda mais feliz. Enfim, simplesmente por existir na minha vida. Te amo, te quero perto. 


\section{Resumo}

O grupo Acanthicus (Siluriformes, Loricariidae) é composto por quatro gêneros: Acanthicus, Megalancistrus, Leporacanthicus e Pseudacanthicus. O monofiletismo do grupo composto por estes géneros foi previamente suportado por dados morfológicos e moleculares. Com o intuito de elucidar as relações filogenéticas entre as espécies do grupo Acanthicus foram analisados 21 representantes do grupo interno e mais 12 táxons de Ancistrini como grupos externos, com base em 121 caracteres fenotípicos de diferentes complexos anatômicos. A análise de parcimônia resultou em duas árvores igualmente parcimoniosas com 453 passos $(\mathrm{CI}=0,32 \mathrm{RI}=0,66)$. O monofiletismo do grupo Acanthicus foi corroborado com base em 11 sinapomorfias, três destas exclusivas: crista do hiomandibular contínua a do quadrado; extremidade distal dos dentes do pré-maxilar acentuadamente curvada e quilhas na lateral do corpo bastante desenvolvidas. As relações entre os táxons do grupo Acanthicus mais Spectracanthicus resultaram na seguinte topologia: ((Spectracanthicus) (Megalancistrus, Acanthicus) (Leporacanthicus, Pseudacanthicus))). A nomenclatura genérica do grupo foi reformulada seguindo a hipótese filogenética e a revisão taxonômica resultou no reconhecimento de 18 espécies válidas no grupo Acanthicus, nove destas novas. No gênero Pseudacanthicus, P. fordii foi considerado sinônimo de $P$. serratus e $P$. histrix sinônimo de $P$. spinosus; ademais seis novas espécies foram descritas para as bacias dos rios Aripuanã, Tocantins, Tapajós, Curuá-Una e Xingu. Oligancistrus foi considerado sinônimo de Spectracanthicus e foram descritas três novas espécies das bacias dos rios Tapajós, Tocantins e Xingu. 


\section{Abstract}

The Acanthicus group (Siluriformes, Loricariidae) is currently composed of four genera: Acanthicus, Megalancistrus, Leporacanthicus e Pseudacanthicus. The monophyly of the group has been previously supported by both morphological and molecular data. To investigate the relationships among the Acanthicus group species, 21 taxa of the ingroup and 12 taxa of other Ancistrini as out-groups were studied on the basis of 121 phenotipic characters of different anatomical complexes. Parsimony analysis resulted in two most parsimonious trees with 453 steps $(\mathrm{CI}=0,32 \mathrm{RI}=0,66)$. Monophyly of the Acanthicus group was corroborated by 11 synapomorphies, three of which exclusive: hiomandibular ridge contiguous with ridge of the quadrate, distal edge of premaxillary teeth strongly curved with well-developed keels. Relationships of the Acanthicus group plus Spectracanthicus resulted in the following topology: (Spectracanthicus ((Megalancistrus, Acanthicus) (Leporacanthicus, Pseudacanthicus))). Genus-level nomenclature of the group was reformed on the basis of the phylogenetic hypothesis and of a taxonomic revision which resulted in the recognition of 18 valid species in the Acanthicus group, nine of which new. In the genus Pseudacanthicus, P. fordii was recognized as a junior synonym of $P$. serratus and $P$. histrix of $P$. spinosus, with six new species from the Aripuanã, Tocantins, Tapajós, Curuá-Una and Xingu Rivers Basins. Oligancistrus was recognized as a junior synonym of Spectracanthicus and three new species were described in the latter, from the Tapajós, Tocantins and Xingu River Basins. 


\section{Sumário}

1. Introdução

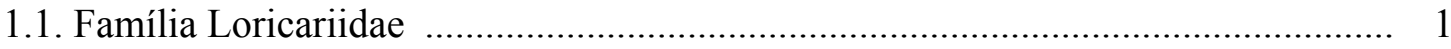

1.2. Subfamília Hypostominae .............................................................................. 2

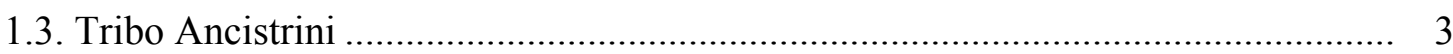

1.4. Histórico taxonômico e distribuição geográfica do grupo Acanthicus .................... 4

1.5. Histórico filogenético do grupo Acanthicus ....................................................... 6

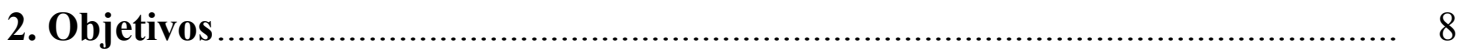

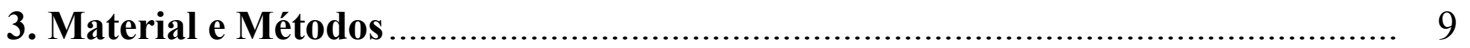

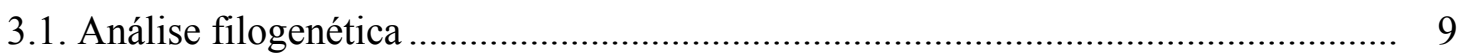

3.2. Lista do material da análise filogenética ...................................................... $\quad 10$

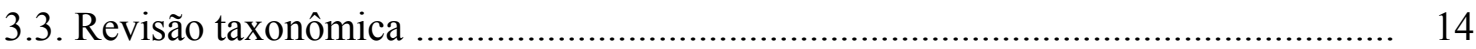

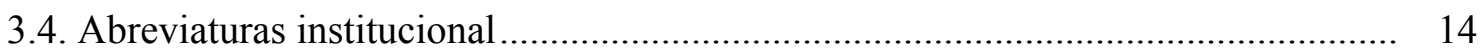

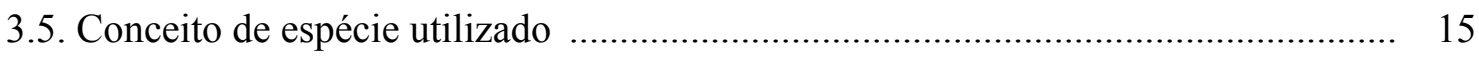

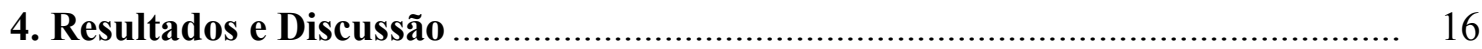

4.1. Análise filogenética ...................................................................................... 16

4.2. Descrição dos caracteres.............................................................................. 16

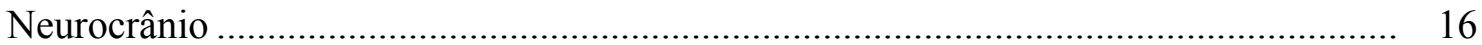

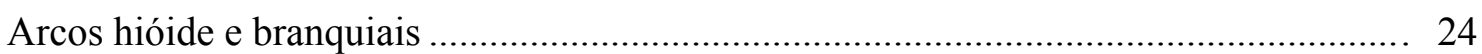

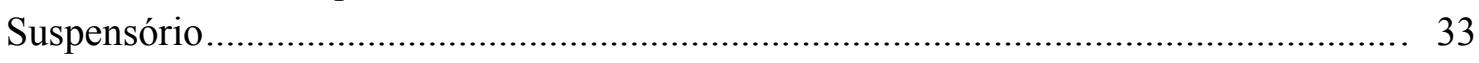

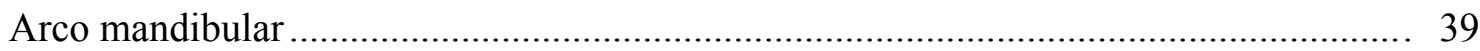

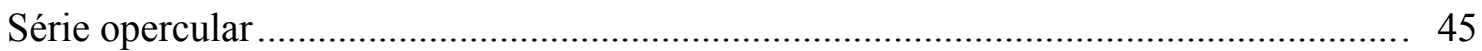

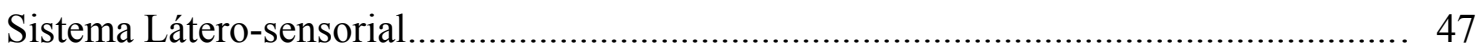

Aparelho de Weber e esqueleto axial ......................................................................... 49

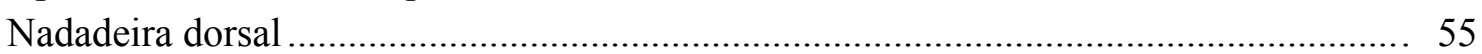

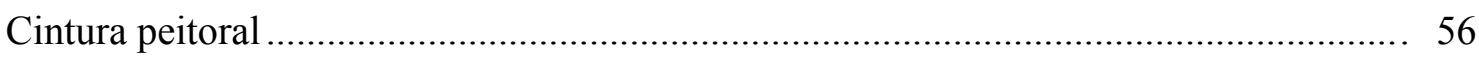

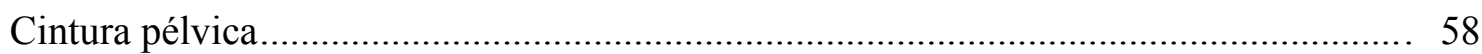

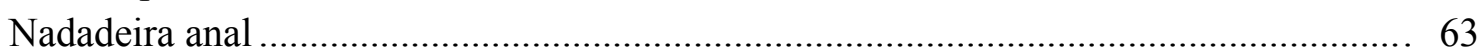

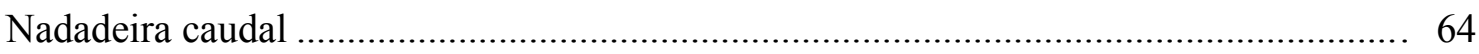

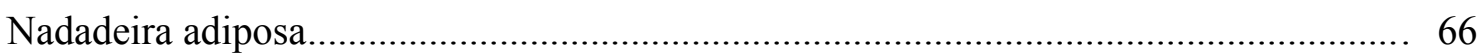

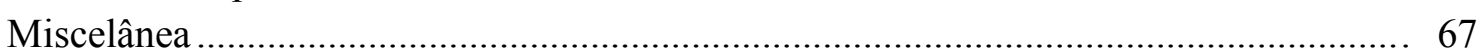

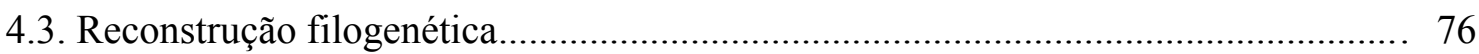

4.3.1. O monofiletismo do grupo Acanthicus ............................................................... 76

4.3.2. Relações entre os táxons do grupo Acanthicus...................................................... 77

4.3.3. Relações entre o grupo Acanthicus e Spectracanthicus ...................................... 82

4.3.4. Relações intra-especícifas de Spectracanthicus .................................................... 82

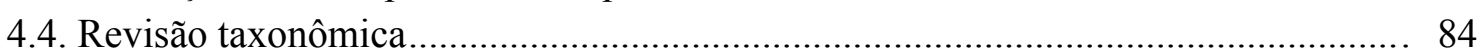

Chave para os gêneros do grupo Acanthicus ............................................................ 84

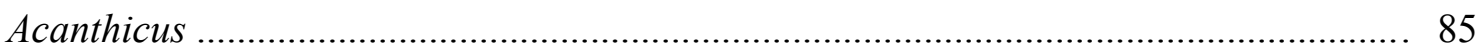

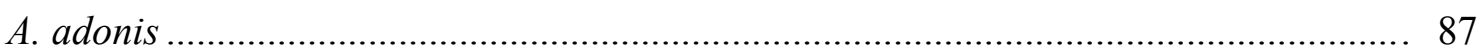

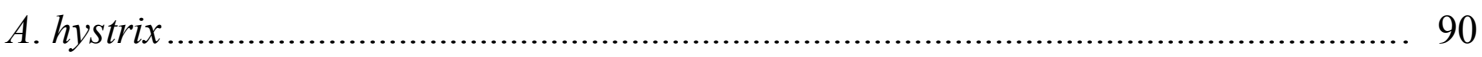

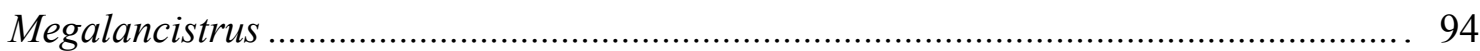

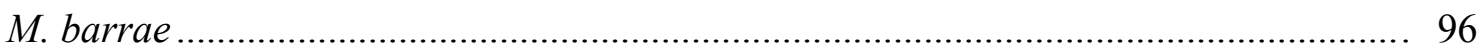




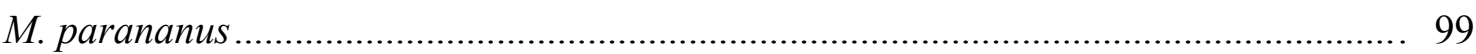

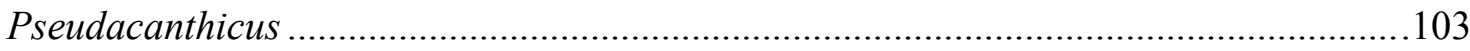

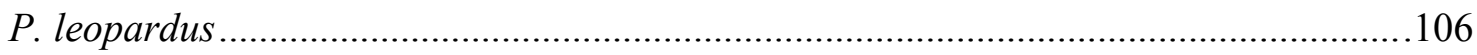

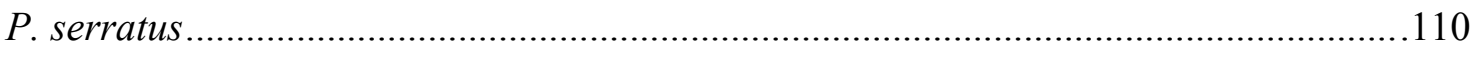

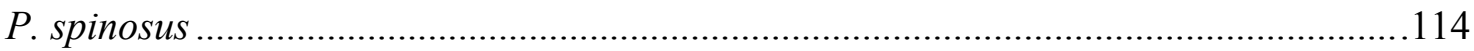

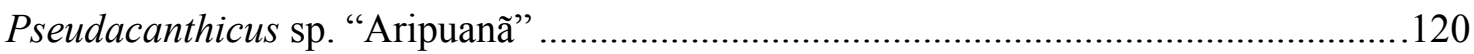

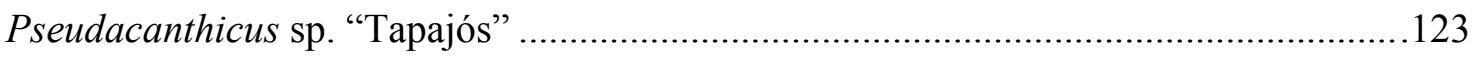

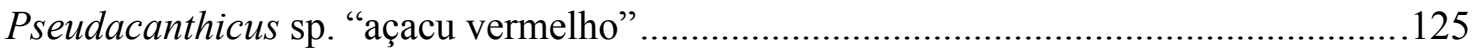

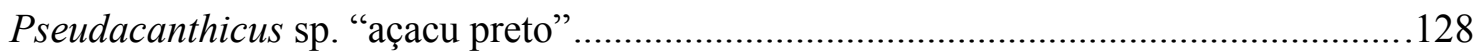

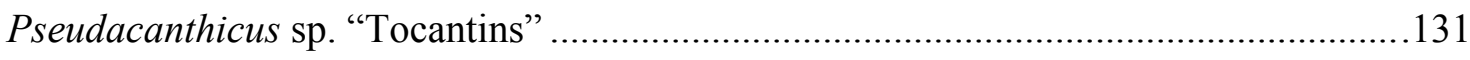

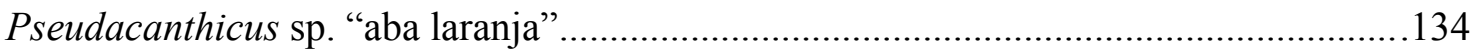

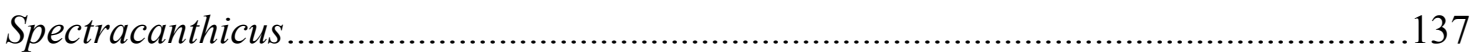

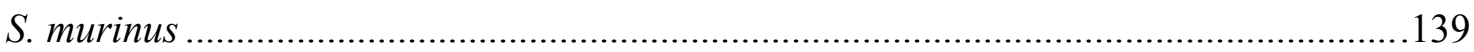

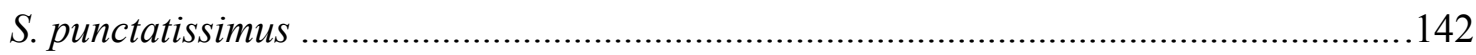

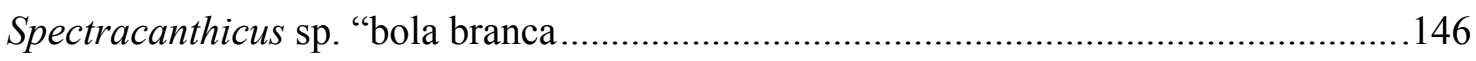

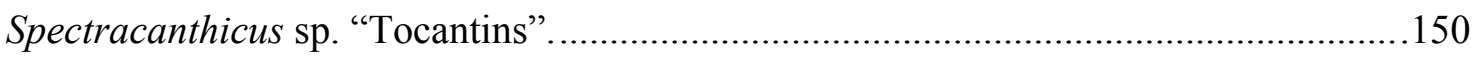

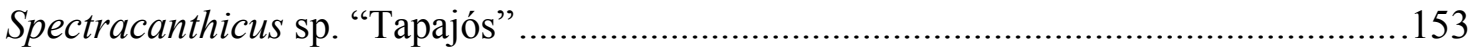

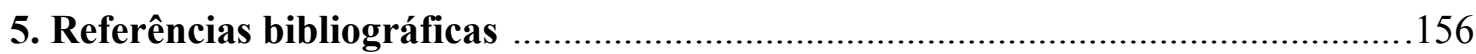

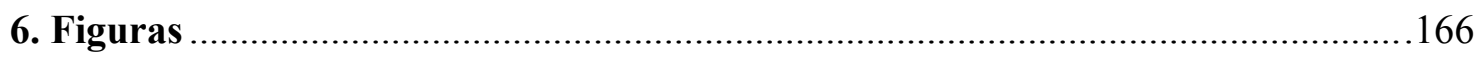

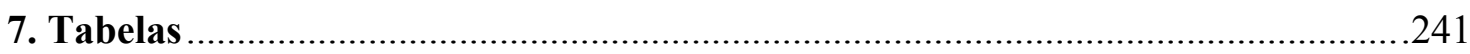

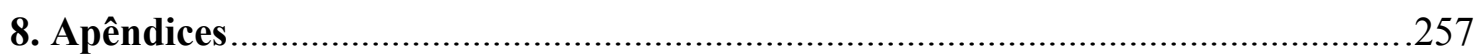


Figura 1. Relações filogenéticas de Loricariidae obtida a partir de caracteres moleculares, mostrando as relações entre Ancistrinae e parte de Hypostominae (adaptado de MontoyaBurgos et al, 1998).

Figura 2. Relações filogenéticas de Ancistrini (Armbruster, 2004).

Figura 3. Relações filogenéticas de Leporacanthicus e demais táxons do grupo Acanthicus (Chamon, 2007)

Figura 4. Vista dorsal e ventral do neurocrânio de Acanthicus hystrix (MZUSP 34244 $174,61 \mathrm{~mm} \mathrm{CP})$.

Figura 5. Cápsula da bexiga natatória de Acanthicus adonis ANSP 19532 - 235,2 mm CP).

Figura 6. Vista dorsal e ventral do neurocrânio de Megalancistrus parananus (MZUSP 4434 - 249,87 mm CP).

Figura 7. Vista dorsal e ventral do neurocrânio de Pseudacanthicus sp. "aba laranja" (MZUSP 34295 - 236,30 mm CP).

Figura 8. Vista dorsal e ventral do neurocrânio de Leporacanthicus galaxias (INPA 6359 $142,6 \mathrm{~mm} \mathrm{CP}$ )

Figura 9. Vista dorsal da cabeça e placas pré-dorsais de Spectracanthicus murinus (MZUSP 24293 - 36,10 mm CP).

Figura 10. Vista dorsal da cabeça e placas pré-dorsais de Spectracanthicus sp. "bola branca" (MZUSP 108569 - 111,7 mm CP).

Figura 11. Vista dorsal e ventral do neurocrânio de Panaque gr. nigrolineatus (MZUSP 94453 - 268,1 mm CP).

Figura 12. Vista dorsal do neurocrânio de Scobinancistrus aureatus INPA 25858 - 130,11 $\mathrm{mm} \mathrm{CP})$.

Figura 13. Vista lateral do mesetmóide de (A) Acanthicus adonis, (B) Megalancistrus barrae e (C) Pseudacanthicus leopardus.

Figura 14. Arcos hióide e branquiais de Acanthicus hystrix.

Figura 15. Arcos hióide e branquiais em Pseudacanthicus leopardus (A) e P. spinosus (B e C).

Figura 16. Arcos hióide e branquiais de Leporacanthicus galaxias (A) e L. triactis (B);

Figura 17. Placa faríngea superior (A) de Leporacanthicus galaxias, placa faríngea inferior (B e C) de L. galaxias e Spectracanthicus sp. "bola branca", respectivamente. 
Figura 18. Vista ventral do suspensório, destacando o inter-hial de (A) Leporacanthicus galaxias e (B) Spectracanthicus punctatissimus.

Figura 19. Vista ventral do suspensório de Acanthicus hystrix.

Figura 20. Vista ventral do suspensório de Acanthicus adonis.

Figura 21. Vista lateral do suspensório de Megalancistrus barrae.

Figura 22. Supensório de Pseudacanthicus leopardus; (A) vista ventral e (B) vista lateral.

Figura 23. Suspensório de (A) Pseudacanthicus sp. "açacu preto" em vista ventral e (B) $P$. spinosus em vista lateral.

Figura 24. Suspensório em vista ventral de Leporacanthicus galaxias.

Figura 25. Suspensório de Spectracanthicus murinus; (A) vista ventral e (B) vista lateral.

Figura 26. Suspensório de S. punctatissimus, (A) vista lateral e (B) vista ventral.

Figura 27. Suspensório de Spectracanthicus sp. "bola branca", (A) vista lateral e (B) vista dorsal.

Figura 28. Suspensório de Spectracanthicus sp. "Tapajós", (A) vista lateral e (B) vista ventral.

Figura 29. Suspensório de Spectracanthicus sp. "Tocantins", (A) vista lateral e (B) vista dorsal.

Figura 30. Suspensório de Panaque gr. nigrolineatus, vista ventral.

Figura 31. Auto-palatino, maxilar e pré maxilar de (A) Acanthicus hystrix, (B) Megalancistrus barrae, (C) Pseudacanthicus sp. "aba laranja", (D) e (E) Leporacanthicus galaxias.

Figura 32. Auto-palatino, maxilar e pré maxilar de (A) Spectracanthicus punctatissimus e (B) Spectracanthicus sp "bola branca".

Figura 33. Auto-palatino, maxilar e pré maxilar de (A) S. murinus, (B) Spectracanthicus sp. "bola branca", (C) Spectracanthicus sp. "Tapajós" e (D) Spectracanthicus sp. "Tocantins".

Figura 34. Esqueleto axial de (A) Megalancistrus barrae e (B) Panaque gr. nigrolineatus.

Figura 35. Cintura peitoral de (A) Leporacanthicus galaxias e (B) Acanthicus hystrix.

Figura 36. Cintura pélvica em (A) Acanthicus hystrix e (B) Leporacanthicus galaxias.

Figura 37. Cintura pélvica de (A) Megalancistrus parananus, (B) Pseudacanthicus sp. "aba laranja", (C) P. leopardus e (D) P. spinosus. 
Figura 38. Cintura pélvica de (A) S. murinus, (B) Spectracanthicus sp. "Tapajós" e (C) Spectracanthicus sp. "Tocantins".

Figura 39. Cintura pélvica de (A) S. punctatissimus, (B) Spectracanthicus sp. "Tocantins". Figura 40. Vista lateral posterior ao pterótico-supracleitro de Pseudacanthicus spinosus.

Figura 41. Cladograma de consenso estrito.

Figura 42. Cladograma com destaque do grupo interno.

Figura 43. Cladograma com suporte de Bremer.

Figura 44. Holótipo de Acanthicus adonis, MZUSP 38580 - 134,6 mm CP.

Figura 45. Neótipo de Acanthicus hystrix, MZUSP 103858 - 182,6 mm CP.

Figura 46. Acanthicus hystrix vivo, rio Xingu.

Figura 47. Mapa de distribuição de Acanthicus adonis (triângulo vermelho) e A. hystrix (círculo laranja).

Figura 48. Síntipo de Megalancistrus barrae, NMW 48019 - 399,4 mm CP.

Figura 49. Mapa de distribuição de Megalancistrus barrae.

Figura 50. Holótipo de Megalancistrus parananus, ZMB 11328 - 462,5 mm CP.

Figura 51. Mapa de distribuição de Megalancistrus parananus.

Figura 52. Holótipo de Pseudacanthicus leopardus, ANSP 39345 - 71,7 mm CP.

Figura 53. Holótipo de Pseudacanthicus serratus, RMNH 3125 - 148,7 mm CP.

Figura 54. Mapa de distribuição de Pseudacanthicus leopardus (círculo vermelho) e $P$. serratus (círculo preto

Figura 55. Holótipo de Pseudacanthicus spinosus, MNHN A-9577-262,6 mm CP.

Figura 56. Mapa de distribuição de Pseudacanthicus spinosus; símbolo aberto representa a localidade tipo.

Figura 57. Pseudacanthicus sp. “Aripuanã”, MZUSP (s/ número) - 105, 6 mm CP.

Figura 58. Pseudacanthicus sp. “Tapajós”, MZUSP 108195 - 121,7 mm CP.

Figura 59. Colorido de (A) Pseudacanthicus leopardus, (B) Pseudacanthicus sp. "Tapajós", (C) e (D) juvenis de P. spinosus. 
Figura 60. Mapa de distribuição de Pseudacanthicus sp. "Aripuanã" (círculo amarelo) e Pseudacanthicus sp. "Tapajós" (círculo vermelho).

Figura 61. Pseudacanthicus sp. “açacu vermelho”, MZUSP (ECIX2010070802) - 246,5 $\mathrm{mm}$ CP.

Figura 62. Pseudacanthicus sp. “açacu preto”, MZUSP (ECIX2010071201\#2) - 113,6 mm CP.

Figura 63. Colorido em vida de Pseudacanthicus sp "açacu vermelho"(A) e Pseudacanthicus sp. "açacu preto" (B).

Figura 64. Mapa de distribuição de Pseudacanthicus sp "açacu vermelho"(círculo amarelo) e Pseudacanthicus sp. "açacu preto" (círculo vermelho).

Figura 65. Pseudacanthicus sp. "aba laranja”, MZUSP 34296 - 220,7 mm CP.

Figura 66. Pseudacanthicus sp. "Tocantins", INPA 32234 - 115,1 mm CP.

Figura 67. Mapa de distribuição de Pseudacanthicus sp. "aba laranja" (círculo laranja) e Pseudacanthicus sp. "Tocantins" (círculo azul).

Figura 68. Holótipo de Spectracanthicus murinus, MZUSP 22011 - 59,7 mm CP.

Figura 69. Holótipo de Spectracanthicus punctatissimus, NMW 47206 - 104,0 mm CP.

Figura 70. Spectracanthicus sp. "bola branca", INPA 3957 - 80,6 mm CP.

Figura 71. Spectracanthicus sp. “Tocantins”, MZUSP 34265 - 49,5 mm CP.

Figura 72. Spectracanthicus sp. “Tapajós”, MZUSP 92797-64,6 mm CP.

Figura 73. Perfil dorsal do focinho de Spectracanthicus sp. "Tocantins" (A), Spectracanthicus sp . "bola branca" (B), S. punctatissimus (C) e Spectracanthicus sp. "Tapajós" (D). Forma da boca em Spectracanthicus sp . "bola branca" (E) e Spectracanthicus sp. "Tapajós" (F).

Figura 74. Colorido em vida das espécies de Spectracanthicus.

Figur 75. Mapa de distribuição de Spectracanthicus. 
Tabela 1. Dados morfométricos e merístico de Acanthicus adonis.

Tabela 2. Dados morfométricos e merísticos de Acanthicus hystrix.

Tabela 3. Dados morfométricos e merísticos de Megalancistrus barrae.

Tabela 4. Dados morfométricos e merísticos de Megalancistrus parananus.

Tabela 5. Dados morfométricos e merísticos de Pseudacanthicus leopardus.

Tabela 6. Dados morfométricos e merísticos de Pseudacanthicus serratus

Tabela 7. Dados morfométricos e merísticos de Pseudacanthicus spinosus.

Tabela 8. Dados morfométricos e merísticos de Pseudacanthicus sp. "Aripuanã".

Tabela 9. Dados morfométricos e merísticos de Pseudacanthicus sp. "Tapajós”.

Tabela 10. Dados morfométricos e merísticos de Pseudacanthicus sp. "açacu vermelho".

Tabela 11. Dados morfométricos e merísticos de Pseudacanthicus sp. "açacu preto".

Tabela 12. Dados morfométricos e merísticos de Pseudacanthicus sp. "Tocantins".

Tabela 13. Dados morfométricos e merísticos de Pseudacanthicus sp. "aba laranja".

Tabela 14. Dados morfométricos e merísticos de Spectracanthicus murinus.

Tabela 15. Dados morfométricos e merísticos de Spectracanthicus punctatissimus.

Tabela 16. Dados morfométricos e merísticos de Spectracanthicus sp, "bola branca".

Tabela 17. Dados morfométricos e merísticos de Spectracanthicus sp. "Tocantins".

Tabela 18. Dados morfométricos e merísticos de Spectracanthicus sp. “Tapajós. 


\section{Apêndice}

1. Matriz de dados

2. Lista de sinapomorfias 


\section{INTRODUÇÃO}

Dentre os peixes que habitam sistemas de água doce do mundo, cerca de $70 \%$, pertence à superordem Ostariophysi. As ordens que compõem o grupo são: Gonorynchiformes (37 espécies), Cypriniformes ( $\approx 3300$ spp.), Characiformes $(\approx 1700$ spp.), Gymnotiformes $(\approx 180$ spp.) e Siluriformes ( $\approx 2900$ spp.) (Nelson, 2006). Com exceção de Gonorynchiformes, o grupo é caracterizado pela presença do aparelho de Weber (= Otophysi), que consiste em uma modificação das quatro ou cinco primeiras vértebras e ligamentos que conectam a bexiga natatória ao ouvido interno permitindo uma percepção estato-acústica muito acurada do ambiente (Britto, 2002).

Siluriformes inclui 35 famílias, 446 gêneros e 2867 espécies descritas (Nelson, 2006). A ordem é a segunda maior e uma das mais diversificadas entre Ostariophysi, apresentando uma grande variedade de formas e ocupando diversos nichos e ambientes. Dentre as espécies que compõem a ordem, algumas são consideradas miniaturas (eg. Scoloplax empousa, Scoloplacidae) e não ultrapassam $20 \mathrm{~mm}$ quando adultos enquanto outras atingem comprimento superior a $2 \mathrm{~m}$ (eg. Brachyplatystoma filamentosum, Pimelodidae). Apesar de a maioria ser exclusivamente de água doce, existe duas famílias com espécies predominantemente marinhas, Ariidae e Plotosidae (Lauder \& Liem, 1983; Britto, 2002).

\subsection{Família Loricariidae}

A família Loricariidae, atualmente com mais de 673 espécies descritas, é a maior da ordem dos Siluriformes e inclui mais de $25 \%$ da diversidade de bagres no mundo (Reis, Kullander \& Ferraris, 2003). Loricariidae está alocada dentro da superfamília Loricarioidea junto com Astroblepidae, Scoloplacidae, Callichthyidae, Trichomychteridae e Nematogenyidae (Baskin, 1973; Schaefer, 1987; de Pinna, 1993). Loricarioidea representa um dos maiores agrupamentos dentro da ordem Siluriformes e abrange mais de um terço das espécies da ordem (Armbruster, 1997, 2004; Britto, 2002). O monofiletismo de Loricarioidea é principalmente sustentado pela presença de dentes tegumentares (odontódeos) na superfície externa do corpo, esta condição foi definida por Peyer (1922) e confirmada por diversos autores (Bhatti, 1938; Baskin, 1973; Howes, 1983a; Schaefer \& Lauder, 1986, 1996; Schaefer, 1988, 1990; de Pinna, 1993; Britto, 2002; entre outros). 
As espécies de Loricariidae geralmente estão divididas em subfamílias historicamente instáveis. Diferentes hipóteses de rearranjo das subfamílias foram propostas ao longo dos anos (Regan, 1904; Gosline, 1947; Isbrücker, 1980; Schaefer, 1986, 1987). Uma das mais recentes foi realizada por Armbruster (2004) que agrupou a família em cinco subfamílias: Hypoptopomatinae, Hypostominae (que inclui cinco tribos, incluindo Ancistrini, Ancistrinae de Isbrücker, 1980), Lithogeninae, Loricariinae e Neoplecostominae. Posteriormente, Reis et al. (2006) descreveram a subfamília Delturinae para incluir os gêneros Delturus e Hemipsilichthys.

Os táxons de Loricariidae encontram-se amplamente distribuídos na região neotropical, desde o sudeste da Costa Rica até o nordeste da Argentina (Isbrücker, 1980). Os loricariídeos podem ser encontrados em uma grande variedade de ambientes de água doce, como riachos com corredeiras, rios de grande porte e sistemas lênticos, representando, portanto, um importante componente da ictiofauna dulcícola.

\subsection{Subfamília Hypostominae}

Gronovius foi o primeiro a publicar o nome Plecostomus e posteriormente Linnaeus (1754, 1758, 1766) percebeu que Plecostomus plecostomus, na realidade pertencia ao gênero Acipenser, um esturjão e não incluiu Plecostomus como um gênero válido. Lacépède (1803) descreveu o gênero Hypostomus incluíndo uma única espécie, H. guacari fazendo deste o primeiro gênero válido pós-Linnaeus. Muitos autores utilizaram o nome Plecostomus até meados do século XX, mesmo com a retirada de Plecostomus do Systema Naturae e a descrição de Hypostomus. (Boeseman, 1968).

Kner (1853) foi um dos poucos autores a utilizar o nome Hypostomus e o primeiro a reconhecer Hypostominae como um subgrupo de Loricariidae. Gosline (1947) transferiu vários gêneros (Pseudorinelepis, Rhinelepis, Pogonopoma, Pogonopomoides, Hemipsilichthys, Kronichthys, Pareiorhina e Pareiorhaphis, agora Isbrueckerichthys) de Hypostominae para Neoplecostominae. Gosline também propôs que todos os gêneros com placas operculares eversíveis fossem transferidos para uma subfamília à parte. Isbrücker (1980) põem em uso Ancistrinae, que não tinha sido utilizada desde sua eleição por Kner (1853). Armbruster (1998) alocou os gêneros Pogonopoma, Pogonopomoides, Rhinelepis e Pseudorinelepis em um grupo ao qual denominou grupo Rhinelepis. Posteriormente, Armbruster (2004) não considerou 
Neoplecostominae como um grupo natural, pois em sua análise algumas espécies de Hypoptopomatinae (Hypoptopoma sp., Nannoptopoma spectabila, Otocinclus vestitus, $O$. vittatus, Hisonotus sp., Parotocinclus britskii, Schizolecis guntheri) estavam situadas entre Neoplecostominae.

Várias modificações com relação à classificação de Hypostominae foram propostas até o presente. A subfamília foi considerada parafilética por diversos autores (Armbruster, 2004; Montoya-Burgos et al., 1998, 1997; Schaefer, 1987). Mais recentemente, Armbruster (2004) alocou dentro de Hypostominae as tribos Ancistrini e Hypostomini. No mesmo trabalho, o autor descreveu as novas tribos Corymbophanini, Pterygoplichthini e Rhinelepini, também incluídas em Hypostominae.

\subsection{Tribo Ancistrini}

A tribo Ancistrini Kner, 1853 contém 44 gêneros (sensu Armbruster, 2004), e está alocada dentro da subfamília Hypostominae. Apesar de Ancistrini não ser diagnosticada por caracteres únicos, segundo Armbruster (2004) a maioria dos táxons de Ancistrini pode ser suportado por uma única sinapomorfia: a modificação do opérculo em uma barra ou numa estrutura em forma de foice. Outros caracteres também podem ser considerados como sinapomorfias para a maioria dos táxons, como a crista do levator arcus palatini alta, orientação vertical do opérculo e o contato do frontal com a órbita. Estes caracteres aparentemente foram perdidos em alguns táxons.

Os táxons que compõem Ancistrini podem ser em sua maioria distinguidos de outros loricariídeos (exceto Pterygoplichthini) pela presença de placas rostrais eversíveis e com odontódeos hipertrofiados. A separação de Ancistrini e Pterygoplichthini é tênue e o único caráter que diferencia as tribos é a presença de uma lâmina de tecido conjuntivo no estômago em Pterygoplichthini (Armbruster, 2004). No mesmo trabalho, Armbruster propôs o grupo Acanthicus, considerado monofilético, pertencente à tribo Ancistrini e inclui os gêneros Acanthicus, Megalancistrus, Pseudacanthicus e Leporacanthicus. Além dos gêneros supracitados, Oligancistrus e Spectracanthicus estão proximamente relacionados ao grupo, sendo considerados irmãos deste. 


\subsection{Histórico taxonômico e distribuição geográfica do grupo Acanthicus}

O grupo Acanthicus é composto por 13 espécies reunidas em quatro gêneros: Acanthicus, Megalancistrus, Pseudacanthicus e Leporacanthicus. Ainda segundo Armbruster (2004), os gêneros Oligancistrus e Spectracanthicus estão relacionados com o grupo Acanthicus e embora o autor não os tenha incluído no grupo.

Dentre os problemas taxonômicos inerentes aos táxons que compõem o grupo pode-se destacar as descrições antigas e pouco informativas. Embora haja algumas descrições mais recentes, a maioria destas foi realizada em revistas de pequena circulação nas quais as espécies apresentam caracterizações inadequadas. A seguir é detalhado um breve histórico taxonômico e a respectiva distribuição geográfica das espécies que compõem o grupo.

Acanthicus Agassiz, in Spix \& Agassiz, 1829. O gênero Acanthicus possui duas espécies consideradas válidas: A. hystrix Agassiz, in Spix \& Agassiz, 1829 distribuído em toda a bacia Amazônica; e A. adonis Isbrücker \& Nijissen, 1988 do baixo rio Tocantins (FischMuller, 2003; Ferraris, 2007). Em 1840, Valenciennes in Cuvier \& Valenciennes fez a combinação Rinelepis acanthicus, que posteriormente foi considerada como sinônimo de Acanthicus hystrix. O holótipo de A. hystrix encontrava-se depositado no "Zoologische Staatssammlung München (ZSM)", Academia de Ciências da Bavária e foi destruído durante um bombardeio britânico, na segunda guerra mundial, na noite de 24-25 de Abril de 1944 (Kottelat, 1988). Nenhum neótipo foi então designado, apenas o iconótipo serve como base para a identificação da espécie.

Megalancistrus Isbrücker, 1980. O gênero Megalancistrus possui duas espécies consideradas válidas: M. parananus Peters, 1881, proveniente das bacias dos rios Paraguai, Paraná e Uruguai; e M. barrae Steindachner, 1910, da bacia do rio São Francisco (FischMuller, 2003). Megalancistrus foi criado para alocar Chaetostomus gigas Boulenger, 1895, assim M. gigas passou a ser a nova combinação para a espécie tipo. Outras combinações também foram criadas para M. parananus: Pterygoplichthys (Ancistrus) parananus Peters, 1881 e Chaetostomus aculeatus Perugia, 1891. Posteriormente Isbrücker, 2001 considerou todas as combinações como sinônimas de Megalancistrus parananus. Armbruster (1997) citou que M. barrae teria o formato do corpo mais parecido com o de Pterygoplichthys, baseado em fotografias do tipo, entretanto, pela minha própria observação do material de $M$. barrae, não resta dúvida de que esta espécie pertence ao gênero Megalancistrus. As duas espécies podem 
ser separadas pela coloração, M. parananus possui grandes pontos pretos cobrindo o corpo enquanto que $M$. barrae tem coloração sem pontos e com manchas estriadas difusas.

Pseudacanthicus Bleeker, 1862. O gênero Pseudacanthicus possui cinco espécies consideradas válidas (Fish-Müller, 2003): P. serratus Valenciennes, 1840; P. fordii Günther, 1868; P. hystrix Valenciennes, 1840; P. leopardus Fowler, 1914; e P. spinosus Castelnau, 1855. A espécie tipo foi inicialmente descrita como Hypostomus serratus Valenciennes in Cuvier \& Valenciennes, 1940, com distribuição nas drenagens costeiras da Guiana e do Suriname.

Posteriormente, Bleeker, 1862 designou a nova combinação, Pseudacanthicus serratus com a descrição do novo gênero. Regan (1904) realizou a última revisão do gênero, onde apresentou uma breve descrição e uma chave de identificação das espécies conhecidas até então.

Pseudacanthicus fordii possui distribuição nas drenagens costeiras do Suriname e foi inicialmente descrita como Chaetostomus fordii. Regan (1904) propôs a nova combinação junto com a redescrição dos tipos.

Pseudacanthicus histrix, distribuída nas bacias do rio Negro e baixo rio Amazonas, foi inicialmente descrita como Loricaria histrix Vandelli in Cuvier \& Valenciennes, 1840. No mesmo trabalho Valenciennes descreve a mesma espécie como Rinelepis histrix. Posteriormente Regan (1904) considerou o táxon como sinônimo de P. hitrix. O holótipo é desconhecido, mas fotografias continuam preservadas nos arquivos do Museu Bocage (MB), Universidade de Lisboa. A descrição original feita por Vandelli em um manuscrito não publicado foi baseada em desenhos preservados no MNHN.

Pseudacanthicus leopardus, distribuída na bacia do rio Rupununi, na Guiana foi inicialmente descrita como Stoniella leopardus. Isbrücker (1980) propôs a nova combinação.

Pseudacanhticus spinosus, distribuída na bacia do rio Amazonas, foi inicialmente descrita como Hypostomus spinosus, sendo a nova combinação proposta por Regan (1904), assim como a redescrição das espécies, incluindo o holótipo.

Leporacanthicus Isbrucker \& Nijssen, 1989. Leporacanthicus é composto por quatro espécies válidas. Isbrücker \& Nijssen (1989) descreveram as três primeiras espécies do gênero: L. galaxias, proveniente do rio Tocantins e está distribuída no médio e alto Amazonas, rios Madeira, Guamá, Ventuari e Orinoco; L. joselimai, restrita à bacia do rio Tapajós e $L$. 
heterodon, restrita à bacia do rio Xingu. Posteriormente, Isbrücker, Nijssen \& Nico (1992) descreveram L. triactis endêmico do rio Orinoco. Chamon (2007) realizou a revisão taxonômica e o estudo filogenético de Leporacanthicus.

Oligancistrus Rapp Py-Daniel, 1989. O gênero Oligancistrus foi estabelecido como um gênero monotípico para incluir Parancistrus punctatissimus Steindachner, 1881. A nova combinação foi proposta porque durante a revisão de Parancistrus Rapp Py-Daniel (1989) descobriu a existência de dois gêneros novos: Baryancistrus e Oligancistrus. Mais recentemente Armbruster (2004) propôs o gênero Oligancistrus como sinônimo de Spectracanthicus.

Spectracanthicus Nijssen \& Isbrücker, 1987. O gênero Spectracanthicus foi descrito como um gênero monotípico: S. murinus proveniente da bacia do rio Tapajós. Spectracanthicus murinus pode se facilmente reconhecido dentro da tribo por não apresentar o opérculo móvel redução do número de raios ramificados da nadadeira anal de quatro para três.

\subsection{Histórico filogenético do grupo Acanthicus}

Alguns estudos utilizaram espécies do grupo Acanthicus como táxons terminais no intuito de elucidar as relações entre os gêneros, mas nenhum trabalho tratou das relações intraespecíficas.

Montoya-Burgos et. al. (1998) utilizaram seqüências dos genes mitocondriais $12 \mathrm{~S}$ e 16S RNA-ribossomal e propuseram que as espécies Acanthicus hystrix, Leporacanthicus galaxias e Pseudacanthicus spinosus, estão proximamente relacionadas formando um grupo monofilético (Figura 1).

A proposta de Armbruster (2004) incluiu mais táxons terminais (Acanhticus hystrix, Megalancistrus gigas, Leporacanthicus galaxias, Pseudacanthicus leopardus, Oligancistrus punctatissimus e Spectracanthicus murinus) e foi baseada em caracteres morfológicos (Figura 2). Entretanto, nenhum trabalho teve como objetivo estabelecer as relações filogenéticas entre as espécies do grupo.

Chamon (2007) realizou a revisão taxonômica e as relações filogenéticas de Leporacanthicus (Figura 3). Na filogenia foram incluídas as quatro espécies de Leporacanthicus e outros táxons pertencentes ao grupo Acanthicus. Como resultado foi obtido 
um cladograma de consenso estrito com a seguinte topologia: ((Acanthicus, Megalancistrus) ((Spectracanthicus) (Leporacanthicus, Pseudacanthicus))). 
1) Revisar taxonomicamente as espécies do grupo Acanthicus, estabelecer diagnoses atualizadas, identificar limites de distribuição geográfica, e eventualmente descrever espécies novas e determinar sinonímias;

(2) testar a hipótese de monofiletismo do grupo Acanthicus e elucidar as relações filogenéticas entre as espécies do grupo. 


\section{MATERIAL E MÉTODOS}

\subsection{Preparação do material e análise filogenética}

O exame osteológico do material foi realizado através de exemplares diafanizados e corados, preparado de acordo com os procedimentos de Taylor \& Van Dyke (1985) e a partir de esqueletos secos. A nomenclatura osteológica segue aquela proposta por Lundberg \& Baskin (1969), na análise do esqueleto caudal e Schaefer (1987), na análise de osteologia geral. Acontagem do número de vértebras foi realizada de acordo com Schaefer (1987), que conta as cinco primeiras vértebras incorporadas ao Aparelho de Weber e fusionadas ao crânio, e também a única vértebra incorporada na placa hipural.

As hipóteses sobre as relações de parentesco foram inferidas de acordo com a metodologia cladística, originalmente proposta por Hennig (1966) e posteriormente discutida e aprimorada por diversos autores (eg. Eldredge \& Cracraft, 1980; Nelson \& Platinick, 1981; Wiley, 1981; Swofford \& Olsen, 1990; Wiley et al. 1991; Kitching et al., 1998). Os 107 caracteres de Chamon (2007) foram reavaliados, alguns destes foram excluidos e novos caracteres obtidos por meio de comparação dos exemplares e de bibliografia referente. Os caracteres obtidos foram codificados em uma matriz de dados a partir de zero e polarizados através do método de comparação com o grupo externo (sensu Nixon \& Carpenter, 1993). Como grupo externo foram utilizadas táxons de Ancistrini que são proximamente relacionadas ao grupo e espécies mais distantes de Ancistrini, de acordo com a proposta de Armbruster (2004).

A análise filogenética foi baseada em 121 caracteres osteológicos e de morfologia externa, analisados em 33. Os caracteres observados estão reunidos em 12 complexos anatômicos: neurocrânio; arco hióide e arcos branquiais; suspensório e arco mandibular; série opercular; sistemas de canais látero-sensoriais; aparelho de Weber e esqueleto axial; nadadeira dorsal; cintura peitoral; cintura pélvica; nadadeira anal; nadadeira caudal; nadadeira adiposa e miscelânea (reunindo caracteres diversos).

A matriz de dados foi construída através do programa Mesquite 1.11 (Madison \& Madison, 2006). A construção e otimização dos cladogramas foram realizadas através do programa "Tree Analysis Using New Technology", TNT (Goloboff, et al., 2003). Para busca de árvores mais parcimoniosas, foi utilizado o algoritmo de parcimônia de Wagner com a estratégia de busca “Tree Bisection Reconection” (TBR). Os caracteres ambíguos foram otimizados pelo critério ACCTRAN “Accelerated Transformation Optimization” (Swofford e Maddison, 1987), onde 
as reversões têm preferências sobre as congruências, preservando as hipóteses de homologia primária (Pinna, 1991). A imagem da árvore mais parcimoniosa com as sinapomorfias de cada clado foi gerada pelo programa WinClada (Nixon, 1999-2002).

Para o suporte de ramos foi utilizado o suporte de Bremer (Bremer, 1988; 1994), também denominado "decay index". Este índice mede para cada ramo presente no consenso estrito dos cladogramas mais parcimoniosos, o número de passos necessários para que este ramo colapse no consenso estrito de árvores sub-ótimas. Isto foi implementado através do TNT, que utiliza os mesmos comandos do NONA (Goloboff, 1999), onde através do comando "subX”, onde X corresponde ao número de passos a mais que as árvores mais parcimoniosas.

\subsubsection{Lista do material utilizado na análise filogenética}

(esq.=esqueleto; $\mathrm{d} \& \mathrm{c}=$ diafanizado e corado e $\mathrm{CP}=$ comprimento padrão)

Acanthicus adonis ANSP 19532, 1 esq., 235,2 mm CP.

Acanthicus hystrix MCNG 53135, 1 esq., 247,4 mm CP. MZUSP 34244, 1 d\&c, 95,02 mm CP e 1 esq., $174,61 \mathrm{~mm} \mathrm{CP}$.

Ancistrus taunay MZUSP 63937, 2 d\&c, 51,6-64,5 mm CP.

Baryancistrus sp. MZUSP 108568, 1 esq., 185,2 mm CP.

Hemiancistrus cerrado MZUSP 89074, 1 d\&c, 77,2 mm CP.

Hypancistrus sp. MZUSP 58679, 3 d\&c, 30,68-42,22 mm CP. MZUSP 84729, 2 d\&c, 39,169,6. MZUSP 23845, $1 \mathrm{~d} \& \mathrm{c}, 139,83 \mathrm{~mm} \mathrm{CP}$.

Leporacanthicus galaxias AUM (sem número), 1 d\&c, 83,20 mm CP. INPA 6359, d\&c, 106,3 mm CP e 2 esq., 119,4-142,6 mm CP. MNRJ 19369, 2 d\&c 67,6-70,4 mm CP.

L. heterodon MZUSP 92437, $1 \mathrm{~d} \& \mathrm{c}, 70,2 \mathrm{~mm} \mathrm{CP}$.

L. joselimai INPA 25856, $3 \mathrm{~d} \& \mathrm{c}, 50,0-85,5 \mathrm{~mm}$ CP. MZUSP 92678, $1 \mathrm{~d} \& \mathrm{c}, 72,6 \mathrm{~mm} \mathrm{CP}$; MZUSP 78136, $3 \mathrm{~d} \& \mathrm{c}, 46,5-67,7 \mathrm{~mm}$.

L. triactis AUM 39243, $1 \mathrm{~d} \& \mathrm{c}, 56,9 \mathrm{~mm} \mathrm{CP}$.

Megalancistrus barrae MZUSP 100807, 1 esq., 174,1 mm CP.

Megalancistrus parananus MZUSP 21143, 1 d\&c, 152,5 mm; MZUSP 4434, 1 esq., 249,87 $\mathrm{mm} \mathrm{CP.}$

Panaqolus sp. MZUSP 108194, 1 d\&c, 59,2 mm CP. 
Panaque gr. nigrolineatus MZUSP 78137, 1 d\&c, 61,88 mm CP; MZUSP 94453, 1 esq., 268,1 $\mathrm{mm}$ CP.

Parancistrus aurantiacus MZUSP 81774, 1 d\&c, 68,9 mm CP.

Parancistrus nudiventris MZUSP 107195, 1 d\&c, 59,2 mm CP.

Peckoltia vittata MZUSP 24292, 1 d\&c, 67,98 mm CP.

Pseudancistrus brevispinis MZUSP 34238, 1 d\&c, 78,80 mm CP.

Pseudacanthicus leopardus AUM 35738, 1 d\&c, 41,06 mm CP. INPA 25865, 1 d\&c, 54,09 $\mathrm{mm} \mathrm{CP.}$

P. spinosus MZUSP 23992, $1 \mathrm{~d} \& \mathrm{c}, 83,27 \mathrm{~mm}$ CP. MZUSP 24010, $1 \mathrm{~d} \& \mathrm{c}, 60,23 \mathrm{~mm} \mathrm{CP}$; MZUSP 108573, 1 esq., 119,8 mm CP.

.Pseudacanthicus sp. “aba laranja” MZUSP 34295,1 esq.; 236,30 mm CP.

Pseudacanthicus sp. "açacu preto" INPA 31804, 1 d\&c, 71,09 mm CP.

Pseudacanthicus sp. "açacu vermelho" MZUSP 108567, 1 esq., 121,2 mm CP. MZUSP 108572, 1 esq., 125,0 mm CP.

Pseudacanthicus sp. “Aripuanã” MZUSP (não catalogado), 1 d\&c, 78,36 mm CP.

Pseudacanthicus sp. “Tapajós” MZUSP 108195, 1 esq., 109,2 mm CP.

Pseudacanthicus sp. “Tocantins" INPA 6309, 1 d\&c 98,94 mm CP.

Scobinancistrus aureatus. INPA 25858, 1 d\&c, 86,44 mm CP e 1 esq., 130,11 mm CP.

Scobinancistrus pariolispos MZUSP 62577, 1 d\&c, 106,1 mm CP.

Spectracanthicus murinus INPA 6984, 2 d\&c, 55,08-58,53. MZUSP 24293, 1 d\&c, 36,10 mm CP. MZUSP 34279, $1 \mathrm{~d} \& \mathrm{c}, 36,83 \mathrm{~mm}$ CP.

Spectracanthicus punctatissimus MZUSP 34289, 1 d\&c, 65,9 mm CP. MZUSP 108570, 2 esq., 77,2-78,2 mm CP.

Spectracanthicus sp. "bola branca" INPA 3957, 1 d\&c, 80,61 mm CP. MZUSP 108569, 1 esq. $111,7 \mathrm{~mm} \mathrm{CP}$.

Spectracanthicus sp. "Tocantins" MZUSP 24125, 1 d\&c, 64,2 mm CP; MZUSP 34265, 1 $\mathrm{d} \& \mathrm{c}, 65,39 \mathrm{~mm}$ CP.

Spectracanthicus sp “Tapajós” MZUSP 92617, 1 d\&c, 58,9 mm CP.

\subsection{Revisão Taxonômica}

O material utilizado na revisão taxonômica é proveniente de diversas instituições brasileiras e estrangeiras (ver lista de instituições a seguir) que foi analisado através de 
empréstimos e/ou visitas às coleções. Para a realização da revisão diversos caracteres morfométricos, merísticos, assim como de morfologia externa e padrão de colorido foram utilizado. Os dados morfométricos foram obtidos com o auxílio de um paquímetro digital e com estereomicroscópio quando necessário. As medidas foram realizadas de acordo com Rapp PyDaniel \& Zuanon (2005) para o gênero Spectracanthicus e para os demais gêneros, de acordo com Armbruster (2003). A contagem de placas foi realizada de acordo com a proposta por Schaefer (1997). As medidas e contagens foram feitas do lado esquerdo dos exemplares, a não ser quando os espécimens se encontraram danificados. As medidas dos raios indivisos das nadadeiras que estavam danificadas não foram incluídas.

Os dados morfométricos e merísticos foram apresentados nas tabelas de 1 a 18. Os dados morfométricos relativos ao corpo foram expressos como porcentagens do comprimento padrão e os relativos à cabeça como porcentagens do comprimento da cabeça. A seguir é apresentada uma definição dos dados morfométricos e merísticos que foram utilizados neste estudo.

\section{Dados Morfométricos}

1. Comprimento padrão (CP): da ponta do focinho até a borda posterior da placa hipural.

2. Comprimento pré-dorsal: da ponta do focinho até a placa pré-dorsal.

3. Comprimento da cabeça $(\mathrm{CC})$ : da ponta do focinho até a extremidade posterior do processo supra-occipital.

4. Largura da cabeça: na região do opérculo.

5. Largura do cleitro: entre as extremidades distais do cleito.

5. Largura do corpo na origem da dorsal: na região da placa pré-dorsal.

6. Largura do corpo na origem da anal: na inserção do primeiro espinho anal.

7. Comprimento torácico: ventralmente da base do primeiro raio peitoral até a base do primeiro raio pélvico.

8. Comprimento do espinho peitoral: da base até a extremidade distal do primeiro raio peitoral.

9. Comprimento abdominal: ventralmente da base do primeiro raio pélvico até a base do primeiro raio anal.

10. Comprimento do espinho pélvico: da base até a extremidade distal do primeiro raio pélvico.

11. Comprimento pós-anal: a partir da base da nadadeira anal até a base superior da nadadeira caudal. 
12. Comprimento do espinho anal: da base até a extremidade distal do primeiro raio anal.

13. Comprimento do espinho dorsal: da base até a extremidade distal do primeiro raio da dorsal.

14. Comprimento da base da dorsal: da inserção do primeiro até a inserção último raio dorsal.

15. Altura do pedúnculo caudal: na linha vertical que passa pela margem anterior da penúltima placa dorsal.

16. Largura horizontal da órbita: do maior diâmetro da órbita.

17. Comprimento do focinho: da ponta do focinho até a margem anterior da órbita.

18. Largura inter-narinal: medida entre as narinas anteriores.

19. Largura interorbital: entre a distância mínima entre as órbitas.

20. Altura da cabeça: da maior altura da cabeça.

21. Comprimento da boca: ventralmente da extremidade distal do lábio superior até a extremidade distal do lábio inferior.

22. Largura da boca: entre os barbilhões.

23. Comprimento do dentário: entre uma extremidade a outra do dentário.

24. Comprimento do pré-maxilar: entre uma extremidade e outra do pré-maxilar.

\section{Dados Merísticos}

1. Série de placas dorsais: de placas da série dorsal.

2. Série de placas médio-dorsais: de placas da série médio-dorsal.

3. Série de placas medianas: de placas da série mediana. Estas placas apresentam canais sensoriais da linha lateral e estão dispostas desde a margem posterior do cleitro até a placa anterior à placa hipural (em alguns casos, até a placa hipural).

4. Série de placas médio-ventrais: de placas da série médio-ventral.

5. Série de placas ventrais: de placas da série ventral.

6. Série de placas na base da caudal: de placas triangulares da base da nadadeira caudal.

7. Dentes pré-maxilares: de dentes do pré-maxilar.

8. Dentes do dentário: de dentes do dentário.

9. Raios das nadadeiras: de raios indivisos (algarismos romanos) e divisos (algarismos arábicos) de cada nadadeira. 
A lista do material examinado foi organizada por países, estados e drenagens. Dentro desta ordem, os lotes se encontram em ordem alfabética das instituições, dos táxons e número de catálogo, nestas estão contidos o comprimento do maior e menor exemplar, o país, o estado, a drenagem, a localidade, a coordenada geográfica, o coletor e a data de coleta. A organização dos lotes da lista foi realizada de seguinte forma: série tipo e demais lotes das instituições nacionais e estrangeiras em ordem alfabética.

A distribuição geográfica das espécies foi baseada na relação do material examinado no estudo e cada ponto no mapa pode representar mais de uma localidade. Os mapas foram obtidos através do programa Quantum GIS 1.5.0 - Tethys (

\subsection{Abreviaturas institucionais}

AMNH - American Museum of Natural History, Nova York.

ANSP - Academy of Natural Sciences of Philadelphia, Filadélfia.

AUM - Auburn University Museum, Auburn.

BMNH - Natural History Museum, Londres.

FMNH - Field Museum of Natural History, Chicago.

INHS - Illinois Natural History Survey, Champaign.

INPA - Instituto Nacional de Pesquisas da Amazônia, Manaus.

MCP - Museu de Ciências da Pontifícia Universidade Católica do Rio Grande do Sul, Porto Alegre.

MCNG - Museo de Historia Natural de Guanare, Guanare.

MNHN - Muséum national d'Histoire naturelle, Paris

MNRJ - Museu Nacional, Universidade Federal do Rio de Janeiro, Rio de Janeiro.

MNW - Das Naturhistorisches Museum, Viena.

MPEG - Museu Paraense Emilio Goeldi, Belém.

MHNG - Muséum d'Histoire Naturelle Geneva, Genebra.

MZUSP - Museu de Zoologia da Universidade de São Paulo, São Paulo.

NUP - Núcleo de Pesquisas em Limnologia, Ictiologia e Aqüicultura - NUPÉLIA, Maringá.

RMNH - Nationaal Natuurhistorisch Museum (formerly Rijksmuseum van Natuurlijke Historie), Leiden. 
UFRO - Universidade Federal de Rondônia, Porto Velho.

USNM - National Museum of Natural History, Smithsonian Institution, Washington D.C..

ZMA - Zoological Museum Amsterdam, Amsterdam.

ZMB - Museum für Naturkunde, Berlin.

\subsection{Conceito de espécie utilizado}

Neste estudo foi utilizado o conceito filogenético de espécie originalmente referido com este nome por Cracraft (1983). Este conceito foi anteriormente proposto por diversos autores: Eldredge \& Cracraft (1980) e Cracraft (1983 e 1987). Em todas estas versões o conceito de espécie é definido pelo agrupamento de organismos que apresentam um padrão de ancestralidade e descendência; se autoperpetuam e possuem um conjunto de caracteres únicos. Este conceito de espécie é baseado exclusivamente na diferenciação de um dado caráter e o quanto este pode ser diagnosticável nos táxons, sem fazer menção à noção de linhagens ou populações (ver discussão em de Pinna, 1999). A decisão pela utilização deste conceito reflete a metodologia aplicada para a separação das espécies, que foi baseada no conjunto de caracteres morfológicos, e não necessariamente em autapomorfias. Diferentes populações, pertencentes a drenagens distintas, foram consideradas como a mesma entidade taxonômica: espécie. 


\section{RESULTADOS E DISCUSSÃO}

A nomenclatura taxonômica foi realizada de acordo com a hipótese de relacionamento proposta neste estudo. Dessa forma, para o melhor entendimento dos resultados a seguir apresentados, a análise filogenética precede a revisão taxonômica.

\subsection{Análise filogenética}

Foram inseridos 33 táxons terminais e 121 caracteres na matriz de dados. A análise filogenética resultou em duas árvores igualmente parcimoniosas com 453 passos $(\mathrm{CI}=0,32$ $\mathrm{RI}=0,66$ ). Os caracteres inseridos foram baseados em osteologia, colorido e morfologia externa dos táxons observados.

Os caracteres foram apresentados de acordo com o complexo anatômico do qual fazem parte e seguidos de seus respectivos estados. Os caracteres muti-estados tratados como ordenados foram indicados entre parêntesis. Após os estados dos caracteres, é apresentada uma breve discussão dos estados do referido caráter. Estas discusões foram baseadas na topologia da árvore de consenso estricto. Os índices de consistência (IC) e retenção (IR), referente à série de transformação de cada caráter encontram-se ao lado dos caracteres. Foram comparados os índices das duas árvores mais parcimoniosas resultantes da análise e nos caracteres em que estes índices diferem foi apresentada a variação.

\subsubsection{Descrição dos caracteres}

\section{Neurocrânio}

\section{Frontal}

1. Contato do frontal com a órbita (ordenado) $[\mathrm{CI}=0,40 ; \mathrm{RI}=0,81]$. Modificado de Armbruster, $2004 \# 94$.

(0) Sem contato com a órbita

(1) Contato com a órbita somente por um pequeno ponto lateral 
(2) Grande contato com a órbita lateralmente.

Na maioria dos Siluriformes, o frontal geralmente não está em contato com o pterótico sendo separados pelo esfenótico e supra-occipital (Britto, 2002). Em Loricariidae o frontal, na maioria das vezes, forma a borda dorsal da órbita. Entretanto, em algumas espécies, esse contato direto com a órbita é interrompido por uma pequena placa que se localiza lateralmente ao esfenótico. Em alguns casos, o frontal faz contato com a órbita apenas por um pequeno ponto lateral. O estado (0) deste caráter é definido como sinapomorfia do clado que inclui Peckoltia vittata mais Scobinancistrus, mais Panaque e Panaqolus. Este caráter no estado (2) é considerado uma sinapomorfia do clado que inclui Spectracanthicus mais o grupo Acanthicus (Figuras 4-8). Em Spectracanthicus murinus houve uma reversão para o estado (1; figura 9).

2. Margem anterior do frontal: $[\mathrm{CI}=0,33 ; \mathrm{RI}=0,60]$

(0) Curta: margem anterior se limita à margem posterior da narina ou alcança a metade do comprimento desta. (Figura 6).

(1) Alongada, margem anterior ultrapassa a metade do comprimento da narina (Figura 4).

A margem anterior do frontal pode ser curta e limitada medialmente à margem posterior da narina ou até metade do comprimento (estado 0), ou ser alongada e ultrapassar a metade desta (estado 1). O estado (0) é uma sinapomorfia exclusiva do clado que inclui todos os táxons analisados exceto Ancistrus e Baryancistrus. No clado que inclui Panaque e Panaqolus e no clado que inclui Acanthicus, houve reversão para o estado (0).

\section{Etmóide lateral}

Em geral, o etmóide lateral dos Siluriformes é um osso alongado, com seu comprimento cerca de duas vezes a largura. Essa forma alongada é o resultado principalmente do processo ântero-orbital, que nesse grupo é curto (Britto, 2002). 
De acordo com Schaefer (1987), os etmóides laterais em Loricariidae, assim com na maioria de Siluriformes, são bastante desenvolvidos. Dorsalmente são expandidos onde encontram o frontal e as placas dérmicas. Possuem um processo póstero-lateral que contribui para formar a margem anterior da órbita. O processo ântero-orbital possui uma grande face côncava para a articulação com o côndilo palatino. O côndilo do etmóide lateral se articula com a face côncava na margem póstero-dorsal do metapterigóide. A cápsula nasal é completamente fechada no etmóide lateral.

3. Tamanho do etmóide lateral: $[\mathrm{CI}=0,50 ; \mathrm{RI}=0,85]$. Modificado de Britto, 2002\#9; Armbruster, 2004\#95.

(0) Curto: metade do comprimento maior que a largura do osso.

(1) Alongado: metade do comprimento menor que a largura do osso (Figura 8).

Em geral, o etmóide lateral dos loricarídeos é um osso alongado. Entretanto, em alguns táxons, este osso pode ser ainda mais alongado, na relação entre o comprimento e a largura. $\mathrm{O}$ etmóide lateral alongado é considerado neste estudo uma sinapomorfia do clado que inclui Scobinancistrus, Panaque e Panaqolus, e do clado, que inclui Leporacanthicus.

4. Forma do etmóide lateral: $[\mathrm{CI}=0,33 ; \mathrm{RI}=0,33]$

(0) Retangular a triangular com expansão ventro-lateral desenvolvida.

(1) Retangular com expansão lateral curta ou ausente.

Em vista ventral, o etmóide lateral dos loricarídeos é, em geral, de forma retangular a triangular e apresenta uma espansão ventro-lateral bastante desenvolvida (estado 0) O etmóide lateral com retangular com expansão lateral curta ou ausente (estado 1) é uma sinapomorfia de Spectracanthicus sp. "Tapajós", de Pseudacanthicus sp. "açacu preto" e do clado que inclui Pseudacanthicus sp. “Tocantins" e Pseudacanthicus sp. "Aripuanã”.

5. Crista do etmóide lateral: $[\mathrm{CI}=1,00 ; \mathrm{RI}=1,00]$. Modificado de Armbruster, $2004 \# 97$. 
(0) Baixa.

(1) Alta.

Na superfície ventral do processo ânterorbital do etmóide lateral há uma crista, às vezes ausente ou pouco desenvolvida, que contata a margem dorsal do metapterigóide. Esta crista é contínua posteriormente até um côndilo grande e oval, o côndilo articular do metapterigóide (Schaefer, 1987). Segundo Armbruster (2004), na maioria dos Loricariidae esta crista é geralmente baixa (estado 0). Entretanto, em vários táxons de Ancistrini, esta crista é desenvolvida (estado 1). Na presente análise, a crista do etmóide lateral baixa é considerada uma sinapomorfia de Parancistrus.

6. Contato do etmóide lateral com o metapterigóide $[\mathrm{CI}=0,14 ; \mathrm{RI}=0,53]$. Modificado de Armbruster, 2004\#99.

(0) Contato apenas em sua parte posterior.

(1) Contato tanto na parte posterior quanto na anterior.

O etmóide lateral dos loricarídeos faz contato com o metapterigóide lateralmente. Este contado pode ser apenas através da parte posterior do osso (estado 0), ou este contato pode ser feito ao longo do comprimento do osso, tanto na parte posterior quanto na anterior (estado 1). O contato do etmóide lateral com o metapterigóide apenas na parte posterior é sinapomorfia de Leporacanthicus e do clado 56, que inclui Pseudacanthicus sp. "Aripuanã” e Pseudacanthicus sp. "Tocantins" (clado 60) mais Pseudacanthicus sp. "Tapajós" mais P. spinosus e $P$. leopardus (clado 55); exceto em P. leopardus.

\section{Mesetmóide}

7. Comprimento do mesetmóide: $[\mathrm{CI}=1,00 ; \mathrm{RI}=1,00]$

(0) relativamente longo;

(1) bastante alongado . 
O mesetmóide dos loricarídeos é relativamente reto, fino e cilíndrico em seção transversa (Schaefer, 1987). Este osso apresenta como características mais notáveis a extrema redução da córnua ânterolateral típica dos Siluriformes, de um modo geral, e a presença de um disco anterior, mediano e vertical na sua superfície ventral. Posteriormente, o mesetmóide forma uma grande estrutura em forma de "V" com o vômer ventralmente e contata o etmóide lateral dorsalmente (Lundberg, 1982). O mesetmóide dos loricarídeos é um osso relativamente alongado, entretanto em Leporacanthicus este osso é ainda mais alongado quando comparado com outros táxons dentro da família. Este caráter é considerado no presente estudo uma sinapomorfia exclusiva de Leporacanthicus (Figura 8).

8. Disco do mesetmóide [CI=0,14; RI=0,60]. Armbruster, $2004 \# 101$.

(0) Anterior ao corpo principal (Figura 13, A e B).

(1) Estendido além do corpo principal (Figura 13, C)

De acordo com Armbruster (2004), na maioria de Loricariidae, o disco do mesetmóide não se estende além do corpo principal (estado 0). Este autor restringe o estado (1) para alguns táxons por ele examinados, dentre estes, Panaque, Megalancistrus parananus, Leporacanthicus galaxias, Pseudacanthicus spinosus e Spectracanthicus. Na presente análise, o estado (1) está presente em Peckoltia, Scobinancistrus, Spectracanthicus, Megalancistrus parananus, Leporacanthicus e em Pseudacanthicus sp. "Aripuanã" e no clado que inclui $P$. spinosus e $P$. leopardus, para o qual representa uma sinapomorfia.

Nasal

9. Forma do nasal $[\mathrm{CI}=0,25 ; \mathrm{RI}=0,45]$. Modificado de Armbruster, 2004\#105.

(0) Quadrangular moderadamente alongado.

(1) Em forma de L, alongado

(2) Retangular, fino e alongado. 
O nasal dos loricarídeos é um osso pequeno localizado medialmente às narinas. Dentro dos táxons analisados, este osso pode apresentar três formas diferentes. Neste trabalho, o nasal retangular, fino e alongado (estado 2) é considerado uma sinapomorfia do clado que inclui Acanthicus e Megalancistrus. Esta mesma condição ocorre em Pseudacanthicus leopardus e Pseudacanthicus sp. "açacu preto".

\section{Petrótico-supracleitro}

A condição basal em Siluriformes dos ossos que suportam a cintura peitoral na região temporal seria o supracleitro, o ligamento de Boudelot e possivelmente o pós-temporal consolidados. Além do osso em forma de placa da região dorsolateral que seria o extraescapular (Fink \& Fink, 1981). Esse osso em forma de placa foi considerado por Lundberg $(1975,1982)$ homólogo ao pós-temporal, que também considerou o supra-cleitro como um elemento único entre o cleitro e o pterótico. O pós-temporal foi perdido em vários grupos de Siluriformes, incluindo Callichthyidae, Astroblepidae e Loricariidae (Britto, 2002).

Nos loricarí́deos, o ligamento de Boudelot ossificado e o supracleitro estão fusionados na face ventro-mesial do pterótico. Há ainda a possibilidade de o pós-temporal ter sido também incorporado a esse complexo de ossos fusionados (Schaefer, 1987). Dessa forma, nos loricariídeos, o pterótico-supracleitro é um osso complexo.

10. Tamanho do pterótico-supracleitro $[\mathrm{CI}=0,50 ; \mathrm{RI}=0,75]$. Modificado de Armbruster, 2004\#107

(0) Pequeno a moderado, não ultrapassando a inserção da nadadeira pélvica.

(1) Bastante expandido, ultrapassando a inserção da nadadeira pélvica (Figuras 4 e 6).

O tamanho do pterótico-supracleitro na maioria dos Loricariidae é pequeno ou moderado. Em Panaque e Megalancistrus, o pterótico-supracleitro também é alongando, assim como a bexiga natatória. Entretanto, em Acanthicus, este é extremamente expandido, isto se deve provavelmente em conseqüência do tamanho da bexiga natatória, que neste gênero é bastante alongada. Nesta análise, a expansão do pterótico-supracleitro é uma sinapomorfia de Acanthicus e Megalancistrus. 
11. Perfurações no pterótico-supracleitro [CI=1,00; RI=1,00]. Armbruster, 2004\#110.

(0) Pequenas.

(1) Grandes (Figuras 4 e 6).

O pterótico-supracleitro nos Loricariidae forma a parede lateral da cápsula da bexiga natatória e é um osso perfurado por pequenas e numerosas fenestras, cobertas por pele, a qual permite transmissão de ondas de som e de pressão entre a cápsula interior e o meio externo (Schaefer, 1991). Estas fenestras podem ser pequenas (estado 0) ou grandes (estado 1). Acanthicus e Megalancistrus apresentam fenestras bastante grandes; este caráter representa uma sinapomorfia exclusiva deste clado.

12. Extremidade anterior do pterótico-supracleitro (ordenado) $[\mathrm{CI}=0,20 ; \mathrm{RI}=0,38]$

(0) sem contato com a margem posterior da órbita;

(1) pequeno contato com a margem posterior da órbita;

(2) grande contato com a margem posterior da órbita.

$\mathrm{Na}$ maioria dos táxons do grupo interno, a extremidade anterior do o pteróticosupracleitro possui pequeno contato com a órbita (estado 1). Com exceção das espécies Spectracanthicus sp. "Tapajós", Pseudacanthicus sp. "Tocantins" e Pseudacanthicus sp. "Curuá-Una", que apresentam o pterótico-supracleitro sem contato com a órbita (estado 0). Além disso, em Leporacanthicus e em Spectracanthicus murinus (Figuras 8 e 9), o pteróticosupracleitro apresenta grande contato com a órbita em sua margem anterior (estado 2). Neste estudo, este caráter é considerado uma sinapomorfia não exclusiva de Leporacanthicus.

\section{Esfenótico}

13. Esfenótico formando uma quilha de odontódes conspícuos em sua porção látero-posterior $[\mathrm{CI}=0,50 ; \mathrm{RI}=0,80]$

(0) não; 
(1) $\operatorname{sim}$.

O esfenótico em Loricariidae é um osso de forma mais ou menos quadrada em perfil dorsal, com um espinho lateral proeminente típico de Siluriformes em geral. O esfenótico dos loricariídeos limita o ramo infra-orbital do canal sensorial temporal, compreende a margem pósteromedial da órbita e sustenta odontódeos em toda a sua extensão (Schaefer, 1987). Estes odontódeos podem ser bastante conspícuos e formar uma quilha na porção látero-posterior do osso (estado 1). Este caráter é uma sinapomorfia de Leporacanthicus (Figura 8) e do clado que inclui Pseudacanthicus spinosus e P. leopardus.

14. Contato do esfenótico com o IO6 [CI=0,14; RI=0,60]

(0) presente;

(1) ausente.

Em sua porção mais próxima da órbita, o esfenótico possui um prolongamento distal que pode envolver toda a margem posterior da órbita, alcançando o sexto infra-orbital (estado 1). Segundo Armbruster (2004), na maioria de Loricariidae ocorre o contato do esfenótico com a órbita. Nesta análise a presença de contato do esfenótico com o IO6 é uma sinapomorfia de Spectracanthicus (Figuras 9 e 10), exceto Spectracanthicus sp. "Tapajós"; de Megalancistrus e de Leporacanthicus.

\section{Parieto- supra-occipital}

O parieto-supra-occipital nos Loricariidae é um osso relativamente grande, com a superfície dorsal coberta de odontódeos. O processo posterior, típico de Siluriformes basais é bastante reduzido e está suturado ao arco neural da sexta vértebra. Embora o supra-occipital participe no suporte da nadadeira dorsal em muitos Siluriformes basais, em Loricariidae isso não ocorre (Schaefer, 1987).

15. Tamanho do parieto-supra-occipital $[\mathrm{CI}=1,00 ; \mathrm{RI}=1,00]$

(0) curto; 
(1) alongado.

Embora o parieto-supra-occipital seja um osso relativamente grande, em algumas espécies, este é ainda mais alongado. Este caráter é considerado uma sinapomorfia exclusiva do clado que incli Acanthicus e Megalancistrus (Figuras 4 e 6).

16. Extremidade posterior do parieto-supra-occipital $[\mathrm{CI}=0,50 ; \mathrm{RI}=0,50-0,90]$

(0) curta;

(1) alongada e bastante pontuda (Figuras 7 e 8 ).

A extremidade posterior do o parieto-supra-occipital alongada e bastante pontuda é uma sinapomorfia exclusiva de Leporacanthicus e Pseudacanthicus, com reversão em Pseudacanthicus sp. "Tocantins".

17. Crista na extremidade posterior do parieto-supra-occipital $[\mathrm{CI}=0,66 ; \mathrm{RI}=0,92]$

(0) ausente (Figuras 10 e 11);

(1) crista em forma de V (Figura 7);

(2) crista pontuda e arredondada (Figura 8).

Dentre a maioria dos loricarídeos, a crista na extremidade posterior do parieto-supraoccipital é ausente. Leporacanthicus possui crista pontuda e arredondada; e em Pseudacanthicus a crista é em forma de V. Este caráter é uma sinapomorfia exclusiva do clado que inclui Leporacanthicus e Pseudacanthicus, com reversão em Pseudacanthicus onde a crista é em forma de V, e em Pseudacanthicus sp. "Tocantins", que não possui crista.

\section{Arco hióide e arcos branquiais}

Arco hióide

Antero-hial ou certo-hial-anterior 
As famílias Astroblepidae e Loricariidae compartilham várias especializações morfológicas na musculatura e na osteologia do arco hióide associadas ao seu modo de vida (Schaefer \& Lauder, 1986). Os ânterohiais são bastante expandidos em Loricariidae. A margem ântero-dorsal é plana e sustenta um forame grande e arredondado para a passagem da artéria mandibular aferente (fma) (Schaefer, 1987).

18. Forma do ântero-hial $[\mathrm{CI}=0,20 ; \mathrm{RI}=0,55]$

(Armbruster, 2004\#1).

(0) alargado, maior comprimento mais ou menos igual ou maior que a metade da largura do osso (Figura 14);

(1) estreito, maior comprimento menor que a metade da largura do osso (Figuras 15 e 16).

O ântero-hial estreito é um caráter sinapomórfico de Leporacanthicus e Pseudacanthicus, com reversão em Pseudacanthicus sp. "açacu preto", Pseudacanthicus sp. "Tocantins" e Pseudacanthicus sp. "Curuá-Una".

19. Fenestras no ântero-hial $[\mathrm{CI}=0,50 ; \mathrm{RI}=0,50]$

(0) ausentes ou pequenas e irregulares;

(1) uma ou duas grandes fenestras em sua porção mais distal, localizadas dentro de uma fossa (Figura 15).

Em Loricariidae, de forma geral, o ântero-hial não apresenta fenestras. Nas espécies de Leporacanthicus, o ântero-hial apresenta fenestras grandes distalmente, dentro de uma leve depressão do osso. Este caráter é uma sinapomorfia exclusiva de Leporacanthicus, com reversão em L. joselimai, onde as fenestras são pequenas.

20. Forame da Artéria Mandibular Aferente (fma) $[\mathrm{CI}=0,20 ; \mathrm{RI}=0,60]$

(0) pequeno; 
(1) grande (Figuras 15 e 16).

Na maioria dos loricarídeos, o forame da artéria mandibular aferente é pequeno. Em alguns táxons, este forame é grande. Este caráter é um sinapomorfia de Leporacanthicus e Pseudacanthicus, com reversões em Pseudacanthicus sp. "açacu vermelho", Pseudacanthicus sp. "aba laranja” e em Pseudacanthicus sp. "Aripuanã”. Dentro do grupo externo, este caráter surgiu de forma independente em Peckoltia e Panaque.

\section{Hipo-hial}

Primitivamente em teleósteos os hipo-hiais consistem em dois elementos (dorsal e ventral) pareados. Ambos os elementos estão presentes em Diplomystes, enquanto que vários Siluriformes, incluindo Trichomycteridae, Astroblepidae e Loricariidade perderam o elemento dorsal (Schaefer, 1987). Em Loricariidae o uro-hial apresenta processos anteriores bem desenvolvidos e pontiagudos, que se articulam com o hipo-hial através de uma fenestra nestes ossos (Britto, 2002).

21. Forma do hipo-hial $[\mathrm{CI}=0,16 ; \mathrm{RI}=0,66]$

(0) curto;

(1) alongado.

Na maioria dos táxons de Loricariidae, o hipo-hial é curto. O hipo-hial alongado é um caráter sinapomórfico do grupo Acanthicus com reversões em Acanthicus adonis e em Leporacanthicus joselimai e L. heterodon. Em alguns táxons do grupo externo, como Hemiancistrus cerrado, Parancistrus aurantiacus e Peckoltia vittata, este caráter surgiu de forma independente.

Arcos branquiais

Basibranquiais 
O termo basibranquial é aplicado para definir os elementos medianos do endoesqueleto dos arcos branquiais. Estes podem ser ossificados ou não e se localizam entre sucessivos elementos pareados dos arcos branquiais. Nos teleósteos os basibranquiais são formados, primitivamente por três cópulas de elementos: uma composta pelo basi-hial; uma formada anteriormente pelos elementos 1-3, geralmente incluindo três basibranquiais ossificados e a outra formada posteriormente pelos elementos 4-5 ou 4-6, que consistem em uma cartilagem única representando dois ou três basibranquiais não independentes (Nelson, 1969).

22. Segundo basi-branquial $[\mathrm{CI}=0,33 ; \mathrm{RI}=0,71]$

(Armbruster, 1997 \# H6, 2004 \# 3; Britto, 2002 \# 87; Rapp Py-Daniel, 1997 \# 64; Paixão, 2004 \# 11):

(0) ossificado (Figura 16, A);

(1) cartilaginoso (Figura 16, B).

Em Loricariidae apenas três elementos basibranquiais estão presentes no esqueleto branquial. A maioria das espécies de Loricariinae e Ancistrini possui os dois primeiros elementos basibranquiais (2 e 3) ossificados (Schaefer, 1987). De modo geral, o basibranquial 2 dos Siluriformes é ossificado, entretanto, em Loricariidae esta condição é considerada derivada (Schaefer, 1987). Nesta análise, a presença do segundo basi-branquial cartilaginoso é uma sinapomorfia de Spectracanthicus e do clado que inclui Pseudacanthicus sp. "Tocantins" e Pseudacanthicus sp. “Aripuanã”. Esta condição também está presente em Leporacanthicus triactis. Em Megalancistrus barrae, Acanthicus adonis e Pseudacanthicus sp. "aba laranja" esse caráter não pode ser observado por falta de material preparado.

\section{Cerato-branquial}

23. Processo acessório do primeiro cerato-branquial (CB1) $[\mathrm{CI}=0,20 ; \mathrm{RI}=0,63]$

(Modificado de Armbruster, 2004\#8): 
(0) cerca de mesma largura do CB1 (Figura 14);

(1) largura cerca de duas vezes o CB1 (Figura 16).

Nos Loricariidae os cerato-branquiais constituem cinco pares de elementos ossificados. O primeiro par possui um processo acessório ossificado, que se projeta póstero-lateralmente da margem ântero-lateral. O processo acessório é único dos loricariídeos dentre todos os Siluriformes e sustenta a primeira fileira de rastros branquiais modificados na sua parte posterior, anterior ao primeiro cerato-branquial (Schaefer, 1987). O processo acessório com cerca da mesma largura de CB1 é uma sinapomorfia do clado que inclui o grupo Acanthicus. No clado que inclui todos os Pseudacanthicus, exceto Pseudacanthicus sp. "açacu preto", o processo acessório é cerca de duas vezes a largura do $\mathrm{CB} 1$, com reversões em Pseudacanthicus sp. "Tocantins", Pseudacanthicus sp. "Aripuanã" e P. spinosus. Em Megalancistrus barrae este caráter não foi observado por falta de material preparado.

24. Quinto cerato-branquial (CB5) $[\mathrm{CI}=1,00 ; \mathrm{RI}=1,00]$

(Modificado de Py-Daniel, 1997\#82; Ghazzi, 2003\#65 e Armbruster, 2004\#10; Paixão, 2004\#13):

(0) moderadamente largo em toda sua extensão;

(1) bastante largo em toda a sua extensão (Figura 14).

A maioria de Loricariidae possui o quinto cerato-branquial alargado em toda a sua extensão para suportar as placas de dentes faríngeos inferiores (Schaefer, 1987). Em Acanthicus e Megalancistrus o quinto cerato-branquial é bastante alargado, sendo este caráter sinapomórfico para o clado que inclui os dois gêneros. Em Megalancistrus barrae este caráter não foi observado por falta de material preparado.

25. Dentes no $\mathrm{CB} 5[\mathrm{CI}=1,00 ; \mathrm{RI}=1,00]$

(Modificado de Britto, 2002\#102):

(0) pouco ou moderadamente desenvolvidos; 
(1) bastante desenvolvidos (Figura 17).

Em Otophysi, o quinto cerato-branquial apresenta-se modificado em uma placa dentígera, com dentes distribuídos por quase toda a sua superfície (Britto, 2002). Nos táxons analisados, nas espécies de Leporacanthicus os dentes do quinto cerato-branquial são bastante desenvolvidos. Este caráter é uma sinapomorfia exclusiva do gênero Leporacanthicus.

\section{Epi-branquiais}

26. Expansão laminar localizada na extremidade distal do primeiro epi-branquial (EB1) [CI= 0,25; RI= 0,72]; (Modificado de Schaefer, 1987\#9; Schaefer, 1997\# 9; Britto, 2002\#103; Armbruster, 2004\#14 e Paixão, 2004\#14):

(0) fina e bastante curta;

(1) robusta e alongada.

Segundo Schaefer (1987), em Loricariidae os quatro primeiros epi-branquiais são ossificados e sustentam cristas laterais suportando os filamentos branquiais. O primeiro epibranquial possui um processo acessório anterior, que suporta a primeira fileira de rastros branquiais modificados e o processo posterior que contata o anterior no segundo epi-branquial. $\mathrm{O}$ processo acessório no primeiro epi-branquial está presente em todos os membros de Hypostominae. A expansão laminar do processo acessório no EB1 fina e bastante curta é uma sinapomorfia não exclusiva do grupo Acanthicus e ocorre também em Spectracanthicus murinus.

27. Superfície ventral do $\mathrm{EB} 1$ [CI=0,50; $\mathrm{RI}=0,88]$

(1) arredondada;

(1) formando uma quilha longitudinal.

De acordo com Armbruster (2004), a superfície ventral do EB1 na maioria dos Loricariidae é arredondada Neste estudo, a presença de quilha na superfície ventral do EB1 é 
uma sinapomorfia do grupo Acanthicus mais Spectracanthicus; e do clado que inclui o gênero Scobinancistrus. Em Megalancistrus barrae este caráter não foi observado por falta de material preparado

28. Processo anterior do quarto epi-branquial (EB4) $[\mathrm{CI}=0,50 ; \mathrm{RI}=0,75]$

(Armbruster, 2004\#16):

(0) ausente ou curto;

(1) desenvolvido.

Na maioria dos Loricariidae, o processo anterior do EB4 é curto ou ausente. Em Leporacanthicus este processo é desenvolvido e este caráter é uma sinapomorfia para o gênero. Dentre os táxons analisados, este caráter ocorre independentemente em Hypancistrus, Em Megalancistrus barrae este caráter não foi observado por falta de material preparado.

29. Expansão laminar posterior do $\mathrm{EB} 4[\mathrm{CI}=0,20 ; \mathrm{RI}=0,55]$

(0) ausente ou bastante curta;

(1) presente e conspícua.

A expansão laminar posterior do EB4 na maioria dos táxons analisados é presente e conspícua. Entretanto, em alguns táxons a expansão é ausente, como em Panaqolus, em Spectracanthicus sp "Tapajós" e em Leporacanthicus. Em Megalancistrus barrae e Pseudacanthicus sp. "aba laranja" este caráter não foi observado por falta de material preparado

Hipo-branquial

30. Forma do primeiro hipo-branquial $[\mathrm{CI}=0,20$; $\mathrm{RI}=0,42]$ 
(ordenado; modificado de Py-Daniel, 1997\#71; Ghazzi, 2003\#51; Armbruster, 2004\#22 e 23; Paixão, 2004\#12.):

(0) curto;

(1) moderadamente alongado;

(2) bastante alongado (Figuras 15 e 16).

Em Loricariidae, cinco pares de hipo-branquaiais estão presentes, o primeiro sempre ossificado e os demais cartilaginosos (Schaefer, 1987). Em geral o primeiro hipo-branquial geralmente é em forma de bastão, entretanto, alguns táxons dentro da família podem apresentar uma condição mais derivada, com as extremidades expandidas conferindo ao osso uma forma mais alongada. O primeiro hipo-branquial bastante alongado é uma sinapomorfia de Pseudacanthicus e Leporacanthicus, com reversões em Pseudacanthicus sp. "açacu preto". P. spinosus e P. leopardus. A mesma condição também ocorre em Spectracanthicus sp. "bola branca", Spectracanthicus sp. "Tocantins" e Acanthicus hystrix. Em Megalancistrus barrae este caráter não foi observado por falta de material preparado.

Inter-hial

31. Posição do inter-hial (ordenado) $[\mathrm{CI}=0,28 ; \mathrm{RI}=0,78]$

(0) no hiomandibular, sem contato com a área de cartilagem do quadrado (Figura 18, A);

(1) no hiomandibular em contato com a área de cartilagem do quadrado, mas sem contato com o quadrado (Figura 18, B);

(2) em contato com o hiomandibular e o quadrado.

De acordo com Schaefer (1987), o inter-hial dos Loricariidae está presente, porém reduzido a um osso bem pequeno e fino que está firmemente associado com a face medial do hiomandibular. Dentre os táxons observados, o inter-hial pode estar aderido ao suspensório de três formas. No grupo Acanthicus o inter-hial está totalmente no hiomandibular, sem nenhum contato com o quadrado ou mesmo a área de cartilagem entre estes dois ossos. Em Spectracanthicus o inter-hial faz contato com o hiomandibular e o quadrado; exceto em 
Spectracanthicus sp. "Tapajós” no qual o inter-hial está localizado no hiomandibular, porém em contato apenas com a área de cartilagem. Em Acanthicus adonis e Megalancistrus barrae este caráter não foi observado por falta de material preparado.

32. Tamanho do inter-hial $[\mathrm{CI}=0,50 ; \mathrm{RI}=0,92]$

(0) pequeno (Figura 18, A);

(1) grande (Figura 18, B).

Nos táxons do grupo Acanthicus o tamanho do inter-hial pequeno é uma sinapomorfia, que também ocorre em Ancistrus taunayi. Em Acanthicus adonis, Baryancistrus sp., Hemiancistrus cerrado e Megalancistrus barrae este caráter não foi observado por falta de material preparado.

\section{Placa faríngea superior}

33. Placa faríngea superior $[\mathrm{CI}=1,00 ; \mathrm{CI}=1,00]$; Armbruster, 2004\#30.

(0) com uma projeção medial e uma área de bulbos elevada, com dentes restritos a esta área e à extremidade posterior da projeção arredondada;

(1) com dentes distribuídos por toda a superfície (Figura 17, A).

Nos teleósteos, a placa faríngea superior consiste em parte de uma ou cinco placas dentígeras, geralmente pareadas ou grupos de placas dentígeras denominadas de "placas faríngeas superiores 1-5” (UP 1-5). Cada uma provavelmente representa a parte medial das séries anteriores de elementos dérmicos associados com o arco branquial. Tipicamente, algumas placas são fusionadas com o segundo e terceiro infrafaringobranquiais (Nelson, 1969). Segundo Armbruster (2004), na maioria dos loricarídeos a placa faríngea superior consiste numa seção bulbosa e uma projeção mediana ou é robusta em todo o seu comprimento. Em alguns táxons dentro da família a placa faríngea pode ser redonda, como no gênero Leporacanthicus, no qual este caráter é considerado como uma sinapomorfia exclusiva. 
34. Base da placa faríngea superior $[\mathrm{CI}=0,33 ; \mathrm{RI}=0,66]$

(0) sem invaginação;

(1) com invaginação.

Na maioria dos Loricariidae, a base da placa faríngea superior possui um invaginação. A placa faríngea superior sem invaginação é uma sinapomorfia de Leporacanthicus.

\section{Suspensório}

De acordo com Arratia (1990), em Teleostei o suspensório se origina ontogeneticamente a partir de duas estruturas cartilaginosas: pars hyosimpletica, correspondente ao ramo dorsal do arco hióide, que origina o hiomandibular e o simplético; e o pars palatoquadrada, que origina o autopalatino, quadrado e metapterigóide. Em Siluriformes ocorreu uma série de modificações no suspensório, entre essas, a perda do simplético; divisão da pars palatoquadrada em pars palatina e pars pterigoquadrada e a fusão desta última com a pars hyosimpletica nos primeiros estágios da ontogenia e a ossificação de alguns ligamentos, originando ossos sesamóides entre o metapterigóide e a região ântero-ventral do neurocrânio (Howes, 1983b, 1985; Arratia \& Schultze, 1991; Arratia, 1992; Britto, 2002).

Em Loricariidae, o suspensório consiste no hiomandibular, quadrado, metapterigóide e pré-opérculo. Os loricariídeos perderam o ecto-, endo-, e mesopterigóide que está variavelmente presente em outros Siluriformes. A homologia da série pterigóide em Siluriformes é problemática e vários grupos perderam um ou mais elementos e os ossos remanescentes possuem uma grande variação na sua forma. Em Diplomystes o mesopterigóide é reduzido a uma pequena placa posterior ao palatino (Arratia, 1992). Nos loricariídeos há apenas um elemento entre o hiomandibular e o palatino; e a forma deste elemento parece com a condição primitiva da porção endocondral do metapterigóide descrito por Fink \& Fink (1981). Este osso possui forma mais ou menos triangular e nos Loricariidae e Astroblepidae está suturado com o hiomandíbular posteriormente e com o quadrado ventralmente (Schaefer, 1987). 
Howes (1985) in Schaefer (1987) sugeriu que o hiomandibular e o metapterigóide tenham se desenvolvido de um mesmo centro endocondral e depois a extensão ântero-dorsal do hiomandibular teria se tornado o composto entre hiomandibular e metapterigóide. Entretanto, a possibilidade destes ossos terem sido originados de um mesmo centro endocondral é uma evidência que sozinha é insuficiente para suportar esta homologia. Em Loricariidae, de acordo com a hipótese de Howes, o hiomandibular e o metapterigóide seriam fusionados e o mesopterigóide expandido na mesma posição, relativo ao hiomandibular e ao quadrado, como o metapterigóide em Diplomystes e outros Ostariophysi (Schaefer, 1987).

\section{Hiomandibular}

35. Margem anterior do hiomandibular suturada ao metapterigóide ao longo de todo comprimento $[\mathrm{CI}=0,14 ; \mathrm{RI}=0,57]$

(0) não (Figuras 19, 20 e 21);

(1) $\operatorname{sim}$ (Figuras 22 e 23).

O hiomandibular é o maior osso que compõe o suspensório de Loricariidae. De forma geral em Loricariidae, o limite póstero-dorsal possui uma articulação cranial sincondral com o pterótico-supracleitro e o pró-otico. Anterior a essa junção sincondral o processo dorsal do hiomandibular contata o pró-otico; e a margem posterior está suturada com o pteróticosupracleitro. A margem anterior está suturada ao metapterigóide, enquanto a margem ventral está suturada ao pré-opérculo (Schaefer, 1987). Segundo Armbruster (2004), na maioria das espécies de Loricariidae a seção ântero-dorsal do hiomandibular não é suturada ao metapterigóide, deixando uma pequena ou grande área entre os dois ossos. O hiomandibular totalmente suturado ao metapterigóide é uma sinapomorfia de Pseudacanthicus. Este caráter ocorre também em Megalancistrus parananus e Spectracanthicus murinus.

36. Hiomandibular defletido além da margem posterior $[\mathrm{CI}=0,20 ; \mathrm{RI}=0,73]$

(0) não;

(1) $\operatorname{sim}$. 
Segundo Amrbruster (2004), o hiomandibular da maioria dos loricarídeos não é defletido além da sua margem posterior. Em alguns Ancistrini, na margem posterior do hiomandibular há um prolongamento. Dentre os táxons analisados, a presença do hiomandiblular defletido é uma sinapomorfia do grupo Acanthicus mais Spectracanthicus, com reversão em Pseudacanthicus. Nos táxons do grupo externo, este caráte também ocorre em Panaque e Panaqolus, Hemiancistrus cerrado e Ancistrus taunayi.

37. Crista no hiomandibular, contínua à crista do quadrado $[\mathrm{CI}=0,50 ; \mathrm{RI}=0,92]$

(0) ausente (Figuras 19 e 20);

(1) presente (Figuras 21, 22, 23 e 24).

No quadrado de grande parte dos Ancistrini há uma crista longitudinal que acompanha o comprimento do osso. Em algumas espécies, esta crista pode se prolongar até o hiomandibular. Na maioria dos táxons de Loricariidae, esta crista é ausente. Neste estudo, a presença de crista no hiomandibular é uma sinapomorfia exclusiva do grupo Acanthicus, com exceção de Acanthicus, onde houve reversão e a crista é ausente.

38. Face de articulação do hiomandibular com o pró-ótico [CI=0,33; RI=0,84]

(0) curta;

(1) alongada.

Em sua porção meso-posterior, o hiomandibular está conectado ao pró-ótico. $\mathrm{Na}$ maioria das espécies analisadas, a face de articulação do hiomandibular com o pró-ótico é curta. Em Leporacanthicus e Pseudacanthicus, esta porção do osso é alongada; este caráter é uma sinapomorfia deste clado e também ocorre no grupo externo em Peckoltia vittata e Scobinancistrus pariolispos.

\section{Metapterigóide}

39. Face lateral do canal metapterigóide $[\mathrm{CI}=0,25-0,28 ; \mathrm{RI}=0,40-0,50]$ : 
(0) arredondada em toda sua extensão (Figuras 22 e 23);

(1) triangular (Figuras 26 e 28);

(2) reta e perpendicular ao metapterigóide (Figura 30).

O metapterigóide é um osso de forma triangular, que ventralmente está suturado com o hiomandibular e o quadrado, que são separados por uma grande área de cartilagem. A margem anterior é espessa medialmente e suporta um tecido de conexão que se estende anteriormente ao dentário, palatino e pré-maxila. A margem dorsal do metapterigóide dos loricarídeos é especializada em um canal pterigóide que anexa parcialmente a subdivisão ventral do músculo extensor tentaculi. A morfologia do canal pterigóide e particularmente a forma é bastante variável nos gêneros de Loricariidae (Schaefer, 1987).

Dentre as espécies analisadas, a maioria possui a face lateral do canal metapterigóide arredondada, exceto Pseudacanthicus sp. "aba laranja", Pseudacanthicus sp. "Tocantins", Pseudacanthicus sp. "Aripuanã", Spectracanthicus sp. "Tapajós” e S. punctatissimus, que possuem a face lateral triangular. Em Panaque e Panaqolus, a face lateral é reta e perpendicular ao metapterigóide, condição que representa uma sinapomorfia exclusiva do clado.

40. Face lateral do canal metapterigóide $[\mathrm{CI}=0,50 ; \mathrm{RI}=0,75]$

(0) alta;

(1) baixa (Figura 21, 22 e 23 B).

Além das diversas formas, a face lateral do canal metapterigóide pode ter também diferença no tamanho. Na maioria das espécies analisadas a face lateral é alta. A face lateral baixa é uma sinapomorfia de Megalancistrus e de Pseudacanthicus sp. "Curuá-Una", P. spinosus e $P$. leopardus.

41. Superfície de articulação entre o metapterigóide e o etmóide lateral $[\mathrm{CI}=0,50 ; \mathrm{RI}=0,87]$ :

(0) sem contato com a parede lateral do metapterigóide; 
(1) totalmente conectada à parede lateral do metapterigóide por uma ponte reta.

De modo geral, em Loricariidae, o metapterigóide faz contado anterior ou posterior com o etmóide lateral e não tem contado na sua porção lateral. Em Megalancistrus e Acanthicus este contato se faz em toda a extensão do osso através de uma ponte reta. Esta condição também ocorre no clado que inclui Peckoltia, Scobinancistrus, Panaque e Panaqolus, sento considerada uma sinapomorfia também para este clado.

42. Processo anterior do metapterigóide $[\mathrm{CI}=0,50 ; \mathrm{RI}=0,75]$

(0) curto (Figura 28);

(1) alongado (Figuras 25, 26, 27 e 29).

Em Loricariidae, o metapterigóide se articula anteriormente ao auto-palatino. Este contato se faz através de um processo anterior que em geral é curto ou ausente. Dentre os táxons analisados, este processo está presente e é curto. Em Spectracanthicus (exceto Spectracanthicus sp. "Tapajós”), este processo é alongado e este caráter é uma sinapomorfia para o gênero. Esta condição também foi observada em Panaque.

43. Processo anterior do metapterigóide (ordenado) $[\mathrm{CI}=0,50 ; \mathrm{RI}=0,66]$

(0) sem projeção (Figura 21);

(1) com uma projeção (Figuras 22 e 23);

(2) com duas projeções (Figura 24).

O processo anterior do metapterigóide pode ser curto e reto e desta forma, não apresentar nenhuma projeção, ou pode apresentar uma ou duas projeções anteriores. A ausência de projeção é uma sinapomorfia de Megalancistrus, condição também compartilhada com Pseudacanthicus sp. "açacu preto" e Pseudacanthicus sp. "Aripuanã”. A presença de duas projeções é considerada neste estudo uma sinapomorfia exclusiva de Leporacanthicus. 
Quadrado

O quadrado dos Loricariidae possui uma forma triangular como na maioria dos Siluriformes; possui uma longa sutura com o metapterigóide e o pré-opérculo e uma pequena sutura com o hiomandibular (Schaefer, 1987).

44. Expansão lateral no quadrado, abaixo do forame simplético $[\mathrm{CI}=0,33 ; \mathrm{RI}=0,50]$

(0) ausente;

(1) presente (Figura 30).

Segundo Armbruster (2004) o quadrado na maioria dos loricarídeos é um osso triangular sem expansão lateral. Em grande parte de Ancistrini, o quadrado possui expansão lateral, exceto no grupo Acanthicus e em Exastilithoxus. Neste estudo, dentre os táxons analisados, esta condição está presente apenas em Parancistrus, em Scobinancistrus e em Panaque.

45. Côndilo de articulação do quadrado com o angulo-articular [CI=0,50; RI=0,85]

(0) fino e pontudo ou de espessura moderada;

(1) grosso e redondo (Figuras 24 e 30).

Em sua posição mais distal, o quadrado possui um côndilo de articulação com o ângulo-articular, que por sua vez está firmemente conectado com o dentário. Em geral, o côndilo de articulação entre o quadrado e o ângulo-articular em Loricariidae é fino e pontudo. Em Leporacanthicus este côndilo é grosso e redondo. Esta condição também ocorre em Scobinancistrus, Panaque e Panaqolus, sendo uma sinapomorfia compartilhada por ambos os clados. Segundo Amrbruster (2004), além de nos táxons citados, este caráter também ocorre no grupo Chaetostoma, alguns Hemipsilichthys e Lithoxancistrus. 
46. Crista longitudinal lateral ao comprimento do quadrado $[\mathrm{CI}=0,33 ; \mathrm{RI}=0,50]$

(0) ausente;

(1) presente.

No quadrado da maioria dos Ancistrini há uma crista longitudinal que acompanha o comprimento do osso. Neste estudo, a presença desta crista é uma sinapomorfia exclusiva do clado que inclui todos os táxons analisados, exceto Ancistrus taunayi, Baryancistrus sp. e Pseudancistrus brevispinis.

\section{Arco mandibular}

Segundo Schaefer \& Lauder (1986), os Loricariidae possuem uma grande diversidade de tamanho e forma de maxilas e dentes, provavelmente em conseqüência da adaptação a diversos tipos de hábitat e substratos que exploram. Além disso, outras especializações em relação à osteologia e a musculatura hióide, adaptadas ao mecanismo alimentar também pode ser notada em Loricariidae.

\section{Dentário}

47. Ângulo dos dentários $[\mathrm{CI}=0,50 ; \mathrm{RI}=0,80]$

(0) oblíquo;

(1) agudo ou reto.

A mandíbula dos Siluriformes compreende o dentário e o ângulo-articular. Nos Siluriformes primitivos, o dentário é geralmente pouco profundo e termina na junção do ângulo-articular, onde este se expande para formar o processo coronóide do dentário para inserção dos músculos adutores (Schaefer, 1987).

A maioria dos Loricariidae possui o ângulo de encontro dos dentários aproximadamente maior que $90^{\circ}$ (oblíquo). Em diversos táxons de Ancistrini e Loricariini, o ângulo de encontro dos dentários é reto ou agudo, aproximadamente $80^{\circ}$ (Armbruster, 2004). $\mathrm{O}$ ângulo de encontro entre os dentários agudo ou reto é uma sinapomorfia exclusiva do clado 
que inclui o grupo Acanthicus, Spectracanthicus, Panaque, Panaqolus, Scobinancistrus, Peckoltia vittata, Parancistrus e Hypancistrus sp. (com exceção de Acanthicus, no qual este ângulo é oblíquo)

Maxilar

48. Ângulo do maxilar $[\mathrm{CI}=0,50 ; \mathrm{RI}=0,90]$

(0) angulado dorsalmente a levemente angulado ventralmente (Figura 31, A);

(1) bastante angulado ventralmente, quase formando um angulo reto (Figuras 31, B-D; 32 e $33)$.

Nos Siluriformes, o maxilar apresenta uma série de modificações em relação à condição deste osso nos demais Otophysi. Entre essas modificações, o maxilar dos Siluriformes (exceto em Diplomystes e Hypsidoris ఔ) é extremamente reduzido e não se articula com a mandíbula. Além disso, o maxilar neste grupo não participa da abertura da boca e está restrito a sustentação do barbilhão maxilar (Britto, 2002).

O maxilar em Loricariidae é relativamente largo e espesso; possui um par e côndilos que se projetam mesialmente e se articulam com a cartilagem palatina (Schaefer, 1987). Segundo Armbruster (2004), a maioria dos loricarídeos possui os maxilares ligeiramente angulados ventralmente e dorsalmente; condição compartilhada com Callichthyidae e Astroblepus. Entretanto, em algumas espécies a orientação dos maxilares forma praticamente um ângulo reto. Esta condição está presente na maioria dos táxons analisados e é uma sinapomorfia exclusiva para o clado que inclui Peckoltia vittata, Scobinancistrus, Panaque e Panaqolus; mais Spectracanthicus e mais o grupo Acanthicus (exceto Acanthicus e Megalancistrus).

49. Forma do maxilar $[\mathrm{CI}=0,50 ; \mathrm{RI}=0,91]$

(0) alongado, estreito, com largura uniforme (Figura 31, A);

(1) largo e arredondado distalmente (Figuras 31 D e D; 33, A). 
Embora o maxilar apresente algumas modificações em Siluriformes em relação aos demais Otophysi, esse osso apresenta um aspecto laminar, com um perfil aproximadamente reto e algumas vezes ligeiramente curvo posteriormente (Britto, 2002). De acordo com Armbruster (2004), na maioria dos loricarí́deos, o maxilar possui uma forma alongada e estreita e é uniformemente largo. Em alguns grupos, entretanto, o maxilar é largo e arredondado distalmente. Este caráter é uma sinapomorfia de Pseudacanthius e Leporacanthicus e está presente também em Spectracanthicus murinus.

\section{Pré-maxilar}

50. Forma do pré-maxilar (ordenado) $[\mathrm{CI}=0,75 ; \mathrm{RI}=0,94]$

(0) largo e curto (Figura 31, A);

(1) moderadamente estreito e alongado (Figura 31, B e C; e 33);

(2) bastante estreito e alongado (Figura 31, D).

O pré-maxilar em Loricariidae não está firmemente associado aos processos laterais do mesetmóide; essa condição também é compartilhada com Astroblepidae e Callichthyidae (Schaefer, 1987). A forma especializada do pré-maxilar em Loricariidae garantiu alta mobilidade dessa estrutura, que é independente ao movimento do maxilar. Esta mobilidade do pré-maxilar está correlacionada à aquisição de musculatura aderida à subdivisão medial do complexo adutor retractor palatini (Schaefer \& Lauder, 1986). A forma do pré-maxilar pode variar dentro dos gêneros de Loricariidae (Schaefer, 1987).

Nos táxons analisados, há uma variação quanto à forma em relação ao seu comprimento e largura; na maioria das espécies o pré-maxilar possui a largura maior que altura ou é tão largo quanto alto. Em Leporacanthicus e Pseudacanthicus o pré-maxilar é alongado, mais alto do que largo e esta condição é uma sinapomorfia exclusiva deste clado. Em Leporacanthicus o pré-maxilar é ainda mais estreito e alongado, condição sinapomórfica do gênero. Isto parece estar relacionado com o número e a forma dos dentes nestes gêneros, que são pouco numerosos, bastante alongados e curvados principalmente em Leporacanthicus. 


\section{Dentes}

Os dentes de Hypostominae possuem uma grande modificação e formas idênticas, tanto no pré-maxilar como no dentário. Entretanto, há uma grande variabilidade no número de dentes e na morfologia da cúspide dentro dos gêneros de Loricariidae (Schaefer, 1987).

Segundo Zuanon (1999), dentre 20 espécies de Loricariidae analisados por ele, o exame do conteúdo estomacal revelou que 17 possuíam alimento de origem animal, embora em pouca quantidade na maioria dos casos. Entretanto, Scobinancistrus aureatus e Scobinancistrus cf. pariolispos foram consideradas carnívoras, pois consumiram alimentos exclusivamente de origem animal. Outras espécies, como Peckoltia vittata, Hypancistrus zebra e Spectracanthicus punctatissimus foram consideradas onívoras, pois apresentaram $63 \%$ e $49 \%$ de freqüência relativa de alimentos de origem vegetal.

Estes resultados indicam que, ao contrário do que se pensava, os loricarídeos consomem diversos recursos alimentares e não apenas algas aderidas ao substrato. Dessa forma, a grande variação na morfologia dentária dentro da família garantiu o sucesso por busca de diferentes recursos alimentares e a conseqüente ocupação de diversos nichos.

51. Número de dentes no pré-maxilar (ordenado) $[\mathrm{CI}=0,50 ; \mathrm{RI}=0,71]$

(0) dentes numerosos (+ de 25 em cada pré-maxila; figura 31, A);

(1) dentes moderadamente numerosos (5 a 25 em cada pré-maxila; figura 31, B e C);

(2) número de dentes bastante reduzidos (no máximo 4 em cada pré-maxila; figura 31, D).

Diversos autores utilizaram o número de dentes como um caráter diagnóstico para os gêneros e espécies de Loricariidae. Inicialmente, esse caráter foi utilizado por Boeseman (1971) como uma evidência das relações entre os loricarídeos. Schaefer (1997) relacionou a presença de 14-18 dentes no pré-maxilar como uma condição plesiomórfica para a subfamília Hypoptopomatinae. Segundo Rapp Py-Daniel (1997), a presença de mais de 50 dentes em cada pré-maxilar é considerada uma condição plesiomórfica para os Siluriformes.

De acordo com Muller \& Weber (1992), o número de dentes, assim como sua forma, podem variar ontogeneticamente em Hypostominae e Ancistrinae. Geralmente indivíduos adultos tendem a apresentar maior número de dentes. Dessa forma, a contagem de dentes 
apresentada neste caráter foi realizada apenas em indivíduos adultos. Dentre os táxons analisados neste estudo, o número de dentes está diretamente relacionado com o tamanho do pré-maxilar. Nas espécies de menor ramo pré-maxilar, há também menor número de dentes.

A maioria das espécies analisadas neste estudo possui dentes moderadamente numerosos no pré-maxilar. A presença de dentes numerosos no pré-maxilar é uma sinapomorfia de Acanhticus, enquanto que a redução extrema de dentes é uma sinapomorfia exclusiva de Leporacanthicus.

52. Forma dos dentes (ordenado) $[\mathrm{CI}=0,40 ; \mathrm{RI}=0,76]$

(0) fino ou pouco robusto (Figuras, 31, A e 33, C);

(1) moderadamente robusto;

(2) bastante robusto (Figura 30).

A maioria das espécies de Loricariidae possui dentes finos. Espécies que se alimentam de madeira possuem os dentes em forma de colher e a cúspide lateral é reduzida ou ausente em alguns casos (Armbruster, 2004).

A maioria dos táxons analisados apresenta os dentes moderadamente robustos. A presença de dentes bastante robustos é uma sinapomorfia exclusiva de Scobinancistrus, Panaque e Panaqolus. Enquanto a presença de dentes finos é uma condição sinapomórfica para Acanthicus; que também é compartilhada com Spectracanthicus sp. "Tapajós" e os demais táxons do grupo externo

53. Cúspide lateral dos dentes (ordenado) $[\mathrm{CI}=0,33 ; \mathrm{RI}=0,57]$

(0) ausente;

(1) bastante reduzida;

(2) pequena;

(3) grande. 
$\mathrm{Na}$ maioria de Loricariidae os dentes possuem cúspide lateral, que geralmente é bem desenvolvida. A forma mais comum de dentes em loricarí́deos é com a coroa bicúspide, com a cúspide "principal" maior e mais larga que a "lateral" (Muller \& Weber, 1992; Zuanon, 1999). Segundo Muller \& Weber (1992), a variação da forma e do número de dentes dentre Hypostominae e Ancistrinae podem ser utilizadas com características diagnósticas de algumas espécies.

A condição de dentes unicúspides parece ser secundária dentro da família Loricariidae, visto que apenas poucas espécies (eg. Pareiorhina rudolphi e P. carrancas) possuem dentes simples. Em algumas espécies (como dentro do grupo Hypostomus unicolor) os machos em períodos reprodutivos obtêm dentes alongados e unicúspides; e posteriormente a este período voltam a apresentar dentes cuspidados (Armbruster, 1997). Segundo Rapp Py-Daniel \& Cox Fernandes (2005), em machos de Loricariidae o alargamento e arredondamento da coroa dos dentes bucais foram diagnosticados como dimorfismo em períodos reprodutivos. Apesar de aparentemente provisório (já que loricarídeos têm uma rápida reposição de dentes bucais), em algumas espécies, este dimorfismo parece ser permanente, podendo ser observado em machos sexualmente imaturos.

Neste estudo, não foi relatado nenhuma forma de dimorfismo sexual através de diferenças de dentes e cúspides. De forma geral, as espécies analisadas possuem dentes com cúspide grande. Em Leporacanthicus, a cúspide é pequena e esta condição também ocorre em Pseudacanthicus sp. "açacu vermelho", Pseudacanthicus sp. "aba laranja" e Pseudacanthicus sp. "Tocantins" e Scobinancistrus. Enquanto Panaqolus possui cúspide bastante reduzida e Panaque ausente.

54. Tamanho dos dentes $[\mathrm{CI}=0,50 ; \mathrm{RI}=0,75]$

(0) curto;

(1) alongado.

A maioria das espécies em Loricariidae possui dentes alongados. Em Scobinancistrus, Panaque e Panaqolus os dentes são curtos e esta condição é uma sinapomorfia para este clado, que também ocorre em Spectracanthicus murinus. 
55. Extremidade distal dos dentes bastante curvada $[\mathrm{CI}=0,50 ; \mathrm{RI}=0,92]$

(0) não (Figura 31, A);

(1) $\operatorname{sim}$ (Figura 31, B-D).

A extremidade distal dos dentes de Loricariidae em geral é pouco curvada. No grupo Acanthicus (exceto Acanthicus), a ponta dos dentes é bastante curvada, dando a impressão de um gancho. Este caráter é uma sinapomorfia exclusiva deste clado, com reversão em Acanthicus.

56. Forma dos dentes $[\mathrm{CI}=1,00 ; \mathrm{RI}=1,00]$

(0) forma cilíndrica;

(1) em forma de colher (Figura 30);

(2) em forma de espátula.

Os dentes de loricarídeos geralmente possuem formato cilíndrico. Em Panaque e Panaqolus, o dente possui forma de colher e em Scobinancistrus, forma de espátula. Em Panaque os dentes modificados são uma adaptação ao modo de alimentação, que consiste em se alimentar de madeiras e troncos (Armbruster, 2004).

\section{Série opercular}

A série opercular de Otophysi é constituída pelo pré-opérculo, sub-opérculo, interopérculo e opérculo. O pré-opérculo também está associado ao suspensório e ao arco mandibular (Britto, 2002). Nos Siluriformes, o sub-opérculo está ausente (Fink \& Fink, 1981) e o inter-opérculo está articulado apenas com o opérculo. Em Loricariidae, houve ainda a perda do inter-opérculo, condição compartilhada também com Scoloplacidae (Schaefer, 1987, 1988, 1990).

Opérculo 
57. Forma do opérculo $[\mathrm{CI}=0,66 ; \mathrm{RI}=0,66]$

(0) triangular (Figura 25);

(1) em forma de barra curvada (Figuras 22, 23 e 24);

(2) em forma de barra longitudinal (Figuras 19 e 20).

Em Siluriforme, o opérculo apresenta um formato laminar, porém com os vértices arredondados (Britto, 2002). De acordo com Schaefer (1988), o opérculo na maioria de Siluriformes possui a forma triangular e é caracterizado pela articulação sindesmótica com o processo do côndilo do hiomandibular. A faceta de articulação do opérculo está situada anteriormente em Diplomystes e na maioria dos Siluriformes. Dentro de Loricarioidea, a articulação foi modificada a uma posição dorsal em Loricariidae e Astroblepidae.

Em Loricariidae, o opérculo apresenta grande variação de formas. No estado primitivo, o opérculo apresenta uma forma triangular, condição encontrada em todos os Hypoptopomatinae, Loricariinae e Hypostominae (Schaefer, 1987). Em Ancistrini, o opérculo apresenta duas formas, em forma de uma barra curvada, como uma foice, típica forma de Peckoltia ou em forma de uma barra longitudinal, típica forma de Ancistrus (Armbruster, 2004). Schaefer $(1986,1987)$ postulou que o opérculo inicialmente perde a projeção pósterolateral e depois a seção lateral se torna desviada. O opérculo modificado está presente em quase todos os Ancistrini, exceto em Spectracanthicus murinus, que possui opérculo triangular. Em Acanthicus, o opérculo é em forma de barra longitudinal e na maioria dos Ancistrini analisados, o opérculo é em forma de barra curva.

58. Mobilidade do operculo [não informativo]

(0) ausente;

(1) presente (eversível até 90 graus).

Dentre a maioria dos Loricariidae, a mobilidade de placas operculares está ausente, entretanto esse caráter está amplamente distribuído em Ancistrini. Dentre os táxons analisados, apenas Spectracanticus murinus não possui mobilidade destas placas e este caráter é uma autapomorfia desta espécie. 
59. Odontódeos desenvolvidos no opérculo [não informativo]

(0) ausente (Figura 25);

(1) presente (Figura 19).

A presença de espinhos no opérculo é uma condição ausente na maioria de Loricariidae, entretanto, este caráter está presente em quase todas as espécies de Ancistrini. Alguns autores (Isbrücker, 1980 e Schaefer, 1986, 1987) diagnosticaram a tribo Ancistrini pela presença e a mobilidade destes espinhos. Regan (1904) também reconheceu que Pterygoplichthys também possuía espinhos eversíveis no opérculo. Mais recentemente, Amrbruster (2004) quebrou a subfamília Hypostominae em cinco tribos, entre elas, Ancistrini Kner, 1853 e Pterygoplichthini nova tribo. A presença de espinhos no opérculo e a mobilidade destes são compartilhadas com quase todos os membros de Ancistrini e Pterygoplichthyni, apenas em Spectracanthicus murinus esta condição não está presente.

\section{Sistema látero-sensorial}

60. Número de infra-orbitais $[\mathrm{CI}=1,00 ; \mathrm{RI}=1,00]$

(0) cinco a seis;

(1) sete a oito (Figuras 7 e 10).

Em Ostariophysi primitivos, os elementos infra-orbitais são placas ósseas que cobrem parcialmente a musculatura adutora do rostro (Fink \& Fink, 1981). Estes elementos são reduzidos ao canal infra-orbital em Siluriformes primitivos (Taylor, 1969). A natureza expandida dos infra-orbitais em Loricariidae e Callichthyidae foi considerada como derivada secundariamente (Fink \& Fink, 1981). Lundberg (1970) considera que o número de infraorbitais dentre os Siluriformes varia de quatro a 12. Schafer (1987) e Rapp Py-Daniel (1997) consideram que o número de infra-orbitais em Loricariidae varia de cinco a seis. 
Segundo Armbruster (2004), em Callichthyidae o número de infra-orbitais é dois, enquanto que a maioria de Loricariidae possui cinco ou seis. Entretanto, em algumas espécies, esse número pode ser maior, variando de sete a 10. Dentre os táxons analisados no presente estudo, várias espécies do grupo Acanthicus, possuem entre sete e oito infra-orbitais. A presença de sete a oito infra-orbitais é uma sinapomorfia exclusiva do clado que inclui Peckoltia vittata, Scobinancistrus, Panaque, Panaqolus; mais Spectracanthicus e o grupo Acanthicus.

61. Contato do quarto infra-orbital ( $\mathrm{IO} 4)$ com a órbita $[\mathrm{CI}=0,16 ; \mathrm{RI}=0,61]$

(0) bastante contato com a órbita através de sua extremidade posterior (Figura 7);

(1) contato com a órbita ausente ou pequeno.

Dentre as espécies de Loricariidae, o quarto infra-orbital normalmente forma a margem anterior da órbita. Em algumas espécies o quarto infra-orbital está completamente separado da órbita ou possui apenas pequeno contato. Em Pseudacanthicus, o IO4 faz bastante contato com a órbita, esta condição também é compartilhada por Acanthicus, Spectracanthicus sp. “Tocantins", Peckoltia vittata e Ancistrus taunayi.

62. Sexto infra-orbital (IO6) $[\mathrm{CI}=0,50 ; \mathrm{RI}=0,75]$

(0) forma apenas a parte póstero-ventral da órbita;

(1) forma toda a borda ventral da órbita (Figura 8).

O sexto infra-orbital de Loricariidae, de modo geral, forma apenas a parte pôsteroventral da órbita. Em Leporacanthicus, o IO6 é bastante alongado ventralmente e circunda toda a borda ventral da órbita. Esse caráter é uma sinapomorfia não exclusiva deste clado e é compartilhado também com Panaque.

63. Linha lateral $[\mathrm{CI}=0,33 ; \mathrm{RI}=0,66]$ 
(0) não ultrapassa a placa hipural;

(1) ultrapassa a placa hipural .

Geralmente, nos Siluriformes, o canal sensorial da linha lateral segue uma orientação aproximadamente reta ao longo da região lateral do corpo, se estendendo próxima ou lateralmente a placa hipural (Arratia \& Huaquin, 1995; Britto, 2002).

Em Loricariidae e em Callichthyidae, os canais da linha lateral estão associados a placas dérmicas. Segundo Schaefer (1988), a linha lateral de Loricariidae é bem similar a de um Siluriforme generalizado. Em Diplomystes, a linha lateral entra no supra-cleitro e passa dorsalmente dentro do pterótico, onde adquire um curto ramo lateral e o ramo pré-opercular antes de dar continuidade dentro do esfenótico. Em Loricariidae, a linha lateral entra no pterótico-supracleitro, logo anteriormente a sexta costela estendida na sexta vértebra e posterior ao cleitro. O canal percorre anterior e medialmente, onde se continua nos ramos pôstero-lateral, pré-opercular e temporal.

Segundo Armbruster (2004), em Callichthyidae, Astroblepus e na maioria de Loricariidae a linha lateral termina antes do fim da placa hipural e em algumas espécies, a linha lateral se estende além da placa hipural, como em Acanthicus, Leporacanthicus e Panaque.

\section{Aparelho de Weber e esqueleto axial}

\section{Aparelho de Weber}

$\mathrm{O}$ aparelho de Weber é constituído por um conjunto de ossículos que liga a bexiga natatória com o ouvido interno de Otophysi. Esse aparelho transmite ao labirinto as variações de pressão sentidas pela bexiga natatória. Essa conexão ajuda na detecção de sons e possibilita localizar a fonte que produz a onda sonora (Chardon, 1968). Segundo Rosen \& Greenwood (1970), a integridade filogenética de Ostariophysi é indicada mais pela presença dessa conexão do que pela presença de outros caracteres.

Nos Characiformes e Cypriniformes, o aparelho de Weber se apresenta a condição mais primitiva em Ostariophysi. Os quatro ossículos são grandes, completos e estão 
claramente conectados às vértebras, e o claustrum está articulado ao escaphium. A bexiga natatória é dividida em uma câmara anterior com função sensorial e uma câmara posterior à função hidrostática. Nos Siluriformes, o claustrum está separado dos canais de ossículos e as vértebras 2-4 são fusionadas em um complexo ósseo. As duas câmaras da bexiga natatória estão reunidas em um órgão cordiforme único (Chardon, 1968).

Em Loricarioidea, o aparelho de Weber possui alta especialização em relação à condição primitiva dos Siluriformes. Em Loricariidae, a bexiga natatória é encapsulada e consiste em duas partes: uma parte mediana contínua e sem sutura com a vértebra complexa e uma parte lateral que é formada pelo pterótico-supracleitro (pós-temporal de Alexander, 1964). A cápsula se comunica com a superfície da pele via os poros do pterótico-supracleitro (Schaefer, 1987).

64. Tamanho do Centro Complexo (CC) $[\mathrm{CI}=0,50 ; \mathrm{RI}=0,75]$ :

(0) relativamente curto;

(0) alongado.

Em Loricariidae, o centro complexo de Weber é fusionado anteriormente ao basioccipital e suturado a sexta vértebra posteriormente (Schaefer, 1987). Na maioria dos Loricariidae, o Centro Complexo de Weber é relativamente curto. O alongamento do CC ocorre em Acanthicus e Megalancistrus (Figuras 4 e 6) e é uma sinapomorfia não exclusiva deste clado. Esta condição também é compartilhada com Panaque (Figura 11).

65. Forma da margem distal do processo transverso $[\mathrm{CI}=1,00 ; \mathrm{RI}=1,00]$ :

(0) fina, estreita distalmente;

(1) larga, dilatada distalmente (Figuras 4 e 6).

Na maioria de Loricariidae, o processo transverso do CC possui a margem distal fina e estreita. Em Acanthicus e Megalancistrus a margem distal do processo transverso é larga e dilatada. Esta condição é uma sinapomorfia exclusiva deste clado. 
66. Forma da margem distal do processo transverso $[\mathrm{CI}=0,25 ; \mathrm{RI}=0,66]$ :

(0) arredondada;

(1) pontuda.

A margem distal do processo transverso na maioria das espécies analisadas é arredondada. Em Scobinancistrus, Panaque e Panaqolus (clado 8); Spectracanthicus (exceto Spectracanthicus sp. "bola branca"); e em Leporacanthicus joselimais e L. heterodon, a margem distal do processo transverso é pontuda. Esta condição é uma sinapomorfia não exclusiva dos clados citados.

67. Contato do Processo transverso do $\mathrm{CC}$ com o pterótico-supracleitro $[\mathrm{CI}=0,50 ; \mathrm{RI}=0,87]$ :

(0) conectando, no mínimo parcialmente, o pterótico-supracleitro (Figuras 7 e 8);

(1) não conectando o pterótico-supracleitro (Figuras 4 e 6).

Dentre os táxons analisados, a maioria possui o processo transverso do $\mathrm{CCW}$ conectado com o pterótico-supracleitro. Em Acanthicus e Megalancistrus (clado 17) não ocorre contato do processo transverso com o pterótico-supracleitro. Este caráter é uma sinapomorfia não exclusiva deste clado que também é compartilhada com o clado que inclui Pseudacanthicus sp. "Tocantins", Pseudacanthicus sp. “Aripuanã”, Pseudacanthicus sp. “Curuá-Una", P. spinosus e P. leopardus.

68. Perfurações na extremidade distal do processo transverso $[\mathrm{CI}=0,25 ; \mathrm{RI}=0,50]$ Modificado de Armbruster (2004\#134):

(0) ausentes ou moderadamente perfuradas;

(1) perfurado com forames largos.

Na maioria dos táxons analisados, a extremidade distal do processo transverso não possui perfurações ou estas são pequenas a moderadas. Em Leporacanthicus (exceto L. 
heterodon), Pseudacanthicus sp. "Curuá-Una", P. spinosus e P. leopardus; e em Panaque, estas perfurações são grandes. Este caráter é uma sinapomorfia não exclusiva destes clados.

69. Forma do processo ventral do $\mathrm{CC}$ (Tripus de Armbruster, 2004) $[\mathrm{CI}=0,16 ; \mathrm{RI}=0,58]$ :

(0) aproximadamente circular;

(1) aproximadamente retangular.

Em Otophysi, as parapófises e costelas da terceira vértebra originam o tripus (Rosen \& Greenwood, 1970). A extremidade distal do tripus possui um processo posterior em forma de gancho que aliado ao os suspensorium sustenta a câmara anterior da bexiga natatória (Britto, 2002). Baskin (1973) considera a perda do intercalarium, claustrum e o processo transformador do tripus em Trichomychteridae, Callichthyidae, Astroblepidae e Loricariidae. Alexander (1964) considera que houve a ausência dos processos articular e ascendente do scaphium de Plecostomus (= Hypostomus) examinado por este. Segundo Alexander (1964), o tripus em Loricariidae está conectado ao centro complexo por uma lâmina óssea. $\mathrm{O}$ intercalarium está ausente, mas o tripus está ligado ao scaphium através de ligamentos denominados por Alexander (1964) de ligamentos três e quatro.

De acordo com Armbruster (2004), em Callichthyidae, Astroblepus e na maioria de Loricariidae o tripus (processo ventral do $\mathrm{CC}$ ) forma um arco quase retangular. Na maioria das espécies analisadas, esse processo é aproximadamente circular. O processo ventral do CC alongado ocorre em Pseudacanthicus (exceto Pseudacanthicus sp. "açacu preto") e Acanthicus. Essa condição representa uma sinapomorfia não exclusiva para estes clados e ocorre também em Spectracanthicus sp. "Tocantins” e em Panaqolus.

70. Processo lateral do processo ventral do $\mathrm{CC}$ (tripus de Armbruster, 2004) $[\mathrm{CI}=0,33 ; \mathrm{RI}=$ $0,33]$

(0) ausente ou pouco desenvolvido;

(1) bastante desenvolvido. 
O processo ventral do CC forma um arco e este arco pode ter um curto processo no seu limite ventro-lateral. Em geral, esse processo lateral, quando presente, é pouco desenvolvido. Em Spectracanthicus sp. "Tocantis" e S. murinus, este processo é bastante desenvolvido. Essa condição é uma sinapomorfia não exclusiva deste clado e também ocorre em Pseudacanthicus sp. "aba laranja" e Panaqolus.

71. Processo dorsal e corpo principal do processo ventral do CC (tripus de Armbruster, 2004) alongados $[\mathrm{CI}=0,33 ; \mathrm{RI}=0,75]$

(0) não;

(1) $\operatorname{sim}$.

$\mathrm{Na}$ maioria dos táxons analisados, o processo dorsal e o corpo principal do processo ventral do CC não são alongados e possuem comprimento equivalente a largura. Em Pseudacanthicus (exceto Pseudacanthicus sp. "açacu preto") essas estruturas são alongadas. Este caráter é uma sinapomorfia não exclusiva deste clado e ocorre também em Panaqolus.

\section{Esqueleto axial}

Os loricarídeos possuem vértebras bastante ossificadas com espinhos neural e hemal comprimidos lateralmente.

72. Número de vértebras a partir do primeiro espinho neural, não incluindo a placa hipural $[\mathrm{CI}=0,12 ; \mathrm{RI}=0,41]$

(0) 12 a 14 ;

(1) oito a 11.

Segundo Armbruster (2004), o número de vértebras em Loricariidae a partir do primeiro espinho neural, localizado atrás da nadadeira dorsal, até a placa hipural, mas sem incluí-la pode variar de 8 a 20. A redução do número de vértebras a partir do primeiro espinho neural para 8 a 11 parece ser uma condição amplamente distribuída em Ancistrini. 
Dentre as espécies observadas, a maioria possui oito a 11 vértebras a partir do primeiro espinho neural. A condição de 12 a 14 vértebras ocorre em Pseudacanthicus sp. "açacu vermelho", Pseudacanthicus sp. "aba laranja” e Pseudacanthicus sp. "Tocantins"; e também em Acanthicus e em S. punctatissimus.

73. Número de espinhos neurais bífidos $[\mathrm{CI}=1,00 ; \mathrm{RI}=1,00]$

(0) 6-9 (Figura 34, A);

(1) 10-11 (Figura 34, B).

Em Loricariidae, os espinhos neurais ao longo da nadadeira dorsal, são bífidos. Este número pode variar de acordo com a extensão da nadadeira dorsal. A grande maioria dos táxons observados possui 6-9 espinhos neurais bífidos. Em Megalancistrus esse número é maior, 10-11 e este caráter é uma sinapomorfia exclusiva deste clado.

74. Número total de vértebras incluindo as do $\mathrm{CC}$ e a placa hipural $[\mathrm{CI}=0,12 ; \mathrm{RI}=0,36]$

(0) 26-29;

(1) $30-32$.

Segundo Schaefer (1987), a maioria de Loricariidae possui 30 ou mais vértebras précaudais, entre o basioccipital e a placa hipural. Hypoptopomatinae possui em geral menos de 26 vértebras, condição compartilhada com Callichthyidae, e Loricariinae possui o maior número de vértebras, 33 a 37 . O aumento deste número de vértebras é considerado derivado dentro da família. Rapp Py-Daniel (1997) observou que alguns Loricariinae possuem até 39 vértebras.

A presença de 30-32 vértebras é uma sinapomorfia não exclusiva do grupo Acanthicus, compartilhada também com Scobinancistrus. Dentro do grupo interno, ocorrem reversões em A. adonis, Leporacanthicus heterodon e na maioria das espécies de Pseudacanthicus, que apresentam menor número de vértebras. 
75. Crista lateral à penúltima vértebra, incluindo a placa hipural (ordenado) $[\mathrm{CI}=0,25 ; \mathrm{RI}=$ $0,33]$

(0) ausente;

(1) pouco desenvolvida;

(2) bastante desenvolvida.

A penúltima vértebra a maioria das espécies observadas neste estudo apresenta uma crista lateral. Esta crista é anterior a hipurapófise, situada na última vértebra, e semelhante a esta estrutura. Não há nenhuma referência a esta crista e a sua função. Entretanto, devido à semelhança em forma e posição à hipurapófise, esta estrutura provavelmente também serve para inserção de músculos dos raios caudais. Em Acanthicus (clado 19) e Pseudacanthicus sp. "Aripuanã" esta crista é bastante desenvolvida. Em P. spinosus, Spectracanthicus sp. “Tapajós”, Spectracanthicus sp. "bola branca” e S. punctatissimus, a crista é ausente.

\section{Nadadeira dorsal}

76. Membrana no último raio dorsal expandida até a nadadeira adiposa $[\mathrm{CI}=0,33 ; \mathrm{RI}=0,71]$

(0) ausente;

(1) presente.

$\mathrm{Na}$ maioria dos loricarídeos a membrana da nadadeira dorsal não se prolonga até a nadadeira adiposa e se estende somente até a base do último raio dorsal. Em Spectracanthicus a membrana é prolongada e se conecta à adiposa. Essa condição também ocorre em Baryancistrus e Parancistrus, sendo uma sinapomorfia não exclusiva destes clados.

77. Número de raios dorsais $[\mathrm{CI}=1,00 ; \mathrm{RI}=1,00]$

(0) i+7 (Figura $34 \mathrm{~B})$;

(1) $\mathrm{i}+8$ ou mais (Figura 34, A). 
De acordo com Armbruster (2004), em geral, os Loricariidae possuem seis ou sete raios ramificados na nadadeira dorsal, no grupo Acanthicus, no grupo Chaetostoma, em Delturus e nas espécies de Pterygoplichthys ocorre um aumento no número de raios para oito ou mais. Neste estudo, a presença de i +8 ou mais raios dorsais é uma sinapomorfia exclusiva do grupo Acanthicus mais Spectracanthicus.

\section{Cintura peitoral}

A cintura peitoral da maioria dos Siluriformes é composta pelo extra-escapular, supracleitro, pós-temporal (elementos mais associados ao neurocrânio) e pelo coracóide, que resulta da fusão entre a escápula, o coracóide e o mesocoracóide, dos outros Otophysi. Nos Siluriformes, a porção dorsal do cleitro está inserida em um espaço delimitado pelos ramos póstero-ventrais do "supracleitro", porém a extremidade livre dessa porção é exposta (Britto, 2002).

Em Loricariidae, a cintura peitoral é basicamente formada pelo cleitro e pelo coracóide, que se articulam através de sínfises. Em Loricariidae o pterótico-supracleitro dorsalmente cobre a superfície dorsal do cleitro, formando então uma fossa, condição compartilhada com Scoloplacidae (Alexander, 1965; Schaefer, 1990). A parte posterior do coracóide se inclina dorsalmente $90^{\circ}$ de forma que os músculos abdutores se originam da parte posterior ao invés de ventral da cintura. $\mathrm{O}$ coracóide forma uma crista ventral, para a inserção dos abdutores (Alexander, 1965).

Segundo Alexander (1965), em Loricariidae, o primeiro elemento da nadadeira peitoral é produzido e co-ossificado como um grande espinho de defesa. Um peixe com os espinhos erguidos é mais difícil para um predador engoli-lo sem que sinta alguma dor ou injúria. Em Loricariidae, geralmente há de seis a sete raios ramificados na nadadeira peitoral, raramente cinco, mais o espinho; e oito raios ramificados na única espécie conhecida de Lithogenes villosus (Schaefer, 1987).

\section{Coracóide}


78. Extremidade distal do processo posterior do coracóide $[\mathrm{CI}=0,20 ; \mathrm{RI}=0,55]$

(0) extremidade distal mais larga que a proximal;

(1) extremidades distal e proximal com aproximadamente a mesma largura;

(2) extremidade distal pontiaguda, bem mais fina que a proximal.

Látero-posteriormente ao coracóide existe um processo pareado, chamado de processo posterior do coracóide, que faz contato com os radiais da nadadeira peitoral. A forma desse processo pode variar muito em Loricariidae. Em Acanthicus, Megalancistrus e Leporacanthicus, a extremidade distal deste processo é pontiaguda. Esta condição também foi observada em Pseudacanthicus sp. "açacu vermelho" e no clado que inclui Pseudacanthicus sp. "Curuá-Una", P. spinosus e P. leopardus. Nas demais espécies de Pseudacanthicus, Spectracanthicus sp. "Tocantins", S. murinus e Scobinancistrus, as extremidades distal e proximal possuem aproximadamente a mesma largura. Os táxons restantes de Spectracanthicus apresentam a extremidade distal mais larga que a proximal.

79. Tamanho do processo posterior do coracóide $[\mathrm{CI}=1,00 ; \mathrm{RI}=1,00]$

(0) curto (Figura 35, A);

(1) alongado (Figura 35, B).

Na maioria das espécies de Loricariidae, o processo posterior do coracóide é curto ou pouco alongado. Em Acanthicus este processo é bastante alongado e este caráter é uma sinapomorfia exclusiva do gênero.

80. Tamanho da área de contato ventral entre o coracóide e o cleitro $[\mathrm{CI}=0,50 ; \mathrm{RI}=0,0]$

(0) pequena;

(1) grande.

Em vista ventral, o coracóide e o cleitro se contatam através de uma sutura. Na maioria dos Loricariidae (exceto Loricariinae), esta área de contato é pequena. Nas espécies aqui 
analisadas, apenas Megalancistrus parananus e Pseudacanthicus sp. “Aripuanã” possuem, comparativamente, maior área de contado entre esses dois ossos.

81. Forma da área posterior de contato entre o coracóide e o cleitro $[\mathrm{CI}=0,14 ; \mathrm{RI}=0,40]$

(0) reta;

(1) expandida ventralmente.

A maioria dos Ancistrini possui a área posterior de contato entre o coracóide e o cleitro com uma expansão ventral. Em Megalancistrus e Pseudacanthicus (exceto Pseudacanthicus sp. "aba laranja" e Pseudacanthicus sp. "Tocantins"), essa área de contato é reta. Essa condição também ocorre em Spectracanthicus sp. "bola branca" e em Spectracanthicus sp. "Tocantins".

\section{Cleitro}

82. Forma da margem anterior do cleitro $[\mathrm{CI}=1,00 ; \mathrm{RI}=1,00]$

(0) reta, levemente curva com proeminência pontuda conspícua;

(1) arredondada, com proeminência pontuda discreta.

A margem anterior do cleitro, na maioria das espécies analisadas, é reta com uma leve curva em sua porção mais distal e apresenta uma proeminência pontuda conspícua. Em Megalancistrus, a margem anterior do cleitro é arredondada em toda a sua extensão e apresenta uma pequena proeminência pontuda, bastante discreta. Este caráter é considerado aqui uma sinapomorfia exclusiva do gênero.

\section{Cintura pélvica}

A cintura pélvica dos Otophysi é constituída de um único elemento ósseo pareado, denominado basipterígio (Shelden, 1937; Schaefer, 1987, Britto, 2002). Em Loricariidae, o 
basipterígio possui dois processos pareados: um processo anterior, interno e medial; e um processo ântero-lateral, suportando um crista na sua superfície ventral. O basipterígio dos loricariídeos possui duas suturas mediais que são separadas por um forame redondo de cartilagem anteriormente e por uma abertura retangular posteriormente.

De modo geral, em Loricariidae estão presentes seis raios das nadadeiras pélvicas. $\mathrm{O}$ lateropterígio é um osso lateral ao basipterígio, que geralmente se apresenta de forma fina e arredondada (Schaefer, 1987); mas este elemento pode estar bastante reduzido ou ausente em alguns táxons, em especial em Loricariinae (Py-Daniel, 1997; Paixão, 2004). Os elementos radiais estão ausentes em Siluriformes (Lundberg, 1970).

\section{Basipterígio}

83. Forma dos processos ântero-laterais (PAL) do basipterígio $[\mathrm{CI}=0,28 ; \mathrm{RI}=0,50]$

(0) bastante curvado, se encontrando ou quase na linha mediana (Figura 36, B);

(1) pouco curvado, não se encontrando na linha mediana (Figura 36, A);

(2) reto (Figura 37, A).

O basipterígio dos loricarídeos possui um processo ântero-lateral pareado que apresenta uma forte crista em sua parte ventral e um processo ântero-medial. A forma do processo ântero-lateral é variável; pode ser bem curvado de modo que as extremidades distais se encontram, ou quase, na linha mediana; pouco curvado ou reto.

$\mathrm{Na}$ maioria das espécies analisadas neste estudo possui o PAL bastante curvado e suas extremidades distais se encontram ou quase na linha mediana (estado 0). Em Acanthicus o PAL é pouco curvado e suas extremidades distais não se contatam. A mesma condição ocorre em Panaque, Scobinancistrus e Parancistrus aurantiacus. Em Megalancistrus, o PAL é reto e perpendicular ao basipterígio; o mesmo ocorre em Pseudancistrus brevispinis.

84. Forma do processo ântero-lateral do basipterigio $[\mathrm{CI}=0,33 ; \mathrm{RI}=0,33]$

(0) delgado;

(1) largo em toda sua extensão (Figura 37, A). 
De forma geral, em Ancistrini o processo ântero-lateral do basipterígio é delgado em toda a sua extensão. Em Megalancistrus, este processo é bastante largo; esta condição é sinapomórfica para o gênero e é também compartilhada com Ancistrus taunayi e Pseudancistrus brevispinnis.

85. Tamanho da área cartilaginosa do basipterígio $[\mathrm{CI}=0,14 ; \mathrm{RI}=0,14]$

(0) curta;

(1) alongada.

Em sua porção medial, o basipterígio apresenta uma área de cartilagem, geralmente retangular. Na maioria dos Ancistrini analisados neste estudo, esta área é alongada (Figuras 36 e 37). Dentre os táxons do grupo interno, Spectracanthicus sp. "Tapajós”, S. murinus (Figura 38) e Pseudacanthicus sp. "Curuá-Una", esta área é curta. O mesmo ocorre no clado que inclui Panaque e Panaqolus e este caréter é uma sinapomorfia não exclusiva deste clado.

86. Tamanho da fenestra anterior à seção cartilaginosa do basipterígio (ordenado) $[\mathrm{CI}=0,25$; $\mathrm{RI}=0,25]$

(0) ausente (Figura 39, A);

(1) pequena a média;

(2) grande (Figura 38, B e C).

Em Loricariidae o basipterígio é suturado em dois locais na linha mediana e separado por uma fenestra (quando presente) acima da área de cartilagem e por uma abertura retangular posterior (Schaefer, 1987). Na maioria dos Loricariidae o basipterígio possui a conexão cartilaginosa posteriormente, mas a fenestra encontra-se ausente. Na maioria dos táxons de Ancistrini examinados a fenestra está presente. A presença de fenestra de tamanho pequeno a médio é o estado mais comum dentre as espécies analisadas. Em Megalancistrus, Spectracanthicus sp. "Tapajós", Spectracanthicus sp. "Tocantins", Peckoltia vittata e Parancistrus, esta fenestra é proporcionalmente grande. Este caráter é uma sinapomorfia não 
exclusiva para o gênero Megalancistrus. Em Pseudacanthicus leopardus a fenestra está ausente.

87. Forma da fenestra anterior a área cartilaginosa do basipterígio $[\mathrm{CI}=0,25 ; \mathrm{RI}=0,0]$

(0) arredondada;

(1) alongada, aproximadamente elíptica.

Em geral, nos loricarídeos, esta fenestra possui forma arredondada. Entretanto em alguns táxons observados, esta estrutura apresenta uma forma mais alongada, aproximadamente elíptica. Esta condição ocorre em Acanthicus adonis, Pseudacanthicus sp. "açacu preto", Panaque e Hypancistrus. Em Pseudacanthicus leopardus este caráter foi codificado como (?), missing data.

88. Crista póstero-ventral do basipterígio $[\mathrm{CI}=0,33 ; \mathrm{RI}=0,50]$

(0) ausente;

(1) presente.

A crista póstero-ventral margeia a área de cartilagem do basepterígio. $\mathrm{Na}$ maioria dos Loricariidae esta crista é ausente e em Hypostominae, geralmente é presente e pequena. Dentre as espécies examinadas neste estudo, a maioria possui crista póstero-ventral. Esta é ausente em Parancistrus, Hemiancistrus cerrado, Pseudancistrus brevispinis e Ancistrus taunayi.

89. Forma da crista ventral do basipterígio $[\mathrm{CI}=0,12 ; \mathrm{RI}=0,41]$

(0) reta ou levemente arredondada;

(1) triangular. 
A crista ventral está localizada acima da fenestra do basipteígio, que está presente na maioria dos Loricariidae. Nos maioria dos táxons observados, a crista possui forma triangular. A presença de crista reta ou arredondada é uma sinapomorfia não exclusiva de Acanthicus e Megalancistrus (exceto M. parananus). Esta condição também ocorre em Pseudacanthicus sp. "açacu vermelho", Scobinancistrus, Panaque e Panaqolus, em Parancistrus e em Pseudancistrus brevispinis.

90. Crista na base interna do processo posterior do basipterígio $[\mathrm{CI}=0,33 ; \mathrm{RI}=0,0]$

(0) ausente ou pouco desenvolvida;

(1) bem desenvolvida .

Dentre as espécies analisadas, a maioria não possui crista na base interna do processo posterior do basipterígio ou esta é pouco desenvolvida. Em Megalancistrus barrae, Pseudacanthicus sp. "açacu vermelho" e Baryancistrus sp. há uma crista bem desenvolvida nesta região.

91. Largura das expansões laminares do processo ântero-lateral (pal) $[\mathrm{CI}=0,20-0,21 ; \mathrm{RI}=0,61$ $0,66]$

(0) dorsal mais larga que ventral (Figura 36, b);

(1) simétricas (Figura 38);

(2) ventral mais larga que dorsal .

O processo ântero-lateral de Loricariidae apresenta duas expansões laminares onde se inserem os músculos arrector dorsalis. As expansões laminares originam-se no processo ântero-lateral, uma delas é orientada ventral ou ventro-lateralmente e a outra, é orientada dorsal ou dorso-lateralmente (Paixão, 2004). Segundo Rapp Py-Daniel (1997), ocorre uma ampla variação na largura dessas expansões dentro de Loricariidae.

A expansão laminar ventral mais larga que a dorsal é uma sinapomorfia não exclusiva do clado que inclui o grupo Acanthicus, Spectracanthicus, Scobinancistrus, Panaque, Panaqolus e Peckoltia vittata. Em alguns táxons ocorreram reversões para o estado (0), como 
em Leporacanthicus e Pseudacanthicus sp. "aba laranja”. Em Pseudacanthicus sp. "açacu vermelho", Spectracanthicus sp. "Tapajós" e S. murinus as expansões laminares são simétricas (estado 1); condição também compartilhada com Scobinancistrus e Panaqolus.

92. Tamanho do lateropterígio $[\mathrm{CI}=0,16 ; \mathrm{RI}=0,50]$

(0) médio, não ultrapassando o (pal);

(1) grande, ultrapassando o (pal).

Além do basipterígio, Loricariidae também possui um osso adicional na cintura pélvica, o lateropterígio (Shelden, 1937). Este está localizado lateralmente ao basipterígio, na sua porção anterior e está articulado com o raio indiviso da nadadeira pélvica. Segundo Rapp Py-Daniel (1997), o lateropterígio dos loricariídeos apresenta uma progressiva redução. Entretanto, de acordo com Howes (1983), a ausência do lateropterígio é uma condição derivada dentro da subfamília Loricariinae. A extremidade distal do lateropterígio (quando presente e de tamanho médio a grande) se conecta as placas laterais do corpo.

Nas espécies examinadas, a maioria apresenta o látero-pterígio grande e este, ultrapassa o processo ântero-lateral. O látero-pterígio de tamanho médio é uma sinapomorfia de Spectracanthicus sp. "bola branca", S. punctatissimus e $S$. murinus (com exceção de Spectracanthicus sp. "Tocantins").

\section{Nadadeira anal}

93. Número de raios ramificados da nadadeira anal $[\mathrm{CI}=0,50 ; \mathrm{RI}=0,0]$

(0) 4;

(1) 3 .

A nadadeira anal da maioria de Loricariidae é constituída por um raio indiviso e quatro raios ramificados. Em geral a nadadeira anal é suportada por quatro pterigióforos, cada um consistindo em radiais proximal e medial fusionados; e um radial distal separado. Os 
pterigióforos são fortemente aderidos uns com os outros ventralmente e suportam um processo transverso lateralmente que contatam as placas dérmicas ventrais (Schaefer, 1987).

De acordo com Armbruster (2004), alguns loricarí́deos tiveram uma redução no número de raios ramificados na anal. Alguns dos Ancistrini, hypoptopomatines, loricariines, neoplecostomines e Rhinelepini, possuem cinco raios ramificados e a maioria dos Hypostomini possui quatro. Em Leporacanthicus triacts e Spectracanthicus murinus houve uma redução para três raios ramificados.

\section{Nadadeira caudal}

A forma basal do esqueleto caudal em Siluriformes é composta por seis hipurais separados, um hipural e um uro-neural. O primeiro centro pré-ural $\left(\mathrm{PU}_{1}\right)$ e o primeiro centro ural $\left(\mathrm{U}_{1}\right)$ estão fusionados formando um centro composto. Neste centro funcional composto se encontra o ponto de suporte dos demais elementos caudais. Ao segundo centro ural $\left(\mathrm{U}_{2}\right)$, que está separado e em geral reduzido, estão fusionados os hipurais 3 e 4. Dentre os Siluriformes, Loricariidae apresenta um alto grau de fusão do esqueleto caudal desde muito cedo no desenvolvimento. Como resultado, a fusão dos cinco elementos hipurais e o uro-neural, formou a placa hipural (Lundberg \& Baskin, 1969).

Segundo Schaefer (1987) Astroblepidae, Callichthyidae e na maioria dos Siluriformes primitivos, as margens posteriores do esqueleto caudal são do mesmo tamanho. Dentre os loricariídeos, a maioria de Hypoptopomatinae, Hypostominae e Ancistrinae (sensu Schaefer, 1987) possui os hipurais 1 e 2, que corresponde à placa hipural

94. Tamanho da hipurapófise (ordenado) $[\mathrm{CI}=0,22 ; \mathrm{RI}=0,58]$

(0) baixa;

(1) média;

(2) alta. 
A hipurapófise é uma projeção formada no parahipural no esqueleto caudal e serve como local de inserção dos músculos hipocordais na sua superfície dorsal; e dos músculos dos raios caudais na sua superfície ventral (Schaefer, 1987).

$\mathrm{Na}$ maioria dos táxons analisados, a hipurapófise originalmente tem tamanho médio, porém ocorreram diversas reversões para os outros estados em alguns ramos. Em Acanthicus adonis e Leporacanthicus heterodon a hipurapófise é alta. Em Pseudacanthicus, Megalancistrus barrae e Spectracanthicus (exceto Spectracanthicus sp. "Tocantins") a hipurapófise é baixa.

95. Forma da hipurapófise $[\mathrm{CI}=0,16 ; \mathrm{RI}=0,28]$

(0) aproximadamente triangular;

(1) aproximadamente quadrada.

De acordo com Lundberg \& Baskin (1969), a hipurapófise pode apresentar diversas formas em Siluriformes e o padrão predominante é o tipo C, inclusive em Loricariidae. A hipurapófise do tipo $\mathrm{C}$ é formada pela fusão da hipurapófise primária, localizada sobre o parahipural, com a hipurapófise secundária sobre os hipurais 1 e 2 .

Dentre as espécies observadas neste estudo, a maioria apresenta hipurapófise de forma aproximadamente triangular. A hipurapófise de forma quadrada é uma sinapomorfia não exclusiva de Acanthicus (exceto A. adonis) e Megalancistrus, condição esta também compartilhada com Spectracanthicus sp. "bola branca", Spectracanthicus sp. "Tocantins" e $S$. punctatissimus (com exceção de S. murinus).

96. Espaço entre o lobo hipural inferior e o último espinho hemal $[\mathrm{CI}=0,16 ; \mathrm{RI}=0,54]$

(0) ausente ou pequeno;

(1) grande.

Na maioria dos táxons observados, entre o último lobo hipural inferior e o último espinho hemal não há espaço ou este é bastante pequeno. Em Leporacanthicus e 
Spectracanthicus (exceto Spectracanthicus sp. “Tocantins”) este espaço é grande. Esta condição é uma sinapomorfia para estes clados.

97. Fenestra no lobo hipural inferior $[\mathrm{CI}=0,50 ; \mathrm{RI}=0,66]$

(0) ausente;

(1) presente.

Dentre as espécies analisadas, a maioria não apresenta nenhuma fenestra no lobo hipural inferior. A presença desta fenestra é uma sinapomorfia não exclusiva do clado que inclui Leporacanthicus triactis, L. joselimai e L. heterodon. Esta condição também ocorre em Panaque.

98. Filamentos caudais $[\mathrm{CI}=0,50 ; \mathrm{RI}=0,88]$

(0) ausente;

(1) presente.

A maioria dos Ancistrini não possui filamentos caudais. Em Pseudacanthicus e Acanthicus a presença de filamentos caudais é uma sinapomorfia não exclusiva destes clados. Estes filamentos são mais comuns em exemplares juvenis, mas em algumas espécies eles persistem até a idade adulta. Neste caráter, os filamentos foram considerados presentes (estado 1) em qualquer estágio de desenvolvimento.

\section{Nadadeira adiposa}

99. Nadadeira adiposa $[\mathrm{CI}=1,00 ; \mathrm{RI}=1,00]$

(0) presente;

(1) ausente. 
Na maioria dos Loricariidae a nadadeira adiposa está presente, o que parece ser uma condição plesiomórfica da família. Com exceção das Subfamílias Loricariinae e Hypoptopomatinae (excluindo Parotocinclus), dos gêneros Pareiorhina, Rhinelepis, Pseudorinelepis e Pogonopomoides, a adiposa está presente em todas as outras espécies de loricariídeos. Alguns gêneros possuem uma membrana que conecta as nadadeiras dorsal e adiposa, essa condição presente em Spectracanthicus também é compartilhada com Parancistrus e algumas espécies de Baryancistrus (Armbruster, 1997; 2004). A ausência da nadadeira adiposa foi proposta por Rapp Py-Daniel (1997) como uma sinapomorfia para a subfamília Loricariinae e posteriormente esta hipótese foi corroborada por Paixão (2004). No presente estudo, as espécies de Acanthicus não possuem nadadeira adiposa e esta é uma sinapomorfia exclusiva do gênero.

\section{Miscelânia}

\section{Coloração}

100. Coloração geral do corpo e/ou nadadeiras $[\mathrm{CI}=0,25 ; \mathrm{RI}=0,0]$

(0) uniforme;

(1) com pontos, manchas, listras ou barras.

A maioria das espécies de Loricariidae apresenta coloração com algum tipo de mancha, listras ou barras. Relativamente, poucas espécies possuem coloração uniforme, sem pontos ou manchas evidentes. Neste estudo, dentre os táxons analisados apenas Acanthicus hystrix, Pseudacanthicus sp. "açacu preto", Spectracanthicus sp. “Tapajós” e Parancistrus aurantiacus apresentam coloração uniforme.

101. Coloração com manchas ou pontos escuros $[\mathrm{CI}=0,14 ; \mathrm{RI}=0,40]$

(0) ausente;

(1) presente. 
O padrão geral mais comum de coloração em Loricariidae é o de manchas escuras espalhadas pelo corpo. Este mesmo padrão ocorre na maioria dos Siluriformes. Dentre as espécies examinadas aqui, este padrão de coloração é bastante comum, entretanto muitos táxons também apresentam coloração com manchas ou pontos claros. A presença de manchas ou pontos escuros é uma sinapomorfia não exclusiva do clado que inclui Pseudacanthicus (exceto Pseudacanthicus sp. "açacu preto"), com reversões em Pseudacanthicus sp, “Tocantins" e Pseudacanthicus sp. "Curuá-Una". Esta mesma condição é compartilhada com Leporacanthicus (exceto L. galaxias) e Megalancistrus parananus.

102. Coloração com manchas ou pontos claros $[\mathrm{CI}=0,12 ; \mathrm{RI}=0,46]$

(0) ausente;

(1) presente.

O padrão de coloração do corpo com pontos ou manchas claras é também bastante comum dentre as espécies analisadas. Este caráter é uma sinapomorfia não exclusiva de Spectracanthicus (exceto Spectracanthicus sp. "Tapajós") e de Scobinancistrus. Este caráter também ocorre em Acanthicus adonis, Leporacanthicus galaxias, Pseudacanthicus sp. “Tocantins" e Pseudacanthicus sp. "Curua-Una".

103. Coloração com listras ou barras $[\mathrm{CI}=0,33 ; \mathrm{RI}=0,33]$

(0) ausente;

(1) presente.

Coloração do corpo com listras ou barras é o menos comum dentre os táxons examinados neste estudo. Este caráter é uma sinapomorfia de Peckoltia vittata, Panaque e Panaqolus (exceto Scobinancistrus).

104. Padrão de manchas no corpo $[\mathrm{CI}=0,25 ; \mathrm{RI}=0,0]$

(0) distribuídos de forma uniforme; 
(1) vermiculadas e irregulares.

Em geral, o colorido do corpo em Loricariidae possui padrão de manchas distribuídas de forma uniforme. Porém, Acanthicus hystrix, Megalancistrus barrae e Pseudacanthicus sp. “Aripuanã" apresentam manchas vermiculadas ou em forma de bolhas disformes ou distribuídas de forma irregular.

105. Nadadeiras com bordas brancas $[\mathrm{CI}=0,25 ; \mathrm{RI}=0,0]$

(0) ausente;

(1) presente.

A maioria das espécies de Loricariidae não possui bordas das nadadeiras brancas. Neste estudo, este caráter ocorre em Leporacanthicus joselimai, Spectracanthicus punctatissimus, S. murinus e Baryancistrus sp.

106. Nadadeiras alaranjadas $[\mathrm{CI}=0,25 ; \mathrm{RI}=0,25]$

(0) ausente;

(1) presente.

A presença de nadadeiras alaranjadas não é comum em Loricariidae. Esta condição é uma sinapomorfia do clado que inclui Pseudacanthicus sp. "açacu vermelho" e Pseudacanthicus sp. "aba laranja”. Este caráter também ocorre em P. leopardus e em Leporacanthicus triactis.

\section{Anatomia externa}

107. Focinho (ordenado) $[\mathrm{CI}=1,00 ; \mathrm{RI}=1,00]$

(0) com grande área nua; 
(1) com uma pequena área nua na extremidade anterior;

(2) totalmente coberto por placas.

Em Loricariidae, a maioria das espécies possui o focinho recoberto por placas apenas com uma pequena porção distal nua. Nas espécies de Ancistrus, além da grande área desprovida de placas, há também o desenvolvimento de tentáculos nos machos em períodos reprodutivos (Armbruster, 2004). De acordo com Schaefer (1991), em como Hypoptopoma, Oxyropsis, Acestridium, Microlepidogaster, Parotocinclus e todas as espécies de Otocinclus, o focinho é completamente recoberto por uma ou duas placas sólidas. Paixão (2004) observou exemplares de Loricaria sp. apresentam o focinho coberto totalmente por placas. Neste estudo, o focinho totalmente coberto por placas é uma sinapomorfia exclusiva do gênero Acanthicus.

108. Perfil dorsal do focinho $[\mathrm{CI}=0,33-0,40 ; \mathrm{RI}=0,66-0,75]$

(0) arredondado;

(1) pontudo;

(2) pontudo com as laterais retas.

Dentre os táxons analisados, a maioria apresenta o perfil dorsal do focinho pontudo. Em Acanthicus e Megalancistrus o perfil dorsal do focinho é arredondado, condição também compartilhada com Pseudacanthicus sp. "Aripuanã" e Pseudacanthicus sp. "Tocantins" e com Spectracanthicus sp. "bola branca" e S. punctatissimus. Em Scobinancistrus, o perfil dorsal do focinho é pontudo com as laterais retas em relação à ponta do focinho (Figura 5). Este caráter é uma sinapomorfia exclusiva deste clado.

109. Papila bucal central $[\mathrm{CI}=0,20 ; \mathrm{RI}=0,50]$

(0) ausente ou pouco desenvolvida;

(1) bastante desenvolvida. 
Muitas espécies de Loricariidae possuem uma papila bucal localizada na região mediana da boca, esta pode ser bem pequena ou conspícua. Na maioria dos táxons analisados a papila bucal central é ausente ou pouco desenvolvida. Em Acanthicus e Megalancistrus a papila bucal central é bastante desenvolvida e este caráter é uma sinapomorfia não exclusiva deste clado, ocorrendo também em Pseudacanthicus sp. "Curuá-Una" e Peckoltia vittata.

110. Tamanho do lábio $[\mathrm{CI}=0,66 ; \mathrm{RI}=0,87]$

(0) largura maior que comprimento;

(1) comprimento mais ou menos igual à largura;

(2) comprimento maior que largura.

A razão entre o comprimento e a largura do lábio varia de três formas nos táxons analisados, podendo ser com o comprimento maior que a largura, com o comprimento aproximadamente igual à largura e com a largura maior que o comprimento. Os táxons que apresentam o estado (0) do caráter possuem os dentários em posição quase reta, formando um ângulo de encontro maior que 90 graus; no estado (1) os dentários possuem um ângulo de encontro aproximadamente de 90 graus e no estado (2), o ângulo de encontro dos dentários é menor que 90 graus.

De modo geral, a maioria das espécies analisadas possui o lábio com comprimento aproximadamente igual à largura. Em Leporacanthicus, o comprimento é maior que a largura e este caráter é uma sinapomorfia exclusiva do gênero. Em Acanthicus, a largura do lábio é maior que o comprimento e esta condição é uma sinapomorfia não exclusiva deste clado (Figura 41).

111. Filamentos labiais em forma de franja $[\mathrm{CI}=1,00 ; \mathrm{CI}=1,00]$

(0) ausente;

(1) presente. 
Filamentos labiais estão ausentes na maioria das espécies de loricarídeos. Armbruster (2004) denomina estes filamentos em forma de franja como "estruturas em forma de barbilhões". Em Leporacanthicus, os filamentos são curtos e espessos e restritos ao lábio superior. Este caráter é considerado aqui como uma sinapomorfia exclusiva do gênero.

112. Área posterior ao pterótico-supracleitro $[\mathrm{CI}=0,66 ; \mathrm{RI}=0,90]$

(0) com grande área nua;

(1) com uma placa média a grande;

(2) com uma ou duas placas pequenas (Figura 40).

A área posterior ao pterótico-supracleitro na maioria dos Loricariidae possui poucas placas pequenas ou uma placa média. Dentre os táxons analisados, a maioria possui uma placa média ou grande nesta área. Em Leporacanthicus, há uma grande área nua posterior ao pterótico-supracleitro e esta condição é uma sinapomorfia não exclusiva do gênero. Pseudacanthicus possui nesta área uma ou duas pequenas placas e este caráter é uma sinapomorfia exclusiva deste clado.

113. Número de placas pré-dorsais $[\mathrm{CI}=0,50 ; \mathrm{RI}=0,93]$

(0) $2-3$;

(1) 4 ou mais .

A contagem de placas pré-dorsais em Loricariidae inclui as placas entre a extremidade posterior do supra-occipital e a placa nucal (também é incluída na contagem) que precede a nadadeira dorsal. Segundo Armbruster (2004), a maioria dos Ancistrini possui duas ou três placas pré-dorsais (em geral três). Neste estudo, a presença de quatro placas pré-dorsais é uma sinapomorfia exclusiva de Spectracanthicus mais o grupo Acanthicus com reversão em Acanthicus e Megalancistrus que possuem três placas. 
114. Placas abdominais $[\mathrm{CI}=0,40 ; \mathrm{RI}=0,40]$

(0) ausentes;

(1) presentes apenas em alguns pontos;

(2) presente em todo o abdome.

O padrão de disposição de placas abdominais em Loricariidae é bastante variável. As placas podem ser pequenas e espalhadas por todo o abdome ou concentradas nas regiões da cintura peitoral, entre as nadadeiras peitorais e pélvicas e anteriores a nadadeira anal; podem formar escudos cobrindo todo o abdome; ou serem ausentes.

Dentre as espécies analisadas, a grande maioria não possui placas abdominais. Em Peckoltia vittata estão presentes apenas plaquinhas em alguns pontos, geralmente nas origens das nadadeiras peitoral e pélvica. Em Acanthicus estão presentes pequenas placas por toda a extensão do abdome. Esta condição é uma sinapomorfia não exclusiva do gênero que também é compartilhada com Panaque. Embora Armbruster (2004) tenha considerado que a maioria do grupo Acanthicus tenha ao menos pequenas placas no abdome, neste estudo só foram considerados os táxons que possuem placas conspícuas nesta região.

115. Número de raios pró-correntes $[\mathrm{CI}=0,25 ; \mathrm{RI}=0,76]$

(0) 3 a 4 ;

(1) 5 a 6 .

A maioria dos Ancistrini possui de três a quatro raios pró-correntes. No presente estudo, entretanto, a maioria dos táxons possui cinco a seis. Esta condição é uma sinapomorfia não exclusiva do clado que inclui o grupo Acanthicus, Sepectracanthicus, Scobinancistrus, e Peckoltia, com reversões em Scobinancistrus, Panaque e Panaqolus; e em Acanthicus e Megalancistrus.

116. Quilhas $[\mathrm{CI}=0,50 ; \mathrm{RI}=0,92]$

(0) ausentes ou moderadas; 
(1) quilhas bastante desenvolvidas.

$\mathrm{Na}$ maioria dos Loricariidae as quilhas laterais ao corpo são ausentes ou pouco desenvolvidas. Segundo Armbruster (2004), no grupo Acanthicus o corpo é fortemente quilhado em toda a sua extensão e as quilhas são formadas por odontódeos grandes e afiados. Este autor propôs a presença de quilhas afiadas e bem desenvolvidas como uma sinapomorfia para o grupo Acanthicus. Neste estudo esta hipótese foi corroborada e a presença de quilhas bastante desenvolvidas é uma sinapomorfia exclusiva do grupo Acanthicus. No clado que inclui Pseudacanthicus sp. "Tocantins" e Pseudacanthicus sp. "Aripuanã" as quilhas são moderadamente desenvolvidas (estado 0).

117. Perfil pós-dorsal do corpo $[\mathrm{CI}=1,00 ; \mathrm{RI}=1,00]$

(0) estreito;

(1) robusto.

Na maioria das espécies de Loricariidae o perfil pós-dorsal do corpo é estreito até o início da caudal. Em Pseudacanthicus sp. "Tocantins" e Pseudacanthicus sp. "Aripuanã" o perfil pós-dorsal do corpo é robusto. Este caráter é considerado uma sinapomorfia exclusiva deste clado.

118. Tamanho da bexiga natatória $[\mathrm{CI}=0,50 ; \mathrm{RI}=0,75]$

(0) pequena e restrita a uma pequena área anterior a sexta costela;

(1) bastante expandida, alcançando ou ultrapassando a sexta costela (Figuras 4, 5 e 6).

Em Siluriformes, o saco posterior da bexiga natatória está ausente e os ductos pneumáticos se abrem diretamente em um saco anterior que é alargado. Tipicamente, estes sacos são divididos em septos, que podem ser de diversas formas em variadas espécies (Alexander, 1964). Segundo Birindelli (2006), dentre os Siluriformes, as espécies de Doradidae possuem maior variação de formas da bexiga natatória. 
Nos Loricariidae a bexiga natatória é reduzida a duas bulas completamente encapsuladas fechadas lateralmente e totalmente soldadas ao pterótico-supracleitro; e as costelas são sésseis (Chardon, 1968). Na maioria das espécies de Loricariidade, a cápsula da bexiga natatória é pequena e restrita a região anterior à sexta costela. As espécies que possuem a bexiga natatória bastante expandida, também possuem aumento de tamanho do pteróticosupracleitro, que forma a porção lateral da cápsula da bexiga. Neste estudo, a bexiga natatória expandida é uma sinapomorfia não exclusiva do clado que inclui Acanthicus e Megalancistrus. Esta condição também ocorre em Panaque.

119. Tamanho da abertura branquial $[\mathrm{CI}=1,00 ; \mathrm{RI}=1,00]$

(0) pequena;

(1) grande.

Em geral, em Loricariidae, a abertura branquial é pequena. Em Parancistrus, a abertura branquial é grande e este caráter é considerado aqui uma sinapomorfia exclusiva do gênero. Segundo Rapp Py-Daniel \& Zuanon (2005), Ancistrus ranunculus e Rhinelepis também possuem abertura branquial grande, entretanto, Parancistrus também possui membrana expandida conectando as nadadeiras dorsal e adiposa.

120. Tamanho do acúleo da nadadeira peitoral quando aduzido $[\mathrm{CI}=100 ; \mathrm{RI}=100]$

(0) curto a médio, alcança a inserção ou se estende até a metade da nadadeira pélvica;

(1) grande, alcança quase o final da extensão do raio indiviso da nadadeira pélvica.

$\mathrm{Na}$ maioria das espécies de Loricariidae, o espinho da nadadeira peitoral quando aduzido é curto ou médio, ou seja, alcança a origem da nadadeira pélvica ou se estende até a metade desta. Em Acanthicus o espinho da nadadeira peitoral é bastante expandido que quando aduzido, alcança quase o fim do raio indiviso da nadadeira pélvica. Esta condição é uma sinapomorfia exclusiva deste gênero. 
121. Canais urogenital e anal $[\mathrm{CI}=0,33 ; \mathrm{RI}=0,77]$

(0) com duas saídas separadas;

(1) unidos na mesma saída, formando uma única projeção tubular.

Na maioria de Loricariidae, há duas saídas separadas para os canais anal (anterior) e urugenital (posterior). No clado que reúne o grupo Acanthicus, Spectracanthicus, Scobinancistrus, Panaque, Panaqolus e Peckoltia esses canais são unidos em uma única projeção tubular. Este caráter é uma sinapomorfia para este clado (exceto Acanthicus e Peckoltia).

\subsection{Reconstrução filogenética}

\subsubsection{O monofiletismo do grupo Acanthicus}

A seguir é discutido o monofiletismo do grupo Acanthicus e seus gêneros. As sinapomorfias de cada clado são referentes ao cladograma fundamental selecionado (Figuras 41, 42 e 43). Algumas hipóteses anteriores já haviam proposto o monofiletismo do grupo Acanthicus (Montoya-Burgos et al., 1998; Armbruster, 2004 e Chamon, 2007). Entretanto, o presente estudo, além de corroborar o monofiletismo do grupo, apresenta uma hipótese de relacionamento entre a maioria dos táxons conhecidos do grupo Acanthicus (exceto Pseudacanthicus serratus e Micracanthicus vandragti). O resultado obtido aqui difere dos resultados que foram apresentados anteriormente.

O monofiletismo do grupo Acanthicus foi corroborado com base em 11 sinapomorfias, sendo três exclusivas (caracteres 37, 55 e 116): extremidade distal dos dentes acentuadamente curvada (caráter 55), presença de crista no hiomandibular contínua à do quadrado (caráter 37) e presença de quilhas bastante desenvolvidas (caráter 116).

Armbruster (2004) também propôs 11 sinapomorfias para o grupo Acanthicus, sendo que três destas são aqui corroboradas (caracteres 23, 37 e 116 no presente estudo; caracteres 8, 49 e 198, respectivamente, de Armbruster, 2004). Os demais caracteres (8, 21, 26, 31, 32, 74 e 78, deste estudo), apesar de já terem sido observados por Amrbruster (2004) são propostos como sinapomorfias do grupo Acanthicus pela primeira vez aqui. Essa diferença nos 
resultados é esperada, uma vez que a análise de Armbruster (2004) foi baseada em um nível de universalidade maior, onde mais táxons e caracteres foram incluídos. Além disso, a forma de interpretação e os estados de alguns dos caracteres propostos por Armbruster (2004) foram modificados.

\subsubsection{Relações entre os táxons do grupo Acanthicus}

No presente estudo, as relações dos gêneros dentro do grupo Acanthicus corroboram apenas em parte as hipóteses anteriores. O clado que inclui Acanthicus e Megalancistrus é grupo irmão do clado que inclui Leporacanthicus e Pseudacanthicus. E o clado que inclui os quatro gêneros do grupo Acanthicus é grupo irmão de Spectracanthicus.

De acordo com a hipótese de Armbruster (2004), Acanthicus e Megalancistrus são táxons irmãos e formam um clado que é grupo irmão de Peseudacanthicus e Leporacanthicus que se posicionam, respectivamente, como grupos-irmãos sucessivos. Os quatro gêneros do grupo Acanthicus são proximamente relacionados com Spectracanthicus+Oligancistrus (clado76), que ocupa uma posição mais basal no clado 72 de Armbruster, (2004).

Em Chamon (2007), o clado 15, que é composto pelas espécies de Spectracanthicus é mais próximo ao clado 16, que inclui Pseudacanthicus e Leporacanthicus e o clado 13, que inclui os gêneros Acanthicus. O gênero Megalancistrus é grupo irmão do clado 14, que contém os clados 15 e 16.

Na presente análise, o clado que inclui Acanthicus e Megalancistrus, é sustentado por 19 sinapomorfias, sendo quatro destas exclusivas. Em Armbruster (2004), 10 sinapomorfias sustentam o clado que inclui estes gêneros e em Chamon (2007), são listadas sete simapomorfias. Entretanto, foram observadas variações nos caracteres bem como modificações nos estados de alguns caracteres utilizados em cada uma das análises mencionadas. Dentre as sinapomorfias do clado que inclui Acanthicus e Megalancistrus, algumas são referentes à morfologia externa do neurocrânio, incluindo o pterótico-supracleitro bastante expandido (caráter 10, nesta análise) e com grandes perfurações (caráter 11, nesta análise), ambas corroboradas em todas as análises citadas acima. A forma do parieto-supraoccipital bastante alongado (caráter 15, nesta análise) é proposto aqui pela primeira vez. Outras sinapomorfias do clado (Acanthicus + Megalancistrus) também corroboradas em análises anteriores estão relacionadas ao centro composto e ao Aparelho de Weber, como por 
exemplo a margem distal do processo transverso alargada (caráter 65, nesta análise) e o aumento da cápsula da bexiga natatória (caráter 118, nesta análise). Este último também ocorre de forma independente em Panaque.

O clado que inclui Megalancistrus parananus e M. barrae e possui nove sinapomorfias, sendo duas exclusivas: presença de 10-11 espinhos neurais bífidos (caráter 73) e a forma da margem anterior do cleitro arredondada, com proeminência pontuda (caráter 82). Nas análises de Armbruster (2004) e Chamon (2007), a presença de 10-11 espinhos neurais bífidos também foi observada em Pterygoplichthys, táxon não incluído no presente estudo. Este caráter está relacionado com o número de raios da nadadeira dorsal que, tanto em Megalancistrus quanto em Pterygoplichthys, é bastante alongada e apresenta I+10-11 raios. Armbruster (2004) propõem como sinapomorfia de Megalancistrus parananus a forma da margem posterior do cleitro reta e alta (caráter 156, de Armbruster 2004). No presente estudo, este estado foi interpretado de outra forma (caráter 82, nesta análise). As demais sinapomorfias deste clado concordam em parte com os resultados das análises anteriores. A face lateral do canal metapterigóide mais baixa que a face mesial (caráter 40, nesta análise) foi corroborada apenas em Armbruster (2004) e a ausência de contato do esfenótico com o sexto infra-orbital (carárter 14, nesta análise) foi corroborada em Armbruster (2004) e em Chamon (2007). O caráter 84, nesta análise: processo lateral do basipterígio largo foi corroborado somente em Chamon (2007). Outros caracteres propostos anteriormente para Megalancistrus foram novamente analisados aqui, entretanto, não representaram sinapomorfias do gênero.

No presente estudo, o gênero Acanthicus é suportado por 21 sinapomorfias, sendo quatro exclusivas. Armbruster (2004) propôs 13 sinapomorfias para Acanthicus hystrix e Chamon (2007), 16. Dentre as sinapomorfias exclusivas do gênero, a maioria é referente à morfologia externa; como nadadeira adiposa ausente (caráter 99); focinho totalmente coberto por placas (caráter 107) e acúleos das nadadeiras peitorais quando adpressos que alcançam quase a porção distal do raio indiviso da nadadeira pélvica (caráter 120). As duas primeiras foram propostas por Armbruster (2004) e corroboradas em Chamon (2007) e a terceira é proposta pela primeira vez nesta análise. Outros caracteres sinapomórficos corroborados na presente análise e nos estudos anteriores são: ângulo de encontro dos dentários oblíquo (caráter 69), linha lateral estendida até a placa hipural (caráter 92) e processo posterior do coracóide alongado (caráter 79). Algumas sinapomorfias propostas neste estudo foram 
corroboradas somente em Chamon (2007), como a forma do pré-maxilar largo e curto (caráter 50); dentes numerosos (caráter 51); 12 a 14 vértebras a partir do primeiro espinho hemal (caráter 72) e presença de placas abdominais (caráter 114). Em relação aos outros gêneros do grupo, que possuem os pré-maxilares e dentários estreitos e alongados com número de dentes reduzidos, observa-se que em Acanthicus há uma reversão ao estado basal dentro de Loricariidae. O que pode ser observado a partir dos caracteres apontados como sinapomorfias do gênero.

O clado que inclui Pseudacanthicus e Leporacanthicus é sustentado por oito sinapomorfias, sendo três exclusivas. Dentre estas, as de mais fácil visualização são a forma do parieto-supra-occipital, que possui a extremidade posterior alongada e bastante pontuda (caráter 16) e suportando uma crista com odontódeos conspícuos (caráter 17). Em Leporacanthicus, esta crista é arredondada e em Pseudacanthicus, os odontódeos ficam dispostos em duas fileiras convergentes em forma de "V". Outro caráter exclusivo do clado é a forma do pré-maxilar, estreito e alongado (caráter 50) com número reduzido de dentes. A condição apresentada no caráter 50 pode estar associada aos recursos alimentares utilizados por estas espécies, cuja dieta é composta de pequenos moluscos e crustáceos. Em Armbruster (2004), Pseudacanthicus e Leporacanthicus não fazem parte do mesmo clado e formam grupo-irmãos sucessivos do clado que inclui Acanthicus e Megalancistrus. Em Chamon (2007) foram propostas cinco sinapomorfias para o clado que inclui os gêneros do grupo Acanthicus. Entretanto, nenhumas destas sinapomorfias foram corroboradas. Isto pode ser explicado pelas modificações que foram realizadas em alguns caracteres e pela inclusão de outros táxons de Pseudacanthicus no presente estudo.

O gênero Leporacanthicus é sustentado por 28 sinapomorfias, das quais 10 são exclusivas. Armbruster (2004) propôs 13 autapomorfias para Leporacanthicus galaxias, a única espécie deste gênero incluída em sua análise e Chamon (2007) propôs 14 sinapomorfias para o gênero. No presente estudo a maioria dos caracteres propostos nos estudos anteriores foi corroborada como sinapomorfias para o gênero, embora não necessariamente exclusivas. Dentre as sinapomorfias exclusivas do gênero, a de mais fácil percepção é relativa à morfologia externa do crânio, que apresenta o parieto-supra-occipital portando uma crista arredondada e pontuda de odontódes conspícuos (caráter 17). Alguns caracteres estão relacionados com as modificações nos arcos branquiais, como a presença de odontódeos 
desenvolvidos no quinto cerato-branquial (caráter 25) e nas placas faríngeas superiores (caráter 33). E outros se referem às modificações do arco mandibular dessas espécies, como o pré-maxilar bastante estreito e alongado (caráter 50) e portando no máximo quatro dentes (caráter 51). Estas modificações podem estar relacionadas ao hábito alimentar dessas espécies, que utilizam os dentes bastante alongados e curvados para retirar pequenos moluscos de suas conchas (Burgess, 1994) e as placas dentígeras para auxiliar na trituração desses alimentos.

A análise das relações filogenéticas de Leporacanthicus indicou que L. galaxias possui uma posição basal em relação às demais espécies congêneres. O clado que inclui L. triactis, $L$. heterodon e L. joselimai possui duas sinapomorfias: fenestra no lobo hipural inferior (caráter 97) e coloração cinza clara com manchas ou pontos escuros (caráter 101). O clado que inclui L. heterodon e L. joselimai também é suportado por duas sinapomorfias: hipo-hial curto (caráter 21) e margem distal do processo transverso pontuda (caráter 66). As espécies Leporacanthicus heterodon e L. joselimai são bastante similares em relação à morfologia externa e poucos caracteres podem ser utilizados para distingui-las, sendo o principal destes o padrão de coloração, em que L. joselimai apresenta barras brancas nas extremidades distais das nadadeiras (caráter 105).

O clado que inclui as espécies de Pseudacanthicus apresenta oito sinapomorfias, uma exclusiva para o gênero: porção posterior ao pterótico-supracleitro com uma ou duas placas pequenas (caráter 112). Embora Ambruster (2004) tenha utilizado este caráter, os estados propostos eram apenas placas presentes ou não, aqui os estados foram modificados. Dentre as demais sinapomorfias propostas para o clado, nenhuma foi corroborada nas hipóteses anteriores de Armbruster (2004) e Chamon (2007). Outro caráter proposto neste estudo é a presença de filamentos caudais (caráter 98), ao menos em espécimes juvenis, que também ocorre em Acanthicus. Este caráter é comum em algumas espécies de Siluriformes que habitam grandes canais de rios na América do Sul (eg. Brachplatystoma spp). O alongamento da nadadeira caudal e a presença de filamentos, provavelmente tenham função de percepção mecânica e sensorial contra predadores (Lujan \& Chamon, 2008).

Dentre as espécies do gênero, Pseudacanthicus sp. "açacu preto" ocupa uma posição mais basal dentro do clado 58. Pseudacanthicus sp. "açacu preto" é bastante similar a alguns exemplares de P. spinosus, entretanto, não apresentam os pontos pretos ao longo do corpo e sim um padrão de coloração uniforme (caráter 100). O clado que inclui as demais espécies de 
Pseudacanthicus é suportado por quatro sinapomorfias (caracteres 23, 69, 71 e 101). Dentre estas, a que pode ser mais facilmente notada é o padrão de colorido apresentando manchas ou pontos pretos (caráter 101).

O clado que inclui as espécies de Pseudacanthicus sp. "aba laranja” e Pseudacanthicus sp. "açacu vermelho" é suportado por seis sinapomorfias não exclusivas Dentre os caracteres que sustentam o clado, a coloração das nadadeiras alaranjadas (caráter 106) é o de mais fácil distinção. Estas duas espécies possuem o padrão de colorido bastante similar ao de $P$. leopardus e é comum serem erroneamente identificadas como esta última. A cúspide lateral pequena (caráter 53) e 12-14 vértebras a partir do primeiro espinho neural (caráter 72) ocorrem também em Pseudacanthicus sp. "Tocantins". O clado que inclui Pseudacanthicus sp. "Aripuanã", Pseudacanthicus sp. "Tocantins", Pseudacanthicus sp. "Curuá-Una", P. leopardus e P. spinosus representa o grupo-irmão do clado 59 e é suportado por duas sinapomorfias não exclusivas: o contato posterior do etmóide lateral com o metapterigóide (caráter 6), que representa uma reversão do estado 1 observado nos demais táxons do grupo Acanthicus, mas que também encontra-se revertido em Leporacanthicus e a extremidade distal do processo transverso do centro complexo não conectando o pterótico-supracleitro (caráter 67) também presente no clado que inclui Acanthicus e Megalancistrus

O clado (Pseudacanthicus sp. "Aripuanã" e Pseudacanthicus sp. "Tocantins") é sustentado por sete sinapomorfias, sendo uma exclusiva, perfil pós-dorsal do corpo robusto (caráter 117). Outro caráter sinapomórfico é a presença de quilhas moderadas ao longo do corpo (caráter 116). No grupo Acanthicus, a presença de quilhas bastante desenvolvidas é considerada uma sinapomorfia, proposta por Armbruster (2004) e corroborada em Chamon (2007). Entretanto, em nenhuma das análises anteriores foram examinados estes táxons, que possuem quilhas moderadamente desenvolvidas em relação ao outras espécies do grupo. Dessa forma, este caráter foi codificado de acordo com o nível de desenvolvimento das quilhas, ausentes ou moderadas (estado 0) e bastante desenvolvidas (estado 1).

O clado (Pseudacanthicus sp. "Curuá-Una (Tapajós", P. spinosus e P. leopardus)) é suportado por três sinapomorfias não exclusivas. O clado ( $P$. spinosus e P. leopardus) é suportado por três sinapomorfias não exclusivas. O disco do mesetmóide estendido além do corpo principal (caráter 8) foi inicialmente proposto por Armbruster (2004) como presente em Megalancistrus parananus, Leporacanthicus galaxias, Pseudacanthicus spinosus e 
Spectracanthicus. Dentre as sinapomorfias do clado (Pseudacanthicus leopardus e P. spinosus), o esfenótico formando uma quilha de odontódes conspícuos em sua porção láteroposterior (caráter 13) é o que melhor pode ser visualizado. Esta condição também está presente em Leporacanthicus.

\subsubsection{Relações do grupo Acanthicus com Spectracanthicus}

Na presente hipótese, o clado que inclui o grupo Acanthicus mais Spectracanthicus é suportado por seis caracteres, dois destes sinapomorfias exclusivas. Nenhuma sinapomorfia proposta por Armbruster (2004) para este clado foi corroborada nessa hipótese. Entretanto, na análise de Armbruster (2004), diversos táxons de Loricariidae foram incluídos e vários caracteres utilizados apresentaram distribuições distintas na topologia da árvore.

Outros caracteres também foram propostos por Armbruster (2004) como sinapomorfias para o clado (Acanthicus mais Spectracanthicus), como a margem anterior do hiomandibular (caráter 36 de Armbruster, 2004) que, na maioria dos táxons observados neste estudo, não é suturada ao metapterigóide ao longo de todo o comprimento. Entretanto, a condição inversa é uma sinapomorfia de Pseudacanthicus e ocorre também independentemente em Megalancistrus parananus e Spectracanthicus murinus O processo anterior do pteróticosupra-cleitro (caráter 111 de Armbruster, 2004) não apresentou variação significativa dentre as espécies analisadas e, portanto, este caráter não foi incluído nesta análise. O processo transverso do centro complexo de Weber perfurado distalmente por forames largos (caráter 134 de Armbruster, 2004) é uma sinapomorfia de Leporacanthicus (exceto L. heterodon), do clado que inclui Pseudacanthicus sp. "Curuá-Una", P. spinosus e P. leopardus; e de Panaque. Entretanto, no presente estudo, a interpretação dos estados deste caráter foi adaptada de acordo com os terminais analisados.

Na hipótese de Chamon (2007), seis sinapomorfias não exclusivas suportam o clado que inclui o grupo Acanthicus mais Spectracanthicus. Dentre estas, duas foram aqui corroboradas: frontal com grande contato com a órbita lateralmente (caráter 1 nesta análise) e I+8 ou mais raios na nadadeira dorsal (caráter 65 nesta análise).Os demais caracteres (caracteres 23, 33, 71 e 93, de Chamon, 2007) também foram analisados aqui, porém não resultaram em sinapomorfias do clado (Acanthicus mais Spectracanthicus). 


\subsubsection{Relações intra-específicas em Spectracanthicus}

O clado que inclui as espécies de Spectracanthicus é suportado por seis sinapomorfias não exclusivas. Dentre estas sinapomorfias, a única que também foi corroborada em Armbruster (2004) é a presença de expansão da membrana da nadadeira dorsal até a nadadeira adiposa (76:1 nesta análise). Em Chamon (2007), a única sinapomorfia do gênero é a ocorrência de 5 a 6 infra-orbitais (caráter 49 de Chamon, 2007), entretanto re-analisando as espécies neste estudo, a codificação deste caráter foi modificada e os táxons foram codificados com 7 a 8 infra-orbitais. Este resultado provavelmente ocorre em função da adição de novos táxons do gênero à análise e a re-interpretação de alguns caracteres.

Spectracanthicus sp. "Tapajós" ocupa uma posição basal em relação aos demais táxons do gênero, que possui sete sinapomorfias não exclusivas, nenhuma corroborada nos estudos anteriores. Dentre estas sinapomorfias, algumas são de fácil observação por serem referentes à morfologia externa, como o contato esfenótico com o IO6 ausente (caráter 14); coloração com manchas ou pontos claros (caráter 102) e o perfil dorsal do focinho arredondado (caráter 108). Embora estes caracteres estejam presentes em outros táxons analisados, são de grande valia na diagnose dessas espécies. O clado (Spectracanthicus sp. "Tapajós” (Spectracanthicus)) é uma politomia composta pelo clado que inclui Spectracanthicus sp. "Tocantins" e S. murinus e as espécies Spectracanthicus sp "bola branca" e $S$. punctatissimus, sendo que o clado é suportado por quatro sinapomorfias, nenhuma corroborada nas análises anteriores de Armbruster (2004) e Chamon (2007).

Armbruster (2004) analisou apenas as espécies tipo de Spectracanthicus e Oligancistrus (considerado sinônimo de Spectracanthicus neste estudo) e de acordo com o alto suporte resultante de sua análise, o autor propôs que estes gêneros fossem sinônimos. Chamon (2007) incluiu mais três espécies não descritas de Spectracanthicus em sua análise, resultando em uma politomia entre Spectracanthicus sp. “Tocantins" e S. murinus como grupo irmão de Spectracanthicus sp. "bola branca" e S. punctatissimus.

Embora nenhuma das hipóteses anteriores sustente as sinapomorfias propostas aqui, a sinonímia proposta inicialmente por Armbruster (2004) foi corroborada, tanto em Chamon (2007) quanto no presente estudo. A princípio pode parecer estranho a inclusão de Oligancistrus em Spectracanthicus, devido às diferenças na morfologia externa, principalmente associadas à região opercular (caracteres 57, 58 e 59). Entretanto, pode-se notar 
certa modificação em alguns complexos osteológicos, associadas aos arcos branquiais, como o segundo basi-branquial cartilaginoso (caráter 22); e também ao centro complexo, esqueleto axial e esqueleto caudal (caracteres 66, 75, 94 e 96).

\subsection{Revisão Taxonômica}

\section{Grupo Acanthicus}

Gêneros incluídos: Acanthicus Spix \& Agassiz, 1829; Megalancistrus Isbrucker, 1980; Pseudacanthicus Bleeker, 1862; Leporacanhticus Isbrucker \& Nijssen, 1989

Diagnose. Os representantes do grupo Acanthicus podem ser diferenciados dos demais Loricariidae por apresentarem a combinação dos seguintes caracteres: corpo com espinhos rígidos e bem desenvolvidos acompanhado as cinco fileiras de placas do corpo; dentes alongados; filamentos caudais nos espécimes juvenis (em Acanthicus e Pseudacanthicus); oito ou mais raios na nadadeira dorsal. Além disso, a maioria das espécies atinge grande tamanho corporal (mais de $60 \mathrm{~cm}$ ). Outros caracteres são considerados como sinapomorfias do grupo, embora ocorram independentemente em outros táxons de Loricariidae. Estes são: hipo-hial alongado; processo acessório do CB1 com aproximadamente a mesma largura do CB1; expansão laminar na extremidade distal do EB1 fina e bastante curta; inter-hial no hiomandibular, sem contato com a área de cartilagem com o quadrado; inter-hial pequeno; processo posterior do coracóide com extremidade distal pontiaguda.

\section{Chave de Identificação dos gêneros do grupo Acanthicus mais Spectracanthicus e Spectracanthicus}

1a. Número de raios na nadadeira dorsal $\mathrm{I}+7-8$. 2

1b. Número de raios na nadadeira dorsal I+9-10. Megalancistrus 
2a. Pterótico supracleitro curto, nadadeira adiposa presente 3

2b. Pterótico supracleitro alongado, nadadeira adiposa ausente...Acanthicus

3a. Nadadeira dorsal sem contato com a adiposa, extremidade posterior do processo supraocipital com quilha de odontódeos conspícuos.. 4

3b. Nadadeira dorsal com membrana expandida conectada à adiposa, extremidade posterior do processo supra-ocipital sem quilhas Spectracanthicus

4a. No máximo quatro dentes alongados em cada pré-maxilar, filamentos labiais em forma de franja no lábio superior. Leporacanthicus

4b. Seis ou mais dentes alongados em cada pré-maxilar, filamentos labiais ausentes em todo o lábio. Pseudacanthicus

\section{Acanthicus Agassiz in Spix \& Agassiz, 1829}

Acanthicus Agassiz in Spix \& Agassiz, 1829: 2 Masc. Acanthicus hystrix Agassiz 1829. Tipo por monotipia. Gênero masculino. Autoria segue a sugestão de Kottelat 1988:78. - Bleeker, 1862 [tribo Acanthicini]. - Isbrücker, 1980: 75 [nomenclatura e catálogo de Loricariidae]. - Isbrücker \& Nijssen, 1988 [descrição de A. adonis; chave de identificação]. Burgess, 1989: 437 [Atlas de aquarismo]. - Eschmeyer, 1998: 1822 [catálogo de peixes]. - de Pinna, 1998: 305 [citação no texto]. - Montoya-Burgos et al., 1998: 367 [filogenia molecular]. - Isbrücker, 2002: 11 [nomenclatura de Loricariidae]. - Ferraris, 2003: 865 [catálogo de peixes]. - Fisch-Muller in Reis et al., 2003: 373 [catálogo de peixes]. - Armbruster, 2004: 5359 [análise filogenética]. - Ferraris, 2007: 218 [catálogo de peixes; autoria à Spix \& Agassiz].

Espécies válidas incluídas. Acanthicus hystrix e A. adonis. 
Diagnose. Acanthicus pode ser distinguido de todos os outros Loricariidae pela presença do pterótico-supracleitro bastante expandido, que está relacionado com o acréscimo no tamanho da cápsula da bexiga natatória. Dentre os táxons de Ancistrini, pode ser diferenciado (exceto de Chaetostoma e Leptoancistrus) pela ausência da nadadeira adiposa. Dentre os táxons do grupo Acanthicus, pode ser diferenciado por possuir o pré-maxilar e o dentário largos; o focinho totalmente coberto por placas forma do lábio com a largura maior que o comprimento; presença de placas abdominais em todo o abdome; espinhos das nadadeiras peitorais quando aduzidos alcançam quase o final da extensão do raio indiviso da nadadeira pélvica. Outros caracteres sinapomórficos que podem ocorrer em outros táxons do grupo: margem anterior do frontal alongada, margem anterior ultrapassa a metade do comprimento da narina (vs. margem anterior curta nos demais táxons); anglo dos dentários oblíquo (vs. ângulo dos dentários reto nos demais táxons); pré-maxilar largo e curto (vs. moderadamente a bastante estreito e alongado nos demais táxons); dentes numerosos, mais de 25 em cada pré-maxilar (vs. dentes pouco numerosos, no máximo 25 em cada pré-maxilar); opérculo em forma de barra longitudinal (vs. opérculo em forma de barra curvada nos demais táxons e em forma triangular em Spectracanthicus murinus); IO4 com bastante contato com a órbita através de sua extremidade posterior (vs.ausente ou pequeno nos demais táxons, exceto em Pseudacanthicus e em Spectracanthicus sp. "Tocantins"); linha lateral ultrapassa a placa hipural (vs. não ultrapassa nos demais táxons, exceto em Leporacanthicus); processo ventral do $\mathrm{CCW}$ aproximadamente retangular (vs. aproximadamente circular, exceto em Pseudacanthicus e em Spectracanthicus sp. "Tocantins"); 12 a 14 vértebras a partir do primeiro espinho neural, não incluindo a placa hipural (vs. 8 a11, exceto em Pseudacanthicus sp. "açacu vermelho", Pseudacanthicus sp. "aba laranja", Pseudacanthicus sp. “Tocantins" e S. punctatissimus); crista lateral à penúltima vértebra (contando a placa hipural) bastante desenvolvida (vs. pouco desenvolvida ou ausente, exceto em Pseudacanthicus sp. “Aripuanã”); processo posterior do coracóide alongado (vs, curto nos demais táxons); filamentos caudais presente (vs. ausente, exceto em Pseudacanthicus); canais urogenital e anal com duas saídas separadas (vs. em uma única saída tubular). 
Etimologia. Acanthicus, que do Grego akanthikus significa espinhos, em referência ao corpo coberto por placas com odontódeos robustos e afiados. Gênero masculino.

\section{Chave para as espécies de Acanthicus}

1a. Padrão de coloração do com pontos brancos; tamanho corporal médio $200 \mathrm{~mm}$ (máximo 304,6 mm CP) A. adonis

1b. Padrão de coloração do corpo, sem pontos brancos, apresenta algumas manchas marrons escuras estriadas nas nadadeiras (principalmente na dorsal e caudal); tamanho corporal máximo de $628,3 \mathrm{~mm} \mathrm{CP}$ A. hystrix

Acanthicus adonis Isbrücker \& Nijssen, 1988

(Figura 44, Tabela 1)

Acanthicus adonis Isbrücker \& Nijssen, 1988: 166, fig. 5. Localidade tipo: rio Tocantins, Cametá, Pará, Brasil $\left(0^{\circ} 14^{`} \mathrm{~S}, 49^{\circ}\right.$ 30,5 $\left.\mathrm{W}\right)$. Holótipo: MZUSP 38580 Parátipos: ZMA 119968 (4), 119992 (1); ZSM 26730 (2).

- Burgess, 1989: 445 [Atlas de aquarismo]. - Eschmeyer, 1988: 41 [catálogo]. - Isbrücker, 2001: 25 [classificação e catálogo]. - Isbrücker, 2002: 11 [nomenclatura]. - Fisch-Muller in Reis et al. 2003:373 [catálogo]. - Ferraris, 2007: 218 [catálogo].

Diagnose Acanthicus adonis se diferencia de seu único congênere, A. hystrix pelo padrão de coloração do corpo castanho escuro a preto com pontos brancos (vs. sem pontos brancos) e por possuir menor tamanho corporal dos indivíduos adultos (até 304,6 $\mathrm{mm}$ de CP vs. até 628,3 mm em A.hystrix). Outros caracteres sinapomórficos para a espécie são: hipo-hial curto (vs. alongado); fenestra anterior a seção cartilaginosa do basipterígio alongada, aproximadamente elíptica (vs. arredondada); hipurapófise alta (vs. baixa ou média). 
Descrição Dados morfométricos e merísticos na Tabela 1. Perfil dorsal entre ponta do focinho e região anterior do processo supra-occipital pouco curvado. Restante do perfil dorsal ligeiramente reto, até placa pré-dorsal. Perfil pós-dorsal do corpo estreito. Pedúnculo caudal bastante estreito. Maior altura do corpo na origem da nadadeira dorsal. Menor altura do corpo na região do pedúnculo caudal. Maior largura do corpo igual largura cleitral. Perfil ventral da ponta do focinho até a base da nadadeira caudal reto. Região abdominal e torácica com pequenas placas.

Cabeça baixa, focinho prolongado anteriormente. Focinho totalmente recoberto por pequenas placas. Perfil dorsal do focinho arredondado. Nasal alongado, fino e retangular. Frontal alongado com grande contato com narina anteriormente e com a órbita lateralmente. Margem anterior do frontal bastante alongada, ultrapassando a metade do comprimento da narina. Supra-occiptal bastante alongado com extremidade posterior com projeção curta e sem crista. Esfenótico alongado ventralmente com grande contato com o IO6, sem odontódeos conspícuos. Pterótico-supracleitro bastante expandido e fenestrado. Processo anterior do pterótico-supracleitro com pequeno contato com a órbita. Área posterior ao pteróticosupracleitro com uma placa de tamanho médio a grande. Olhos medianos e súpero-laterais com íris em forma de meia lua.

Lábios de tamanho médio a grande com largura aproximadamente maior que o comprimento. Lábio coberto de pequenas papilas que aumentam de tamanho em direção à borda externa. Sem fialmentos labiais. Papila bucal central presente e bem desenvolvida. Barbilhões maxilares pequenos. Pré-maxilar e dentário grandes, largos e curtos. Ângulo de encontro dos dentários oblíquo. Dentes do pré-maxilar e do dentário numerosos, alongados, finos e com cúspide lateral desenvolvida. Ponta dos dentes pouco curvada.

Nadadeiras peitoral e pélvica alongadas. Pélvica sem mecanismos de trava; margens distais pouco arredondadas. Primeiro raio das nadadeiras peitoral e pélvica conspicuamente espesso, coberto por odontódeos bem desenvolvidos. Nadadeira peitoral I+6. Extremidade distal da nadadeira peitoral quando adpressa ultrapassa metade do raio indiviso da nadadeira pélvica. Nadadeira pélvica I+5; primeiro raio espesso e suportando odontódeos. Extremidade da nadadeira pélvica quando adpressa alcançando a base da nadadeira anal. Nadadeira dorsal com mecanismo de trava com placa pré-dorsal em forma de V (“spinelet"). Nadadeira dorsal 
I+8. Nadadeira anal I+4, curta. Nadadeira adiposa ausente. Nadadeira caudal I+14+I, lobo inferior maior que o superior. Exemplares juvenis apresentam filamentos caudais prolongados.

Corpo coberto por cinco fileiras de placas suportando odontódeos. Quilhas bastante desenvolvidas. Grandes placas pares pré-dorsais (geralmente três placas). Placas operculares eversíveis até 90 graus, sustentando espinhos bastante desenvolvidos. Raios procorrentes em pequeno número (três a quatro) posicionados anteriormente aos raios caudais indivisos. Vinte e nove vértebras totais. Doze vértebras a partir do primeiro espinho neural simples. Seis espinhos neurais bífidos. Bexiga natatória bastante expandida ultrapassa a sexta costela. Extremidade distal da bexiga natatória afilada. Canais urogenital e anal com duas saídas separadas.

Sete a oito infra-orbitais. Infra-orbital 4 com grande contato com a órbita através de sua extremidade posterior. Infra-orbital 6 forma apenas a parte póstero-ventral da órbita. Poros da linha lateral ultrapassam a placa hipural.

Coloração. Corpo castanho escuro a preto. Nadadeiras com coloração escura. Pequenos pontos brancos espalhados de forma irregular sobre o corpo e nadadeiras; mais concentrados na superfície dorsal do corpo. Superfície ventral ocre a castanho escuro, sem manchas ou pontos.

Distribuição. Rio Tocantins, nas cidades de Cametá e Tucuruí (Figura 47).

Etimologia. De origem mitológica grega Adonis foi um jovem de grande beleza que era amado por Vênus. O nome faz alusão à beleza da espécie.

\section{Material examinado}

MZUSP 38580 (h), 135,56; Brasil, Pará, Rio Tocantins, Cametá, ( $0^{\circ} 14^{`}$ S, 49³ 30,5`W); 1987, A. Werner. ZMA 119.992 (p), 194,43, coletado junto com o holótipo.

Brasil, Pará, Tocantins: INPA 6311 (1) 191,83; Icangui, Tucuruí, 18/07/1982, Equipe Ictiologia INPA. MHNG 2546.090 (7), 81,17-112,26, rio Tocantins, próximo à Cametá, Pará, Brasil ( $\left.0^{\circ} 14^{`} \mathrm{~S}, 49^{\circ} 30,5^{`} \mathrm{~W}\right)$; 10/1989, A. Werner. Sem dados de localidade: AMNH 96749 (2) 301,99-304,55; espécimens de aquário, 14/02/1988, importador \& R. Kulek. ANSP 
179532 (1) 235,22; Brasil (?); espécime de aquário. ANSP 181084 (4) 114,43-169,35; Peru (?); espécimes de aquário. AUM 44605 (1) 154,32; espécime de aquário, compardo em Sun Pets, Atlanta, GA, EUA. INHS 43256 (1) 121,58; Peru (?).

Acanthicus hystrix Agassiz, in Spix \& Agassiz, 1829

(Figura 45 e 46, Tabela 2)

Acanthicus hystrix Agassiz in Spix \& Agassiz 1829:3, Pl. 1 (figs. 1-2) Localidade tipo: rio Amazonas. Holótipo: destruído em 1944 (Terofal, 1983).

Rinelepis acanthicus Valenciennes in Cuvier \& Valenciennes, 1840:487. Nome de recolocação e sinônimo objetivo de Acanthicus hystrix.

- Cuvier, 1829 [nome publicado pela primeira vez]. - Agassiz, 1829 [válido como Acanthicus hystrix]. - Günther, 1868b: 233 [autoria à Spix; exemplar de 22 polegadas obtido por Mr. Bartlett em Xeberos]. - Eigenmann \& Eigenmann, 1889: 46 [autoria à Spix; Acanthicus genigarbis Cuvier \& Valenciennes (?); Pará]. - Regan, 1904: 261 [autoria a Spix; um exemplar, rio Amazonas, Guiana]. - Devincenze, 1933:1-5 [nota sobre a aquisição de um exemplar de Acanthicus hystrix no museu de Montevidéu; coletado por Spix no alto Amazonas sem localidade específica durante a expedição de 1817-1820; descrição com ilustração]. - Gosline, 1945: 98 [citação]. - Fernandez-Yepez, 1949 [sétimo exemplar de Acanthicus coletado; rio Guárico, Orinoco; descrição do exemplar; ilustrações]. - Fowler, 1954: 135 [citação; autoria a Spix]. - Isbrücker, 1980: 75 [classificação e catálogo de Loricariidae]. - Ortega \& Vari, 1986: 16 [catálogo de peixes de água doce do Peru]. Burgess, 1989: 438 [Atlas de aquarismo; pequena descrição da espécie]. - Montoya-Burgos et al., 1998: 367 [análise filogenética molecular]. - Eschmeyer, 1998: 757 [catálogo de peixes; volume 1]. - Isbrücker, 2001: 25 [nomenclatura de Loricariidae]. - Isbrücker 2002:11 [nomenclatura de Loricariidae]. - Ferraris 2003:865 [catálogo de peixes]. - Fisch-Muller in Reis et al., 2003: 373 [catálogo de peixes]. - Santos et al., 2004: 156 [catálogo ilustrado; 
diagnose da espécie]. - Ferraris, 2007: 218 [catálogo de peixes; com autoria da espécie como Spix \& Agassiz, 1929].

Diagnose. Acanthicus hystrix se diferencia de A. adonis pelo padrão de coloração do corpo ocre a castanho escuro uniforme, sem pontos brancos, apresenta algumas manchas marrons escuras estriadas nas nadadeiras (principalmente na dorsal e caudal); e por alcançar maior tamanho corporal (ultrapassa de 600,0 mm de CP vs. no máximo 134,5 em A. adonis). Outros caracteres sinapomórficos do gênero, embora ocorra em outros táxons: primeiro hipobranquial bastante alongado (vs. curto ou pouco alongado em $A$. adonis); manchas no corpo irregulares e/ou vermiculadas (vs. distribuídas de forma uniforme em A. adonis).

Descrição. Dados morfométricos e merísticos na Tabela 2. Perfil dorsal entre ponta do focinho e região anterior do processo supra-occipital pouco curvado. Restante do perfil dorsal ligeiramente reto, até placa pré-dorsal. Perfil pós-dorsal do corpo estreito. Pedúnculo caudal bastante estreito. Maior altura do corpo na origem da nadadeira dorsal. Menor altura do corpo na região do pedúnculo caudal. Maior largura do corpo igual largura cleitral. Perfil ventral da ponta do focinho até a base da nadadeira caudal reto. Região abdominal e torácica com pequenas placas.

Cabeça baixa, focinho prolongado anteriormente. Focinho totalmente recoberto por pequenas placas. Perfil dorsal do focinho arredondado. Nasal alongado, fino e retangular. Frontal alongado com grande contato com narina anteriormente e com a órbita lateralmente. Margem anterior do frontal bastante alongada, ultrapassando a metade do comprimento da narina. Supra-occiptal bastante alongado com extremidade posterior com projeção curta e sem crista. Esfenótico alongado ventralmente com grande contato com o IO6, sem odontódeos conspícuos. Pterótico-supracleitro bastante expandido e fenestrado. Processo anterior do pterótico-supracleitro com pequeno contato com a órbita. Área posterior ao pteróticosupracleitro com uma placa de tamanho médio a grande. Olhos medianos e súpero-laterais com íris em forma de meia lua.

Lábios de tamanho médio a grande com largura aproximadamente maior que o comprimento. Lábio coberto de pequenas papilas que aumentam de tamanho em direção à borda externa. Sem fialmentos labiais. Papila bucal central presente e bem desenvolvida. 
Barbilhões maxilares pequenos. Pré-maxilar e dentário grandes, largos e curtos. Ângulo de encontro dos dentários oblíquo. Dentes do pré-maxilar e do dentário numerosos, alongados, finos e com cúspide lateral desenvolvida. Ponta dos dentes bastante curvada.

Nadadeiras peitoral e pélvica alongadas. Pélvica sem mecanismos de trava; margens distais pouco arredondadas. Primeiro raio das nadadeiras peitoral e pélvica conspicuamente espesso, coberto por odontódeos bem desenvolvidos. Nadadeira peitoral I+6. Extremidade distal da nadadeira peitoral quando adpressa alcançando quase metade do raio indiviso da nadadeira pélvica. Nadadeira pélvica I+5; primeiro raio espesso e suportando odontódeos. Extremidade da nadadeira pélvica quando adpressa alcançando a base da nadadeira anal. Nadadeira dorsal com mecanismo de trava com placa pré-dorsal em forma de V (“spinelet"). Nadadeira dorsal I+8. Nadadeira anal I+4, curta. Nadadeira adiposa ausente. Nadadeira caudal $\mathrm{I}+14+\mathrm{I}$, lobo inferior maior que o superior. Exemplares juvenis apresentam filamentos caudais prolongados.

Corpo coberto por cinco fileiras de placas suportando odontódeos. Quilhas bastante desenvolvidas. Grandes placas pares pré-dorsais (geralmente três placas). Placas operculares eversíveis até 90 graus, sustentando espinhos bastante desenvolvidos. Raios procorrentes em pequeno número (três a quatro) posicionados anteriormente aos raios caudais indivisos. Trinta vértebras totais. Treze vértebras a partir do primeiro espinho neural simples. Sete espinhos neurais bífidos. Bexiga natatória bastante expandida ultrapassa a sexta costela. Canais urogenital e anal com duas saídas separadas.

Sete a oito infra-orbitais. Infra-orbital 4 com grande contato com a órbita através de sua extremidade posterior. Infra-orbital 6 forma apenas a parte póstero-ventral da órbita. Poros da linha lateral ultrapassam a placa hipural.

Coloração. Corpo e nadadeiras castanhos médio a escuro, sem pontos ou manchas. Superfície ventral com colorido apresentando padrão vermiculado de manchas em alguns exemplares. Alguns exemplares (rios Madeira, Branco e Xingu; figura 45) apresentam coloração do corpo bastante escura, quase preta, sem pontos ou manchas. Exemplares maiores com manchas estriadas pouco definidas ao longo das nadadeiras dorsal e caudal. 
Distribuição. A espécie apresenta ampla distribuição na Bacia Amazônica, nas drenagens dos rios Branco, Uraricoera, Ucayali, Negro, Solimões, Trombetas, Japurá, Madeira, Xingu e Tocantins; e na Bacia do rio Orinoco (Figura 47).

Ecologia. A espécie Acanthicus hystrix é encontrada nas calhas principais dos rios, com fundo de pedras e corredeiras.

Etimologia. De origem grega hystrix significa porco-espinho em referência aos espinhos que cobrem o corpo.

Comentários. De acordo com Terofal (1983), holótipo de A. hystrix foi destruído em 1944 durante a Segunda Guerra Mundial. A localidade tipo citada por Agassiz é "rio Amazonas". Dentre o material examinado, foi designado um exemplar do baixo Amazonas para ser o neótipo da espécie.

\section{Material examinado}

MZUSP (n) 103858 (1), 182,5; Brasil, Pará, Oriximiná, rio Amazonas, confluência com o rio Trombetas, (145'52.05"S, 5552'51.90"W) 14/09/1983, R. Barthem.

Brasil, Amazonas, Amazonas: INPA 587 (1), 285,0; Manaus, Catalão, rio Solimões, 01/11/1984, W. Boeger. INPA 2423 (1), 112,67; Paraná Jaraua, rio Japurá, Amazonas, ( $\left.2^{\circ} 11^{\prime} 49.34^{\prime \prime S}, 65^{\circ} 9^{\prime} 9.20^{\prime \prime W}\right) ; 31 / 01 / 1980$, Equipe Sr. José. INPA 6376 (1) 145,22; Porto da

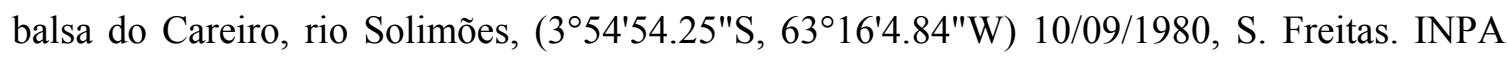
32226 (7); 387,0-600,0; rio Purus. Pará, Tocantins: INPA 2487 (2), 98,27-260,0; Tucuruí, Pará31/10/1987, F. Martinho. INPA 6306 (6), 114,36-240, lago Tucuruí, 02/08/1985, Equipe de Ictiologia do INPA. INPA 6307 (4), 38,8-101,22; poco d'agua a jusante da barragem, 09/10/1984, Equipe de Ictiologia do INPA. INPA 6312 (1), 171,51 Tucuruí, igarapé Jatobal, 31/10/1980, Equipe de Ictiologia do INPA INPA 31850 (22), 43,34-209,43; Tucuruí, a jusante da represa, 01/09/1984, G. M. dos Santos. ZMA 119.969 (3), 93,05-125,75 mm CP; Cametá (02 14' S; 49 30' W); 1987, A. Werner. Xingu: INPA 31803 (4), 140,30-185,87; Belo Monte Ilha do Merencio (Pontão), (0306'17"S, 05143'33"W); 05/11/2008, L. Rapp Py-Daniel et al. Roraima, Branco: MZUSP 34244 (4; 1 d\&c, 1 esq.), rio Branco, cachoeira do Bem Querer, 
(155'57.83"N, 6059'54.52"W); 08/01/1984, M. Goulding. . INPA 1970 (3), 56,68-140,26; Alto Alegre, rio Uraricoera, Furo Santa Rosa, (3²1'34.03"N 61²1'45.32"W) 12/03/1988, M. Jegu. INPA 6305 (2) 168,29-189,95, rio Mucajaí, tronco caído, pedral, $\left(2^{\circ} 26^{\prime} 6.95^{\prime \prime} \mathrm{N}\right.$ 6051'57.70"W); 20/02/1987, E. G. Ferreira \& M. Jegu. ZMA 120.196 (1), 184,1 mm CP; rio Branco, Cachoeira do Bem Querer, remanso, (06100'00"; W01 $\left.{ }^{\circ} 56^{\prime} 00^{\prime \prime N}\right)$ 08/01/1984, M. Goulding. Mato Grosso e Rondônia, Madeira: UFRO-I 000689 (4), 54,64-182,28; Porto Velho, rio Madeira, ensecadeira da cachoeira de Santo Antônio, (8 48' 30" S; 63 36' 53" W); 01/11/2008, Equipe LIP/UNIR. UFRO-I 000695 (1), 251,65 mm CP; Porto Velho, rio Madeira, ensecadeira da cachoeira de Santo Antônio, (8 48' 30" S; 63 36' 53" W). : MZUSP 82210 (1), 522,0; rio Madeira, boca do Aripuanã, Mato Grosso, Brasil (5 7'4.07"S, 60²3'0.90"W); 01/01/1980, M. Goulding. Peru, Ucayali: AMNH 9934 (1) 628,3; Iquitos, Loreto, rio Ucayali, (344'6.23"S, 73¹1'28.52"W); 1925. BMNH 1867.6.13.28 (1), 400,69 $\mathrm{mm} \mathrm{CP}$, Jeberos, rio Ucayali, Peru ( $\left.5^{\circ} 6^{\prime} 23.59^{\prime \prime} \mathrm{S}, 75^{\circ} 35^{\prime} 1.18^{\prime \prime} \mathrm{W}\right)$. Venezuela, Orinoco: ANSP 162384 (3); 518,0-576,3; El Burro, rio Orinoco, (242'41.38"N, 65 9'49.61"W); 26/11/1985, B. Chernoff et al. AUM 42135 (1) 26,10 mm CP; Pasaganado, $38 \mathrm{~km}$ N of San Fernando de Atabapo, on Rio Orinoco (4 23' 3.9120"N; 67 46' 38.7841" W. MCNG 50865 (2), Orinoco, rio Apure. MCNG 53135 (2 ex. 1 d\&c); rio Orinoco, rio Apure. Sem dados de localidade: ANSP 189661 (1) 57,39. BMNH 1997.6.26.70 (1) 247,04 mm CP; doado por M. Hardman; INHS 36803, 1 d\&c, 146,41 mm CP; MZUSP 81088 (1), sem dados de localidade.

Gênero Megalancistrus Isbrücker, 1980

Megalancistrus Isbrücker 1980:52 - Epécie tipo: Chaetostomus gigas Boulonger, 1895. Tipo por designação original. Gênero masculino. - Heitmans et al., 1983: 33 [diagnose comparativa de Lasiancistrus]. - Burgess, 1989: 434 [atlas de aquarismo; breve descrição]. Eschmeyer, 1998: 1013 [catálogo de peixes; volume 3, gêneros]. -Britski et al., 1999: 134 [manual de identificação dos peixes do Pantanal; diagnose e breve descrição; ilustração]. Armbruster, 2002: 87 [diagnose comparativa de Hypancistrus]. - Isbrücker, 2002: 23 [catálogo de Loricariidae]. - Fisch-Muller in Reis et al., 2003: 390 [catálogo de peixes]. Armbruster, 2004: 53, 59 [análise filogenética]. - Britski et al., 2007: 164 [manual de peixes 
do Pantanal, 2a edição; diagnose e breve descrição; ilustração]. - Ferraris, 2007: 272 [catálogo de peixes]. - Graça \& Pavanelli, 2007: 137 [lista de peixes do alto rio Paraná].

Espécies válidas. Megalancistrus barrae e M. parananus.

Diagnose. Megalancistrus pode ser diferenciado dos demais Ancistrini pela combinação dos seguintes caracteres: maior número de raios na nadadeira dorsal (10-11 vs. 7-9); quilhas bem desenvolvidas nas placas laterais e pterótico-supracleitro bem desenvolvido. Dentre os gêneros do grupo Acanthicus, pode ser diferenciado de Leporacanthicus e Pseudacanthicus pela presença do pterótico-supracleitro desenvolvido (vs. pequeno); e de Acanthicus pela presença de nadadeira adiposa (vs. ausente) e dentários curtos (alongados). Outros caracteres sinapomórficos: contato do IO6 com o esfenótico ausente (vs. presente nos demais gêneros, exceto em Spectracanthicus); face lateral do canal metapterigóide baixa (alta nos outros gêneros, exceto em Pseudacanthicus sp. "Curuá-Una", P. spinosus e P. leopardus); processo anterior do metapterigóide sem projeção (vs. com pelo menos uma projeção, exceto em Pseudacanthicus sp. "açacu preto" e Pseudacanthicus sp. “Aripuanã”); 10-11 espinhos neurais bífidos (vs. 6-9 nos demais táxons); área de contato posterior entre o cleitro e o coracóide reta (vs. expandida ventralmente nos demais táxons, exceto em Pseudacanthicus, Spectracanthicus sp. "bola branca" e em Spectracanthicus sp. "Tocantins"); forma da margem anterior do cleitro arredondada, com proeminência pontuda discreta (vs. reta com proeminência conspícua nos demais gêneros); processo ântero-lateral do basipterigio largo em toda sua extensão (vs. delgado nos demais táxons); fenestra anterior à seção cartilaginosa do basipterígio grande (vs. pequena, média ou ausente nas demais espécies, exceto em Spectracanthicus sp. "Tapajós", Spectracanthicus sp. "Tocantins").

Etimologia. Do grego "megas" significa grande. Ancistrus, gênero tipo de Ancistrini, que também tem origem grega "ancistro, ankistron" que significa gancho de peixe. O nome do gênero é em alusão ao grande tamanho corporal que atingem as espécies do gênero.

Chave para as espécies de Megalancistrus 
1a. Padrão de coloração do corpo com grandes manchas pretas arredondadas em toda a extensão corporal. .M. parananus

1b. Padrão de coloração do corpo com pontos ou manchas arredondadas ausentes, apresenta manchas irregulares de formas vermiculadas castanho-escuras M. barrae

Megalancistrus barrae (Steindachner, 1910)

(Figura 48, Tabela 3)

Ancistrus barrae Steindachner, 1910: 58 [Anzeiger der Akademie der Wissenschaften in Wien v. 47 (no. 8)]. Localidade tipo: Rio São Francisco, próximo de Barra, Bahia, Brasil. Síntipos: NMW 48019 (1), 48020 (1). - Fowler, 1941: 155 [Ancistrus barra]. - Gosline, 1945: (33)88 [Ancistrus barrae]. - Fowler, 1954: (9)205 [breve descrição].- Travassos, 1960: 52 [peixes do rio São Francisco; Pterygoplichthys barrae, nome vulgar: Guacari].- Isbrücker, 1980: 52 [nomenclatura de Loricariidae; síntipos macho e fêmea; $480 \mathrm{~mm}$ de comprimento total]. .Burgess, 1989: 434 [atlas de aquarismo]. - Eschmeyer, 1998: 200 [catálogo de peixes, volume 1]. - Isbrücker, 2001: 25-30 [catálogo de Loricariidae]. - Isbrücker, 2002: 23 [catálogo de Loricariidae]. - Fisch-Muller in Reis et al., 2003: 390 [catálogo de peixes]. Ferraris, 2007: 272 [catálogo de Siluriformes].

Diagnose. Pode ser diferenciado de M. parananus pelo padrão de coloração do corpo ocre a castanho dourado,sem pontos ou manchas arredondadas, apresenta manchas irregulares de forma vermiculadas castanha escura. A espécie está restrita à bacia do rio São Francisco. Outros caracteres sinapomorficos são: crista na base interna do processo posterior do basipterígio bem desenvolvida (vs. pouco desenvolvida em M. parananus); hipurapófise baixa (vs. média em M. parananus).

Descrição. Dados morfométricos e merísticos na Tabela 3. Perfil dorsal entre ponta do focinho e região anterior do processo supra-occipital pouco curvado. Restante do perfil dorsal ligeiramente reto, até placa pré-dorsal. Perfil pós-dorsal do corpo robusto, estreitando-se 
gradualmente até o pedúnculo caudal. Pedúnculo caudal robusto. Maior altura do corpo na origem da nadadeira dorsal. Menor altura do corpo na região do pedúnculo caudal. Maior largura do corpo igual largura cleitral. Perfil ventral da ponta do focinho até a base da nadadeira caudal reto. Região abdominal e torácica sem placas.

Cabeça baixa, focinho prolongado anteriormente. Focinho recoberto por pequenas placas, exceto pequena área nua na extremidade distal. Perfil dorsal do focinho arredondado. Nasal alongado, fino e retangular. Frontal pouco alongado com grande contato com narina anteriormente e com a órbita lateralmente. Margem anterior do frontal curta, limitada a margem posterior ou alcança a metade do comprimento da narina. Supra-occiptal bastante alongado com extremidade posterior com projeção curta e sem crista. Esfenótico curto sem contato com o IO6, sem odontódeos conspícuos. Pterótico-supracleitro bastante expandido e fenestrado. Processo anterior do pterótico-supracleitro com pequeno contato com a órbita. Área posterior ao pterótico-supracleitro com uma placa de tamanho médio a grande. Olhos medianos e súpero-laterais com íris em forma de meia lua.

Lábios de tamanho médio com largura aproximadamente igual ao comprimento. Lábio coberto de pequenas papilas que aumentam de tamanho em direção à borda externa. Sem fialmentos labiais. Papila bucal central presente e bem desenvolvida. Barbilhões maxilares pequenos. Pré-maxilar e dentário moderadamente estreitos e alongados. Ângulo de encontro dos dentários quase reto. Dentes do pré-maxilar e do dentário pouco numerosos, alongados, finos e com cúspide lateral desenvolvida. Ponta dos dentes bastante curvada.

Nadadeiras peitoral e pélvica alongadas. Pélvica sem mecanismos de trava; margens distais pouco arredondadas. Primeiro raio das nadadeiras peitoral e pélvica conspicuamente espesso, coberto por odontódeos. Nadadeira peitoral I+6. Extremidade distal da nadadeira peitoral quando adpressa alcançando quase metade do raio indiviso da nadadeira pélvica. Nadadeira pélvica I +5 ; primeiro raio espesso e suportando odontódeos. Extremidade da nadadeira pélvica quando adpressa alcançando a base da nadadeira anal. Nadadeira dorsal com mecanismo de trava com placa pré-dorsal em forma de V (“spinelet"). Nadadeira dorsal I+910. Nadadeira anal I+4, curta. Nadadeira adiposa presente. Nadadeira caudal I+14+I, lobo inferior maior que o superior.

Corpo coberto por cinco fileiras de placas suportando odontódeos. Quilhas bastante desenvolvidas. Grandes placas pares pré-dorsais (geralmente três placas). Placas operculares 
eversíveis até 90 graus, sustentando espinhos bastante desenvolvidos. Raios procorrentes em pequeno número (três a quatro) posicionados anteriormente aos raios caudais indivisos. Trinta e uma vértebras totais. Dez vértebras a partir do primeiro espinho neural simples. Onze espinhos neurais bífidos. Bexiga natatória bastante expandida alcança a sexta costela. Extremidade distal da bexiga natatória arredondada. Canais urogenital e anal em uma única saída tubular.

Sete a oito infra-orbitais. Infra-orbital 4 com pouco ou sem contato com a órbita através de sua extremidade posterior. Infra-orbital 6 forma apenas a parte póstero-ventral da órbita. Poros da linha lateral limitados a placa hipural.

Coloração. Colorido do corpo castanho claro dourado, com manchas escuras irregulares e vermiculadas ao longo do dorso, nadadeiras e na região abdominal.

Distribuição. Bacia do rio São Francisco, nas cidades de Barra e Paulo Afonso (BA), Itacarambi (MG) e Belém do São Francisco (PE) (Figura 49).

Ecologia. Megalancistrus barrae habita a calha principal do rio, com fundo de pedras e corredeiras; alimenta-se de esponjas de água doce e provavelmente de outros invertebrados (Armbruster, com. pess.).

Etimologia. O nome barrae é em referência à localidade tipo da espécie, Barra (BA). Nome em aposição.

\section{Material examinado}

Síntipos. NMW 48019 (s), 399,4 mm CP; Brasil, Bahia, rio São Francisco (11 5'34.90"S, 43 8'9.32"W); 1903, Brás. Exp. NMW 48020 (s), 356,2 mm CP; Brasil, Bahia, rio São Francisco (11 5'34.90"S, 43 8'9.32"W); 1903, Brás. Exp.

Brasil, Bahia, São Francisco: MZUSP 100805 (1), 259,08; Paulo Afonso, Corpo central do reservatório de Paulo Afonso, a jusante do sangradouro da UHE Apolônio Salles (09²1'47"S, 038¹2'37"W); 26/04/2008, W. Severi. MZUSP 100807 (2), 174,13-180,52; Reservatório de Paulo Afonso I, II, III. Corpo central do reservatório, a jusante do sangrdouro da UHE 
Apolônio Salles, Paulo Afonso, Bahia, Brasil, (09²1'47"S, 038¹2'37"W); 21/04/2008, W. Severi. Minas Gerais, São Francisco: MNRJ 13602 (1), 342,0; Itacarambi (15 5'49.05"S 44 4'57.99"W), 17 a 19/08/1990, J. C. Oliveira \& D.F.Moraes Jr. Pernambuco, São Francisco: MZUSP 100806 (2), 177,09-198,41; Belém de São Francisco Reservatório de Itaparica. Calha central do rio São Francisco, margem esquerda, a montante do reservatório de Itaparica $\left(08^{\circ} 47^{\prime} 44^{\prime \prime S}, 038^{\circ} 56^{\prime} 41^{\prime \prime W}\right) ; 21 / 04 / 2008$, W. Severi.

Megalancistrus parananus (Peters, 1881)

(Figura 50, Tabela 4)

Pterygoplichthys (Ancistrus) paranannus Peters, 1881:637. Localidade tipo: rio Paraná perto de La Paz em Entre-Rios, Argentina. Holótipo: ZMB 11328.

Chaetostomus aculeatus Perugia 1891:637-638. Localidade tipo: Assunção, rio Paraguai. Holótipo: MSNG 8937.

Chaetostomus gigas Boulenger, 1895: 526 [descrição da espécie baseado em apenas um exemplar de $530 \mathrm{~mm}$ de comprimento total; localidade tipo: Paraguai; possivelmente um exemplar adulto de Chaetostomus aculeatus]. Holótipo: BMNH 1895.5.17.72. - Gosline, 1945: 88 [catálogo de peixes de água doce da América do Sul; válido como Pterygoplichthys gigas].

Megalancistrus aculeatus (Perugia 1891) - Isbrücker, 1980: 52 [nomenclatura e catálogo de Loricariidae]. - Burgess, 1989: 434 [Atlas de aquarismo]. - Gómez \& Chebez, 1996: 65 [catálogo de vertebrados da Província de Miciones]. - Sverlij et al., 1998: 71 [guia de peixes do rio Uruguai]. - Britski et al., 1999: 134 [manual de peixes do Pantanal; breve descrição da espécie]. - Isbrücker, 2002: 23 [catálogo de Loricariidae]. - Isbrücker, 2001: 26 [catálogo de Loricariidae]. - Isbrücker, 2002: 13 [catálogo de Loricariidae]. - Fisch-Muller in Reis et al., 2003: 390 [catálogo de peixes]. - Ferraris, 2007: 272 [catálogo de Siluriformes].

Megalancistrus gigas (Boulenger 1895) - Isbrücker, 1980: 52 [classificação e catálogo de Loricariidae; nova combinação; sinônimo de M. aculeatus]. - Burgess, 1989: 434 [atlas de 
aquarismo; breve descrição da espécie]. - Eschmeyer, 1998: 645 [catálogo de peixes, volume 1]. - Isbrücker, 2001: 26 [nomenclatura de Loricariidae]. - Isbrücker, 2002: 14 [nomenclatura de Loricariidae]. - Fisch-Muller in Reis et al., 2003: 390 [catálogo de peixes]. - Ferraris, 2007: 272 [catálogo de Siluriformes].

Diagnose. Diferencia-se de Megalancistrus barrae por apresentar a coloração ocre a castanho dourado, com grandes manchas pretas arredondadas ao longo do corpo e nadadeiras. Outros caracteres são considerados sinapomórficos de $M$. parananus, embora ocorram em outros táxons independentemente. Estes são: hiomandibular com. margem anterior suturada ao metapterigóide ao longo de todo comprimento (vs. margem não suturada completamente em M. barrae); área ventral de contato entre o coracóide e o cleitrum grande (vs. pequena em $M$. barrae).

Descrição. Dados morfométricos e merísticos na Tabela 4. Perfil dorsal entre ponta do focinho e região anterior do processo supra-occipital pouco curvado. Restante do perfil dorsal ligeiramente reto, até placa pré-dorsal. Perfil pós-dorsal do corpo robusto, estreitando-se gradualmente até o pedúnculo caudal. Pedúnculo caudal robusto. Maior altura do corpo na origem da nadadeira dorsal. Menor altura do corpo na região do pedúnculo caudal. Maior largura do corpo igual largura cleitral. Perfil ventral da ponta do focinho até a base da nadadeira caudal reto. Região abdominal e torácica sem placas.

Cabeça baixa, focinho prolongado anteriormente. Focinho recoberto por pequenas placas, exceto pequena área nua na extremidade distal. Perfil dorsal do focinho arredondado. Nasal alongado, fino e retangular. Frontal pouco alongado com grande contato com narina anteriormente e com a órbita lateralmente. Margem anterior do frontal curta, limitada a margem posterior ou alcança a metade do comprimento da narina. Supra-occiptal bastante alongado com extremidade posterior com projeção curta e sem crista. Esfenótico curto sem contato com o IO6, sem odontódeos conspícuos. Pterótico-supracleitro bastante expandido e fenestrado. Processo anterior do pterótico-supracleitro com pequeno contato com a órbita. Área posterior ao pterótico-supracleitro com uma placa de tamanho médio a grande. Olhos medianos e súpero-laterais com íris em forma de meia lua. 
Lábios de tamanho médio com largura aproximadamente igual ao comprimento. Lábio coberto de pequenas papilas que aumentam de tamanho em direção à borda externa. Sem fialmentos labiais. Papila bucal central presente e bem desenvolvida. Barbilhões maxilares pequenos. Pré-maxilar e dentário moderadamente estreitos e alongados. Ângulo de encontro dos dentários quase reto. Dentes do pré-maxilar e do dentário pouco numerosos, alongados, finos e com cúspide lateral desenvolvida. Ponta dos dentes bastante curvada.

Nadadeiras peitoral e pélvica alongadas. Pélvica sem mecanismos de trava; margens distais pouco arredondadas. Primeiro raio das nadadeiras peitoral e pélvica conspicuamente espesso, coberto por odontódeos. Nadadeira peitoral I+6. Extremidade distal da nadadeira peitoral quando adpressa alcançando quase metade do raio indiviso da nadadeira pélvica. Nadadeira pélvica I+5; primeiro raio espesso e suportando odontódeos. Extremidade da nadadeira pélvica quando adpressa alcançando a base da nadadeira anal. Nadadeira dorsal com mecanismo de trava com placa pré-dorsal em forma de V ("spinelet"). Nadadeira dorsal I+910. Nadadeira anal I+4, curta. Nadadeira adiposa presente. Nadadeira caudal I+14+I, lobo inferior maior que o superior.

Corpo coberto por cinco fileiras de placas suportando odontódeos. Quilhas bastante desenvolvidas. Grandes placas pares pré-dorsais (geralmente três placas). Placas operculares eversíveis até 90 graus, sustentando espinhos bastante desenvolvidos. Raios procorrentes em pequeno número (três a quatro) posicionados anteriormente aos raios caudais indivisos. Trinta vértebras totais. Dez vértebras a partir do primeiro espinho neural simples. Dez espinhos neurais bífidos. Bexiga natatória bastante expandida alcança a sexta costela. Extremidade distal da bexiga natatória arredondada. Canais urogenital e anal em uma única saída tubular.

Sete a oito infra-orbitais. Infra-orbital 4 com pouco ou sem contato com a órbita através de sua extremidade posterior. Infra-orbital 6 forma apenas a parte póstero-ventral da órbita. Poros da linha lateral limitados a placa hipural.

Coloração. Corpo e nadadeiras castanhos claros com pontos ou manchas grandes distribuídos de forma irregular. 
Distribuição. A espécie está distribuída nas bacias dos rios Paraná, Paraguai, Uruguai e Prata; e alguns poucos exemplares foram coletados no rio São Marcus, afluente do Paranaíba (Figura $51)$.

Ecologia. Megalancistrus parananus habita a calha principal do rio, com fundo de pedras e corredeiras; alimenta-se de esponjas de água doce e provavelmente de outros invertebrados (Armbruster, com. pess.).

Etimologia. Nome em referência à localidade tipo da espécie, rio Paraná. Nome em aposição.

\section{Material examinado}

Holótipo. ZMB 11328 (h) 462, 46 mm CP; Parana fluss bei La Paz in Entre-Rios, Argentina (32²7'31.80"S 59 4'56.82"W); Dr. Wien. MSNG 8937 (h) 150,0 mm CP; Paraguay,

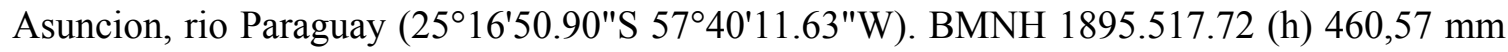
$\mathrm{CP}$; Paraguay, Assuncion, rio Paraguay $\left(25^{\circ} 16^{\prime} 50.90^{\prime \prime S} 57^{\circ} 40^{\prime} 11.63^{\prime \prime} \mathrm{W}\right)$; purch'd of Dr. Ternetz.

Goiás, Paranaíba: MNRJ 19752 (1), 162,93 mm CP; Porto Carapina, rio São Marcos, afluente da margem direita do rio Paranaíba, sob a ponte na GO 506, 21/09/1999, C. A. Figueiredo, F. A. Bockmann \& A. P. R. Pires. MNRJ 19973 (1), 224,6 mm CP; divisa Catalão-Divinópolis, Catalão, rio São Marcos, afluente da margem direita do Paranaíba. MNRJ 21748 (1), 202,44 mm CP; Porto Carapina, Catalão, rio São Marcos, afluente margem direita do rio Paranaíba, a montante do eixo da futura barragem do AHE Serra do Facão, sob a ponte na GO 506, (1754'35"S; 04740'45"W); 22/09/1999, C. A. Figueiredo, F. A. Bockmann \& A. P. R. Pires. MNRJ 21749 (1),183,8 mm CP; Divisa Catalão-Davinópolis, rio São Marcos, afluente margem direita do rio Paranaíba, fazenda Dorvinas, a jusante do eixo onde será a barragem do AHE Serra do Facão (184'5"S; 047²0'26"W); 23/09/1999, C. A. Figueiredo, F. A. Bockmann \& A. P. R. Pires. MNRJ 27939 (1), 330,0 mm CP. NUP 2530 (3), Caldas Novas, Corumbaíba, rio Corumbá, afluente do rio Paranaíba $\left(17^{0}\right.$ a $\left.18^{0} \mathrm{~S} ; 48^{0} \mathrm{~W}\right)$; 03/1996-03/2000; Nupélia. 05/1972, Excursão MZUSP. Mato Grosso, Paraguai: MNRJ 14982 (2), 123,9-129,2 mm CP; rio Cuiabá, mais ou menos $1 \mathrm{~km}$ abaixo da localidade de Baús, 05 a 28/07/1983, G. W.Nunan \& Bandeira. MZUSP 4434 (2), 109,4-266; rio Cuiabá, 
Santo Antônio do Leverger, Mato Grosso, Brasil; (05605'00"W; 1552'00"S); 1965, G. Olson. MZUSP 38189 (1), 252,0; rio Cuiabá, Santo Antônio do Leverger, Mato Grosso, Brasil; (1552'00"S; 05605'00"W); 1965, G. Olson. Mato Grosso do Sul, Paraná: FMNH 95543 (1) 85,71 mm CP; Ilha Solteira, rio Paraná (enseada beira margem direita); (20²2'59,77' 'S; 51¹9'59,98'’W); MZUSP 22501 (3) 192,47-231,0; Três Lagoas, rio Paraná, em frente a Jupiá. (ensecadeira 2) $\left(052^{\circ} 40^{\prime} 00^{\prime \prime}\right.$ W26²7'00"S); 1962, Expedição Permanente à Amazônia. MZUSP 22639 (1) 231,0; Três Lagoas, rio Paraná, em frente a Jupiá. (ensecadeira 2), (05240'00" W26 27'00"S); 11/12/1060, P. E. Vanzolini, S. Saiar \& J. H. Vanzolini. MZUSP 23069 (5) 115,0-395,0; Ilha Solteira, rio Paraná (ensecadeira), (05107'00"W; 20¹5'00"S); 09/1965, Expedição do Departamento de Zoologia. MZUSP 23070 (4) 71,03332,0; Ilha Solteira, rio Paraná (ensecadeira), (05107'00"W; 20¹5'00"S); 09/1965, Expedição do Departamento de Zoologia. MZUSP 23206 (1), 125,35; barragem de Jupiá, ensecadeira na margem esquerda do rio Paraná, 02/1967, Serviço de Desenvolvimento. MZUSP 24435 (7), Ilha Solteira, rio Paraná (20²2'59,77'’S; 51¹9'59,98'’W); 05/1972, Excursão MZUSP. MZUSP 70604 (2) 159,17-271,0; Três Lagoas, rio Paraná, reservatório de Jupiá (montante), 09/07/2001, Welber S. Smith. Minas Gerais, Alto Paraná: MZUSP 24777 (1), rio Grande, Usina Peixoto, 18/12/1975, CETESB. MZUSP 39963 (1), rio Grande, represa de Água Vermelha Brasil; 27/06/1978. Paraná, Paraná: MNRJ 26165 (1), 181,83 mm CP; ribeirão Claro, rio Paranapanema, frente da fazenda Ribeirão Claro, rea do Clube de Pesca, propriedade Irmãos Quagliatto. MNRJ 27432 (1), 118,84 mm CP; ribeirão Claro, rio Paranapanema, frente da fazenda Ribeirão Claro, rea do Clube de Pesca, propriedade Irmãos Quagliatto. MZUSP 21143 (2), 110,95-152,56; 1 d\&c; rio Paraná, abaixo de Sete Quedas (241’'S; 54¹9’W). NUP 2588 (2), 137,14-150,8 mm CP; rio Laranjinha, afluente do rio das Cinzas (Paranapanema), 06/2001, Nupélia. São Paulo, Alto Paraná: MNRJ 27597 (1), 147,27; Ourinhos; rio Paranapanema, no trecho denomidado Paredão, a jusante do córrego do caf, margem direita, MNRJ 27933 (2), 175,93-187,6 mm CP; Ourinhos, rio Paranapanema, no trecho denomidado Paredão, a jusante do córrego do caf, margem direita. MZUSP 332 (1) 242,0; Piracicaba, rio Piracicaba, $\left(047^{\circ} 25^{\prime} 00^{\prime \prime} \mathrm{W} 22^{\circ} 00^{\prime} 00^{\prime \prime S}\right)$; 1906, R. Von Ihering. MZUSP 1172 (1), Piracicaba, rio Piracicaba $\left(047^{\circ} 25^{\prime} 00^{\prime \prime} \mathrm{W} 22^{\circ} 00^{\prime} 00^{\prime \prime S}\right)$; 1906, R. Von Ihering. MZUSP 3193 (1) 367,0; rio Paraná, Canella 1942, J. MZUSP 3652 (1), Cachoeirinha, rio Piracicaba $\left(047^{\circ} 25^{\prime} 00^{\prime \prime} \mathrm{W} \quad 22^{\circ} 00^{\prime} 00^{\prime \prime} \mathrm{S}\right)$. MZUSP 24381 (2), Penápolis, rio Tietê 
(21ํ'13'35.29"S; 4959'18.47"W), 20/12/71, F. Casasco. Sem dados de localidade: ZMA s/ catálogo (1), 156,67 $\mathrm{mm}$ de CP.

\section{Gênero Pseudacanthicus Bleeker, 1862}

Pseudacanthicus Bleeker, 1862: 2. - Espécie tipo: Hypostomus serratus Valenciennes, 1840. Tipo por designação original. Gênero masculino.

Stoneiella Fowler, 1914:271 - Espécie tipo: Stoneiella leopardus Fowler, 1914. Tipo por designação original. Gênenro feminino. Grafia errada Stoniella em Jordan, 1920:553 [nomenclatura de gênero de peixes de 1881 a 1920]. - Eigenmann \& Eigenmann, 1988: 43 [sinonímia de Pseudacanthicus e Chaetostomus em Hemiancistrus; exame de apenas dois exemplares do gênero]. - Regan, 1904: 259 [revisão do gênero]. - Gosline, 1945: 97 [catálogo de nematognatos de água doce da América do Sul]. - Fowler, 1954: 200 [peixes de água doce do Brasil; descrição com desenhos]. - Isbrücker 1980: 76 [catálogo de Loricariidae; nova tribo Pseudacanthicini e nova subtribo Pseudacanthicina]. - Burgess, 1989: 438 [atlas de aquarismo]. - Stawikowski, 1992a [figuras de exemplares vivos]. - Eschmeyer, 1998: 2093 [catálogo de peixes, volume 3: gêneros] - Montoya-Burgos et al., 1998: 367 [filogenia molecular]. Armbruster, 2002: 87 [diagnose comparative de Hypancistrus]. - Isbrücker, 2002: 27 [catálogo de Loricariidae]. - Fisch-Muller in Reis et al., 2003: 393 [catálogo de peixes]. Armbruster, 2004: 53-59 [análise filogenética]. - Ferraris, 2007: 286 [catálogo de Siluriformes].

Diagnose. Pseudacanthicus pode ser diferenciado de ourtos Ancistrini (exceto do grupo Acanthicus, Chaetostoma e Pterygoplichthys) por apresentar oito ou mais raios na nadadeira dorsal. De Chaetostoma e Pterygoplichthys se diferencia pela presença de odontódeos afiados e bem desenvolvidos formando quilhas nas placas laterais (vs. odontódeos ausentes). Diferencia-se de todos os gêneros do grupo Acanthicus por possuir a área posterior ao pterótico-supracleitro com uma ou duas pequenas placas (vs. uma placa média, ou uma área nua). Diferencia-se ainda de Acanthicus por possuir nadadeira adiposa, pterótico-supracleitro 
pequeno, pré-maxilares e dentários curtos e angulados; de Megalancistrus por apresentar menor número de raios dorsais (oito ou nove vs. 10-11); de Leporacanthicus pelo maior número de dentes no pré-maxilar (até 10 vs. no máximo quatro). Outros caracteres sinapomórficos, que podem ocorrer em outros táxons do grupo: margem anterior do hiomandibular suturada ao metapterigóide ao longo de todo comprimento (vs. não suturada completamente nos outros táxons do grupo exceto em Megalancistrus parananus e Spectracanthicus murinus); hiomandibular não defletido além da margem posterior (vs. defletido em outros táxons do grupo Acanthicus e em Spectracanthicus); grande contato do IO4 com a órbita através de sua extremidade posterior (vs. contato pequeno ou ausente, exceto em Acanthicus e Spectracanthicus sp. "Tocantins"); área de contato posterior entre o cleitro e o coracóide reta (vs. expandida ventralmente, exceto em Pseudacanthicus sp. "aba laranja" e Pseudacanthicus sp. "Tocantins"); hipurapófise baixa (vs. média ou alta, exceto em Acanthicus adonis, Leporacanthicus heterodon e Spectracanthicus sp. "Tocantins"); filamentos caudais presentes (vs. ausentes nos outros gêneros, exceto Acanthicus).

Etimologia. Do grego Pseudo significa falso, em alusão à semelhança entre o gênero com Acanthicus.

\section{Chave para as espécies de Pseudacanthicus}

1a. Coloração do corpo com fundo marrom escuro a preto com pontos ou manchas brancas ou pretas ou marrons. .2

1b. Coloração do corpo cinza escuro uniforme, sem pontos ou manchas.......Pseudacanthicus sp. "açacu preto".

2a. Presença de pontos ou manchas pretos ou marrons em alguma parte da superfície corporal............3

2b. Presença de pontos ou manchas brancos em alguma parte da superfície corporal. .4 
3a. Extremidade das nadadeiras com coloração laranja .................5

3b. Extremidade das nadadeiras sem coloração laranja P. spinosus

4a. Manchas brancas transversais presentes apenas nas nadadeiras dorsal e caudal Pseudacanthicus sp. "Tocantins".

4b. Pontos brancos distribuídos por todo o corpo. 6

5a. Sem pontos ou manchas aparentes na superfície dorsal do corpo e cabeça, apenas poucos pontos marrom escuros a pretos na superfície ventral; distribuída na bacia do rio Tocantins Pseudacanthicus sp. "aba laranja”.

5b. Com manchas ou pontos marrons ou pretos bem definidos em toda a superfície corporal...........7

6a. Pontos brancos bastante abundantes (concentrados em todo o corpo) em todo o corpo; menor proporção da distância interorbital, no máximo até 31,3\%; distribuída nas bacias dos rios Curuá-Una e Tapajós Pseudacanthicus sp. "Tapajós"

6b. Pontos brancos pouco abundantes (concentrados na região abdominal) em todo o corpo; maior proporção da distância interorbital, no máximo até 40,9\% do CC; distribuída nas drenagens costeiras das Guianas e Suriname. P. serratus

7a. Com manchas marrom escuras a pretas grandes e dispostas de forma irregular pelas superfícies dorsal, ventral e nadadeiras, sendo mais conspícuas na superfície ventral, as vezes não muito definidas na cabeça; no máximo 13 dentes no dentário; distribuída nas drenagens dos rios Rupununi, Takutu e Branco P. leopardus.

7b. Com pontos pretos alongados na região dorsal que se unem e formam manchas contínuas em forma de "zigue-zague" entre as séries de placas do corpo; e cabeça com pontos pretos bem definidos; com no máximo 21 dentes no dentário; distribuída na bacia do rio Xingu. Pseudacanthicus sp. "vermelho"

\section{Pseudacanthicus leopardus (Fowler, 1914)}

(Figura 52 e 59, Tabela 5) 
Stoneiella leopardus Fowler, 1914: 271-274, Fig. 17 [Proceedings of the Academy of Natural Sciences of Philadelphia v. 66]. Localidade tipo: rio Rupununi, Guiana, $2^{\circ}-3^{\circ} \mathrm{N}, 50^{\circ} 20^{\prime} \mathrm{W}$. Holótipo: ANSP 39345. - Böhlke, 1984:123 [catálogo de tipos]. - Isbrücker, 1980:77 [catálogo de Loricariidae]. - Burgess, 1989: 438 [atlas de aquarismo]. - Seidel, 1996: 23-30 [criação em aquário]. Eschmeyer, 1998: 890 [catálogo de peixes]. - Isbrücker, 2001: 31- 32 [catálogo de Loricariidae]. Isbrücker, 2002: 27 [catálogo de Loricariidae]. - Fisch-Muller in Reis et al. 2003:393 [catalogo de peixes]. - Ferraris, 2007: 286 [catálogo de Siluriformes]. Ferreira et al., 2007: 157 [nome comum Acari-pirarara; habitat; categoria trófica].

Diagnose. Pseudacanthicus leopardus pode ser diferenciado dos demais congêneres (exceto Pseudacanthicus sp. "açacu vermelho" e Pseudacanthicus sp. "aba laranja") por possuir padrão de coloração das extremidades das nadadeiras dorsal, peitoral e caudal laranja alaranjado. Se diferencia de Pseudacanthicus sp. "açacu vermelho" e Pseudacanthicus sp. "aba laranja" por possuir o padrão de colorido do corpo com manchas marrom escuras a pretas grandes e dispostas de forma irregular pelas superfícies dorsal, ventral e nadadeiras, sendo mais conspícuas na superfície ventral, às vezes não muito definidas na cabeça (vs. superfície do corpo com pontos pretos alongados na região dorsal que se unem e formam manchas contínuas em forma de "zigue-zague" entre as séries de placas do corpo; e cabeça com pontos pretos bem definidos em Pseudacanthicus sp. "açacu vermelho"; sem pontos ou manchas aparentes na superfície dorsal do corpo e cabeça, apenas poucos pontos marrom escuros a pretos na superfície ventral em Pseudacanthicus sp. "aba laranja"); e se diferencia ainda por possuir menor contagem de dentes, no máximo sete no pré-maxilar e 13 no dentário (vs. no máximo 11 e 21, respectivamente em Pseudacanthicus sp. "açacu vermelho" e no máximo 10 e 16, respectivamente em Pseudacanthicus sp. "aba laranja”). Pode ainda ser diferenciado das outras espécies de Pseudacanthicus por possuir os seguintes caracteres sinapomórficos: contato do etmóide lateral com o metapterigóide posterior e anterior (vs. contato apenas na parte posterior nas outras espécies do gênero); nasal retangular, fino e alongado (vs. em forma de L, alongado); fenestra anterior à seção cartilaginosa do basipterígio ausente (vs. presente).

Descrição. Dados morfométricos e merísticos na Tabela 5. Perfil dorsal entre ponta do focinho e região anterior do processo supra-occipital pouco curvado. Restante do perfil dorsal 
ligeiramente reto, até placa pré-dorsal. Perfil pós-dorsal do corpo, estreitando-se gradualmente até o pedúnculo caudal. Pedúnculo caudal robusto. Maior altura do corpo na origem da nadadeira dorsal. Menor altura do corpo na região do pedúnculo caudal. Maior largura do corpo igual largura cleitral. Perfil ventral da ponta do focinho até a base da nadadeira caudal reto. Região abdominal e torácica sem placas.

Cabeça alta, focinho prolongado anteriormente. Focinho recoberto por pequenas placas, exceto pequena área nua na extremidade distal. Perfil dorsal do focinho pontudo. Nasal alongado, fino e retangular. Frontal pouco alongado com grande contato com narina anteriormente e com a órbita lateralmente. Margem anterior do frontal curta, limitada a margem posterior ou alcança a metade do comprimento da narina. Supra-occiptal pouco alongado com extremidade posterior com projeção alongada com crista em forma de "V". Esfenótico curto em contato com o IO6, com odontódeos conspícuos formando quilha. Pterótico-supracleitro curto e pouco fenestrado. Processo anterior do pterótico-supracleitro com pequeno contato com a margem posterior da órbita. Área posterior ao pteróticosupracleitro com uma ou duas placas pequenas. Olhos medianos e súpero-laterais com íris em forma de meia lua.

Lábios de tamanho médio com largura aproximadamente igual ao comprimento. Lábio coberto de pequenas papilas que aumentam de tamanho em direção à borda externa. Sem fialmentos labiais. Papila bucal central ausente ou pouco desenvolvida. Barbilhões maxilares pequenos. Pré-maxilar e dentário estreitos e alongados. Ângulo de encontro dos dentários quase reto. Dentes do pré-maxilar e do dentário pouco numerosos, alongados, finos e com cúspide lateral desenvolvida. Ponta dos dentes bastante curvada.

Nadadeiras peitoral e pélvica alongadas. Pélvica sem mecanismos de trava; margens distais pouco arredondadas. Primeiro raio das nadadeiras peitoral e pélvica conspicuamente espesso. Espinho da nadadeira peitoral coberto por odontódeos hipertrofiados e afiados. Nadadeira peitoral $\mathrm{I}+6$. Extremidade distal da nadadeira peitoral quando adpressa alcançando quase metade do raio indiviso da nadadeira pélvica. Nadadeira pélvica $\mathrm{I}+5$; primeiro raio espesso e suportando odontódeos. Extremidade da nadadeira pélvica quando adpressa alcançando a base da nadadeira anal. Nadadeira dorsal com mecanismo de trava com placa pré-dorsal em forma de V (“spinelet"). Nadadeira dorsal I+8. Nadadeira anal I+4, curta. Nadadeira adiposa presente. Nadadeira caudal I+14+I, lobo inferior maior que o superior. 
Corpo coberto por cinco fileiras de placas suportando odontódeos. Quilhas bastante desenvolvidas. Quatro a cinco pares de placas pré-dorsais, às vezes pequenas placas ázigas placas pré-dorsais. Placas operculares eversíveis até 90 graus, sustentando espinhos bastante desenvolvidos. Cinco a seis raios procorrentes posicionados anteriormente aos raios caudais indivisos. Vinte e oito vértebras totais. Onze vértebras a partir do primeiro espinho neural simples. Sete espinhos neurais bífidos. Bexiga natatória encapsulada e curta, não alcança a sexta vértebra. Canais urogenital e anal em uma única saída tubular.

Sete a oito infra-orbitais. Infra-orbital 4 com bastante contato com a órbita através de sua extremidade posterior. Infra-orbital 6 forma apenas a parte póstero-ventral da órbita. Poros da linha lateral não ultrapassam a placa hipural.

Coloração. Superfície dorsal do corpo com coloração castanha clara, com diversos pontos e manchas marron escuras a pretas ditribuídas de forma irregular por todo o corpo e nadadeiras. Superfície ventral ocre ou bege com manchas similares as da superfície do corpo. Em alguns exemplares, as manchas não são muito definidas na região da cabeça. Extemidade das nadadeiras com intenso colorido laranja. Nos exemplares adultos, cerca da primeira metade anterior da nadadeira dorsal, as duas metades mais distais da nadadeira caudal e o espinho e raios indivisos das demais nadadeiras possuem coloração alaranjada. Nos exemplares juvenis, as manchas do corpo são grandes e podem confluir umas com as outras, formando um mesclado de manchas laranja, castanho escuro e claro.

Distribuição. Bacias dos rios Rupununi, Essequibo, Takutu e Branco (Figura 54).

Etimologia. De origem grega leopardus significa leopardo, nome em referência ao colorido do corpo com manchas similar as de um leopardo.

\section{Material examinado}

Holótipo. ANSP 39345 (h) 71,67; rio Rupununi, Guiana (353'57.56"N, 59¹7'32.19"W); 1911, J. Olgivier.

Brasil: Roraima: Branco: INPA 1971 (6) 31,73-128,83; Alto Alegre, rio Uraricoera, furo Santa Rosa, (3²1'46.32"N, 61²2'0.85"W); 12/13/1982, M. Jégu. INPA 1985 (1) 107,42; Alto 
Alegre, rio Uraricoera, a jusante da ilha de Maracá $\left(2^{\circ} 53^{\prime} 17.77^{\prime \prime N}, 61^{\circ} 29^{\prime 28.76} \mathrm{WW}\right)$; 12/13/1982, M. Jégu. MZUSP 43686 (1) 285,0; cachoeira do Bem Querer (01ํ56'00"N, 06100'00"W); 08/01/1984, M. Goulding. Takutu: INPA 2011 (2), 199,43-210,5; rio Takutu $\left(3^{\circ} 4^{\prime} 59.78^{\prime \prime N}, 59^{\circ} 57^{\prime} 0.07^{\prime \prime}\right)$; 17/13/1982, M. Jégu. Guiana: Takutu, Rupununi e Essequibo: ANSP 179613 (1) $2.75 \mathrm{~km} \mathrm{~W} \mathrm{de} \mathrm{Saint} \mathrm{Ignatius,} \mathrm{rio} \mathrm{Takutu} \mathrm{(Negro} \mathrm{Dr.),}$ Rupununi, (3²0'25.71"N, 5949'48.66"W); 05/11/2002, H. H. Sabaj, J. W. Armbruster, M. R. Thomas. AUM 35550 (1) 83,56; Kurukupari, banco leste, rio Essequibo (3³9'34.9" N, 58 $40^{\prime} 35.18^{\prime \prime}$ ); 24/10/2002, J. W. Armbruster, M. H. Sabaj, D. C. Werneke, C. L. Allison, M. R. Thomas, C. J. Chin, D. Arjoon, S. M. James. AUM 35538 (5) 15,04-53,95; 4,6 Km NW

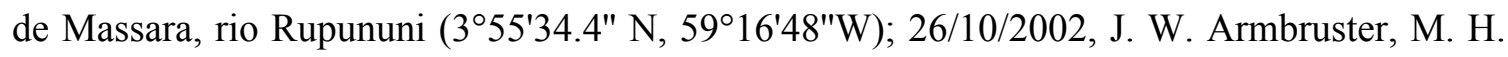
Sabaj, D. C. Werneke, C. L. Allison, M. R. Thomas, C. J. Chin, D. Arjoon, S. M. James. AUM 35738 (9, 2 d\&c), 25,09-51,79; 3,7 km SE de Massara, rio Rupununi, alto Tacutu e Essequibo (351'45.9" N, 59¹7'82"W); 27/10/2002, J. W. Armbruster, M. H. Sabaj, D. C. Werneke, C. L. Allison, M. R. Thomas, C. J. Chin, D. Arjoon, S. M. James. AUM 35739 (5) 25,54-126,27; 2,75 km W de Saint Ignatius, rio Tacutu (3²1'18.01" N, 5949'76"); 5-6/11/2002, J. W. Armbruster, M. H. Sabaj, D. C. Werneke, C. L. Allison, M. R. Thomas, C. J. Chin, D. Arjoon, S. M. James. AUM 37911 (1) 34,75; Saint Ignatius, rio Tacutu (3²1'20.9" N, 5948'18.58"W); 02/11/2003, 26/10/2002, J. W. Armbruster, M. H. Sabaj, M. Hardman, D. Arjoon, N. K. Lujan, L. S. de Souza. AUM 44440 (1) 122,27; Kwatsmang, rio Rupununi (355'3.42" N, 5906'63"W); 24/11/2005, L. S. de Souza, N. K. Lujan, D. C. Taphorn, J. A. Hartsell, E. Liverpool \& S. Lord. BMNH 1972.7.17.188-197 (8), 46,44-159,14 mm CP; Karanambo e Wichabai área, rio Rupununi, (345'5.89"N, 59¹8'1.73"W). USNM 197105 (2) 104,22-103,57; Wichabai, rio Rupununi (2॰51'54.55"N 59³1'17.68"W); 05/1961, S. Singh. ZMA 116.849 (1), 120,55 mm CP; rio Rupununi. Sem dados de localidade: AMNH 225761 (1) 185,16 ; sem dados de localidade.

Pseudacanthicus serratus (Valenciennes, 1840)

(Figura 53, Tabela 6) 
Hypostomus serratus Valenciennes in Cuvier \& Valenciennes 1840:503 [Histoire naturelle des poissons. v. 15]. Localidade tipo: região próxima de Paramaribo, Suriname. Holótipo: RMNH 3125 .

- Bleeker, 1862: 13-15 [descrição do gênero; nova combinação com designação da espécie tipo]. - Eigenmann \& Eigenmann, 1889: 43 [Hemiancistrus serratus]. - Regan, 1904: 259 [rio Amazonas, Guiana; três exemplares]. - Gosline, 1945:97 [catálogo]. - Boeseman, 1972: 304 [apenas um exemplar no museu de Leiden, sem dúvida o holótipo da espécie]. - Isbrücker, 1980:77 [catálogo de Loricariidae]. - Burgess, 1989: 438 [Atlas de aquarismo]. - Eschmeyer, 1998: 1545 [catálogo de peixes]. - Le Bail et al., 2000: 250 [Atlas dos peixes da Guiana; descrição da espécie; foto; observações sobre a biologia; mapa de distribuição da espécie na Guiana]. - Isbrücker, 2001:28, 31 [catalogo de Loricariidae]. - Isbrücker, 2002:27 [catálogo de Loricariidae]. - Fisch-Muller in Reis et al., 2003: 393 [catálogo de peixes]. - Ferraris, 2007: 286 [catálogo de Siluriformes].

Pseudacanthicus fordii (Günther, 1868)

Chaetostomus fordii Günther, 1868: 476 [Annals and Magazine of Natural History (Series 4) v. 1 (no. 6)]. Localidade tipo: provavelmente Suriname. Síntipos: BMNH 1866.8.14.148-152 (4). - Eigenmann \& Eigenmann, 1889: 43 [Hemiancistrus fordii]. - Regan, 1904: 261 [nova combinação e redescrição das espécies tipo; 4 síntipos; Suriname]. - Isbrücker, 1980: 76 [catálogo de Loricariidae; síntipos machos de nove polegadas]. - Burgess, 1989: 438 [atlas de aquarismo]. Eschmeyer, 1998: 599 [catálogo de peixes]. - Isbrücker, 2001: 26, 31 [catálogo de Loricariidae]. - Isbrücker, 2002: 27 [catálogo de Loricariidae]. - Fisch-Muller in Reis et al., 2003: 393 [catálogo de peixes]. - Ferraris, 2007: 286 [catálogo de Siluriformes].

Diagnose. Pseudacanthicus serratus pode ser diferenciado dos seus demais congêneres pelo padrão de colorido do corpo com fundo marrom escuro a preto com pontos brancos espalhados pelas superfícies ventral e dorsal (exceto Pseudacanthicus sp. "Tapajós"). Pode ainda ser distinguido das demais espécies (exceto P. spinosus) por possuir maior proporção da distância interobital, até 40,9\% do CC (vs. até 38\% em P. leopardus, até 36\% em Pseudacanthicus sp. "açacu preto", até 34\% em Pseudacanthicus sp. "Aripuanã", até 33,7\% em Pseudacanthicus sp. "açacu vermelho", até 38,4\% em Pseudacanthicus sp. "aba laranja", até 29,8\% em 
Pseudacanthicus sp. "Tocantins" e até 31,3\% em Pseudacanthicus sp. "Curuá-Una”). Se diferencia ainda de Pseudacanthicus sp. "Curuá-Uma e Tapajós" por apresentar pontos claros em menor quantidade, sendo mais concentrados no abdome (vs. pontos claros abundantes e igualmente concetrados no corpo e nas nadadeira.

Descrição. Dados morfométricos e merísticos na Tabela 6. Perfil dorsal entre ponta do focinho e região anterior do processo supra-occipital pouco curvado. Restante do perfil dorsal ligeiramente reto, até placa pré-dorsal. Perfil pós-dorsal do corpo, estreitando-se gradualmente até o pedúnculo caudal. Pedúnculo caudal robusto. Maior altura do corpo na origem da nadadeira dorsal. Menor altura do corpo na região do pedúnculo caudal. Maior largura do corpo igual largura cleitral. Perfil ventral da ponta do focinho até a base da nadadeira caudal reto. Região abdominal e torácica sem placas.

Cabeça alta, focinho prolongado anteriormente. Focinho recoberto por pequenas placas, exceto pequena área nua na extremidade distal. Perfil dorsal do focinho pontudo. Nasal alongado, em forma de "L". Frontal pouco alongado com grande contato com narina anteriormente e com a órbita lateralmente. Margem anterior do frontal curta, limitada a margem posterior ou alcança a metade do comprimento da narina. Supra-occiptal pouco alongado com extremidade posterior com projeção alongada com crista em forma de "V". Esfenótico curto em contato com o IO6, sem odontódeos conspícuos. Pterótico-supracleitro curto e pouco fenestrado. Processo anterior do pterótico-supracleitro com pequeno contato com a margem posterior da órbita. Área posterior ao pterótico-supracleitro com uma ou duas placas pequenas. Olhos medianos e súpero-laterais com íris em forma de meia lua.

Lábios de tamanho médio com largura aproximadamente igual ao comprimento. Lábio coberto de pequenas papilas que aumentam de tamanho em direção à borda externa. Sem fialmentos labiais. Papila bucal central ausente ou pouco desenvolvida. Barbilhões maxilares pequenos. Pré-maxilar e dentário estreitos e alongados. Ângulo de encontro dos dentários quase reto. Dentes do pré-maxilar e do dentário pouco numerosos, alongados, finos e com cúspide lateral desenvolvida. Ponta dos dentes bastante curvada.

Nadadeiras peitoral e pélvica alongadas. Pélvica sem mecanismos de trava; margens distais pouco arredondadas. Primeiro raio das nadadeiras peitoral e pélvica conspicuamente espesso. Espinho da nadadeira peitoral coberto por odontódeos hipertrofiados e afiados. 
Nadadeira peitoral I+6. Extremidade distal da nadadeira peitoral quando adpressa alcançando quase metade do raio indiviso da nadadeira pélvica. Nadadeira pélvica $\mathrm{I}+5$; primeiro raio espesso e suportando odontódeos. Extremidade da nadadeira pélvica quando adpressa alcançando a base da nadadeira anal. Nadadeira dorsal com mecanismo de trava com placa pré-dorsal em forma de V (“spinelet"). Nadadeira dorsal I+8. Nadadeira anal I+4, curta. Nadadeira adiposa presente. Nadadeira caudal I+14+I, lobo inferior maior que o superior.

Corpo coberto por cinco fileiras de placas suportando odontódeos. Quilhas bastante desenvolvidas. Quatro a cinco pares de placas pré-dorsais, às vezes pequenas placas ázigas placas pré-dorsais. Placas operculares eversíveis até 90 graus, sustentando espinhos bastante desenvolvidos. Cinco a seis raios procorrentes posicionados anteriormente aos raios caudais indivisos. Canais urogenital e anal em uma única saída tubular.

Sete a oito infra-orbitais. Infra-orbital 4 com bastante contato com a órbita através de sua extremidade posterior. Infra-orbital 6 forma apenas a parte póstero-ventral da órbita. Poros da linha lateral não ultrapassam a placa hipural.

Coloração. Superfície dorsal do corpo marrom escura a preta, com pontos brancos distribuídos de forma irregular. Em alguns exemplares os pontos não são muito conspícuos. Superfície ventral cinza escuro com pontos brancos não muito aparentes em alguns exemplares. Os pontos da superfície ventral podem ser mais visíveis na região abdominal, pouco acima da origem da nadadeira anal.

Distribuição. Bacia dos rios Essequibo, Guiana e Marowijne, Suriname; Guiana Francesa (Figura 54)

Etimologia. De origem grega serratus significa serra, dentado com uma serra; em alusão aos odontódeos bastante conspícuos que foram quilhas ao longo do corpo.

Comentários. De acordo com Günther (1868b), diversas espécies de peixes de água doce do Suriname e do Brasil foram doadas ao BMNH. Os exemplares dessa espécie faziam parte da coleção do Dr. Van Lidth de Jeude. Infelizmente as localidades onde esses exemplares foram coletados não foram preservadas, mas provavelmente a maioria, se não todos, são das colônias 
Holandesas nas Guianas. Apenas os síntipos da espécie e mais um exemplar do AMNH, proveniente da Guiana, foram examinados. No presente estudo, Pseudacanthicus fordii é considerado sinônimo de $P$. serratus, pela similaridade entre os exemplares examinados, que além de ocorrerem na mesma região, apresenta o formato do corpo e padrão de colorido bastante similares. E possuem ainda as mesmas proporções de dados morfométricos e merísticos.

\section{Material examinado}

Holótipo. RMNH 3125 (h), 148,75 mm CP; Suriname, 1824-1842, don. H. H. Dieperink. Pseudacanthicus fordii BMNH 1866.8.14.148-152 (s), (4), 117,08-144,97 mm CP; Surinam [Probably Suriname (Günther, 1868b)].

Guiana: AMNH 72951 (1) ca $100 \mathrm{~m}$ of the poit of confluence of Mazaruni e Cuyuni Rivers, Essequibo ( $6^{0} 21^{\prime}$ N; $58^{0} 41^{\prime}$ S $)$; 15/08/1983, R. E. Schmidt \& Pappantoniou. AMNH 220426 (1) 118,94; junção dos rios Mazaruni e Cuyuni, Kartabo Potaro, Essequibo; 18/04/1924, C. W. Beebe. Guiana Francesa: MHNG 1223.14 (1) 337,13 mm CP; Saut Sabba (5²3'9.55"N 5340'12.73"W); 10/1971. MNHN B-337 (1) 288,93 mm CP; Mélinon. MNHN B-338 (1) 250,61 mm CP. MNHH 2002-0803 (1) 102,21 mm CP; 2001, Fermon, et al. MNHN 20030003 (1) 99,97 mm CP; 2002, Fermon, Ksas, Commergnat et al. Suriname: RMNH 6915 (1), 255,59 mm CP; 1879, P. Bleeker. RMNH 25414 (1) 241,73 mm CP; Afobaka, (458'60.00"N $\left.54^{\circ} 58^{\prime} 60.00^{\prime \prime} \mathrm{W}\right)$, in quarry 11/3/1964; don. Sur. Mus. Paramaribo via Dr. Boeseman, 12/11/1964. RMNH 25868 (1), 169,09 mm CP; Brokopondo (446'15.69"N, 55²'57.62"W), 2/5/1964, Brokopondo Research, Dr. M. Boeseman, 1963/64.. ZMA 106.523 (2) 259,62287,04 mm CP; district of Marowijne; Marowijne River, ca $3 \mathrm{Km}$ north of Albina $\left(5^{\circ} 45^{\prime} 0^{\prime \prime} \mathrm{N}\right.$,

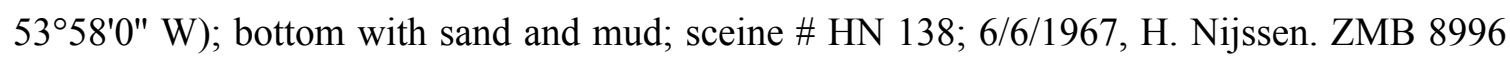
(1) 234 mm CP; Surinam, Berzen od. Barzen Dai.; Moschler. 
Hypostomus spinosus Castelnau 1855:45, Pl. 22 (fig. 3) [Animaux nouveaux or rares recueillis pendant l'expédition dans les parties centrales de l' Amérique du Sud, de Rio de Janeiro a Lima, ... v. 2]. Localidade tipo: rio Amazonas, Brasil. Holótipo: MNHN A-9577. - Eigenmann \& Eigenmann, 1889: 43 [Hemiancistrus spinosus]. - Regan, 1904: 260-261 [rio Amazonas, Ilha de Marajó; dois exemplares]. - Gosline, 1945:97 [catálogo].- Bertin \& Estève 1950:72 [catálogo de tipos do Museu de Paris]. - Fowler, 1954: 201-202 [peixes de água doce do Brasil; descrição; ilustração] - Isbrücker 1980:77 [catálogo de Loricariidae]. - Santos et al., 1984: 55 [peixes comerciais do baixo rio Tocantins; identificação duvidosa]. - Burgess, 1989: 438 [Atlas de aquarismo]. - Eschmeyer, 1998: 1592 [catálogo de peixes]. - Montoya-Burgos et al., 1998: 367 [filogenia molecular]. - Isbrücker, 2001: 28, 31 [catálogo de Loricariidae]. Isbrücker, 2002: 27 [catálogo de Loricariidae]. - Fisch-Muller in Reis et al., 2003: 394 [Catálogo de peixes]. Santos et al., 2004: 163 [peixes do baixo rio Tocantins; comparação da ictiofauna 20 anos depois da construção da Usina de Tucuruí; foto, diagnose da espécie; identificação duvidosa]. - Ferraris, 2007: 286 [catálogo de Siluriformes].

Pseudacanthicus histrix (Valenciennes, 1840)

Loricaria histrix Vandelli in Cuvier \& Valenciennes, 1840: 486 [Histoire naturelle des poissons. v. 15]

Rinelepis histrix Valenciennes in Cuvier \& Valenciennes, 1840 [Histoire naturelle des poissons. v. 15]. Sem localidade tipo. Holótipo perdido, fotografias preservadas no Museu Bocage de Lisboa, MB.

Loricaria spinosae Ferreira in França, 1922: 84 [Boletim da Sociedade Broteriana v. 1]. Localidade tipo: rio Negro River, Brasil. Sem tipos conhecidos; mesmo espécime do holótipo de Rinelepis histrix; sinônimo objetivo.

- Capello, 1870: 64-69 [descrição; aloca a espécie em Chaetostomus pela existência de nadadeira adiposa; apenas um exemplar no museu de Lisboa; rio Negro, confluente do Amazonas; nome indígena Uacari-Guassú]. - Eigenmann \& Eigenmann, 1889: 43 
[Hemiancistrus histrix]. - Regan, 1904: 261 [nova combinação; apenas um exemplar conhecido do rio Negro]. - França, 1922: 83-85 [Loricaria spinosae, coletade e descrita inicialmente pelo naturalista Alexandre R. Ferreira]. - Gosline, 1945: 97 [catálogo]. - Fowler, 1954: 201[catálogo]. - Isbrücker, 1980: 76 [catálogo de Loricariidae]. - Burgess, 1989: 438 [atlas de aquarismo]. Eschmeyer, 1998: 736 [catálogo de peixes]. - Isbrücker, 2001: 26, 31 [catálogo de Loricariidae]. - Isbrücker, 2002: 27 [catálogo de Loricariidae]. - Fisch-Muller in Reis et al., 2003: 393 [catálogo de peixes]. - Santos et al., 2004: 162 [peixes do baixo rio Tocantins; citação; foto; duvidas a cerca da identificação] - Ferraris, 2007: 286 [catálogo de Siluriformes].

Diagnose. Pseudacanthicus spinosus pode ser diferenciado das demais espécies do gênero por possui padrão de colorido de fundo cinza claro com pontos pretos distribuídos pelas superfícies dorsal e ventral. Pode ainda se distinguido dos demais congêneres (exceto $P$. serratus) por possuir maior porcentagem da distância interorbital, até $40,5 \%$ do CC (vs. até $38 \%$ em P. leopardus, até 36\% em Pseudacanthicus sp. "açacu preto", até 34\% em Pseudacanthicus sp. "Aripuanã", até 33,7\% em Pseudacanthicus sp. "Açacu vermelho", até 38,4\% em Pseudacanthicus sp. "aba laranja", até 29,8\% em Pseudacanthicus sp. "Tocantins" e até 31,3\% em Pseudacanthicus sp. "Curuá-Una"). Outro caráter sinapomórfico da espécie que a diferencia de suas congêneres é a ausência de crista lateral à penúltima vértebra (vs. crista bastante desenvolvida em Pseudacanthicus sp. "Aripuanã" e crista pouco desenvolvida nas demais espécies).

Descrição. Dados morfométricos e merísticos na Tabela 7. Perfil dorsal entre ponta do focinho e região anterior do processo supra-occipital pouco curvado. Restante do perfil dorsal ligeiramente reto, até placa pré-dorsal. Perfil pós-dorsal do corpo, estreitando-se gradualmente até o pedúnculo caudal. Pedúnculo caudal robusto. Maior altura do corpo na origem da nadadeira dorsal. Menor altura do corpo na região do pedúnculo caudal. Maior largura do corpo igual largura cleitral. Perfil ventral da ponta do focinho até a base da nadadeira caudal reto. Região abdominal e torácica sem placas.

Cabeça alta, focinho prolongado anteriormente. Focinho recoberto por pequenas placas, exceto pequena área nua na extremidade distal. Perfil dorsal do focinho pontudo. Nasal 
alongado, em forma de "L". Frontal pouco alongado com grande contato com narina anteriormente e com a órbita lateralmente. Margem anterior do frontal curta, limitada a margem posterior ou alcança a metade do comprimento da narina. Supra-occiptal pouco alongado com extremidade posterior com projeção alongada com crista em forma de "V". Esfenótico curto em contato com o IO6, sem odontódeos conspícuos. Pterótico-supracleitro curto e pouco fenestrado. Processo anterior do pterótico-supracleitro com pequeno contato com a margem posterior da órbita. Área posterior ao pterótico-supracleitro com uma ou duas placas pequenas. Olhos medianos e súpero-laterais com íris em forma de meia lua.

Lábios de tamanho médio com largura aproximadamente igual ao comprimento. Lábio coberto de pequenas papilas que aumentam de tamanho em direção à borda externa. Sem fialmentos labiais. Papila bucal central ausente ou pouco desenvolvida. Barbilhões maxilares pequenos. Pré-maxilar e dentário estreitos e alongados. Ângulo de encontro dos dentários quase reto. Dentes do pré-maxilar e do dentário pouco numerosos, alongados, moderadamente robustos e com cúspide lateral desenvolvida. Ponta dos dentes bastante curvada.

Nadadeiras peitoral e pélvica alongadas. Pélvica sem mecanismos de trava; margens distais pouco arredondadas. Primeiro raio das nadadeiras peitoral e pélvica conspicuamente espesso. Espinho da nadadeira peitoral coberto por odontódeos hipertrofiados e afiados. Nadadeira peitoral $\mathrm{I}+6$. Extremidade distal da nadadeira peitoral quando adpressa alcançando quase metade do raio indiviso da nadadeira pélvica. Nadadeira pélvica $\mathrm{I}+5$; primeiro raio espesso e suportando odontódeos. Extremidade da nadadeira pélvica quando adpressa alcançando a base da nadadeira anal. Nadadeira dorsal com mecanismo de trava com placa pré-dorsal em forma de V ("spinelet"). Nadadeira dorsal I+8. Nadadeira anal I+4, curta. Nadadeira adiposa presente. Nadadeira caudal I+14+I, lobo inferior maior que o superior. Exemplares juvenis apresentam espinhos da caudal prolongados.

Corpo coberto por cinco fileiras de placas suportando odontódeos. Quilhas bastante desenvolvidas. Quatro a cinco pares de placas pré-dorsais, às vezes pequenas placas ázigas placas pré-dorsais. Placas operculares eversíveis até 90 graus, sustentando espinhos bastante desenvolvidos. Cinco a seis raios procorrentes posicionados anteriormente aos raios caudais indivisos. Vinte e oito vértebras totais. Onze vértebras a partir do primeiro espinho neural simples. Sete espinhos neurais bífidos. Bexiga natatória encapsulada e curta, não alcança a sexta vértebra. Canais urogenital e anal em uma única saída tubular. 
Sete a oito infra-orbitais. Infra-orbital 4 com bastante contato com a órbita através de sua extremidade posterior. Infra-orbital 6 forma apenas a parte póstero-ventral da órbita. Poros da linha lateral não ultrapassam a placa hipural.

Coloração. Superfície dorsal do corpo com padrão de colorido cinza a marrom clara com pontos pretos distribuídos de forma irregular. Em alguns exemplares estes pontos são mais concentrados na superfície ventral e nas nadadeiras. Nos espécimens juvenis a superfície do corpo exibe manchas lanranjas e pretas ou marrom escuras (Figura 55), semelhante aos juvenis de P. leopardus. Em exemplares de grande porte (acima de $500 \mathrm{~mm}$ ) os pontos são menos conspícuos na superfície dorsal e ventral, sendo mais notáveis em todas as nadadeiras, principalmente nas dorsal e caudal.

Distribuição. Bacias dos rios Amazonas, Xingu, Tapajós e Tocantins (Figura 56).

Etimologia. Do latim spinosus significa espinhos, em alusão aos odontódeos conspícuos que recobrem as placas do corpo formando quilhas afiadas.

Comentários. De acordo com França (1922) a espécie Pseudacanthicus histrix foi coletada durante a "Expedição Philosophica pelas Capitanias do Grão Pará, Rio Negro, Mato Grosso e Cuyabá", liderada pelo naturalista português Alexandre R. Ferreira no período de 1783 e 1792. Este exemplar (o holótipo da espécie) teria sido doado aos membros da expedição pelo "Ilustríssimo e Excelentíssimo Senhor João Pareira Caldas" que governou as capitanias do Grão Pará e do Rio Negro (Almaça et al., 2002). Nesta ocasião, a espécie foi descrita como Loricaria spinosae. Em 1786, o holótipo, acompanhado da descrição e a da ilustração, foi enviado para o Museu da Ajuda. Domingos Vandelli renomeia a espéice como Loricaria histrix e envia ao naturalista francês Lacépède suas descrição e ilustração. Com a morte de Lacépède, o manuscrito contendo a ilustração da espécie foi aproveitado por Valenciennes que então o descreve como Rinelepis histrix. De acordo com os dados desta expedição, a localidade tipo de P. histrix é provavelmente rio Negro. Entretanto os exemplares de Pseudacanthicus examinados, durante este estudo, oriundos do rio Negro pertencem a $P$. spinosus. Comparando os espécimens de $P$. spinosus com a ilustração de $P$. histrix, nota-se 
que são bastante semelhantes. Dessa forma, $P$. histrix é aqui tratado como sinônimo de $P$. spinosus. Em coletas recentes no rio Xingu foi coletada uma espécie bastante semelhante à da ilustração. Os exemplares desta espécie foram identificados como Pseudacanthicus cf. histrix. Entretanto, trata-se de uma espécie ainda não descrita formalmente, mas conhecida na região como açacu preto. Esta espécie é caracterrizada mais adiante neste trabalho.

\section{Material examinado}

Holótipo. MNHN A-9577 (h) 262, 61; la rivière des Amazone, Brésil (2॰ 9'12.85"S, $\left.55^{\circ} 33^{\prime} 47.89^{\prime \prime} \mathrm{W}\right)$.

Brasil, Amazonas: INPA 15133 (2) 90,0-114,32; Presidente Figueiredo, rio Uatumã, cachoeira Morena, (27'27.53"S 59¹9'33.14"W); 07/10/1987, E. G. Ferreira, R. Leite, S. Kullander. INPA 25865 (4) 37,42-66,78; Barcelos, rio Demení, igarapé Maruim, acima de Barcelos (0³2'50.04"S, 6254'34.55"W); F.E., P.E., O.R. USNM 052594, (1) 100, 45; rio Amazonas, Pará para Manaus; 1901, J. B. Steere. Brasil, Pará, Amazonas: MPEG 9306 (1)

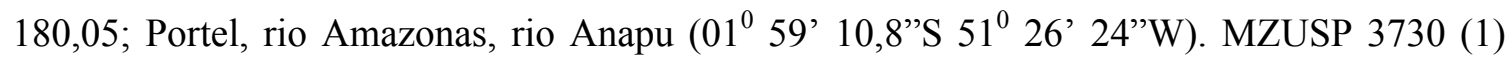
209,43; Belém (1²7'7.14"S, 48³0'50.84"W); 1944, A. A. Campos. MZUSP 23950 (1) 125,26; Vila Maiauatá, igarapé Uruazinho, (143'3.95"S, 4853'41.50"W); 27/08/1970, Expedição Permanente à Amazônia. MZUSP 23983 (1) 97,85; furo do Panaquera, braço do igarapé São Lourencinho (143'2.32"S, 4853'49.83"W); 30/08/1970, Expedição Permanente à Amazônia. MZUSP 23992 (5) 83,27-113,44; Furo de Panaquera, igarapé Inó (143'2.32"S, 4853'49.83"W); 01/09/1970, Expedição Permanente à Amazônia. Guamá: MPEG 3016 (1), rio Turiaçu, a $1 \mathrm{~km}$ acima e abaixo do posto indígena Guajá, MPEG 4116 (1), Ourém, (1³2'55.27"S, 47 6'41.70"W). Tapajós: INPA 26474 (2), 48,25-210,0; Itaituba, rio Tapajós, doado por pescadores de peixes ornamentais na região de Itaituba e Pimental; 08/11/2006, L.M. Sousa \& J.L. Birindelli. INPA 26497 (1), 118,41; Itaituba, rio Tapajós, a montante de Itaituba e a jusante das cachoeiras de Pimental (04 21 ' $34^{\prime \prime}$ S, $\left.056^{\circ} 10^{`} 02^{\prime \prime} \mathrm{W}\right)$; 08/11/2006, L.M. Sousa \& J.L. Birindelli. Tocantins: FMNH 95554 (1, d\&c), 106,76 mm CP; Pindobazinho, igarapé do Grilo, 03/09/1970, Expedição Permanente à Amazônia. INPA 4502 (1), 164,05; Tucuruí, rio Tocantins; 01/05/1982, F. Martinho. INPA 4559 (1), 148,15; rio Tocantins, poço do Paulo; 26/07/1980, Equipe Ictiologia INPA. INPA 32237 (3) 430,5-590,0; Paraná do Ramos (256'29.85"S, 58 5'25.19"W). MNRJ 19346 (1), rio Tocantins, próximo da cidade de 
Tucuruí, 09/1984, L. C. Alvarenga. MPEG 1503 (1), rio Tocantins, entre Cametá e Limoeiro do Ajuru (159'46.66"S 49¹8'49.74"W). MZUSP 24010 (4) 48,7-130,65; Pindobazinho, igarapé do Grilo (2॰5'2.20"S, 49²2'59.44"W); 23/09/1970, Expedição Permanente à Amazônia. MZUSP 24022 (1) 78,95; Paraná Samuuma, igarapé Mapará (25'2.20"S, 49²2'59.44"W). MZUSP 24024 (4) 48,74-92,05; Paraná Samuuma, igarapé Mapará (25'2.20"S, 49²2'59.44"W); 05/09/1970, Expedição Permanente à Amazônia. MZUSP 24042 (6) 121,17-180,81; Cametá, igarapé Aricurá, (2¹4'19.90"S, 49²9'26.18"W); 07/09/1970, Expedição Permanente à Amazônia. MZUSP 74724 (1), Barcarena, igarapé Tauá (1³1'23.98"S 48³4'46.59"W); 02/10/1984, R. B. Barthem. ZMA 119.828 (3) 89,73-73,96 mm CP; Cametá (02 ${ }^{0}$ 14’ S 49 30’ W); 07/1985, A. Werner. ZMA 107.863 (1) 151,47 mm CP; Cametá, igarapé Aricurá; 07/09/1970, Expedição Permanente à Amazônia. Xingu: MZUSP 107205 (2), 130,93-236,15; Belo Monte, rio Xingu, Pontão em frente à propriedade de Dona Maria e Sr. Valdomiro $\left(03^{\circ} 06^{\prime} 45.5^{\prime \prime S}, 51^{\circ} 43^{\prime} 22,9^{\prime \prime} \mathrm{W}\right), 12 / 07 / 2010$, Equipe ECIX. Venezuela, Orinoco: ZMA 120.464 (1) 152,09 mm CP (753'15.26"N, 65³8'19.68"W); 10/1986, H. Bleker. Sem dados de localidade: AMNH 58329 (1) 152,73; Equador (?); 18/01/1988, C. J. Ferraris. ZMA s/ número, doado por André Werner, 17/09/2000.

\section{Pseudacanthicus sp. "Aripuanã"}

(Figura 57, Tabela 8)

Diagnose. Pseudacanthicus sp. "Aripuanã" pode ser diferenciado dos demais congêneres por apresentar o padrão de colorido do corpo marrom escuro com manchas vermiculadas na superfície dorsal e coloração bege com manchas disformes similares a bolhas marrons escuras na superfície ventral. Possui ainda corpo relativamente mais baixo, com proporção de até 18,5\% do CP (vs. até 24\% em Pseudacanthicus sp "açacu preto", até 28\% em P. leopardus, até 29,6\% em P. serratus, até 28,9\% em P. spinosus, até 26,5\% em Pseudacanthicus sp. “açacu vermelho", 24,6\% em Pseudacanthicus sp. "aba laranja”, até 21\% em Pseudacanthicus sp. “Tocantins", até 26,4\% em Pseudacanthicus sp. "Cruá-Una e Tapajós”. Outros caracteres que distinguem a espécies das suas congêneres são: disco do mesetmóide se estendendo além do corpo principal, exceto em P. spinosus e P. leopardus (vs. disco do mesetmóide restrito ao 
corpo principal); Contato do esfenótico com o IO6 ausente (vs. presente nas demais espécies); forame da artéria mandibular aferente (fma) pequeno, exceto em Pseudacanthicus sp. "açacu vermelho", Pseudacanthicus sp. "aba laranja” (vs. forame grande nas demais espécies); processo anterior do metapterigóide sem projeção, exceto em Pseudacanthicus sp. "açacu preto" (vs. com uma projeção nas demais espécies); crista lateral à penúltima vértebra bastante desenvolvida (vs. crista de tamanho médio nas demais espécies); área de contato ventral entre o coracóide e o cleitrum grande (vs. pequena nas demais espécies).

Descrição. Dados morfométricos e merísticos na Tabela 8. Perfil dorsal entre ponta do focinho e região anterior do processo supra-occipital pouco curvado. Restante do perfil dorsal ligeiramente reto, até placa pré-dorsal. Perfil pós-dorsal do corpo robusto. Pedúnculo caudal robusto. Maior altura do corpo na origem da nadadeira dorsal. Menor altura do corpo na região do pedúnculo caudal. Maior largura do corpo igual largura cleitral. Perfil ventral da ponta do focinho até a base da nadadeira caudal reto. Região abdominal e torácica sem placas.

Cabeça alta, focinho prolongado anteriormente. Focinho recoberto por pequenas placas, exceto pequena área nua na extremidade distal. Perfil dorsal do focinho pontudo. Nasal alongado, em forma de "L". Frontal pouco alongado com grande contato com narina anteriormente e com a órbita lateralmente. Margem anterior do frontal curta, limitada a margem posterior ou alcança a metade do comprimento da narina. Supra-occiptal pouco alongado com extremidade posterior com projeção alongada com crista em forma de "V". Esfenótico curto sem contato com o IO6, sem odontódeos conspícuos. Pterótico-supracleitro curto e pouco fenestrado. Processo anterior do pterótico-supracleitro com pequeno contato com a margem posterior da órbita. Área posterior ao pterótico-supracleitro com uma ou duas placas pequenas. Olhos medianos e súpero-laterais com íris em forma de meia lua.

Lábios de tamanho médio com largura aproximadamente igual ao comprimento. Lábio coberto de pequenas papilas que aumentam de tamanho em direção à borda externa. Sem fialmentos labiais. Papila bucal central ausente ou pouco desenvolvida. Barbilhões maxilares pequenos. Pré-maxilar e dentário estreitos e alongados. Ângulo de encontro dos dentários quase reto. Dentes do pré-maxilar e do dentário pouco numerosos, alongados, moderadamente robustos e com cúspide lateral desenvolvida. Ponta dos dentes bastante curvada. 
Nadadeiras peitoral e pélvica alongadas. Pélvica sem mecanismos de trava; margens distais pouco arredondadas. Primeiro raio das nadadeiras peitoral e pélvica conspicuamente espesso. Espinho da nadadeira peitoral coberto por odontódeos hipertrofiados e afiados. Nadadeira peitoral I+6. Extremidade distal da nadadeira peitoral quando adpressa alcançando quase metade do raio indiviso da nadadeira pélvica. Nadadeira pélvica $\mathrm{I}+5$; primeiro raio espesso e suportando odontódeos. Extremidade da nadadeira pélvica quando adpressa alcançando a base da nadadeira anal. Nadadeira dorsal com mecanismo de trava com placa pré-dorsal em forma de V (“spinelet”). Nadadeira dorsal I+8. Nadadeira anal I+4, curta. Nadadeira adiposa presente. Nadadeira caudal I+14+I, lobo inferior maior que o superior. Exemplares juvenis apresentam espinhos da caudal prolongados.

Corpo coberto por cinco fileiras de placas suportando odontódeos. Quilhas bastante desenvolvidas. Quatro a cinco pares de placas pré-dorsais, às vezes pequenas placas ázigas placas pré-dorsais. Placas operculares eversíveis até 90 graus, sustentando espinhos bastante desenvolvidos. Cinco a seis raios procorrentes posicionados anteriormente aos raios caudais indivisos. Vinte e oito vértebras totais. Onze vértebras a partir do primeiro espinho neural simples. Sete espinhos neurais bífidos. Bexiga natatória encapsulada e curta, não alcança a sexta vértebra. Canais urogenital e anal em uma única saída tubular.

Sete a oito infra-orbitais. Infra-orbital 4 com bastante contato com a órbita através de sua extremidade posterior. Infra-orbital 6 forma apenas a parte póstero-ventral da órbita. Poros da linha lateral não ultrapassam a placa hipural.

Coloração. Padrão de colorido da superfície dorsal do corpo marrom escuro com manchas vermiculadas castanho claro. Superfície ventral bege com manchas em forma de bolhas. Nadadeiras com coloração marron escura com manchas brancas longitudinais formando um padrão estriado.

Distribuição geográfica. Bacia do rio Aripuanã (Figura 60).

\section{Material examinado.}

MZUSP, sem número, (9) 58,13-105,62; Brasil, Mato Grosso, rio Aripuanã (1009'53.2”S; $\left.59^{0} 27^{\prime} 25.99^{\prime \prime} \mathrm{W}\right)$. 


\section{Pseudacanthicus sp. "Tapajós".}

(Figuras 58 e 59; Tabela 9)

Diagnose. Pseudacanthicus sp. "Tapajós" pode ser diferenciado dos seus congêneres (exceto P. serratus), por possuir o padrão de colorido do corpo cinza escuro a preto coberto com pontos brancos. Diferencia-se de P. serratus por possuir maior número de pontos distribuídos nas superfícies dorsal e ventral. Diferencia-se ainda das outras espécies do gênero por apresentar as seguintes sinapomorfias: extremidade anterior do pterótico-supracleitro sem contato com a margem posterior da órbita (vs. pequeno contato com a órbita, exceto em Pseudacanthicus sp. "Tocantins"); área cartilaginosa do basipterígio curta (vs. alongada nas demais espécies e ausente em $P$. leopardus); crista ventral do basipterígio reta ou arredondada (vs. triangular, exceto em Pseudacanthicus sp. "açacu vermelho"); papila bucal central bem desenvolvida (vs. ausente ou pouco desenvolvida, exceto em Pseudacanthicus sp. "CuruáUna").

Descrição. Dados morfométricos e merísticos na Tabela 9. Perfil dorsal entre ponta do focinho e região anterior do processo supra-occipital pouco curvado. Restante do perfil dorsal ligeiramente reto, até placa pré-dorsal. Perfil pós-dorsal do corpo robusto. Pedúnculo caudal robusto. Maior altura do corpo na origem da nadadeira dorsal. Menor altura do corpo na região do pedúnculo caudal. Maior largura do corpo igual largura cleitral. Perfil ventral da ponta do focinho até a base da nadadeira caudal reto. Região abdominal e torácica sem placas.

Cabeça alta, focinho prolongado anteriormente. Focinho recoberto por pequenas placas, exceto pequena área nua na extremidade distal. Perfil dorsal do focinho pontudo. Nasal alongado, em forma de "L". Frontal pouco alongado com grande contato com narina anteriormente e com a órbita lateralmente. Margem anterior do frontal curta, limitada a margem posterior ou alcança a metade do comprimento da narina. Supra-occiptal pouco alongado com extremidade posterior com projeção alongada com crista em forma de "V". Esfenótico curto e em contato com o IO6, sem odontódeos conspícuos. Pterótico-supracleitro curto e pouco fenestrado. Processo anterior do pterótico-supracleitro sem contato com a margem posterior da órbita. Área posterior ao pterótico-supracleitro com uma ou duas placas pequenas. Olhos medianos e súpero-laterais com íris em forma de meia lua. 
Lábios de tamanho médio com largura aproximadamente igual ao comprimento. Lábio coberto de pequenas papilas que aumentam de tamanho em direção à borda externa. Sem fialmentos labiais. Papila bucal central ausente ou pouco desenvolvida. Barbilhões maxilares pequenos. Pré-maxilar e dentário estreitos e alongados. Ângulo de encontro dos dentários quase reto. Dentes do pré-maxilar e do dentário pouco numerosos, alongados, moderadamente robustos e com cúspide lateral grande. Ponta dos dentes bastante curvada.

Nadadeiras peitoral e pélvica alongadas. Pélvica sem mecanismos de trava; margens distais pouco arredondadas. Primeiro raio das nadadeiras peitoral e pélvica conspicuamente espesso. Espinho da nadadeira peitoral coberto por odontódeos hipertrofiados e afiados. Nadadeira peitoral I+6. Extremidade distal da nadadeira peitoral quando adpressa alcançando quase metade do raio indiviso da nadadeira pélvica. Nadadeira pélvica $\mathrm{I}+5$; primeiro raio espesso e suportando odontódeos. Extremidade da nadadeira pélvica quando adpressa alcançando a base da nadadeira anal. Nadadeira dorsal com mecanismo de trava com placa pré-dorsal em forma de V ("spinelet"). Nadadeira dorsal I+8. Nadadeira anal I+4, curta. Nadadeira adiposa presente. Nadadeira caudal I+14+I, lobo inferior maior que o superior. Exemplares juvenis apresentam espinhos da caudal prolongados.

Corpo coberto por cinco fileiras de placas suportando odontódeos. Quilhas bastante desenvolvidas. Quatro a cinco pares de placas pré-dorsais, às vezes pequenas placas ázigas placas pré-dorsais. Placas operculares eversíveis até 90 graus, sustentando espinhos bastante desenvolvidos. Cinco a seis raios procorrentes posicionados anteriormente aos raios caudais indivisos. Oito espinhos neurais bífidos sustentando a nadadeira dorsal. Dez vértebras a partir do primeiro espinho neural simples. Vinte e oito vértebras totais. Bexiga natatória encapsulada e curta, não alcança a sexta vértebra. Canais urogenital e anal em uma única saída tubular.

Sete a oito infra-orbitais. Infra-orbital 4 com bastante contato com a órbita através de sua extremidade posterior. Infra-orbital 6 forma apenas a parte póstero-ventral da órbita. Poros da linha lateral não ultrapassam a placa hipural.

Coloração. Superfície dorsal do corpo com coloração escura recoberta de pontos brancos, uniformente distribuídos. Nadadeiras com os raios escuros e também recobertos de pontos brancos. Superfície ventral bege com pontos brancos suaves.

Distribuição geográfica. Bacia dos rios Curuá-Una e Tapajós (Figura 60). 


\section{Material examinado.}

Brasil, Pará, Tapajós e Curuá-Uma: INPA 26515 (4), 103,63-144,83; Santarém peixes pegos com o Samuel (aquarista) que procedem do Curuá-Una; 13/11/2006, L.M. Sousa \& J.L. Birindelli. MNRJ 33732 (2), 69,61-92.72; Itaituba, peixes pegos por pescadores de peixes ornamentais, rios Tapajós e Jamaxim, nos arredores de Itaituba; 28/09/2008, Equipe AquaRios. MZUSP 108195 (17, 1 esq. 1 d\&c); 65,9-121,7; rio Curuá-Una, a jusante da represa; enviados por esportadores através do IBAMA ( $\left.3^{\circ} 39^{\prime} 45.70^{\prime \prime S} 54^{\circ} 24^{\prime} 19.87^{\prime \prime}\right)$.

\section{Pseudacanthicus sp. "açacu vermelho"}

(Figuras 61 e 63, Tabela 10)

Diagnose. Pseudacanthicus sp. "açacu vermelho" se diferencia dos demais congêneres (exceto P. leopardus e Pseudacanthicus sp. "aba laranja") pelo padrão de colorido das nadadeiras com intenso colorido laranja. Pode ser diferenciado de P. leopardus pelo padrão da superfície do corpo com pontos pretos alongados na região dorsal que se unem e formam manchas contínuas em forma de "zigue-zague" entre as séries de placas do corpo; e cabeça com pontos pretos bem definidos (vs. padrão de colorido do corpo com manchas marrom escuras a pretas grandes e dispostas de forma irregular pelas superfícies dorsal, ventral e nadadeiras, sendo mais conspícuas na superfície ventral, às vezes não muito definidas na cabeça em $P$. leopardus e sem pontos ou manchas aparentes na superfície dorsal do corpo e cabeça, apenas poucos pontos marrom escuros a pretos na superfície ventral em Pseudacanthicus sp. "aba laranja") e se diferencia ainda por possuir maior contagem de dentes no máximo 11 no pré-maxilar e 21 no dentário (vs. no máximo sete a 13, respectivamente em P. leopardus e no máximo 10 e 16, respectivamente em Pseudacanthicus sp. "aba laranja). Outras sinapomorfias da espécie que a diferenciam de suas congêneres são: crista ventral do basipterígio reta ou arredondada (vs. triangular); crista na base interna do processo posterior do basipterígio bem desenvolvida (vs. crista ausente ou pouco desenvolvida). 
Descrição. Dados morfométricos e merísticos na Tabela 10. Perfil dorsal entre ponta do focinho e região anterior do processo supra-occipital pouco curvado. Restante do perfil dorsal ligeiramente reto, até placa pré-dorsal. Perfil pós-dorsal do corpo robusto. Pedúnculo caudal robusto. Maior altura do corpo na origem da nadadeira dorsal. Menor altura do corpo na região do pedúnculo caudal. Maior largura do corpo igual largura cleitral. Perfil ventral da ponta do focinho até a base da nadadeira caudal reto. Região abdominal e torácica sem placas.

Cabeça alta, focinho prolongado anteriormente. Focinho recoberto por pequenas placas, exceto pequena área nua na extremidade distal. Perfil dorsal do focinho pontudo. Nasal alongado, em forma de "L". Frontal pouco alongado com grande contato com narina anteriormente e com a órbita lateralmente. Margem anterior do frontal curta, limitada a margem posterior ou alcança a metade do comprimento da narina. Supra-occiptal pouco alongado com extremidade posterior com projeção alongada com crista em forma de "V". Esfenótico curto em contato com o IO6, sem odontódeos conspícuos. Pterótico-supracleitro curto e pouco fenestrado. Processo anterior do pterótico-supracleitro com pequeno contato com a margem posterior da órbita. Área posterior ao pterótico-supracleitro com uma ou duas placas pequenas. Olhos medianos e súpero-laterais com íris em forma de meia lua.

Lábios de tamanho médio com largura aproximadamente igual ao comprimento. Lábio coberto de pequenas papilas que aumentam de tamanho em direção à borda externa. Sem fialmentos labiais. Papila bucal central ausente ou pouco desenvolvida. Barbilhões maxilares pequenos. Pré-maxilar e dentário estreitos e alongados. Ângulo de encontro dos dentários quase reto. Dentes do pré-maxilar e do dentário pouco numerosos, alongados, moderadamente robustos e com cúspide lateral pequena. Ponta dos dentes bastante curvada.

Nadadeiras peitoral e pélvica alongadas. Pélvica sem mecanismos de trava; margens distais pouco arredondadas. Primeiro raio das nadadeiras peitoral e pélvica conspicuamente espesso. Espinho da nadadeira peitoral coberto por odontódeos hipertrofiados e afiados. Nadadeira peitoral I+6. Extremidade distal da nadadeira peitoral quando adpressa alcançando quase metade do raio indiviso da nadadeira pélvica. Nadadeira pélvica $\mathrm{I}+5$; primeiro raio espesso e suportando odontódeos. Extremidade da nadadeira pélvica quando adpressa alcançando a base da nadadeira anal. Nadadeira dorsal com mecanismo de trava com placa pré-dorsal em forma de V (“spinelet”). Nadadeira dorsal I+8. Nadadeira anal I+4, curta. 
Nadadeira adiposa presente. Nadadeira caudal I+14+I, lobo inferior maior que o superior. Exemplares juvenis apresentam espinhos da caudal prolongados.

Corpo coberto por cinco fileiras de placas suportando odontódeos. Quilhas bastante desenvolvidas. Quatro a cinco pares de placas pré-dorsais, às vezes pequenas placas ázigas placas pré-dorsais. Placas operculares eversíveis até 90 graus, sustentando espinhos bastante desenvolvidos. Cinco a seis raios procorrentes posicionados anteriormente aos raios caudais indivisos. Oito espinhos neurais bífidos sustentando a nadadeira dorsal. Onze vértebras a partir do primeiro espinho neural simples. Vinte e nove vértebras totais. Bexiga natatória encapsulada e curta, não alcança a sexta vértebra. Canais urogenital e anal em uma única saída tubular.

Sete a oito infra-orbitais. Infra-orbital 4 com bastante contato com a órbita através de sua extremidade posterior. Infra-orbital 6 forma apenas a parte póstero-ventral da órbita. Poros da linha lateral não ultrapassam a placa hipural.

Coloração. Padrão de colorido das nadadeiras nja. Superfície dorsal do corpo com pontos pretos alongados na região dorsal que se unem e formam manchas contínuas em forma de "zigue-zague" entre as séries de placas do corpo, cabeça com pontos pretos bem definidos. Superfície ventral cinza claro com pontos pretos por toda a extensão. Nadadeiras com intenso colorido laranja, mais conspícuo nos raios não ramificados.

Distribuição geográfica. Bacia do rio Xingu (Figura 64).

Ecologia. A espécie pode ser encontrada em pedrais no meio do rio, onde as corredeiras são fortes, em uma profundidade entre 2 a 3 metros. Geralmente há vegetação aquática associada a esses pedrais.

\section{Material examinado.}

Brasil, Pará, Xingu: INPA 4037 (1) 310,0; rio Xingu, 01/10/1990, L. Rapp Py-Daniel \& J. A. Zuanon. INPA 4038 (1) 169,56; rio Xingu04/10/1990, L. Rapp Py-Daniel \& J. A. Zuanon. INPA 31466 (4), 115,46-210,5; Vitória do Xingu, Itaobinha, pedral no rio Xingu (3²3'45" S, $\left.52^{\circ} 12^{\prime} 16^{\prime \prime} \mathrm{W}\right) ; 04 / 11 / 2008$, L. Rapp Py-Daniel, et al. INPA 31776 (1), 230,5; Altamira, rio 
Xingu, Ilha do Davi (0332 39’'S; 051 57 29’W); 10/11/2008, L. Rapp Py-Daniel, et al. INPA 31807 (2), 130,57-188,25; Babaquara, rio Xingu, Gorgulho do Rita (03²0`14”S; 052 ${ }^{\circ} 11^{`} 18^{\prime \prime W}$ ); 07/11/2008, L. Rapp Py-Daniel, et al. MZUSP s/ número (ECIX 2010070803 esq.) (1) 261,69; Altamira, rio Xingu, próximo ao Morro do Forte (comprado de pescador ornamental, coordenada aproximada) ( $\left.3^{\circ} 12^{\prime} 18^{\prime \prime} \mathrm{S}, 52^{\circ} 11^{\prime} 29.1^{\prime \prime}\right)$; 08/07/2010, Equipe ECIX. MZUSP s/ número (ECIX2010070604 esq.) (2) 122,2-127,68; Altamira, rio Xingu, Morro do Forte (coletado por mergulhadores de peixes ornamentais) $\left(3^{\circ} 12^{\prime} 18^{\prime \prime} \mathrm{S}, 52^{\circ} 11^{\prime} 29.1^{\prime \prime} \mathrm{W}\right)$; 08/07/2010, Equipe ECIX. MZUSP s/ número (ECIX 2010070802 esq.) (1) 246,49; Altamira, localidade de Paratinzinho, rio Xingu, (coletados por pescadores de peixes ornamentais) (3॰14'59"S, 52॰5'56.9"W); 08/07/2010; Equipe ECIX. MZUSP 107175 (7) 38,24-184,15; Altamira, rio Xingu, Gorgulho da Rita (320'26.6" S, 52 $\left.11^{\prime} 4.5^{\prime \prime W}\right) ; 06 / 07 / 2010$, Equipe ECIX. MZUSP s/ número (ECIX2010071201) (1), 138,98; Belo Monte, rio Xingu, Pontão em frente à propriedade de Dona Maria e Sr. Valdomiro $\left(03^{\circ} 06^{\prime} 45.5^{\prime \prime} \mathrm{S}, 51^{\circ} 43^{\prime} 22,9^{\prime \prime} \mathrm{W}\right)$; 12/07/2010, Equipe ECIX. Sem dados de localidade: ZMA s/ número (3) 233,88-248,41 mm CP.

\section{Pseudacnthicus sp. "açacu preto"}

(Figura 62 e 63, Tabela 11)

Diagnose. Dentre as suas congêneres, a espécies pode ser diferenciada por apresentar padrão de colorido do corpo e nadadeiras cinza escuro uniforme, sem pontos ou manchas bem definidos (vs. com pontos ou manchas bem definidos). Também pode ser distinguido dos demais congêneres por apresentar o focinho arredondado em perfil dorsal (vs. focinho pontudo) e cabeça baixa (vs. cabeça alta). Outras sinapomorfias da espécie que a diferenciam de suas congêneres são: etmóide lateral retangular, expansão lateral curta ou ausente (vs. retangular a triangular com expansão ventro-lateral desenvolvida, exceto em Pseudacanthicus sp. “Tocantins" e Pseudacanthicus sp. "Aripuanã"); nasal retangular, fino e alongado, (vs. nasal em forma de L, exceto em P. leopardus); processo anterior do metapterigóide sem projeção, (vs. com uma projeção, exceto em Pseudacanthicus sp. “Aripuanã”); fenestra 
anterior a seção cartilaginosa do basipterígio alongada, aproximadamente elíptica (vs. ausente em P. leopardus e arredondada nas demais espécies).

Descrição. Dados morfométricos e merísticos na Tabela 11. Perfil dorsal entre ponta do focinho e região anterior do processo supra-occipital pouco curvado. Restante do perfil dorsal ligeiramente reto, até placa pré-dorsal. Perfil pós-dorsal do corpo robusto. Pedúnculo caudal robusto. Maior altura do corpo na origem da nadadeira dorsal. Menor altura do corpo na região do pedúnculo caudal. Maior largura do corpo igual largura cleitral. Perfil ventral da ponta do focinho até a base da nadadeira caudal reto. Região abdominal e torácica sem placas.

Cabeça alta, focinho prolongado anteriormente. Focinho recoberto por pequenas placas, exceto pequena área nua na extremidade distal. Perfil dorsal do focinho pontudo. Nasal retangular, fino e alongado. Frontal pouco alongado com grande contato com narina anteriormente e com a órbita lateralmente. Margem anterior do frontal curta, limitada a margem posterior ou alcança a metade do comprimento da narina. Supra-occiptal pouco alongado com extremidade posterior com projeção alongada com crista em forma de "V". Esfenótico curto e em contato com o IO6, sem odontódeos conspícuos. Pterótico-supracleitro curto e pouco fenestrado. Processo anterior do pterótico-supracleitro com pequeno contato com a margem posterior da órbita. Área posterior ao pterótico-supracleitro com uma ou duas placas pequenas. Olhos medianos e súpero-laterais com íris em forma de meia lua.

Lábios de tamanho médio com largura aproximadamente igual ao comprimento. Lábio coberto de pequenas papilas que aumentam de tamanho em direção à borda externa. Sem fialmentos labiais. Papila bucal central ausente ou pouco desenvolvida. Barbilhões maxilares pequenos. Pré-maxilar e dentário estreitos e alongados. Ângulo de encontro dos dentários quase reto. Dentes do pré-maxilar e do dentário pouco numerosos, alongados, moderadamente robustos e com cúspide lateral pequena. Ponta dos dentes bastante curvada.

Nadadeiras peitoral e pélvica alongadas. Pélvica sem mecanismos de trava; margens distais pouco arredondadas. Primeiro raio das nadadeiras peitoral e pélvica conspicuamente espesso. Espinho da nadadeira peitoral coberto por odontódeos hipertrofiados e afiados. Nadadeira peitoral I+6. Extremidade distal da nadadeira peitoral quando adpressa alcançando quase metade do raio indiviso da nadadeira pélvica. Nadadeira pélvica $\mathrm{I}+5$; primeiro raio espesso e suportando odontódeos. Extremidade da nadadeira pélvica quando adpressa 
alcançando a base da nadadeira anal. Nadadeira dorsal com mecanismo de trava com placa pré-dorsal em forma de V (“spinelet"). Nadadeira dorsal I+8. Nadadeira anal I+4, curta. Nadadeira adiposa presente. Nadadeira caudal I+14+I, lobo inferior maior que o superior. Exemplares juvenis apresentam espinhos da caudal prolongados.

Corpo coberto por cinco fileiras de placas suportando odontódeos. Quilhas bastante desenvolvidas. Quatro a cinco pares de placas pré-dorsais, às vezes pequenas placas ázigas placas pré-dorsais. Placas operculares eversíveis até 90 graus, sustentando espinhos bastante desenvolvidos. Cinco a seis raios procorrentes posicionados anteriormente aos raios caudais indivisos. Sete espinhos neurais bífidos sustentando a nadadeira dorsal. Onze vértebras a partir do primeiro espinho neural simples. Vinte e sete vértebras totais. Bexiga natatória encapsulada e curta, não alcança a sexta vértebra. Canais urogenital e anal em uma única saída tubular.

Sete a oito infra-orbitais. Infra-orbital 4 com bastante contato com a órbita através de sua extremidade posterior. Infra-orbital 6 forma apenas a parte póstero-ventral da órbita. Poros da linha lateral não ultrapassam a placa hipural.

Coloração. Padrão de coloração do corpo e nadadeiras cinza escuro uniforme sem pontos ou manchas (Figura 61). Superfície ventral cinza claro com cromatóforos unifomemente distribuídos, mais concentrados na região urogenital. Com o tempo, os exemplares podem apresentar coloração bege ventralmente.

Distribuição geográfica. Os exemplares desta espécie estão distribuídos no rio Xingu, na localidade de Belo Monte (Figura 64).

Ecologia. A espécie habita a calha principal do rio com fundo de pedras grandes, corredeiras e vegetação aquática. Os exemplares foram capturados através de mergulho em uma profundidade de dois a três metros.

\section{Material examinado.}

Brasil, Pará, Xingu: INPA 31467 (3), 44,85-250,2; Vitória do Xingu, Itaboinha, rio Xingu (2॰53’22', S, 5156'26'’ W); 04/11/2008, L. Rapp Py-Daniel et al. INPA 31804 (11), 71,09-

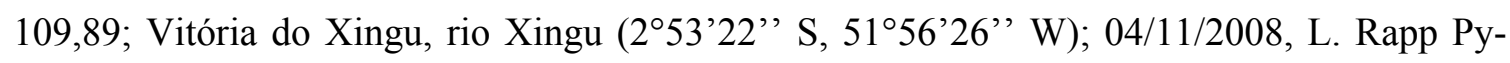


Daniel et al. INPA 31805 (1), 202,3; Belo Monte, rio Xingu, ilha do Merencio (Pontão) 306'17', S, 5143'33', W); 05/11/2008, L. Rapp Py-Daniel et al. INPA 31806 (1), 198,95;

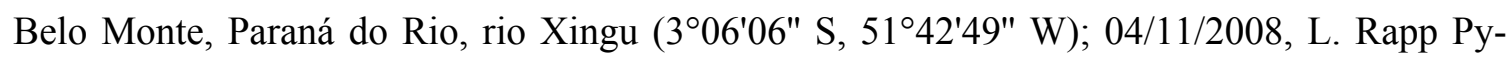
Daniel et al. MZUSP 107205 (3), 86,5-116,2,

\section{Pseudacanthicus sp. "Tocantins".}

(Figura 65, Tabela 12)

Diagnose. Pseudacanthicus sp. "Tocantins" pode ser diferenciado das demais espécies do gênero pelo padrão de colorido do corpo marrom escuro sem pontos ou manchas e com nadadeiras com manchas brancas transversais, geralmente mais conspícuas na dorsal e na caudal. Pode ainda se distinguido dos demais congêneres (exceto Pseudacanthicus sp. "Aripuanã") por apresentar o corpo relativamente mais baixo, com no máximo $21 \%$ do CP (vs. até 24\% em Pseudacanthicus sp. "açacu preto", até 28,7\% em P. leopardus, até 29,6\% em $P$. serratus, até 29\% em P. spinosus, até 26,5\% em Pseudacanthicus sp. "açacu vermelho", até 24,6\% em Pseudacanthicus sp. "aba laranja" e até 26,4\% Pseudacanthicus sp. "Tapajós". Outras sinapomorfias da espécie que a distingue de suas congêneres são: processo anterior do pterótico-supracleitro sem contato com a margem posterior da órbita (vs. com pequeno contato com a órbita, exceto em Pseudacanthicus sp. "Curuá-Una"); extremidade posterior do supraoccipital com projeção curta (vs. alongada e e pontuda nas outras espécies); crista na extremidade posterior do supra-occipital ausente (crista presente e em forma de V); cúspide lateral pequena (vs. grande nas demais espécies, exceto em Pseudacanthicus sp. "açacu vermelho" e Pseudacanthicus sp. "aba laranja"); 12 a 14 vértebras a partir do primeiro espinho neural, não incluindo a placa hipural (vs. 8 a 11 vértebras, exceto em Pseudacanthicus sp. “açacu vermelho", Pseudacanthicus sp. "aba laranja”); área posterior de contato entre o cleitro e o coracóide expandida ventralmente (reta nas outras espécies, exceto em Pseudacanthicus sp. "aba laranja"); crista ventral do basipterígio reta ou arredondada (vs. triangular nas demais espécies, exceto em Pseudacanthicus sp. "açacu vermelho"). 
Descrição. Dados morfométricos e merísticos na Tabela 12. Perfil dorsal entre ponta do focinho e região anterior do processo supra-occipital pouco curvado. Restante do perfil dorsal ligeiramente reto, até placa pré-dorsal. Perfil pós-dorsal do corpo robusto. Pedúnculo caudal robusto. Maior altura do corpo na origem da nadadeira dorsal. Menor altura do corpo na região do pedúnculo caudal. Maior largura do corpo igual largura cleitral. Perfil ventral da ponta do focinho até a base da nadadeira caudal reto. Região abdominal e torácica sem placas.

Cabeça alta, focinho prolongado anteriormente. Focinho recoberto por pequenas placas, exceto pequena área nua na extremidade distal. Perfil dorsal do focinho pontudo. Nasal alongado, em forma de "L". Frontal pouco alongado com grande contato com narina anteriormente e com a órbita lateralmente. Margem anterior do frontal curta, limitada a margem posterior ou alcança a metade do comprimento da narina. Supra-occiptal pouco alongado com extremidade posterior com projeção curta sem crista. Esfenótico curto e em contato com o IO6, sem odontódeos conspícuos. Pterótico-supracleitro curto e pouco fenestrado. Processo anterior do pterótico-supracleitro sem contato com a margem posterior da órbita. Área posterior ao pterótico-supracleitro com uma ou duas placas pequenas. Olhos medianos e súpero-laterais com íris em forma de meia lua.

Lábios de tamanho médio com largura aproximadamente igual ao comprimento. Lábio coberto de pequenas papilas que aumentam de tamanho em direção à borda externa. Sem fialmentos labiais. Papila bucal central ausente ou pouco desenvolvida. Barbilhões maxilares pequenos. Pré-maxilar e dentário estreitos e alongados. Ângulo de encontro dos dentários quase reto. Dentes do pré-maxilar e do dentário pouco numerosos, alongados, moderadamente robustos e com cúspide lateral pequena. Ponta dos dentes bastante curvada.

Nadadeiras peitoral e pélvica alongadas. Pélvica sem mecanismos de trava; margens distais pouco arredondadas. Primeiro raio das nadadeiras peitoral e pélvica conspicuamente espesso. Espinho da nadadeira peitoral coberto por odontódeos hipertrofiados e afiados. Nadadeira peitoral $\mathrm{I}+6$. Extremidade distal da nadadeira peitoral quando adpressa alcançando quase metade do raio indiviso da nadadeira pélvica. Nadadeira pélvica $\mathrm{I}+5$; primeiro raio espesso e suportando odontódeos. Extremidade da nadadeira pélvica quando adpressa alcançando a base da nadadeira anal. Nadadeira dorsal com mecanismo de trava com placa pré-dorsal em forma de V (“spinelet”). Nadadeira dorsal I+8. Nadadeira anal I+4, curta. 
Nadadeira adiposa presente. Nadadeira caudal I+14+I, lobo inferior maior que o superior. Exemplares juvenis apresentam espinhos da caudal prolongados.

Corpo coberto por cinco fileiras de placas suportando odontódeos. Quilhas bastante desenvolvidas. Quatro a cinco pares de placas pré-dorsais, às vezes pequenas placas ázigas placas pré-dorsais. Placas operculares eversíveis até 90 graus, sustentando espinhos bastante desenvolvidos. Cinco a seis raios procorrentes posicionados anteriormente aos raios caudais indivisos. Seis espinhos neurais bífidos sustentando a nadadeira dorsal. Quatorze vértebras a partir do primeiro espinho neural simples. Trinta vértebras totais. Bexiga natatória encapsulada e curta, não alcança a sexta vértebra. Canais urogenital e anal em uma única saída tubular.

Sete a oito infra-orbitais. Infra-orbital 4 com bastante contato com a órbita através de sua extremidade posterior. Infra-orbital 6 forma apenas a parte póstero-ventral da órbita. Poros da linha lateral não ultrapassam a placa hipural.

Distribuição geográfica. Bacia do rio Tocantins (Figura 67).

\section{Material examinado.}

Brasil, Goiás, Tocantins: MZUSP 79084 (1) 460; Itaguatins, rio Tocantins, praia do Imbiral; 21-23/12/1987, José Neves Fontenele. Pará, Tocantins: INPA 4557 (1), 120,9; Tucuruí, rio Tocantins, a jusante da represa a UHE de Tucuruí; 09/10/1984, G. M. Santos. INPA 6309 (11)

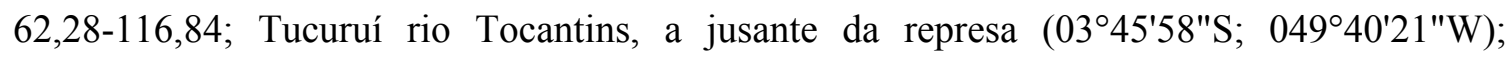
31/08/1984, Equipe Ictiologia INPA. INPA 32234 (1) 115,1; Tucuruí, rio Tocantins, a jusante da represa (034' $\left.58^{\prime \prime} \mathrm{S} ; 049^{\circ} 40^{\prime} 21^{\prime \prime W}\right)$; 31/08/1984, Equipe Ictiologia INPA. MNRJ 19346 (1) 166,66; rio Tocantins, próximo à cidade de Tucuruí; 09/1984. 27719 (1) 117,97; rio Tocantins, próximo à cidade de Tucuruí, 09/1984. MNRJ 19351 (1) 143,13; rio Tocantins, próximo à cidade de Tucuruí; 09/1984. Sem dados de localidade: AMNH 22583 (1) 58,31. ZMA s/ número (1) 243,89; Tapajós (?), doado por André Werner 17-iv-2000. ZMA s/ número (1) 276,46; exemplar de aquário. 
Pseudacanthicus sp. "aba laranja"

(Figuras 66, Tabela 13)

Diagnose. Pseudacanthicus sp. "aba laranja" se diferencia dos demais congêneres (exceto $P$. leopardus e Pseudacanthicus sp. "açacu vermelho") pelo padrão de colorido das nadadeiras com intenso colorido laranja. Pode ser diferenciado de P. leopardus e Pseudacanthicus sp. "açacu vermelho" pelo colorido marrom escuro sem pontos ou manchas aparentes na superfície dorsal do corpo e cabeça, apenas poucos pontos marrom escuro a pretos na superfície ventral (vs. padrão de colorido da superfície do corpo com pontos pretos alongados na região dorsal que se unem e formam manchas contínuas em forma de "zigue-zague" entre as séries de placas do corpo; e cabeça com pontos pretos bem definidos em Pseudacanthicus sp. "açacu vermelho" e padrão de colorido do corpo com manchas marrom escuras a pretas grandes e dispostas de forma irregular pelas superfícies dorsal, ventral e nadadeiras, sendo mais conspícuas na superfície ventral, às vezes não muito definidas na cabeça em $P$. leopardus). Outras sinapomorfias da espécie que a separa das demais congêneres são: contato do esfenótico com o IO6 ausente (vs. presente nas demis espécies do gênero); face lateral do canal metapterigóide triangular (arredondada, exceto em Pseudacanthicus sp. "Tocantins", Pseudacanthicus sp. "Aripuanã"); processo lateral do processo ventral do centro complexo bastante desenvolvido (vs. ausente ou pouco desenvolvido); área posterior de contato entre o cleitro e o coracóide expandida ventralmente (vs. reta, exceto em Pseudacanthicus sp. “Tocantins").

Descrição. Dados morfométricos e merísticos na Tabela 13. Perfil dorsal entre ponta do focinho e região anterior do processo supra-occipital pouco curvado. Restante do perfil dorsal ligeiramente reto, até placa pré-dorsal. Perfil pós-dorsal do corpo robusto. Pedúnculo caudal robusto. Maior altura do corpo na origem da nadadeira dorsal. Menor altura do corpo na região do pedúnculo caudal. Maior largura do corpo igual largura cleitral. Perfil ventral da ponta do focinho até a base da nadadeira caudal reto. Região abdominal e torácica sem placas.

Cabeça alta, focinho prolongado anteriormente. Focinho recoberto por pequenas placas, exceto pequena área nua na extremidade distal. Perfil dorsal do focinho pontudo. Nasal retangular, fino e alongado. Frontal pouco alongado com grande contato com narina 
anteriormente e com a órbita lateralmente. Margem anterior do frontal curta, limitada a margem posterior ou alcança a metade do comprimento da narina. Supra-occiptal pouco alongado com extremidade posterior com projeção alongada com crista em forma de "V". Esfenótico curto e sem contato com o IO6, sem odontódeos conspícuos. Pterótico-supracleitro curto e pouco fenestrado. Processo anterior do pterótico-supracleitro com pequeno contato com a margem posterior da órbita. Área posterior ao pterótico-supracleitro com uma ou duas placas pequenas. Olhos medianos e súpero-laterais com íris em forma de meia lua.

Lábios de tamanho médio com largura aproximadamente igual ao comprimento. Lábio coberto de pequenas papilas que aumentam de tamanho em direção à borda externa. Sem fialmentos labiais. Papila bucal central ausente ou pouco desenvolvida. Barbilhões maxilares pequenos. Pré-maxilar e dentário estreitos e alongados. Ângulo de encontro dos dentários quase reto. Dentes do pré-maxilar e do dentário pouco numerosos, alongados, moderadamente robustos e com cúspide lateral pequena. Ponta dos dentes bastante curvada.

Nadadeiras peitoral e pélvica alongadas. Pélvica sem mecanismos de trava; margens distais pouco arredondadas. Primeiro raio das nadadeiras peitoral e pélvica conspicuamente espesso. Espinho da nadadeira peitoral coberto por odontódeos hipertrofiados e afiados. Nadadeira peitoral I+6. Extremidade distal da nadadeira peitoral quando adpressa alcançando quase metade do raio indiviso da nadadeira pélvica. Nadadeira pélvica I+5; primeiro raio espesso e suportando odontódeos. Extremidade da nadadeira pélvica quando adpressa alcançando a base da nadadeira anal. Nadadeira dorsal com mecanismo de trava com placa pré-dorsal em forma de V (“spinelet"). Nadadeira dorsal I+8. Nadadeira anal I+4, curta. Nadadeira adiposa presente. Nadadeira caudal I+14+I, lobo inferior maior que o superior. Exemplares juvenis apresentam espinhos da caudal prolongados.

Corpo coberto por cinco fileiras de placas suportando odontódeos. Quilhas bastante desenvolvidas. Quatro a cinco pares de placas pré-dorsais, às vezes pequenas placas ázigas placas pré-dorsais. Placas operculares eversíveis até 90 graus, sustentando espinhos bastante desenvolvidos. Cinco a seis raios procorrentes posicionados anteriormente aos raios caudais indivisos. Sete espinhos neurais bífidos sustentando a nadadeira dorsal. Doze vértebras a partir do primeiro espinho neural simples. Vinte e nove vértebras totais. Bexiga natatória encapsulada e curta, não alcança a sexta vértebra. Canais urogenital e anal em uma única saída tubular. 
Sete a oito infra-orbitais. Infra-orbital 4 com bastante contato com a órbita através de sua extremidade posterior. Infra-orbital 6 forma apenas a parte póstero-ventral da órbita. Poros da linha lateral não ultrapassam a placa hipural.

Coloração. Superfície dorsal do corpo e cabeça com colorido marrom escuro sem pontos ou manchas aparentes. Superfície vemtral com apenas poucos pontos marrons escuros a pretos. Extremidade das nadadeiras com colorido laranja, sendo este mais conspícuo nos raios não ramificados.

Distribuição geográfica. Bacia do rio Tocantins, nos arredores de Tucuruí e Cametá, Pará. (Figura 67).

\section{Material examinado.}

Brasil, Pará, Tocantis: INPA 4502 (1) 164,05; Tucuruí, rio Tocantins (3²45'39.16"S, 49³9'50.85"W); 01/05/1986, F. Martinho. INPA 4558 (4), 91,41-147,51; Tucuruí, rio Tocantins, a jusante da represa da UHE de Tucuruí (346'2.84"S, 49³9'36.68"W); 09/10/1984, G. M. dos Santos. INPA 4559 (1) 148,15; Tucurú, rio Tocantins, poço do Paulo (345'31.63"S, 49³9'50.75"W); 26/07/1980, Equipe Ictiologia INPA. INPA 6308 (1), 94,06; Tucuruí, rio Tocantins, a jusante da represa da UHE de Tucuruí (345'58.19"S, 49³9'43.57"W). INPA 6309 (17), rio Tocantins; 09/10/1984, Equipe Ictiologia INPA. INPA 6311 (7), 30,19-230,3; rio Tocantins (345'59.43"S, 49³9'40.41"W). INPA 6348 (1) 270,0; Jatobal, rio Tocantins (428'26.61"S, 49²7'18.23"W); 05/07/1982, M. Jegu. INPA 6349 (1) 252,0; Tucuruí, rio Tocantins, igarapé Jatobal; 31/10/1980, Equipe Ictiologia INPA. INPA 6350 (1) 300,0; Breu Branco, rio Tocantins (4 4'4.52"S, 49³8'12.87"W); 31/10/1980, Equipe Ictiologia INPA. INPA 10919 (1), 210,4; Tucuruí, rio Tocantins, jusante da barragem (034ㄷ 58”S, 04940`21”W); 01/11/1980, Equipe Ictiologia ZMA 119.395 (3) 88,45-89,18; Tucuruí, rio Tocantins, about $2 \mathrm{~km}$ below dam (346'29.47"S 49³9'9.64"W); 9/10/1984, G. Mendes dos Santos. MZUSP 24135 (1) 110,76; Jatobal, rio Tocantins, lagoa em frente à Jatobal (049³9'00"W 04³4'00"S), 16/09/1970, Expedição Permanente à Amazônia. MZUSP 34295 (6) 170,33-256,98; rio Itacaiunas, Caldeirão (050³2'00"W 0552'00"S); 04/05/1983, M. Goulding. MZUSP 34296 (2) 181,12-220,67; Serra dos Carajás, rio Itacaiunas, Caldeirão, 
Pedral (050³2'00"W 0552'00"S); 11/1983, M. Goulding. ZMA 119.829 (1) 82,8; Cametá, rio Tocantins $\left(02^{\circ} 14^{`} \mathrm{~S}, 049^{\circ} 30^{\prime} \mathrm{W}\right) ; 7 / 1985$, A. Werner. Sem dados de localidade: AMNH 97659 (1) $82,8$.

\section{Gênero Spectracanthicus Nijssen \& Isbrucker, 1987}

Spectracanthicus Nijssen \& Isbrücker 1987:94, Figs. 1-3 [Revue française d'Aquariologie Herpetologie v. 13 (no. 4) (1986)]. Tipo por designação original. Monotípico. Gênero masculino. Localidade tipo: Poça de Pedra, Rio Tapajós, Pará, Brasil. Holótipo: MZUSP 22011. Parátipos: MZUSP 21849 (2), 24293 (2), 27663 (1); ZMA 107876-78 (1, 1, 2).

Oligancistrus Rapp Py-Daniel, 1989: 246. Espécie tipo: Chaetostomus punctatissimus Steindachner, 1881. Tipo por designação original. Gênero masculino. Chaetostomus punctatissimus Steindachner, 1881: 119 [19]. Pl. 3 (figs. 3-3a) [Denkschriften der Mathematisch-Naturwissenschaftlichen Classe der Kaiserlichen Akademie der Wissenschaften in Wien v. 43]. Tipo por designação original (monotípico). Gênero masculino. Localidade tipo: leste do rio Xingu, Porto de Mós, Pará, Brasil, $1^{\circ} 45^{\prime} \mathrm{S}, 52^{\circ} 10^{\prime} \mathrm{W}$. Holótipo: NMW 47206.

Diagnose. Spectracanthicus pode ser diferenciado de outros Ancistrini (exceto alguns Baryancistrus e Parancistrus) pela presença de uma membrana expandida que conecta a nadadeira dorsal com a nadadeira adiposa (vs. nadadeira dorsal sem membrane exapandida conectando a adipose); de Baryancistrus por possuir no máximo 25 dentes em cada prémaxilar (vs. mais de 25); e de Parancistrus por possuir aberturas branquiais pequenas (vs. aberturas branquiais grandes). Sinapomorfias que diferenciam o gênero dentre os outros táxons do grupo: segundo basibranquial cartilaginoso (vs. ossificado, exceto em Pseudacanthicus sp. "Tocantins" e Pseudacanthicus sp. "Aripuanã"); margem distal do processo transverso do centro complexo pontuda (vs. arredondada, exceto em Leporacanthicus joselimais e L. heterodon); membrana da nadadeira dorsal expandida e conectada à adiposa (vs. não conectada à adiposa); hipurapófise baixa (vs. média ou alta, exceto em 
Pseudacanthicus e Megalancistrus barrae); espaço entre o lobo hipural inferior e o último espinho hemal grande (vs. espaço ausente ou pequeno, exceto em Leporacanthicus).

Etimologia. Do latim spectrum significa aparência, em alusão à semelhança com o gênero Acanthicus.

\section{Chave para as espécies de Spectracanthicus}

1a. Opérculo com odontódeos conspícuos e eversíveis; quatro raios ramificados na nadadeira anal....... 2

1b. Opérculo sem odontódeos conspícuos e sem mobilidade; três raios ramificados na nadadeira anal. S. murinus

2a. Padrão de colorido do corpo castanho escuro a preto com pequenos pontos amarelos ou com corpo de colorido castanho acinzentado uniforme sem pontos ou manchas.......3

2b. Padrão de colorido do corpo castanho escuro acinzentado com pontos grandes e brancos Spectracanthicus sp. "bola branca"

3a. Superfície do corpo castanho acinzentado uniforme, sem pontos ou manchas; perfil dorsal do focinho pontudo; dentes do pré-maxilar e do dentário bastante fino e alongado........ Spectracanthicus sp. "Tapajós"

3b. Superfície do corpo coberta com pontos amarelos de tamanho pequeno a médio .3

4a. Superfície do corpo coberta com pontos amrelos de tamanho médio; perfil dorsal do focinho levemente pontudo; menor número de dentes do pré-maxilar e do dentário (5-8 e 8-16, respectivamente) e dentes bastante robustos. Spectracanthicus sp. "Tocantins".

4b. Superfície do corpo coberta com pontos amarelos de tamanho pequeno; perfil dorsal do focinho arredondado; maior número de dentes no pré-maxilar e dentário (12-17 e 21-30, respectivamente) e dentes moderadamente robustos. S. punctatissimus 
Spectracanthicus murinus Nijssen \& Isbrucker, 1987

(Figuras 68 e 74, Tabela 14)

Spectracanthicus murinus Nijssen \& Isbrucker, 1987: 94, fig. 1. Localidade tipo: Poça de pedra no rio Tapajós, São Luis, Pará, Brasil. Holótipo: MZUSP 22011. - Burgess, 1989: 445 [atlas de aquarismo]. Eschemeyer, 1998: 1138 [catálogo de peixes]. - Isbrücker, 2001:32 [catálogo de Loricariidae]. - Isbrücker, 2002:29 [catálogo de Loricariidae]. - Fisch-Muller in Reis et al., 2003:395 [catálogo de peixes]. - Ferraris, 2007:297 [catálogo de Siluriformes]. Lujan et al., 2009: 50-56 [diagnose comparativa de Baryancistrus beggini; considera Oligancistrus como sinônimo júnior de Spectracanthicus; tabela comparativa entre Parancistrus, Spectracanthicus, Oligancistrus e Baryancistrus].

Diagnose. Spectracanthicus murinus pode ser diferenciado de seus congêneres pela ausência de mobilidade das placas operculares (vs. presença); opérculo em forma triangular (vs. em forma de barra); por possuir três raios ramificados na nadadeira anal (vs. quatro); presença de barras claras nas margens das nadadeiras dorsal e caudal (vs. ausente). De Spectracanthicus sp. "Tapajós" pode ser diferenciado pelo colorido com pequenos pontos claros (vs. padrão de colorido cinza escuro sem pontos). Outros caracteres sinapomórficos que diferenciam a espécie dos demais táxons do gênero: frontal contatando a órbita somente em um pequeno ponto lateral (vs. frontal com grande contato com a óbita nas demais espécies); processo anterior do pterótico-supracleitro com grande contato com a margem posterior da órbita (vs. sem contato com a margem posterior da órbita em Spectracanthicus sp. "Tapajós" e com pequeno contato com a órbita nos demais táxons); expansão laminar do EB1 fina e bastante curta (vs. espessa e alongada); margem anterior do hiomandibular suturada ao metapterigóide ao longo de todo comprimento (vs. hiomandibular não suturado completamente ao metapterigóide); maxilar largo e arredondado distalmente (vs. maxilar alongado, estreito e com largura uniforme); dentes curtos (vs. dentes alongados); área cartilaginosa do basipterígio curta (vs. alongada nas demais espécies, exceto em Spectracanthicus sp. “Tapajós”); bordas brancas nas nadadeiras presente (vs. ausente nas demais espécies, exceto em $S$. punctatissimus). 
Descrição Dados morfométricos e merísticos na Tabela 14. Perfil dorsal entre ponta do focinho e região anterior do processo supra-occipital pouco curvado. Restante do perfil dorsal ligeiramente reto, até placa pré-dorsal. Perfil pós-dorsal do corpo robusto. Pedúnculo caudal robusto. Maior altura do corpo na origem da nadadeira dorsal. Menor altura do corpo na região do pedúnculo caudal. Maior largura do corpo igual largura cleitral. Perfil ventral da ponta do focinho até a base da nadadeira caudal reto. Região abdominal e torácica sem placas.

Cabeça alta, focinho prolongado anteriormente. Focinho recoberto por pequenas placas, exceto pequena área nua na extremidade distal. Perfil dorsal do focinho pontudo. Nasal alongado, em forma de "L'. Frontal pouco alongado com pequeno contato com narina anteriormente e com grande contato com a órbita lateralmente. Margem anterior do frontal curta, limitada a margem posterior ou alcança a metade do comprimento da narina. Supraocciptal curto com extremidade posterior com projeção curta sem crista. Esfenótico curto, em contato com o IO6, sem odontódeos conspícuos. Pterótico-supracleitro curto e pouco fenestrado. Processo anterior do pterótico-supracleitro com grande contato com a margem posterior da órbita. Área posterior ao pterótico-supracleitro com uma placa pequenas. Olhos medianos e súpero-laterais com íris em forma de meia lua.

Lábios de tamanho médio com largura aproximadamente igual ao comprimento. Lábio coberto de pequenas papilas que aumentam de tamanho em direção à borda externa. Sem fialmentos labiais. Papila bucal central ausente ou pouco desenvolvida. Barbilhões maxilares pequenos. Pré-maxilar e dentário estreitos e alongados. Ângulo de encontro dos dentários quase reto. Dentes do pré-maxilar e do dentário pouco numerosos, alongados, moderadamente robustos e com cúspide lateral grande. Ponta dos dentes pouco curvada.

Nadadeiras peitoral e pélvica alongadas. Pélvica sem mecanismos de trava; margens distais pouco arredondadas. Primeiro raio das nadadeiras peitoral e pélvica conspicuamente espesso. Espinho da nadadeira peitoral coberto por odontódeos hipertrofiados e afiados. Nadadeira peitoral I+6. Extremidade distal da nadadeira peitoral quando adpressa alcançando quase metade do raio indiviso da nadadeira pélvica. Nadadeira pélvica $\mathrm{I}+5$; primeiro raio espesso e suportando odontódeos. Extremidade da nadadeira pélvica quando adpressa alcançando a base da nadadeira anal. Nadadeira dorsal com mecanismo de trava com placa pré-dorsal em forma de V (“spinelet”). Nadadeira dorsal I+8, bastante longa, alcança a placa 
pré-adiposa e se conecta à adiposa por uma espessa membrana. Nadadeira anal $\mathrm{I}+3$, curta. Nadadeira adiposa presente. Nadadeira caudal I+14+I, lobo inferior maior que o superior.

Corpo coberto por cinco fileiras de placas suportando odontódeos. Quilhas ausentes. Quatro a cinco pares de placas pré-dorsais, às vezes pequenas placas ázigas placas pré-dorsais. Placas operculares não eversíveis. Opérculo sem odontódeos desenvolvidos. Cinco a seis raios procorrentes posicionados anteriormente aos raios caudais indivisos. Sete espinhos neurais bífidos sustentando a nadadeira dorsal. Nove vértebras a partir do primeiro espinho neural simples. Vinte e cinco vértebras totais. Bexiga natatória encapsulada e curta, não alcança a sexta vértebra. Canais urogenital e anal em uma única saída tubular.

Sete a oito infra-orbitais. Infra-orbital 4 com pouco contato com a órbita através de sua extremidade posterior. Infra-orbital 6 forma apenas a parte póstero-ventral da órbita. Poros da linha lateral não ultrapassam a placa hipural.

Coloração. Superfície dorsal marrom escuro coberta por pequenos pontos amarelos. Em alguns exemplares é notável uma pequena barra amarelada na ponta da nadadeira caudal. Superfície ventral ocre sem pontos.

Distribuição. Bacia do rio Tapajós (Figura 75).

Etimologia. Do latim murinus significa camundongo, em alusão ao tamanho da espécie.

\section{Material examinado (todos Brasil, Pará)}

Holótipo: MZUSP 22011 (h), 59,7; São Luis, poça de pedra no rio Tapajós ( $4^{\circ} 27^{\prime} 0.02^{\prime \prime S}$, $56^{\circ} 15^{\prime} 0.00^{\prime \prime} \mathrm{W}$ ).

Parátipos: MZUSP 21849 (p) (2), 44,17-58,22; São Luis, rio Tapajós, Cachoeira Lombo de Anta, (4²7'60.00"S, 56²14'60.00"W). MZUSP 27633 (p) (1), 44,99; São Luis, rio Tapajós, cahoeira do Maranhãozinho ( $\left.4^{\circ} 28^{\prime} 0.00^{\prime \prime} \mathrm{S} 56^{\circ} 15^{\prime} 0.00^{\prime \prime} \mathrm{W}\right)$. ZMA 107.878 (p) (2) 55,52-63,59; São Luis, rio Tapajós, Cachoeira Lombo de Anta (4²7'60.00"S, 56¹4'60.00"W); 6/XI/1970; EPA. ZMA 107.877 (p) 58.57; São Luis, poça de pedra no rio Tapajós; 8/XI/1970. ZMA 107.876 (p) 44.1; Cachoeira do Maranhãozinho, rio Tapajós, perto de São Luis Pará, Brasil $\left(04^{0} 28^{\prime} \mathrm{S} ; 056^{0} 15^{\prime} \mathrm{W}\right)$; 06-07/XI/1970, EPA. 
Brasil, Pará, Tapajós: INPA 6774 (6ex.) Trairão, rio Jamanxim, ilha Terra Preta $\left(05^{\circ} 27^{\prime} 11^{\prime \prime S}, 55^{\circ} 52^{\prime} 40^{\prime \prime W}\right)$. INPA 6990 (1), 62,63; Trairão, rio Jamaxim, ilha Terra Preta (05²7'11"S, 5552'40"W); 20/10/1991, L.Rapp Py-Daniel, J.Zuanon. INPA 6984 (33), Pimental, rio Tapajós, abaixo da foz do rio Jamanxim (44' $\left.8.47^{\prime \prime S} 56^{\circ} 22^{\prime} 29.60^{\prime \prime} \mathrm{W}\right)$; 20/10/1991, L.Rapp Py-Daniel, J.Zuanon. INPA 26480 (1), 62,55; Itaituba, rio Tapajós, doado por pescadores de peixes ornamentais na região de Itaituba e Pimental; 08/11/2006, L.M. Sousa \& J.L. Birindelli. INPA 26483 (6), 44,45-84,81; Itaituba, rio Tapajós, doados por pescadores de peixes ornamentais na região de Itaituba e Pimental; 08/11/2006, L.M. Sousa \& J.L. Birindelli. INPA 26488 (8), 60,41-96,66; Itaituba, rio Tapajós, a montante de Itaituba e a jusante das cachoeiras de Pimental (04²1'34"S, 056 $\left.10^{\prime} 02^{\prime \prime W}\right)$; 08/11/2006, L.M. Sousa \& J.L. Birindelli. INPA 26507 (2) 47,3-57,59; Pimental, rio Tapajós, corredeira do Pajaú e arredores $\left(04^{\circ} 35^{\prime} 04^{\prime \prime S}, 056^{\circ} 15^{\prime} 32^{\prime \prime} \mathrm{W}\right)$; 11/11/2006, L.M. Sousa \& J.L. Birindelli.MZUSP 24293 (2, 1 d\&c), 36,1-39,11; São Luis, rio Tapajós, cahoeira do Maranhãozinho ( $04^{0}$ 28'S; $056^{0}$ 15'W); 06-07/11/1970, Expedição Permanente à Amazônia. MZUSP 34279 (13, 1 d\&c),

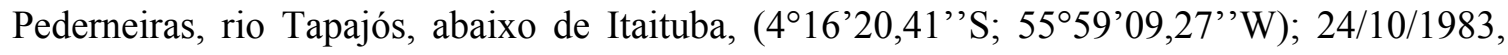
M. Goulding.

Spectracanthicus punctatissimus (Steindachner, 1881)

(Figuras 69 e 74, Tabela 15)

Oligancistrus Rapp Py-Daniel, 1989: 246. Espécie tipo: Chaetostomus punctatissimus Steindachner, 1881. Tipo por designação original. Gênero masculino. Chaetostomus punctatissimus Steindachner, 1881: 119. Tipo por designação original (monotípico). Gênero masculino. Localidade tipo: leste do rio Xingu, Porto de Mós, Pará, Brasil, $1^{\circ} 45^{\prime} \mathrm{S}, 52^{\circ} 10^{\prime} \mathrm{W}$. Holótipo: NMW 47206. - Eigenmann \& Eigenmann, 1889: 44 [Parancistrus punctatissimus; Hypostomus niveatus; Porto de Moz]. - Fowler, 1954: 172 [Parancistrus punctatissimus; descrição]. - Isbrücker, 1980: 58 [nomenclatura de Loricariidae; válido como Parancistrus punctatissimus]. Burgess, 1989: 435 [Atlas de aquarismo]. - Rapp Py-Daniel, 1989: 239 [estabelecimento do gênero Oligancistrus para alocar Parancistrus punctatissimus; nova combinação; diagnose]. - Isbrücker \& Nijssen, 1991: 349 [informações sobre a localidade tipo; descrição de Chaetostomus punctatissimus baseada em apenas um exemplar que sem dúvida é 
o holótipo; localidade "Porto Moz]. Eschmeyer, 1998: 1398 [catálogo de peixes]. - Isbrücker, 2001: 26-30 [catálogo de Loricariidae]. Isbrücker, 2002: 23 [catálogo de Loericariidae]. Fisch-Muller in Reis et al., 2003: 390 [catálogo de peixes]. ]. - Armbruster, 2004: 53 [análise filogenética; considera o gênero como sinônimo de Spectracanthicus]. - Ferraris, 2007: 274 [catálogo de Siluriformes]. - Lujan et al., 2009: 50-56 [diagnose comparativa de Baryancistrus beggini; considera Oligancistrus como sinônimo júnior de Spectracanthicus; tabela comparativa entre Parancistrus, Spectracanthicus, Oligancistrus e Baryancistrus]

Diagnose. Pode ser difrenciado das demais espécies, exceto S. murinus, por apresentar a bordas das nadadeiras dorsal e caudal brancas (vs. sem bordas brancas nas nadaderias). Se diferencia ainda por apresentar padrão de colorido com pontos claros, exceto em Spectracanthicus sp. "Tocantins" e S. murinus (vs. colorido uniforme em Spectracanthicus sp. "Tapajós" e com grandes manchas brancas em Spectracanthicus sp. "bola branca"). Se diferencia de Spectracanthicus sp. "Tapajós" por apresentar o perfil dorsal do focinho arredondado (vs. pontudo). Outro caráter sinapomórfico da espécie, que embora ocorra em outros táxons do grupo Acanthicus é possuir 12 a 14 vétebras a partir do primeiro espinho neural, não incluindo a placa hipural (vs. 8 a 11 nas demais espécies do gênero).

Descrição. Dados morfométricos e merísticos na Tabela 15. Perfil dorsal entre ponta do focinho e região anterior do processo supra-occipital pouco curvado. Restante do perfil dorsal ligeiramente reto, até placa pré-dorsal. Perfil pós-dorsal do corpo robusto. Pedúnculo caudal robusto. Maior altura do corpo na origem da nadadeira dorsal. Menor altura do corpo na região do pedúnculo caudal. Maior largura do corpo igual largura cleitral. Perfil ventral da ponta do focinho até a base da nadadeira caudal reto. Região abdominal e torácica sem placas.

Cabeça alta, focinho prolongado anteriormente. Focinho recoberto por pequenas placas, exceto pequena área nua na extremidade distal. Perfil dorsal do focinho arredondado. Nasal alongado, em forma de 'L'. Frontal pouco alongado com pequeno contato com narina anteriormente e com a órbita lateralmente. Margem anterior do frontal curta, limitada a margem posterior ou alcança a metade do comprimento da narina. Supra-occiptal curto com extremidade posterior com projeção curta sem crista. Esfenótico curto, sem contato com o IO6, sem odontódeos conspícuos. Pterótico-supracleitro curto e pouco fenestrado. Processo 
anterior do pterótico-supracleitro com grande contato com a margem posterior da órbita. Área posterior ao pterótico-supracleitro com uma placa média. Olhos medianos e súpero-laterais com íris em forma de meia lua.

Lábios de tamanho médio com largura aproximadamente igual ao comprimento. Lábio coberto de pequenas papilas que aumentam de tamanho em direção à borda externa. Sem fialmentos labiais. Papila bucal central ausente ou pouco desenvolvida. Barbilhões maxilares pequenos. Pré-maxilar e dentário estreitos e alongados. Ângulo de encontro dos dentários quase reto. Dentes do pré-maxilar e do dentário modeiradamente numerosos, alongados, moderadamente robustos e com cúspide lateral grande. Ponta dos dentes pouco curvada.

Nadadeiras peitoral e pélvica alongadas. Pélvica sem mecanismos de trava; margens distais pouco arredondadas. Primeiro raio das nadadeiras peitoral e pélvica conspicuamente espesso. Espinho da nadadeira peitoral coberto por odontódeos hipertrofiados e afiados. Nadadeira peitoral I+6. Extremidade distal da nadadeira peitoral quando adpressa alcançando quase metade do raio indiviso da nadadeira pélvica. Nadadeira pélvica $\mathrm{I}+5$; primeiro raio espesso e suportando odontódeos. Extremidade da nadadeira pélvica quando adpressa alcançando a base da nadadeira anal. Nadadeira dorsal com mecanismo de trava com placa pré-dorsal em forma de V ("spinelet"). Nadadeira dorsal I+8, bastante longa, alcança a placa pré-adiposa e se conecta à adiposa por uma espessa membrana. Nadadeira anal I+4, curta. Nadadeira adiposa presente. Nadadeira caudal I+14+I, lobo inferior maior que o superior.

Corpo coberto por cinco fileiras de placas suportando odontódeos. Quilhas ausentes. Quatro a cinco pares de placas pré-dorsais, às vezes pequenas placas ázigas placas pré-dorsais. Placas operculares eversíveis. Opérculo suportando odontódeos desenvolvidos. Cinco a seis raios procorrentes posicionados anteriormente aos raios caudais indivisos. Oito espinhos neurais bífidos sustentando a nadadeira dorsal. Oito vértebras a partir do primeiro espinho neural simples. Vinte e sete vértebras totais. Bexiga natatória encapsulada e curta, não alcança a sexta vértebra. Canais urogenital e anal em uma única saída tubular.

Sete a oito infra-orbitais. Infra-orbital 4 com pouco contato com a órbita através de sua extremidade posterior. Infra-orbital 6 forma apenas a parte póstero-ventral da órbita. Poros da linha lateral não ultrapassam a placa hipural. 
Coloração. Superfície dorsal do corpo cinza escuro a morrom escuro com pequenos pontos claros distribuídos de forma irregular. Superfície ventral bege sem pontos. Alguns exemplares apresentam nas extremidades dos raios indivisos da caudal uma pequena barra branca.

Distribuição. Bacia do rio Xingu (Figura 75).

Ecologia. A espécie habita areas com fundo de pedras e bastantes corredeiras. Geralmente ocorre vegetação aquática nesses ambientes.

Etimologia. Do latim punctum significa ponto e issimus adjetivo superlativo. Em referência à grande quantidade de pontos espalhados na superfície do corpo.

\section{Material examinado}

Holótipo: NMW 47206 (h) 103,96; Porto Moz, rio Xingu (144'55.10"S, 52¹4'17.04"W); Staindachner don.

Brasil, Pará, Xingu: INPA 3958 (4), 20,99-54,18; Altamira, rio Xingu, cachoeira de Kaituka (312'0" S, 52¹2'0" W); 09/10/1990, L. Rapp Py-Daniel \& J. A. Zuanon. INPA 25786 (42), 35,57-42,7; rio Xingu, Kaituká; INPA 31417 (3), 54,42-119,84; Comunidade do Maia, rio Xingu, acampamento, pedral em frente ao Xingu (033' $\left.44^{\prime \prime S} 051^{\circ} 44^{\prime} 43^{\prime \prime W}\right)$; 09/11/2008, L. Rapp Py-Daniel, et al. INPA 31446 (2), 46,26-57,43; Comunidade do Maia, rio Xingu (331'42" S, 5245'02" W); 09/11/2008, L. Rapp Py-Daniel, et al. INPA 31453 (24), 34,9579,20; Babaquara, rio Xingu, 45 minutos acima de Altamira ( $\left.3^{\circ} 23^{\prime} 45^{\prime \prime} \mathrm{S}, 52^{\circ} 12^{\prime} 16^{\prime \prime} \mathrm{W}\right)$; 07/11/2008, L. Rapp Py-Daniel, et al. INPA 31461 (9), 36,48-69,70; Vitória do Xingu, Itaobinha, pedral no rio Xingu ( $3^{\circ} 23^{\prime} 45^{\prime \prime}$ S, 52 $12^{\prime} 16^{\prime \prime}$ W); 04/11/2008, L. Rapp Py-Daniel, et al. INPA 31464 (3), 54,42-119,84; Belo Monte, rio Xingu, ilha de Merencio, Pontão (306'17" S, 514'33" W); 05/11/2008, L. Rapp Py-Daniel, et al. INPA 31781 (5), 36,57-77,99; Belo Monte, Coqueiro, rio Xingu ( $3^{\circ} 06^{\prime} 54^{\prime \prime}$ S, 514' $15^{\prime \prime}$ W); 05/11/2008, L. Rapp Py-Daniel, et al. INPA 31784 (9), 33,71-49,11; Babaquara, rio Xingu, Gorgulho da Rita (3²0'14" S, 52¹1'18" W); 07/11/2008, L. Rapp Py-Daniel, et al. INPA 31785 (5), 46,96-119,02; Belo Monte, Paraná do Rio, rio Xingu ( $3^{\circ} 06^{\prime} 06^{\prime \prime}$ S, 5142'49" W); 05/11/2008, L. Rapp Py-Daniel, et al. INPA 3956 (8), Altamira, cachoeira de Kaituka, 09/10/1990, L. Rapp Py-Daniel \& J. A. Zuanon. 
INPA 29304 (1), 70,85; Altamira, Costa do Junior, rio Xingu. INPA 31416 (2), 33,66-110,8; Comunidade do Maia, pedral em frente ao rio Xingu ( $\left.3^{\circ} 30^{\prime} 44^{\prime \prime} \mathrm{S}, 51^{\circ} 44^{\prime} 43^{\prime \prime} \mathrm{W}\right)$; 11/10/1996, J. A. Zuanon. INPA 31424 (3), 87,4-110,9; rio Xingu, Cachoeira do Landi (3³5'01" S, 5149'21" W); 08/11/2008, L. Rapp Py-Daniel, et al. INPA 31463 (2), 65,97-96,04; Vitória do Xingu, Itaboinha, pedral no rio Xingu (253'22" S, 5156'26" W); 04/11/2008, L. Rapp PyDaniel, et al. INPA 31486 (2), 79,55-114,78; Arroz Cru, rio Xingu (03²5'20”S; 051 $57^{\circ} 22^{\prime \prime W) ; ~ 06 / 11 / 2008, ~ L . ~ R a p p ~ P y-D a n i e l, ~ e t ~ a l . ~ I N P A ~} 31782$ (9), 59,41-62,36; Vitória do Xingu, Itaboinha, pedral no rio Xingu (03 $533^{\circ} 22^{\prime \prime}$; $051^{\circ} 56$ '26”W); 04/11/2008, L. Rapp Py-Daniel, et al. INPA 31783 (2), 41,32-77,43; Babaquara, rio Xingu, gorgulho da Rita (0320`14”S; 052 $\left.{ }^{\circ} 11 ` 18^{\prime \prime W}\right)$; 07/11/2008, L. Rapp Py-Daniel, et al. INPA 31786 (2), 42,250,05; Belo Monte, Coqueiro, rio Xingu (0306 54”S; 051 $\left.{ }^{\circ} 43^{`} 15^{\prime \prime} \mathrm{W}\right)$; 05/11/2008, L. Rapp Py-Daniel, et al. MHNG 2546.100 (4) 32,84-53,23; Altamira, rio Xingu, Balneário de Altamira ( $\left.3^{\circ} 12^{\prime} 32.74^{\prime \prime} \mathrm{S}, 52^{\circ} 12^{\prime} 17.58^{\prime \prime}\right)$; U. Werner, H. et al., 31/VII-1/VIII/1999. MHNG 2555.14 (16) 39,48-70,67; Altamira, rio Xingu (3²'32.74"S, 52¹2'17.58"W); A. Werner, XII/1992. MZUSP s/ número (ECIX2010070602) (55) 86,06-35,11; Altamira, rio Xingu, Ilha

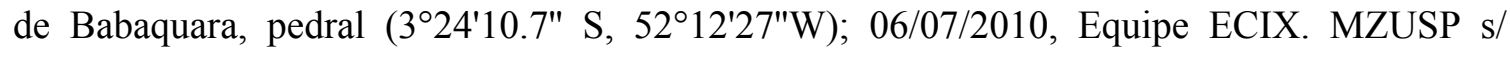
número (ECIX2010070601) (6) 36,29-68,70; Altamira, rio Xingu, gorgulho da Rita $\left(3^{\circ} 20^{\prime} 26.6^{\prime \prime} \quad\right.$ S, 52¹1'4.5"W); 06/07/2010, Equipe ECIX. MZUSP s/ número (ECIX2010070701) (3), 73,33-112,04; Altamira localidade de Jericoá, próximo à cachoeira do

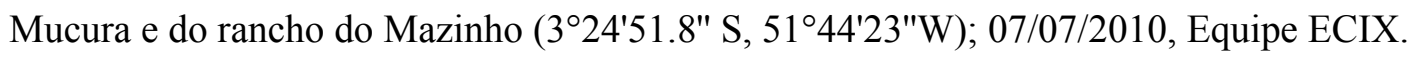

\section{Spectracanthicus sp. "bola branca"}

(Figuras 70 e 74, Tabela 16)

Diagnose. Spectracanthicus sp. "bola branca" pode ser distinguida des suas congeneres pelo padrão de coloração apresentando grandes pontos brancos pelo corpo. (vs. peuqenos pontos brancos em O. punctatissimus e Spectracanthicus sp. "tocantins"; sem pontos ou manchas em Spectracanthicus sp. "tapajós"); pela maior proporção do diâmetro horizontal da órbita, até $28.8 \%$ CC (vs. up to $23 \%$ em O. punctatissimus, até $20 \%$ em Spectracanthicus. sp. "tocantins" e até 16,2\% em Spectracanthicus sp. "tapajós). Outro caráter sinapomórfico da 
espécie, único dentro do gênero, embora compartilhado com outros Ancistrini é a margem distal do processo transverso do centro complexo arredondada (vs. pontuda).

Descrição. Dados morfométricos e merísticos na Tabela 16. Perfil dorsal entre ponta do focinho e região anterior do processo supra-occipital pouco curvado. Restante do perfil dorsal ligeiramente reto, até placa pré-dorsal. Perfil pós-dorsal do corpo robusto. Pedúnculo caudal robusto. Maior altura do corpo na origem da nadadeira dorsal. Menor altura do corpo na região do pedúnculo caudal. Maior largura do corpo igual largura cleitral. Perfil ventral da ponta do focinho até a base da nadadeira caudal reto. Região abdominal e torácica sem placas.

Cabeça alta, focinho prolongado anteriormente. Focinho recoberto por pequenas placas, exceto pequena área nua na extremidade distal. Perfil dorsal do focinho arredondado. Nasal alongado, em forma de "L'. Frontal pouco alongado com pequeno contato com narina anteriormente e com a órbita lateralmente. Margem anterior do frontal curta, limitada a margem posterior ou alcança a metade do comprimento da narina. Supra-occiptal curto com extremidade posterior com projeção curta sem crista. Esfenótico curto, sem contato com o IO6, sem odontódeos conspícuos. Pterótico-supracleitro curto e pouco fenestrado. Processo anterior do pterótico-supracleitro com grande contato com a margem posterior da órbita. Área posterior ao pterótico-supracleitro com uma placa média. Olhos medianos e súpero-laterais com íris em forma de meia lua.

Lábios de tamanho médio com largura aproximadamente igual ao comprimento. Lábio coberto de pequenas papilas que aumentam de tamanho em direção à borda externa. Sem fialmentos labiais. Papila bucal central ausente ou pouco desenvolvida. Barbilhões maxilares pequenos. Pré-maxilar e dentário estreitos e alongados. Ângulo de encontro dos dentários quase reto. Dentes do pré-maxilar e do dentário modeiradamente numerosos, alongados, moderadamente robustos e com cúspide lateral grande. Ponta dos dentes pouco curvada.

Nadadeiras peitoral e pélvica alongadas. Pélvica sem mecanismos de trava; margens distais pouco arredondadas. Primeiro raio das nadadeiras peitoral e pélvica conspicuamente espesso. Espinho da nadadeira peitoral coberto por odontódeos hipertrofiados e afiados. Nadadeira peitoral I+6. Extremidade distal da nadadeira peitoral quando adpressa alcançando quase metade do raio indiviso da nadadeira pélvica. Nadadeira pélvica $\mathrm{I}+5$; primeiro raio espesso e suportando odontódeos. Extremidade da nadadeira pélvica quando adpressa 
alcançando a base da nadadeira anal. Nadadeira dorsal com mecanismo de trava com placa pré-dorsal em forma de V (“spinelet"). Nadadeira dorsal I+8, bastante longa; alcança a placa pré-adiposa e se conecta à adiposa por uma espessa membrana. Nadadeira anal $\mathrm{I}+4$, curta. Nadadeira adiposa presente. Nadadeira caudal I+14+I, lobo inferior maior que o superior.

Corpo coberto por cinco fileiras de placas suportando odontódeos. Quilhas ausentes. Quatro a cinco pares de placas pré-dorsais, às vezes pequenas placas ázigas placas pré-dorsais. Placas operculares eversíveis. Opérculo suportando odontódeos desenvolvidos. Cinco a seis raios procorrentes posicionados anteriormente aos raios caudais indivisos. Oito espinhos neurais bífidos sustentando a nadadeira dorsal. Oito vértebras a partir do primeiro espinho neural simples. Vinte e cinco vértebras totais. Bexiga natatória encapsulada e curta, não alcança a sexta vértebra. Canais urogenital e anal em uma única saída tubular.

Sete a oito infra-orbitais. Infra-orbital 4 com pouco contato com a órbita através de sua extremidade posterior. Infra-orbital 6 forma apenas a parte póstero-ventral da órbita. Poros da linha lateral não ultrapassam a placa hipural.

Coloração. Superfície dorsal do corpo e das nadadeiras marrom coberta por grandes pontos brancos. Pontos mais conspícuos e freqüentes nas nadadeiras dorsal e caudal. Cabeça com poucos pontos. Superfície ventral ocre e sem pontos.

Distribuição. Bacia do rio Xingu (Figura 75).

Ecologia. Segundo Zuanon (1999) e Rapp Py-Daniel and Zuanon (2005), Spectracanthicus sp. "bola branca" é uma espécie moderadamente reofílica que é encontrada em áreas com forte correnteza e com fundo de pedras. Os espécimes são encontrados individualmente ou em grupos de três, em refúgios em pedrais ou em espaços debaixo das pedras até $2 \mathrm{~m}$ de profundidade. Os juvenis dividem o refúgio com outros loricaríideos como Ancistrus sp. A. ranunculus, Baryancistrus sp., Spectracanthicus punctatissimus, Hopliancistrus tricornis, Parancistrus nudiventris, Peckoltia vittata e Pseudancistrus aff. barbatus. Spectracanthicus sp. "bola branca" é uma espécie noturna e sua alimentação consiste em raspar algas na superfície das rochas e em outros itens do perifíton. 


\section{Material examinado.}

Brasil, Pará, Xingu: INPA 3957 (5), 20,11-58,76; cachoira de Baituká (1³0'0" S, 51 $53^{\prime} 0^{\prime \prime}$ W); 09/10/1990, L. Rapp Py-Daniel \& J. Zuanon. INPA 3966 (2), 67,08-96,61; Praia do Pedral (1³0'0" S, 5153'0" W); 07/10/1990, L. Rapp Py-Daniel \& J. Zuanon. INPA 4013 (2), ilha de Kaituka (1³0'0" S, 51 ${ }^{\circ} 53^{\prime} 0^{\prime \prime}$ W); 09/10/1990, L. Rapp Py-Daniel \& J. Zuanon. INPA 4030 (3), rio Xingu (1³0'0" S, 5153'0" W); 30/09/1990, L. Rapp Py-Daniel \& J. Zuanon. INPA 4031 (2), 78,2-127,95; rio Xingu (1³0'0" S, 5153'0" W); 05/10/1990, L. Rapp PyDaniel \& J. Zuanon. INPA 4147 (1), 84,96; ilha de Babaquara (1³0'0" S, 51 $\left.{ }^{\circ} 53^{\prime} 0^{\prime \prime} \mathrm{W}\right)$; 05/10/1990, J. A. Zuanon. INPA 25874 (4), 69,94-122,47; rio Xingu, ilha do Sr. Izaltino, pedral ao lado da ilha, margem esquerda $\left(1^{\circ} 30^{\prime} 0^{\prime \prime} \mathrm{S}, 51^{\circ} 53^{\prime} 0^{\prime \prime} \mathrm{W}\right)$; J. A. Zuanon. INPA 25876 (1), 123,08; rio Xingu (130'0" S, 51 $\left.{ }^{\circ} 53^{\prime} 0^{\prime \prime} \mathrm{W}\right)$; INPA 25877 (2), 70,59-129,3; rio Xingu, margem esquerda da ilha do Sr. Izaltino (130'0" S, 51 $\left.{ }^{\circ} 53^{\prime} 0^{\prime \prime} \mathrm{W}\right)$; J. A. Zuanon. INPA 25878 (1), 107,35; rio Xingu ( $\left.{ }^{\circ} 30^{\prime} 0^{\prime \prime} \mathrm{S}, 5^{\circ} 53^{\prime} 0^{\prime \prime} \mathrm{W}\right)$. INPA 25879 (2), 76,9-112,8; rio Xingu (1³0'0" S, 51 53'0" W). INPA 25881 (1) 93,22; Senador José Porfírio, rio Xingu, ilha do Bananal; J. A. Zuanon. INPA 25882 (2), 55,95-82,77; rio Xingu, corredeiras do Arini (1³0' $0^{\prime \prime}$ S, 51 $53^{\prime} 0 "$ W); J. A. Zuanon. INPA 26675 (1), Senador José Porfírio, rio Xingu, porta da ilha Bela Vista; 29/09/1996, J. Zuanon et al. INPA 28545 (2), 27,46-23,79; Costa do Junior, corredor ao redor do acampamento (03 $29^{\circ} 28^{\prime \prime}$ 'S $\left.052^{\circ} 19^{`} 07^{\prime \prime} \mathrm{W}\right)$; 23/09/1997, J. A. Zuanon. INPA 31411 (4), 78,41-92,94; Comunidade do Maia, pedral em frente ao Xingu (03³0 44”'S; 051 44 `43”W); 09/11/2008, L. Rapp Py-Daniel, et al. INPA 31422 (3), 59,32-111,3; cachoeira

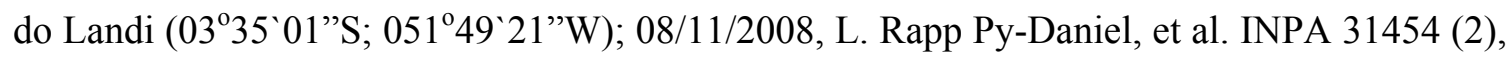
47,58-71,08; Babaquara, gorgulho da Rita (0320`14”S; 052 $\left.{ }^{\circ} 11^{`} 18^{\prime \prime} \mathrm{W}\right)$; 07/11/2008, L. Rapp Py-Daniel, et al. INPA 31455 (6), 41,4-72,4; Babaquara, 45 minutos acima de Altamira (032ㄱ 45”S; 052 $\left.{ }^{\circ} 12 ` 16^{\prime \prime W}\right)$; 07/11/2008, L. Rapp Py-Daniel, et al. INPA 31460 (8), 35,2789,83; Vitória do Xingu, Itaboinha, pedral (03 53 '22”S; $051^{\circ} 56$ 26”W); 04/11/2008, L. Rapp Py-Daniel, et al. INPA 31480 (11), 53,11-126,85; Arroz Cru (0325 20”S; 051 $\left.{ }^{\circ} 57^{\circ} 22^{\prime \prime} \mathrm{W}\right)$; 06/11/2008, L. Rapp Py-Daniel, et al. INPA 31775 (1) 113,05; Altamira, ilha do Davi (0332 39”'S; 051 57 29”W); 01/11/2008, L. Rapp Py-Daniel, et al. INPA 31794 (2), 50,4854,04; Belo Monte, Coqueiro (0306 54”S; 05143`15”W); 05/11/2008, L. Rapp Py-Daniel, et al. MZUSP s/ número (ECIX2010070601) (3) 37,84-95,34; Altamira, gorgulho da Rita, $\left(3^{\circ} 20^{\prime} 26.6^{\prime \prime} \quad \mathrm{S}, \quad 52^{\circ} 11^{\prime} 4.5^{\prime \prime} \mathrm{W}\right) ; \quad 06 / 07 / 2010$, Equipe ECIX. MZUSP s/ número 
(ECIX2010070602) (17) 98,07-41,32; Altamira, ilha de Babaquara, pedral (3²4'10.7" S, $52^{\circ} 12^{\prime} 27^{\prime \prime W}$ ); 06/07/2010, Equipe ECIX. MZUSP s/ número (ECIX2010070702) (1) 80,36; Altamira, localidade de Jericoá, próximo à cachoeira do Mucura e a jusante do rancho do

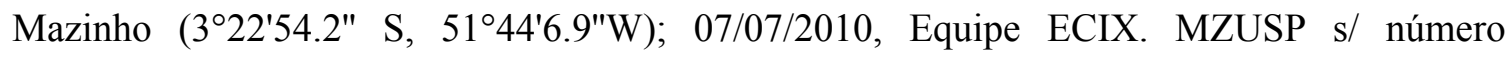
(ECIX2010070701) (3) 59,44-86,06; Altamira, localidade de Jericoá, próximo à cachoeira do Mucura e a jusante do rancho do Mazinho (3²4'51.8" S, 5144'23"W); 07/07/2010, Equipe ECIX. Sem dados de localidade: MHNG 2578.027 (1) 81,8; Altamira (?), inported Belém; D. Fisher. MHNG 2.680 .014 (1) 79,89; import aquariphile, Brésil; R, Covan. MHNG 2684.026 (2) 62,23-66,64; import aquariphile, Brésil; R, Covan.

\section{Spectracanthicus sp. "Tocantins"}

(Figura 71, Tabela17)

Diagnose. Spectracanthicus sp."tocantins" pode ser distinguido dos seus congêneres (exceto Spectracanthicus sp. "Tapajós" e S. murinus) pelo perfil pontudo do focinho; e pelo menor número de dentes no dentário, oito a 16 (vs. 21 a 43 em Spectracanthicus sp. "bola branca", 21 a 30 em S. puncatatissimus). De Spectracanthicus sp. "Tapajós" difere pelo padrão de coloração com pontos pequenos e amarelos no corpo e nadadeiras (vs. sem pontos) e pelos dentes robustos (vs. finos, exceto em $S$. murinus). Outros caracteres considerados sinapomórficos para a espécie são: IO4 bastante contato com a órbita através de sua extremidade posterior (vs. contato do IO4 com a órbita ausente ou reduzido); fenestra anterior à seção cartilaginosa do basipterígio grande (vs. média nas demais espécies do gênero, exceto em Spectracanthicus sp. "Tapajós”); hipurapófise com tamanho médio (vs. baixo); espaço entre o lobo hipural inferior e o último espinho hemal ausente ou pequeno (vs. grande).

Descrição. Dados morfométricos e merísticos na Tabela 17. Perfil dorsal entre ponta do focinho e região anterior do processo supra-occipital pouco curvado. Restante do perfil dorsal ligeiramente reto, até placa pré-dorsal. Perfil pós-dorsal do corpo robusto. Pedúnculo caudal robusto. Maior altura do corpo na origem da nadadeira dorsal. Menor altura do corpo na região 
do pedúnculo caudal. Maior largura do corpo igual largura cleitral. Perfil ventral da ponta do focinho até a base da nadadeira caudal reto. Região abdominal e torácica sem placas.

Cabeça alta, focinho prolongado anteriormente. Focinho recoberto por pequenas placas, exceto pequena área nua na extremidade distal. Perfil dorsal do focinho arredondado. Nasal alongado, em forma de 'L'. Frontal pouco alongado com pequeno contato com narina anteriormente e com a órbita lateralmente. Margem anterior do frontal curta, limitada a margem posterior ou alcança a metade do comprimento da narina. Supra-occiptal curto com extremidade posterior com projeção curta sem crista. Esfenótico curto, sem contato com o IO6, sem odontódeos conspícuos. Pterótico-supracleitro curto e pouco fenestrado. Processo anterior do pterótico-supracleitro com grande contato com a margem posterior da órbita. Área posterior ao pterótico-supracleitro com uma placa média. Olhos medianos e súpero-laterais com íris em forma de meia lua.

Lábios de tamanho médio com largura aproximadamente igual ao comprimento. Lábio coberto de pequenas papilas que aumentam de tamanho em direção à borda externa. Sem fialmentos labiais. Papila bucal central ausente ou pouco desenvolvida. Barbilhões maxilares pequenos. Pré-maxilar e dentário estreitos e alongados. Ângulo de encontro dos dentários quase reto. Dentes do pré-maxilar e do dentário modeiradamente numerosos, alongados, moderadamente robustos e com cúspide lateral grande. Ponta dos dentes pouco curvada.

Nadadeiras peitoral e pélvica alongadas. Pélvica sem mecanismos de trava; margens distais pouco arredondadas. Primeiro raio das nadadeiras peitoral e pélvica conspicuamente espesso. Espinho da nadadeira peitoral coberto por odontódeos hipertrofiados e afiados. Nadadeira peitoral I+6. Extremidade distal da nadadeira peitoral quando adpressa alcançando quase metade do raio indiviso da nadadeira pélvica. Nadadeira pélvica $\mathrm{I}+5$; primeiro raio espesso e suportando odontódeos. Extremidade da nadadeira pélvica quando adpressa alcançando a base da nadadeira anal. Nadadeira dorsal com mecanismo de trava com placa pré-dorsal em forma de V (“spinelet"). Nadadeira dorsal I+8, bastante longa, alcança a placa pré-adiposa e se conecta à adiposa por uma espessa membrana. Nadadeira anal $\mathrm{I}+4$, curta. Nadadeira adiposa presente. Nadadeira caudal I+14+I, lobo inferior maior que o superior.

Corpo coberto por cinco fileiras de placas suportando odontódeos. Quilhas ausentes. Quatro a cinco pares de placas pré-dorsais, às vezes pequenas placas ázigas placas pré-dorsais. Placas operculares eversíveis. Opérculo suportando odontódeos desenvolvidos. Cinco a seis 
raios procorrentes posicionados anteriormente aos raios caudais indivisos. Oito espinhos neurais bífidos sustentando a nadadeira dorsal. Sete vértebras a partir do primeiro espinho neural simples. Vinte e sete vértebras totais. Bexiga natatória encapsulada e curta, não alcança a sexta vértebra. Canais urogenital e anal em uma única saída tubular.

Sete a oito infra-orbitais. Infra-orbital 4 com bastante contato com a órbita através de sua extremidade posterior. Infra-orbital 6 forma apenas a parte póstero-ventral da órbita. Poros da linha lateral não ultrapassam a placa hipural.

Coloração. Superfície dorsal do corpo e nadadeiras marron escuro com pequenos a medianos pontos espalhados. Superfície ventral marrom claro com pequenos cromatófaros espalhados.

Distribuição. Bacia do rio Tocantins (Figura 75).

\section{Material examinado.}

Brasil, Pará, Tocantins: INPA 6045 (7), 43,13-76,93; poço d'’agua a jusante de Tucuruí; 09/10/1984, Equipe Ictiologia INPA. INPA 6049 (1) 61,81; Tucuruí, rio Tocantins; 05/07/1982, Equipe Ictiologia INPA. INPA 6050 (1) 62,86; Tucuruí, rio Tocantins; 17/07/2008, Equipe Ictiologia INPA. INPA 2990 (140), 16,27-92,9; rio Tocantins, a jusante da represa da UHE de Tucuruí $\left(03^{\circ} 45^{`} 58^{\prime}\right.$ 'S, $049^{\circ} 40 ` 21$ ”W); 31/08/1984, Equipe Ictiologia INPA. INPA 11133 (2), 78,3-86,29; Tucuruí rio Tocantins01/09/1981, Equipe Ictiologia INPA. MNRJ 19359 (29), 60,86-82,67 mm CP; rio Tocantins, próximo a cidade de Tucuruí. MNRJ 19347, 175 ex., 35,97-85,35 mm CP; rio Tocantins, próximo a cidade de Tucuruí; MNRJ 19373 (7), rio Tocantins, próximo da cidade de Tucurui; 15/09/1999, L. C. Alvarenga. FMNH 95555 (1), 64,0; Jatobal, lagoa em frente à Jatobal (04³4’S 49³9’W); 16/09/1970, Expedição Permanente à Amazônia. MZUSP 24125 (7, 1 c\&s); 56,43-74,02; Jatobál, lagoa em frente a Jatobal $\left(049^{\circ} 39^{\prime} 00^{\prime \prime} \mathrm{W}, 04^{\circ} 34^{\prime} 00^{\prime \prime S}\right) ; 16 / 09 / 1970$, Expedição permanente à Amazônia. MZUSP 34265 (12, 1 c\&s) 72,0-38,71; Carreira Comprida, rio Itacaiunas (05 $\left.22^{\circ} \mathrm{S} 49^{\circ} 07^{\prime} \mathrm{W}\right)$; 14/10/1983, M. Goulding. MZUSP 39927 (1), 64,47; Jatobal, lagoa em frente à Jatobal (04³4’S 49³9’W); 16/09/1970, Expedição Permanente à Amazônia. 


\section{Spectracanthicus sp. "Tapajós"}

(Figura 72 e 74, Tabela 18)

Diagnose. Spectracanthicus sp. "Tapajós" pode ser distinguido dos seus congêneres (exceto Spectracanthicus sp. "Tocantins" e S. murinus) pelo perfil pontudo do focinho em vista dorsal e pelo padrão de coloração marrom escuro sem pontos ou manchas (vs. com pontos pequenos claros em S. murinus, S. punctatissimus e Spectracanthicus sp. "Tocantins"; e manchas grandes brancos em Spectracanthicus sp. "bola branca") e pelos dentes bastante finos (vs. maderadamente finos em S. punctatissimus e Spectracanthicus sp. "bola branca"; e robustos em Spectracanthicus sp. “Tocantins”). Outras sinapomorfias da espécie são: etmóide lateral retangular com expansão lateral curta ou ausente (vs. triangular com expansão ventro-lateral desenvolvida); nasal quadrangular, moderadamente alongado (vs. nasal alongado em forma de L); processo anterior do pterótico-supracleitro sem contato com a margem posterior da órbita (vs. grande contato com a órbita em S. murinus e pequeno contato nas demais espécies); expansão laminar posterior do EB4 ausente ou bastante curta (vs. presente ou curta); processo ventral do VCW aproximadamente retangular (vs. aproximadamente circular); área cartilaginosa do basipterígio curta (vs. alongada nas demais espécies, exceto em S. тиrinus); fenestra anterior à seção cartilaginosa grande (vs. pequena a média nas demais espécies, exceto em Spectracanthicus sp. "Tocantins").

Descrição. Dados morfométricos e merísticos na Tabela 18. Perfil dorsal entre ponta do focinho e região anterior do processo supra-occipital pouco curvado. Restante do perfil dorsal ligeiramente reto, até placa pré-dorsal. Perfil pós-dorsal do corpo robusto. Pedúnculo caudal robusto. Maior altura do corpo na origem da nadadeira dorsal. Menor altura do corpo na região do pedúnculo caudal. Maior largura do corpo igual largura cleitral. Perfil ventral da ponta do focinho até a base da nadadeira caudal reto. Região abdominal e torácica sem placas.

Cabeça alta, focinho prolongado anteriormente. Focinho recoberto por pequenas placas, exceto pequena área nua na extremidade distal. Perfil dorsal do focinho arredondado. Nasal quadrangular, pouco alongado. Frontal pouco alongado com pequeno contato com narina anteriormente e com a órbita lateralmente. Margem anterior do frontal curta, limitada a margem posterior ou alcança a metade do comprimento da narina. Supra-occiptal curto com 
extremidade posterior com projeção curta sem crista. Esfenótico curto, em contato com o IO6, sem odontódeos conspícuos. Pterótico-supracleitro curto e pouco fenestrado. Processo anterior do pterótico-supracleitro sem contato com a margem posterior da órbita. Área posterior ao pterótico-supracleitro com uma placa média. Olhos pquenos e súpero-laterais com íris em forma de meia lua.

Lábios de tamanho médio com largura aproximadamente igual ao comprimento. Lábio coberto de pequenas papilas que aumentam de tamanho em direção à borda externa. Sem fialmentos labiais. Papila bucal central ausente ou pouco desenvolvida. Barbilhões maxilares pequenos. Pré-maxilar e dentário estreitos e alongados. Ângulo de encontro dos dentários quase reto. Dentes do pré-maxilar e do dentário modeiradamente numerosos, alongados, finos e com cúspide lateral grande. Ponta dos dentes pouco curvada.

Nadadeiras peitoral e pélvica alongadas. Pélvica sem mecanismos de trava; margens distais pouco arredondadas. Primeiro raio das nadadeiras peitoral e pélvica conspicuamente espesso. Espinho da nadadeira peitoral coberto por odontódeos hipertrofiados e afiados. Nadadeira peitoral I+6. Extremidade distal da nadadeira peitoral quando adpressa alcançando quase metade do raio indiviso da nadadeira pélvica. Nadadeira pélvica $\mathrm{I}+5$; primeiro raio espesso e suportando odontódeos. Extremidade da nadadeira pélvica quando adpressa alcançando a base da nadadeira anal. Nadadeira dorsal com mecanismo de trava com placa pré-dorsal em forma de V ("spinelet"). Nadadeira dorsal I+8, bastante longa, alcança a placa pré-adiposa e se conecta à adiposa por uma espessa membrana. Nadadeira anal I+4, curta. Nadadeira adiposa presente. Nadadeira caudal $\mathrm{I}+14+\mathrm{I}$, lobo inferior maior que o superior.

Corpo coberto por cinco fileiras de placas suportando odontódeos. Quilhas ausentes. Quatro a cinco pares de placas pré-dorsais, às vezes pequenas placas ázigas placas pré-dorsais. Placas operculares eversíveis. Opérculo suportando odontódeos desenvolvidos. Cinco a seis raios procorrentes posicionados anteriormente aos raios caudais indivisos. Seis espinhos neurais bífidos sustentando a nadadeira dorsal. Nove vértebras a partir do primeiro espinho neural simples. Vinte e sete vértebras totais. Bexiga natatória encapsulada e curta, não alcança a sexta vértebra. Canais urogenital e anal em uma única saída tubular.

Sete a oito infra-orbitais. Infra-orbital 4 com bastante contato com a órbita através de sua extremidade posterior. Infra-orbital 6 forma apenas a parte póstero-ventral da órbita. Poros da linha lateral não ultrapassam a placa hipural. 
Coloração. Superfície dorsal do corpo e nadadeiras marron a cinza escuro sem pontos ou manchas. Superfície ventral ocre a marrom claro.

Distribuição. Bacia do rio Tapajós, na região de Itaituba e Pimental (Figura 74).

\section{Material examinado.}

Holótipo: MZUSP 92797 (h), 63,8; Brasil, Pará, Itaituba, rio Tapajós, nos arredores de Itaituba (pegos pelo pescador de peixes ornamentais "Chiquinho"). 07/11/2006, L. M. Sousa \& J. L. Birindelli.

Brasil, Pará, Tapajós: MZUSP 92617 (11), 38,23-82,24; Itaituba peixes pegos por pescadores de peixes ornamentais no rio Tapajós na região de Itaituba e Pimental; 08/11/2006, L. M. Sousa \& J. L. Birindelli. 


\section{REFERÊNCIAS BIBLIOGRÁFICAS}

Agassiz, L. in Spix, J.B. and L. Agassiz, 1829. Selecta genera et species piscium quos in itinere per Brasiliam annos MDCCCXVII-MDCCCXX jussu et auspiciis Maximiliani Josephi I. colleget et pingendso curavit Dr J.B. de Spix. Monachii. Selecta Piscium Brasiliam: Part 1:I-xvi +I-ii +1-82, Pls. 1-48.1829.

Alexander R. M. 1964. The structure of the Weberian apparatus in the Siluri. Proccedings of the Zoological Society of London, 142: 419-440.

Alexander R. M. 1965. Structure and functions in the catfishes. Journal of Zoology, 148: 88152.

Armbruster, J. W. 1997. Phylogenetic relationships of the suckmouth armoured catfishes (Loricariidae) with emphasis on the Ancistrinae, Hypostominae and Neoplecostominae. Unpublished Ph.D. Thesis. University of Illinois at Urbana-Champaing. 405 p.

Armbruster, J. W. 2002. Hypancistrus inspector: a new species of suckermouth armored catfish (Loricariidae: Ancistrinae). Copeia 2002 (no. 1): 86-92.

Armbruster, J. W. 2003. Peckoltia sabaji, a new species from Guiana Shield (Silurifomes: Loricariidae). Zootaxa 334: 1-12.

Armbruster, J. W. 2004. Phylogenetic relationships of the suckmouth armoured catfishes (Loricariidae) with emphasis on the Hypostominae and the Ancistrinae. Zool. Jounal Linn. Soc. 141: 1-80.

Armbruster, J. W. 2008. The genus Peckoltia with the description of two new species and a reanalysis of the phylogeny of the genera of the Hypostominae (Siluriformes: Loricariidae). Zootaxa 1822: 1-76.

Arratia. G. 1990. Development and Diversity of the Suspensorium of Trichomycterids and comparison with Loricariioid (Teleostei: Siluriformes). Journal of Morphology, 205: 193-218.

Arratia G. 1992. Development and variation of the suspensorium of primitive Catfishes (Teleostei: Ostariophysi) and their phylogenetic relationships. Bonner Zoologische Monographien, 32: 1-149.

Arratia G. \& L. Huaquin. 1995. Morphology of the lateral line system and the skin of diplomystid and certain primitive loricarioid catfishes and systematic and ecological considerations. Bonner Zoologische Monographien, 36: 5-109.

Baskin, J. N. 1973. Structure and relationships of the Trichomycteridae. Unpublished PhD Dissertation, City University of New York. 389 p. 
Bertin, L. \& R. Estève. 1950. Catalogue des types de poissons du muséum National d'Histoire Naturelle. 5e partie. Ostariophysaires (Siluriformes). Imp. Nationale, Paris. Catalogue des types de poissons du Muséum National d'Histoire Naturelle. 4e partie. 5e partie: 185.

Bhatti, H. K. 1938. The integument and dermal skeleton of Siluroidea. Transcritions of the Zoological Society of London, 24(1): 1-122.

Bleeker, P. 1862-63. Atlas Icthyologique des Indes Orientales Néêrlandaises, publié sous les auspices du Gouvernement colonial néêrlandais. Tome II. Siluroïdes, Chacoïdes et Hétérobranchoïdes. Amsterdan. 112 p., pls. 49-101.

Boeseman, M. 1968. The genus Hypostomus Lacépède, 1803, and its Surinam representatives (Siluriformes, Loricariidae). Zoologische Verhandelingen, 99: 1-89.

Boeseman, M. 1971. The comb-toothed Loricariinae of Surinam, with reflections on the phylogenetic tendencies within the family Loricariidae (Siluriformes, Siluroidei). Zoologische Verhandelingem, 116: 156.

Boeseman, M. 1972. Notes on South American catfishes, including remarks on Valenciennes and Bleeker types in the Leiden Museum. Zoologische Mededelingen (Leiden) v. 47 (no. 23): 293-320, Pls. 1-2.

Böhlke, E. B.1984. Catalog of type specimens in the ichthyological collection of the Academy of Natural Sciences of Philadelphia. Spec. Publ. 14: i-viii + 1-246 Spec. Publ. 14: i-viii + $1-246$.

Boulenger, G. A. 1885. Abstract of a report on a large collection of fishes formed by Dr. C. Ternetz in Matto Grosso and Paraguay, with descriptions of new species. Proc. Zool. Soc. London, 1885 (pt 3): 523-529.

Bremer, K. 1988. The limits of amino acid sequence data in angiosperm phylogenetic reconstruction. Evolution, 42: 795-803.

Bremer, K. 1994. Branch support and tree stability. Cladistics, 10: 295-304.

Britto, M. R. 2002. Análise filogenética da ordem Siluriformes com ênfase nas relações de Loricarioidea (Teleostei: Ostariophysi). Tese de Doutorado não publicada. Universidade de São Paulo, 511 p.

Britski, H. A.; K. Z. de Sz. de Silimon, and B. S. Lopes. 1999. Peixes do Pantanal. Manual de identificaçao. Embrapa. Serviçao de Produçal -SPI, Brasía, DF. Peixes do Pantanal. Manual de identificaçao.: 1-184 
Britski, H. A. , K. Z. de Sz. de Silimon, and B. S. Lopes. 2007. Peixes do Pantanal. Manual de identificaçao. Segunda edição revista e ampliada. Brasía, DF: Embrapa Informação Tecnológica. 1-230.

Burgess, W. E. and L. Finley. 1996. An atlas of freshwater and marine catfishes: Update. Tropical Fish Hobbyist Oct. 1996: 163-174.

Capello, F. B. 1870. Noticia ácerca de um peixe pouco conhecido proveniente do Brasil. J. Sci. Math. Phys. Nat. Lisboa, 2 (3): 64-69, pl.7.

Castelnau, F. L. 1855. Poissons. In: Animaux noveaux ou rares recueillis pendant l'expédition dans les parties centrales de l'Amérique du Sud, de Rio de Janeiro a Lima, at de Lima au Para; exécutée par ordre du gouvernement Français pedant les annéss 1843 a 1847. xii + 112 p., pls. 1-50.

Chamon, C. C. 2007. Revisão taxonômica e relações filogenéticas do gênero Leporacanthicus Isbrücker \& Nijssen, 1989 (Siluriformes, Loricariidae). Dissertação de mestrado não publicada. Universidade de São Paulo. 230 p.

Chardon, M. 1968. Anatomie compare de l'appareil de Weber et des structures connexes chez les Siluriformes. Musée Royal de l'ÁArique Centrale, Annales, Série 8, Sciences Zoologiques, 169: $277 \mathrm{p}$.

Cracraft, J. 1983. Species concepts and speciation analysis. Current Ornithology, 1: 159-187.

Cracraft, J. 1987. Species concepts and the ontology of evolution. Biological Philosophy, 2: 239-246.

Cuvier, G. \& A. Valenciennes. 1840. Historie naturalle des poissons. Tome quinzième. Suite du livre dix-sepitème. Siluroïdes. Ch. Pitois \& V. ${ }^{\mathrm{c}}$ Levrault, paris \& Strasbourg. Xxxi + 540p., pls. 421-455.

Devincenzi, G. J. 1933. Sobre um raro ejemplar del Amazonas (Acanthicus hystrix Spix). Notas Ictiolígicas. Anales do Museó de Montevidéo (2) vol.4. 7p.

Eigenmann, C. H. \& R. S. Eigenmann. 1889. Preliminary notes on South American Nematognathi. II. Proceedings of the California Academy of Sciences (Series 2) v. 2: 2856. [Separate issued 18 Aug. 1889.]

Eldredge, N. \& J. Cracraft. 1980. Phylogenetic Patterns and the evolutionary process. Columbia University Press, New York.

Eschmeyer, W. N. 1998. Catalog of fishes. California Academy of Science. Vol. 1: 1-958. 
Farris, J. S. 1982. Outgroups and parsimony. Systematic Zool. 31: 328-334.

Fernandez-Yepez, A. 1949. La presencia de Acanthicus hystrix Spix en la hoya del Rio Orinoco. Evidencias. Contribuiciones ocasionales de la coleccion ictiológica de Agustín Fernandez-Yepez. Cumaná, Apartado, Venezuela. No. 9. 4p.

Ferraris, C. J., Jr. 2003. Auchenipteridae, Piumelodidae, Aspredinidae, and Loricariidae. Pp. 853-865. In: Carpenter 2003. The living marine resources of the Western Central Atlantic. v. 2.

Ferraris, C. J., Jr. 2007. Checklist of catfishes, recent and fossil (Osteichthyes: Siluriformes), and catalogue of siluriform primary types. Zootaxa No. 1418: 1-628.

Ferreira, E; Zuanon, J.; Forsberg, B.; Goulding, M. \& Briglia-Ferreira, S. R. 2007. Rio Branco. Peixes, Ecologia e Conservação de Roraima. Amazon Conservation Association (ACA); Instituto Nacional de Pesquisas da Amazônia (INPA); Sociedade Civil Mamirauá. 201 p.

Fink, S. V \& W. L. Fin. 1981. Interrelationships of the ostariophysian fishes (Teleostei). Zoological Journal of Linnean Society, 72: 297-353.

Fisch-Muller, S. in Reis, R. E., S. O. Kullander \& C. J. Ferraris, Jr. 2003. Check list of the freshwater fishes of South and Central America. CLOFFSCA. 2003: i-xi + 1-729.

Fowler, H. W. 1914. Fishes from the Rupununi River, British Guiana. Proc. Acad. Nat. Sci. Philadelphia, 66: 229-284.

Ghazzi, M. S. 2003. Relações filogenéticas e revisão do gênero Sturisoma Swainson, 1838 (Siluriformes: Loricariidae: Loricariinae). Tese de doutorado não publicada. Universidade de São Paulo,

Goloboff, P. A., Farris, J. \& K. Nixon. 2003. TNT. Tree Analysis Using New Technology.

Gómez, S. E. and J. C. Chebez. 1996. Peces de la provincia de Misiones. Chapter 4 in J. C. Chebez: Fauna Misionera. Catálogo sistemático y zoogeográfico de los vertebrados de la Provincia de Misiones (Argentina). L.O.L.A., Buenos Aires. Peces de la provincia de Misiones.: 38-70 + Addenda 315-316.

Gosline, W. A. 1945. Catálogo dos nematognatos de água doce da América do Sul e Central. Bol. Do Museu Nacional (33): 1-138.

Gosline, W. A. 1947. Contributions to the classification of the loricariid catfishes. Arquivos do Museu Nacional do Rio de Janeiro, 41: 79-134. 
Graça, W. J. \& Pavanelli, C. S. 2007. Peixes da Planície de inundação do alto rio Paraná e áreas adjacentes. Maringá: EDUEM, 241p.

Günther, A. 1868b. Descripitions of some freshwaters fishes from Suriname and Brazil. Proc. Zool. Soc. London, 1868 (2): 229-247, pls. 20-22.

Harvey, P. H., A. J. L. Brbrown, J. M. Smith \& S. Nee. 1996. New uses for new phylogenies. Oxford University Press, Oxford, xi +349 pp.

Heitmans, W. R. B., H. Nijssen, and I. J. H. Isbrücker. 1983. The mailed catfish genus Lasiancistrus Regan, 1904, from French Guiana and Surinam, with descriptions of two new species (Pisces, Siluriformes, Loricariidae). Bijdragen tot de Dierkunde v. 53 (no. 1): $33-48$.

Hennig, W. 1966. Phylogenetic Systematics. University of Illinois Press. Urbana, 263 pp.

Howes, G. J. 1983. The cranial muscles of loricarioid catfishes, their homologies and value as taxonomic characters (Teleostei: Siluroidei). Bulletin of the Britsh Museum of Natural History, Zoology series, 45 (6): 309-345.

Isbrücker, I. J. H. 1980. Classification and catalogue of the mailed Loricariidae (Pisces, Siluriformes). Versl. Techn. Gegevens, Univ. van Amsterdam No22, Amsterdam, The Netherlands.

Isbrücker, I. J. H. 2001. Nomenklator der gattungen und Arten der Harnischwelse, familie Loricariidae Rafinesque, 1815 (Teleostei, Ostariophysi), P. 25-32. In: R. Stawikowski (ed.), Harnischwelse. Die Aquarien-und Terrarienzeitschrift, Sonderheft, Eugen Ulmer Stuttgart.

Isbrücker, I. J. H. 2002. Nomenclator of the 108 genera with 692 species of the mailed catfishes, family Loricariidae Rafinesque, 1815 (Teleostei, Ostariophysi). Cat Chat, Journal of the catfish study group (UK) v. 3 (no. 1). 11-30.

Isbrücker, I. J. H. \& H. Nijssen, 1988. Acanthicus adonis, ein neuer Harnischwels aus dem Rio Tocantins, Brasilien (Pisces, Siluriformes, Loricariidae). Aquar. Terrar. Z., 41 (6): 164-167

Isbrücker, I. J. H. \& H. Nijssen, 1989. Diagnose dreier neuer Harnischwelsgattungen mit fünf neuen Arten aus Brasilien (Pisces, Siluriformes, Loricariidae). Aquar. Terrar. Z. 541-547

Isbrücker, I. J. H. and H. Nijssen. 1991. Hypancistrus zebra, a new genus and species of uniquely pigmented ancistrine loricariid fish from the Rio Xingu, Brazil (Pisces: Siluriformes: Loricariidae). Ichthyological Exploration of Freshwaters v. 1 (no. 4): 345350.

Isbrücker, I. J. H., Nijssen, H. \& L. G. Nico. 1992. Ein neuer Rüsselzahnwels aus oberen Orinoco-Zuflüssen in Venezuela und Kolumbien: Leporacanthicus triactis n. sp, (Pisces, Siluriformes, Loricariidae). Aquar. Terrar. Z. 1-5. 
Jordan, D. S. 1920. The genera of fishes, part IV, from 1881 to 1920, thirty-nine years, with the accepted type of each. A contribution to the stability of scientific nomenclature. Leland Stanford Jr. University Publications, University Series No. 43: 411-576 + i-xviii.

Kitching, I. J., P. L. Forey, C. J. Humphries \& D. M. Willians. 1998. Cladistic - The theory and pratice of parsimony analysis. Oxford University Press, Oxford, xiii +228 pp.

Kner, R.1853. Die Hypostomiden. Zweite Hauptgruppe der familie der Panzerfische. (Loricata vel Goniodontes). Denkschr. Akad. Wiss. Wien, 7: 251-286, pls. 1-5.

Kottelat, M. 1988. Authorship, dates of publication, status and types of Spix and Agassiz's Brazilian fishes. Spixiana, 11: 69-93.

Lacépède, B. G. E de la Ville. 1803. Historie naturalle des poisons, dédiée à Anne-Caroline La Cepède. P. Plassan, Paris. 5(1): 1-803.

Lauder, G. V. \& K. F. Liem. 1983. The evolution and interrelationships of the actinopterygian fishes. Bulletin of the Museum of Comparative Zoology, 150: 95-197.

Le Bail, P. Y.; Keith, P \& Planquete, P. 2000. Atlas des poissonsmdéau douce de Guyane. Tome 2. fasciculeII: Siluriformes. Patrimoines naturels (M.N.H.N./S.P.N.), 43(II): 307p. (pág. 250 (descrição, biologia e distribuição).

Linnaeus, C., 1758. Systema naturae per regna tria naturae, secundum classes, ordinus, genera, species, cum characteribus, differentiis, synonymis, locis. Tomus I. Editio decima, reformata. Impensis Direct. Laurentii Salvii, Holmiae. 824 p.

Linnaeus, C., 1766. Systema naturae per regna tria naturae, secundum classes, ordinus, genera, species, cum characteribus, differentiis, synonymis, locis. Tomus I. Editio duodecima, reformata. Impensis Direct. Laurentii Salvii, Holmiae. 532 p.

López, H. L., A. M. Miquelarena, and R. C. Menni. 2003. Lista comentada de los peces continentales de la Argentina. ProBiotA -- Serie Técnica y Didáctica. No. 5: 1-85.

Lujan, N. K., M. Arce, and J. W. Armbruster. 2009. A new black Baryancistrus with blue sheen from the upper Orinoco (Siluriformes: Loricariidae). Copeia 2009 (no. 1): 50-56.

Lundberg, J. G. 1970. The evolutionary history of the North American catfishes family Ictaluridae. Tese de doutorado não publicada. The University of Michigan, Ann Arbor, xiii $+524 \mathrm{p}$.

Maddison, W. P. \& D. R. Maddison. 2006. Mesquite. A modular system for evolutionary analysis, version 1.11 released. 
Menni, R. C. 2004. Peces y ambientes en la Argentina continental. Monografías del Museo Argentina Ciencias Natureles, Buenos Aires No. 5: 1-316.

Montoya-Burgos, J.-I., S. Muller, C. Weber and J. Pawlowski, 1998. Phylogenetic relationships of the Loricariidae (Siluriformes) based on mitochondrial rRNA gene sequences. p. 363-374. In L.R. Malabarba, R.E. Reis, R.P. Vari, Z.M.S. Lucena and C.A.S. Lucena (eds.) Phylogeny and classification of neotropical fishes. Porto Alegre: EDIPUCRS.

Muller S. \& C. Weber, 1992. Les dents des sous-familles Hypostominae et Ancistrinae (Pisces, Siluriformes, Loricariidae) et leur valeur taxonomique. Revue Suisse Zoologie, 99(4): 747-754.

Nelson, 2006.

Nelson, G. J. 1969. Gill arches and the phylogeny of fishes, with notes on the classification of vertebrates. Bulletin of the American Museum of Natural History, 141 (4): 477-552, plates 79-92.

Nelson, G. J. \& Platinik, N. I. 1981. Systematic and Biogeography: Cladistics and Vicariance. Columbia University Press, New York.

Nixon, K. C., 1999. The Parsimony Ratchet, a New Method for Rapid Parsimony Analysis. Cladistics, 15: 407-414.

Nixon, K. C. \& J. M. Carpenter, 1993. On Outgroups. Cladistics, 9: 413-426.

Ortega, H. and R. P. Vari. 1986. Annotated checklist of the freshwater fishes of Peru. Smithsonian Contributions to Zoology No. 437: iii +25 p.

Paixão, A. C. 2004. Revisão taxonômica e análise filogenética das espécies de Lamonthichthys Miranda-Ribeiro, 1939. Dissertação de Mestrado não publicada. Universidade de São Paulo, 268 p.

Perugia, A. 1891. Appunti sopra alcuni pesci sud-americacani conservati nel Museo Civico de Storia naturale di Genova. Ann. Mus. Civ. Sto. Nat. Genova (Ser. 2a), 10: 605-657.

Peters, W. 1881. Über vier neue fische. Sitzungsber. Ges. Naturf. Freunde Berlin, 1881: 17-19.

Peyer, B. 1922. Über die Flossenstalchen der Welse und Panzerwelse, sowie des Karpfens. Morphologisches Jahrbuch, 51: 495-554. 
de Pinna, M. C. C. 1991. Concepts and tests of homology in the cladistic paradigm. Cladistics, 7: $367-394$

de Pinna, M. C. C. 1993. Higher-level phylogeny of Siluriformes, with a new classification of the order (Teleostei, Ostariophysi). Unpublished $\mathrm{PhD}$ dissertation. City University of New York, 482 p.

de Pinna, M. C. C. 1996. A phylogenetic analysis of the Asian catfish families Sisoridae, Akysidae and Amblycipitidae, with a hypothesis on the relationships of the Neotropical Aspredinidae (Teleostei, Ostariophysi). Fieldiana, 1478: 1-83.

de Pinna, M. C. C. 1998. Phylogenetic relationships of neotropical Siluriformes (Teleostei: Ostariophysi): historical overview and synthesis of hypotheses. Pp. 279-330. In: Malabarba et al. 1998.

de Pinna, M. C. C., 1999. Species concepts and phylogenetics. Reviews in Fish Biology and Fisheries, 9: 353-373.

Rapp Py-Daniel, L. H. 1989. Redescription of Parancistrus aurantiacus (Castelnau, 1855) and preliminary establishment of two new genera: Baryancistrus and Spectracanthicus (Siluriformes, Loricariidae). Cybium, 13 (3): 235-246.

Rapp Py-Daniel, L. H. 1997. Phylogeny of the neotropical armored catfishes of the subfamily Loricariinae (Siluriformes, Loricariidae). Unpublished PhD. Thesis, University of Arizona. 280 p.

Rapp Py-Daniel, L. H. \& C. Cox Fernandes. 2005. Dimorfismo sexual em Siluriformes e Gymnotiformes (Ostariophysi) da Amazônia. Acta Amazônica, 35(1) 2005: 97 - 110.

Rapp Py-Daniel, L. H. \& Zuanon, J. A. 2005. (2005). Description of a new species of Parancistrus (Siluriformes: Loricariidae) from the rio Xingu, Brazil. Neotropical Ichthiology, 3 (4): 571-577.

Regan, C. T. 1904. A monograph of the fishes of the family Loricariidae. Trans. Zool. Soc. London, 17 (3, no 1): 191-350, pls. 9-21.

Reis, R. E, Kullander, S. \& Ferraris, 2003. Check List of the Freshwater Fishes of South and Central America. 729p.

Reis, R. E.; Pereira, E. H. L. \& J. W. Armbruster. 2006. Delturinae, a new loricariid catfish subfamily (Teleostei, Siluriformes), with revisions of Delturus and Hemipsilichthys. Zoological Journal of Linnean Society, 147: 277-299. 
Reis, R. E. \& S. A. Schaefer. 1998. New cascudinhos from Southern Brazil: Systematics, Endemism, and Relationships (Siluriformes, Loricariidae, Hypoptopomatinae). Am. Mus. Novit. 3254, 25 pp.

Santos, G. M., Jegu, M. \& Merona, B. 1984. Catálogo de peixes comerciais do baixo rio Tocantins; projeto Tucuruí. Manaus, ELETRONORTE/CNPq/INPA. Vol.1 83p.

Santos, G. M., Merona, B. Juras, A. A. \& Jegu, M. 2004. Peixes do Baixo Rio Tocantins: 20 anos depois da Usina Hidrelétrica Tucuruí. Brasília: Eletronorte. 216p.

Schaefer, S. A. 1987. Osteolology of Hypostomus plecostomus (Linnaeus), with a filogenetic analysis of the loricariid subfamilies (Pisces, Siluroidei). Cont. Sci. Nat. Hist. Mus. Los Angeles Co., 394: 1-31.

Schaefer, S. A. 1988. Homology and evolution of the opercular series in the loricarioid catfishes (Pisces: Siluroidei). Journal of Zoology, 214: 81-93.

Schaefer, S. A. 1997. The Neotropical cascudinhos: systematics ans biogeography of the Otocinclus catfishes (Siluriformes; Loricariidae). Proc. Acad. Nat. Sci. Philadelphia, 148:1-120.

Schaefer, S. A. \& G. V. Lauder. 1986. Historical transformation of function design: evolutionary morphology of feeding mechanisms in loricarioid catfishes. Systematic Zoology, 35 (4): 489-508.

Seidel, I. 1996. Neue Zuchterfolge in der Sparte Welse. BSSW Report, Nr.3/96: 23-30.

Steindachner, F. 1881. Beiträge zur Kenntniss der Flussfische Südamerika's. II. Denkschriften der Mathematisch-Naturwissenschaftlichen Classe der Kaiserlichen Akademie der Wissenschaften in Wien v. 43: 103-146, Pls. 1-7. [Earlier (1880) abstract (lists species in name only [ref. 20481]). Also as a separate (1881), pp. 1-46, Pls. 1-7.]

Shelden, F. F. 1937. Osteology, myology and probably evolution of the nematognath pelvic girdle. Annal of New York Academy of Science, 37:1-96.

Sverlij, S. B., R. L. D. Schenke, H. L. López and A. E. Ros. 1998. Peces del Rio Uruguay. Guia ilustrada de las especies mas comúnes del río Uruguay inferior y el embalse de Salto Grande. Peces del Rio Uruguay.: 1-89.

Swofford, D. L. \& W. P. Maddison. 1987. Reconstructing ancestral character states under Wagner parsimony. Mathematical Biosciences 87: 199-229.

Swofford, D. L. \& G. J. Olsen. 1990. Phylogeny reconstruction, pp. 411-501 in D. M. Hills \& C. Moritz. Molecular Systematics. Sinauer, Suderland.

Taylor, W. R. e Van Dyke, G. C. 1985. Revised procedures for staining and clearing small fishes and other vertebrates for bone cartilage. Cybium 9:107-119. 
Tortonese, E. 1963. Catalogo dei tipi di pesci del Museo Civico di Storia Naturale di Genova. (Parte II). Annali del Museo Civico di Storia Naturale 'Giacomo Doria' v. 73: 306-316.

Travassos, H. 1960. Catálogo de peixes do vale do rio São Francisco. Bol. Soc. Cear. Agron., 1: 1-66. Fortaleza, Ceará.

Valenciennes, A. in: Cuvier, G. and A. Valenciennes, 1840. Histoire naturelle des poissons. Tome 17. Chez Pitois Levrault, Paris. 464 p.

Wiley, E.O. 1981. Phylogenetics: the theory and practice of phylogenetic systematics. John Wiley and Sons. New York. 439p.

Wiley, E.O., D. Siegel-Causay, D. R. Brooks \& V. Funk. 1991. The complete cladistics: A primer of phylogenetic procedures. Special Publication 19. The University of Kansas Mus. Nat. Hist., Lawrence, ix +158 pp.

Zuanon, J. A. 1999. História natural da ictiofauna de corredeiras do rio Xingu, na região de Altamira, Pará. Tese de doutorado não publicada. Universidade Estadual de Campinas. $199 \mathrm{p}$. 


\section{FIGURAS}

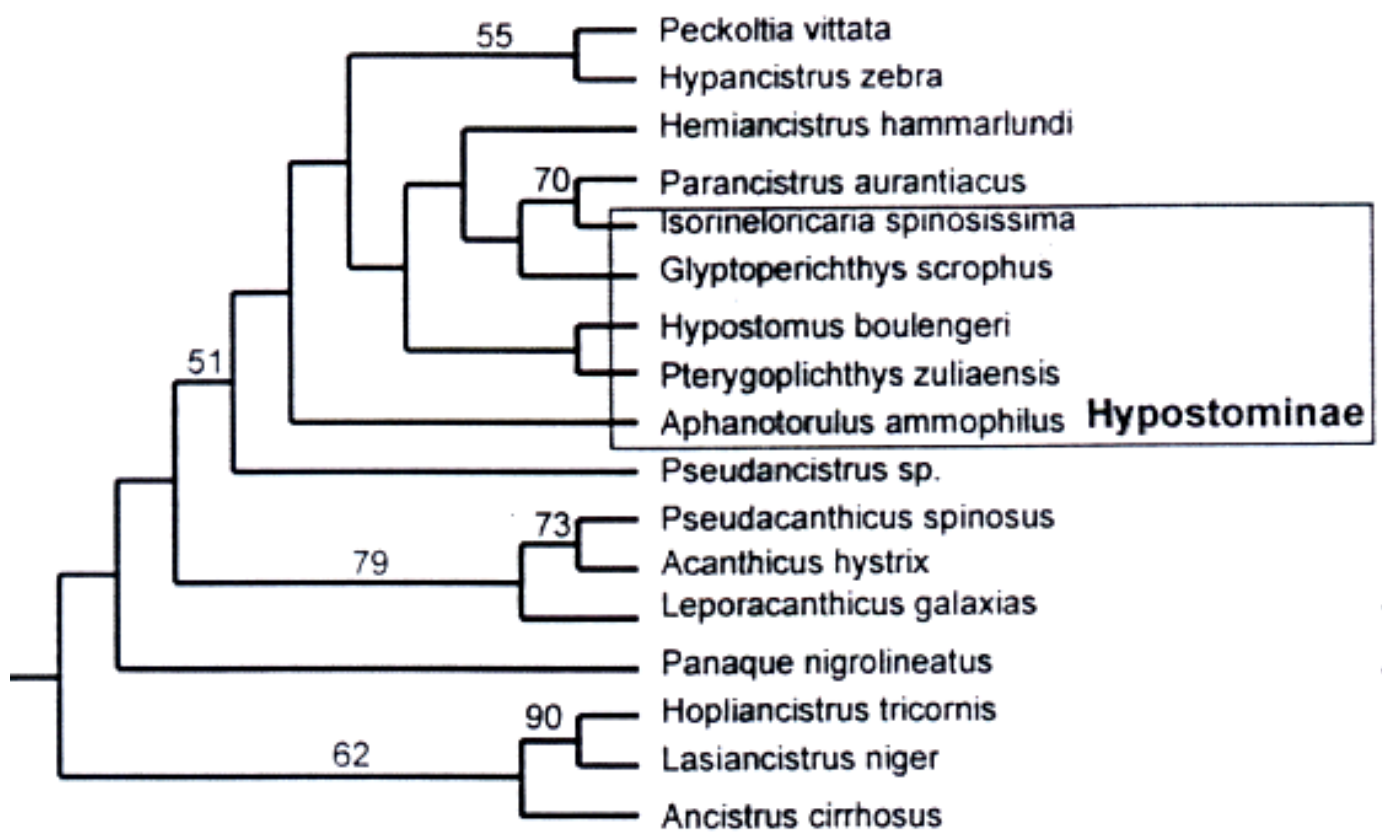

离

Figura 1. Relações filogenéticas de Loricariidae obtida a partir de caracteres moleculares, mostrando as relações entre Ancistrinae e parte de Hypostominae (adaptado de MontoyaBurgos et al, 1998) 


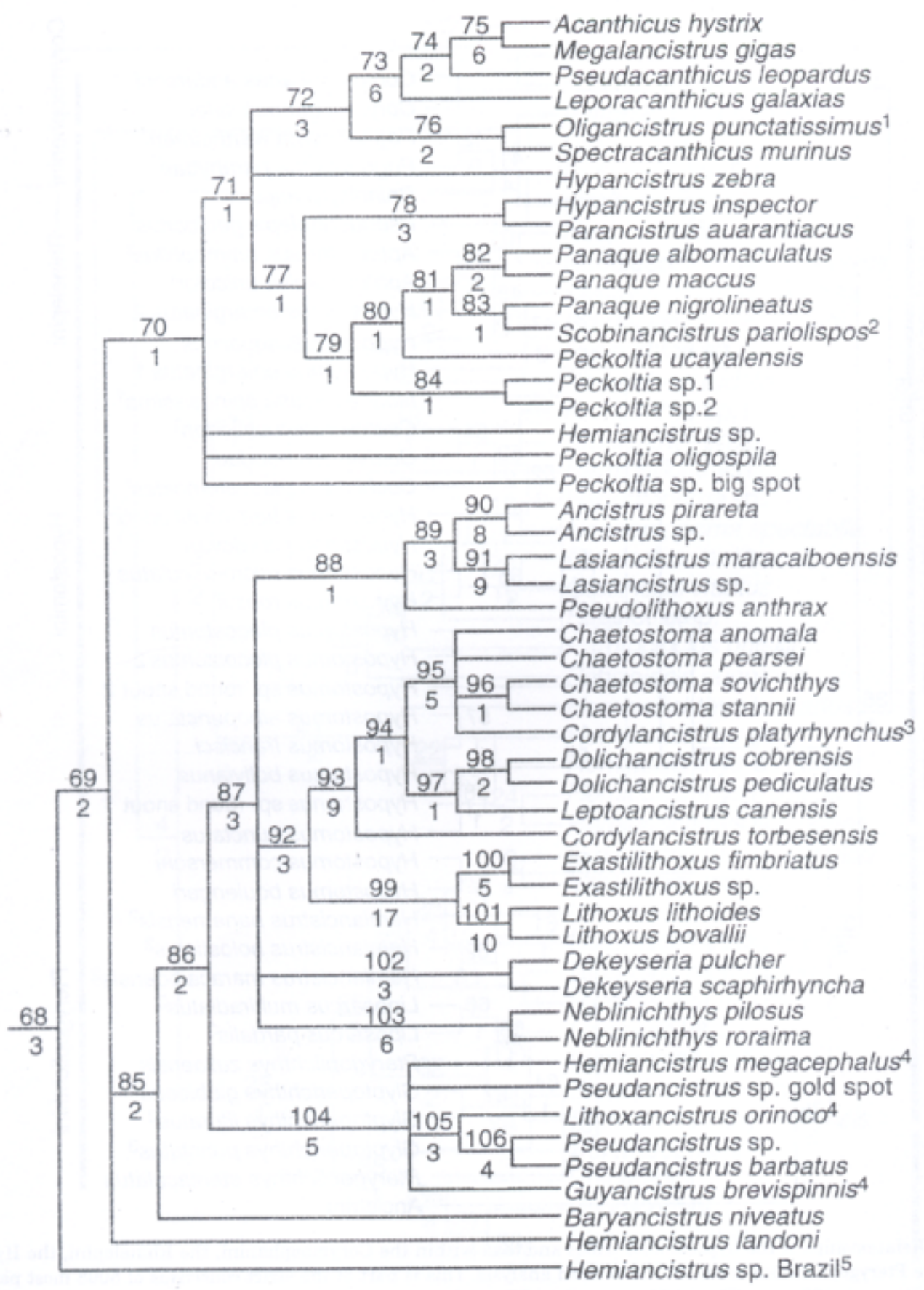

Figura 2. Relações filogenéticas de Ancistrini (Armbruster, 2004). 


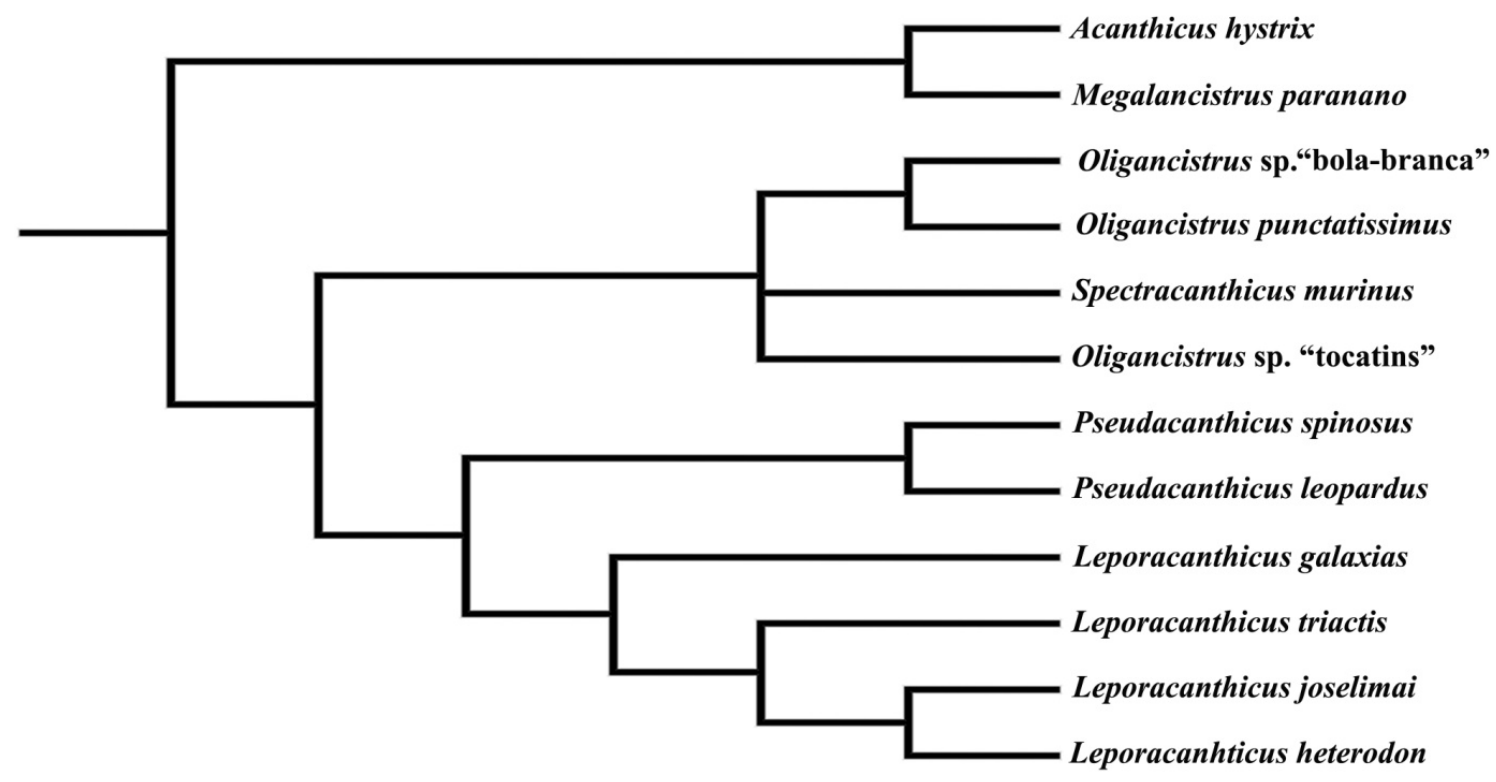

Figura 3. Relações filogenéticas de Leporacanthicus e outros táxons do grupo Acanthicus (modificado de Chamon, 2007). 


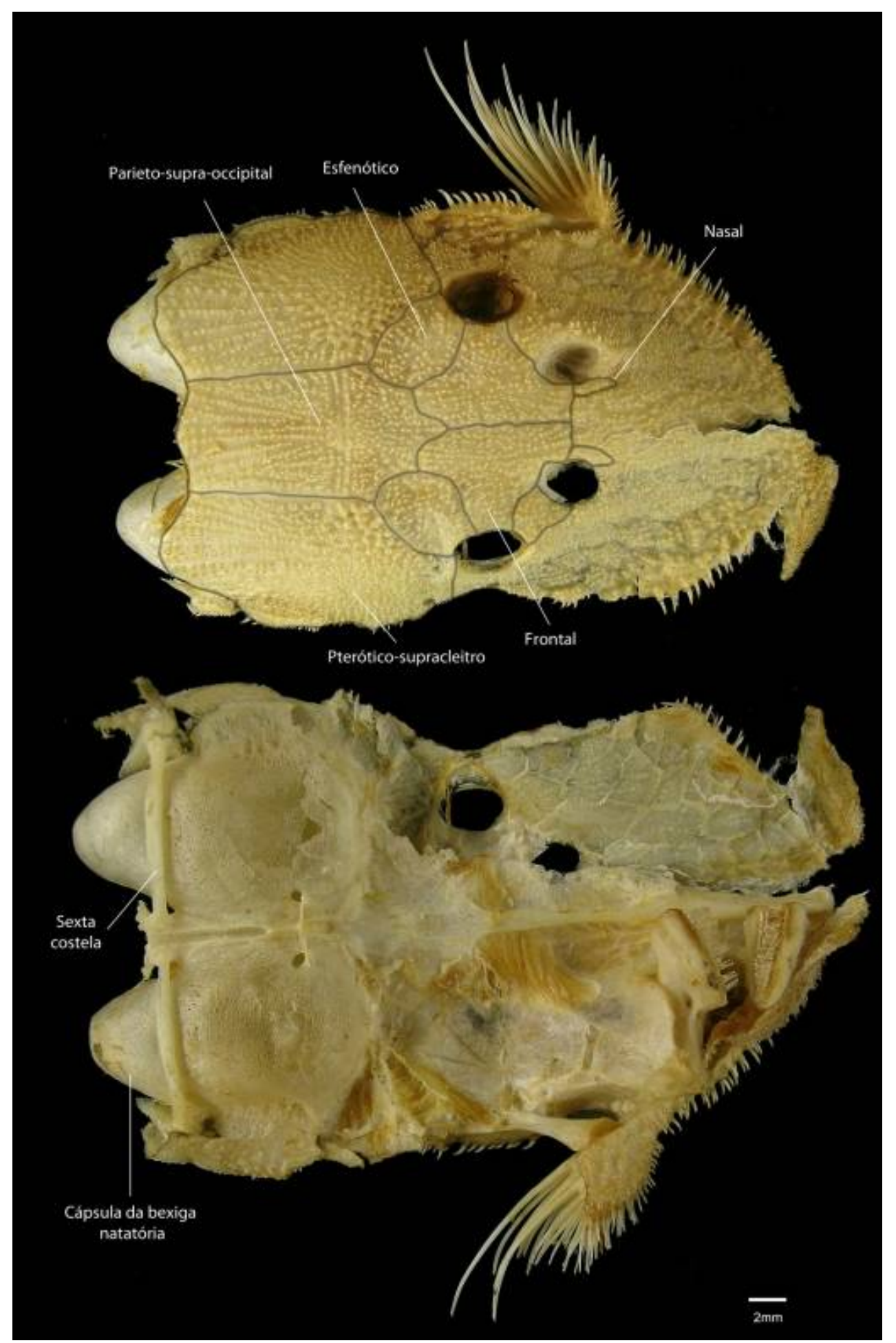

Figura 4. Vista dorsal e ventral do neurocrânio de Acanthicus hystrix (MZUSP 34244 -174,61 $\mathrm{mm} \mathrm{CP})$. 


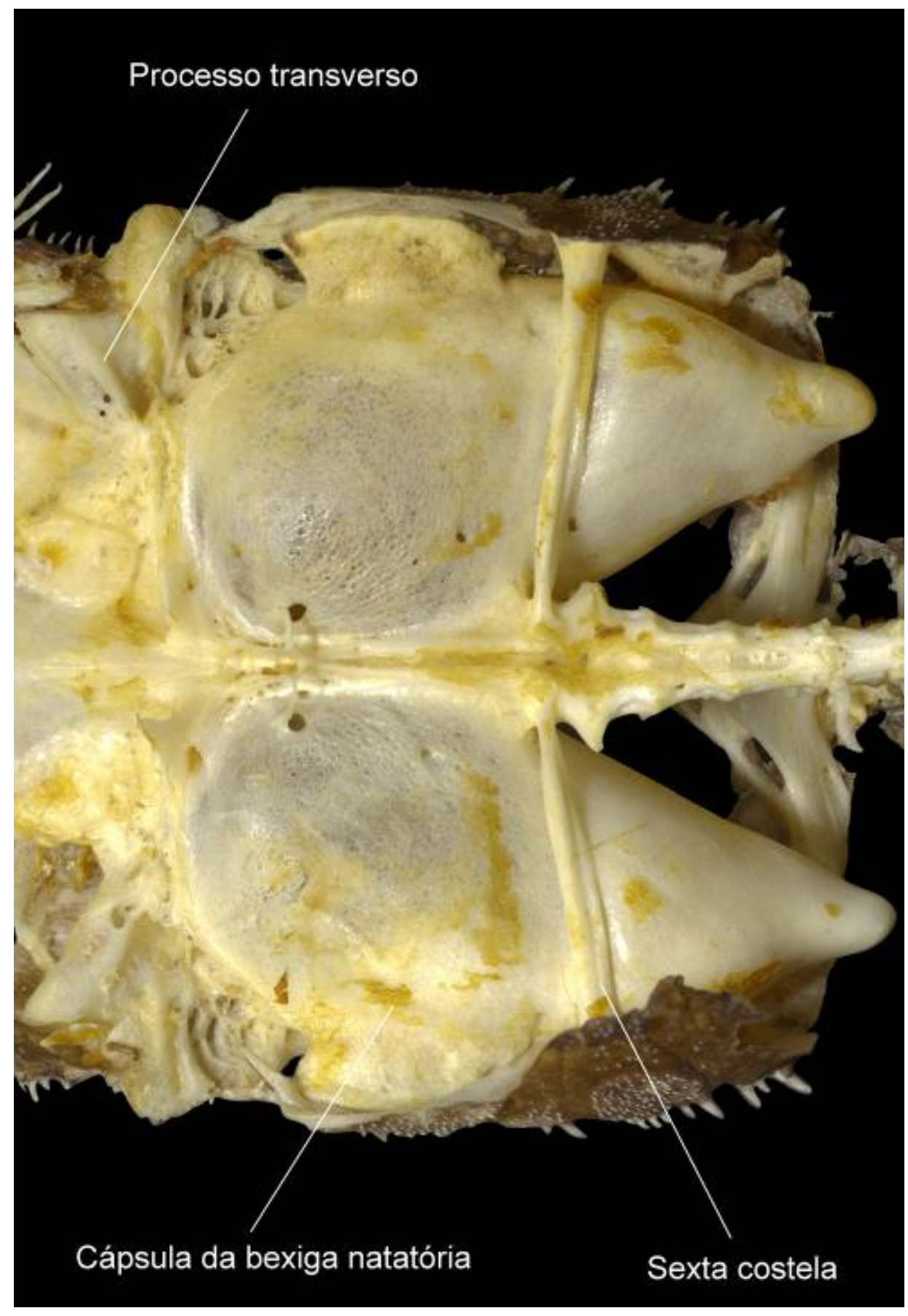

Figura 5. Cápsula da bexiga natatória de Acanthicus adonis ANSP 19532 - 235,2 mm CP). 


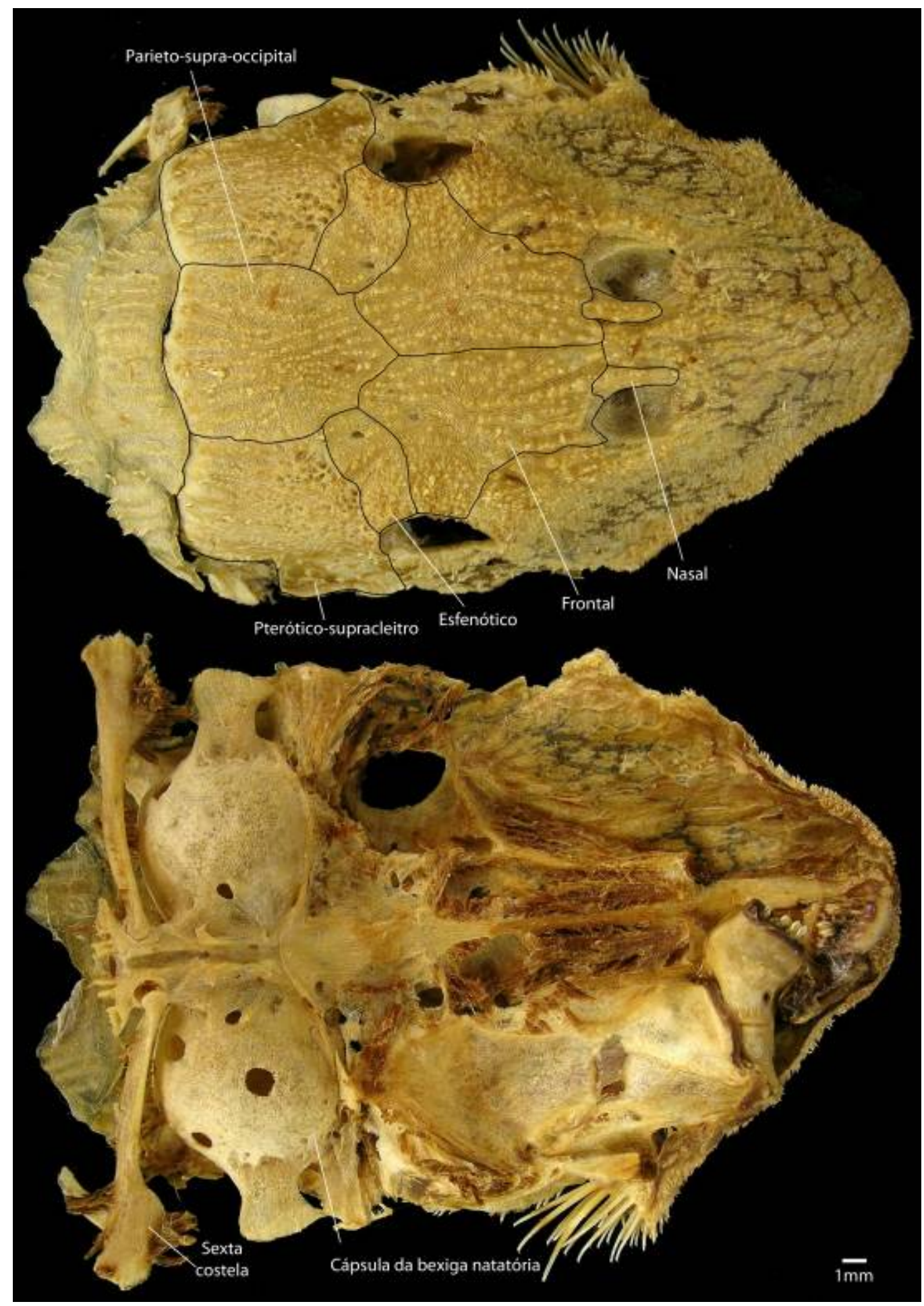

Figura 6. Vista dorsal e ventral do neurocrânio de Megalancistrus parananus (MZUSP 4434 249,87 mm CP). 


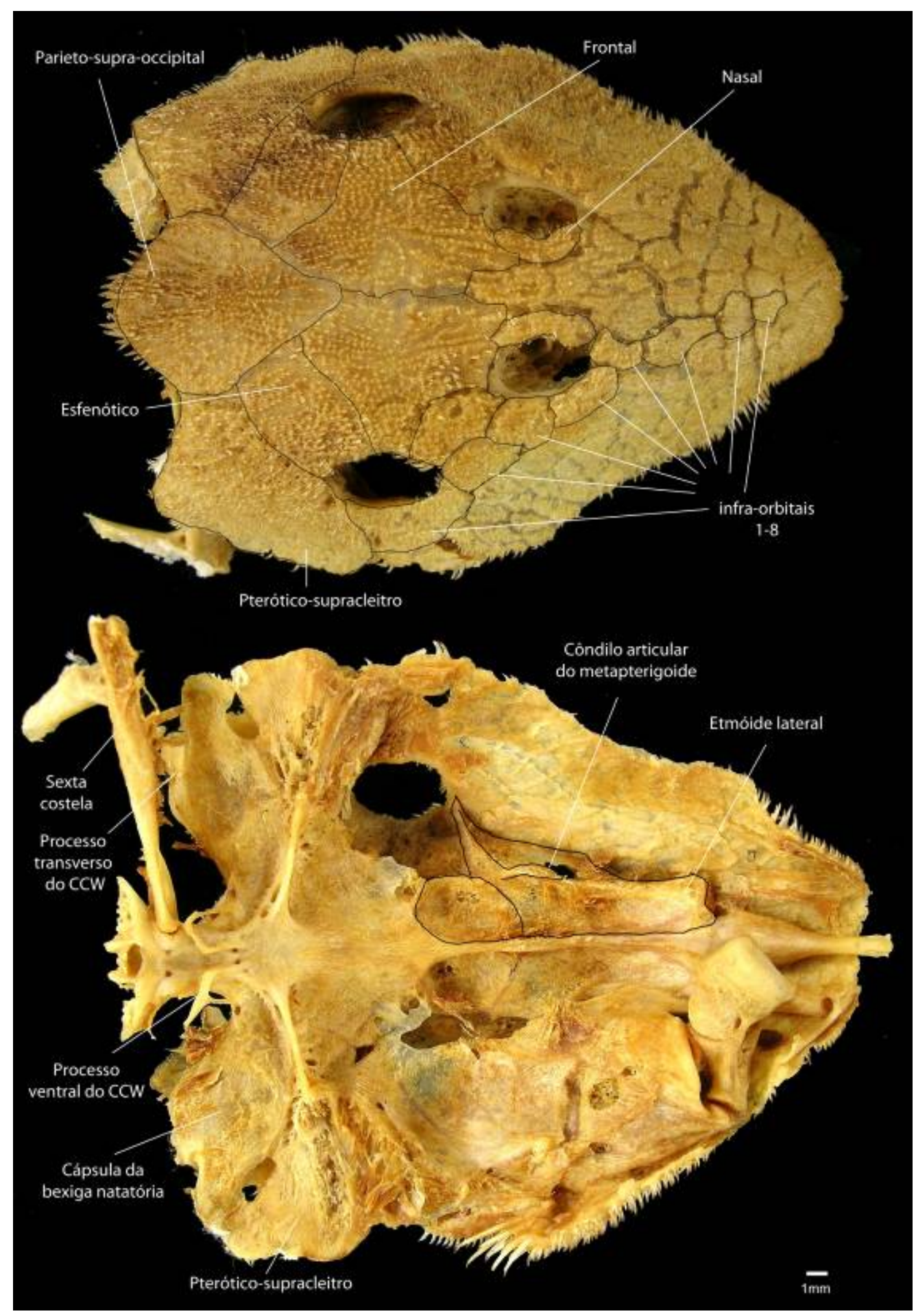

Figura 7. Vista dorsal e ventral do neurocrânio de Pseudacanthicus sp. "aba laranja” (MZUSP 34295 - 236,30 mm CP). 


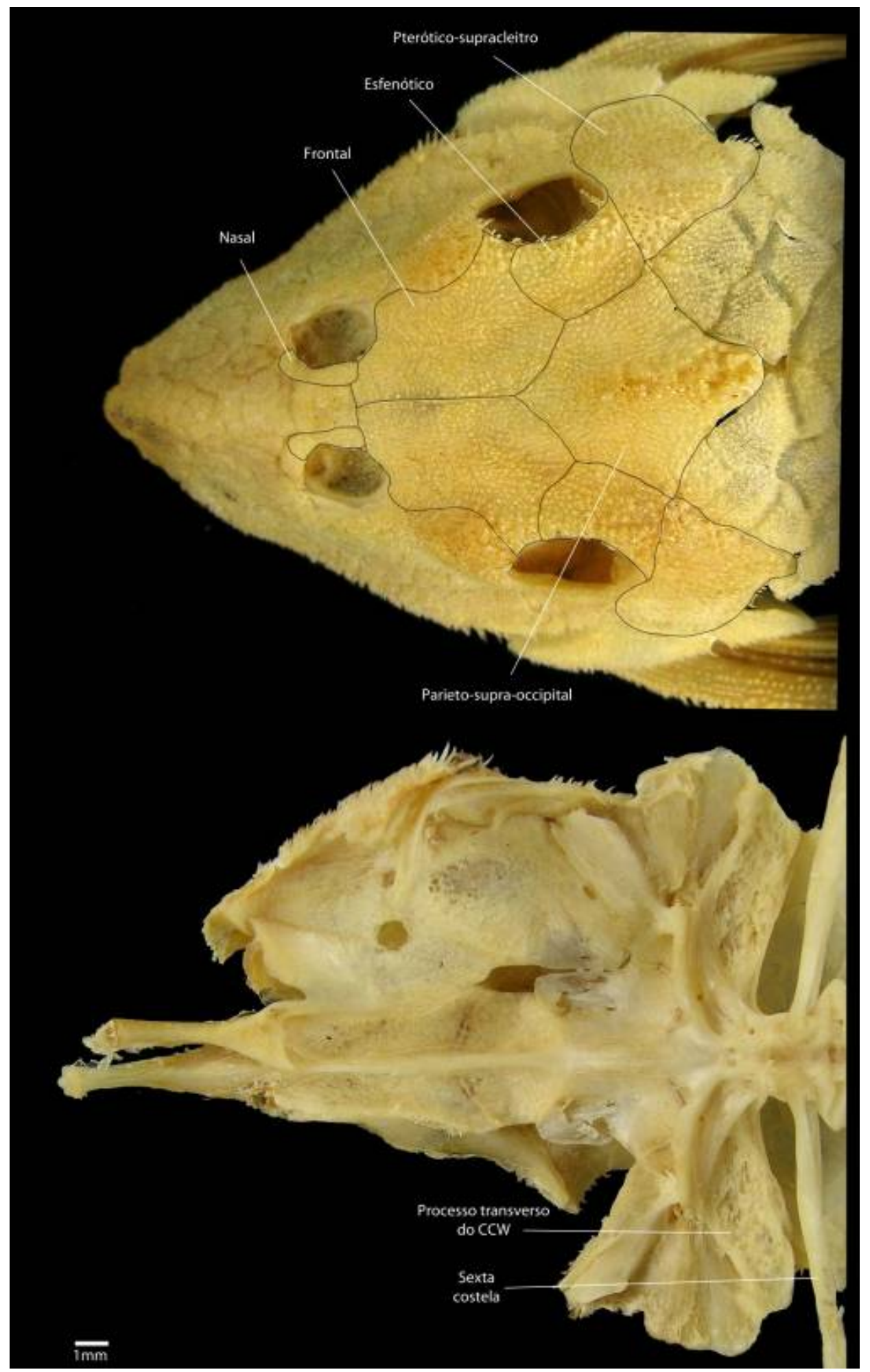

Figura 8. Vista dorsal e ventral do neurocrânio de Leporacanthicus galaxias (INPA 6359 $142,6 \mathrm{~mm} \mathrm{CP})$ 


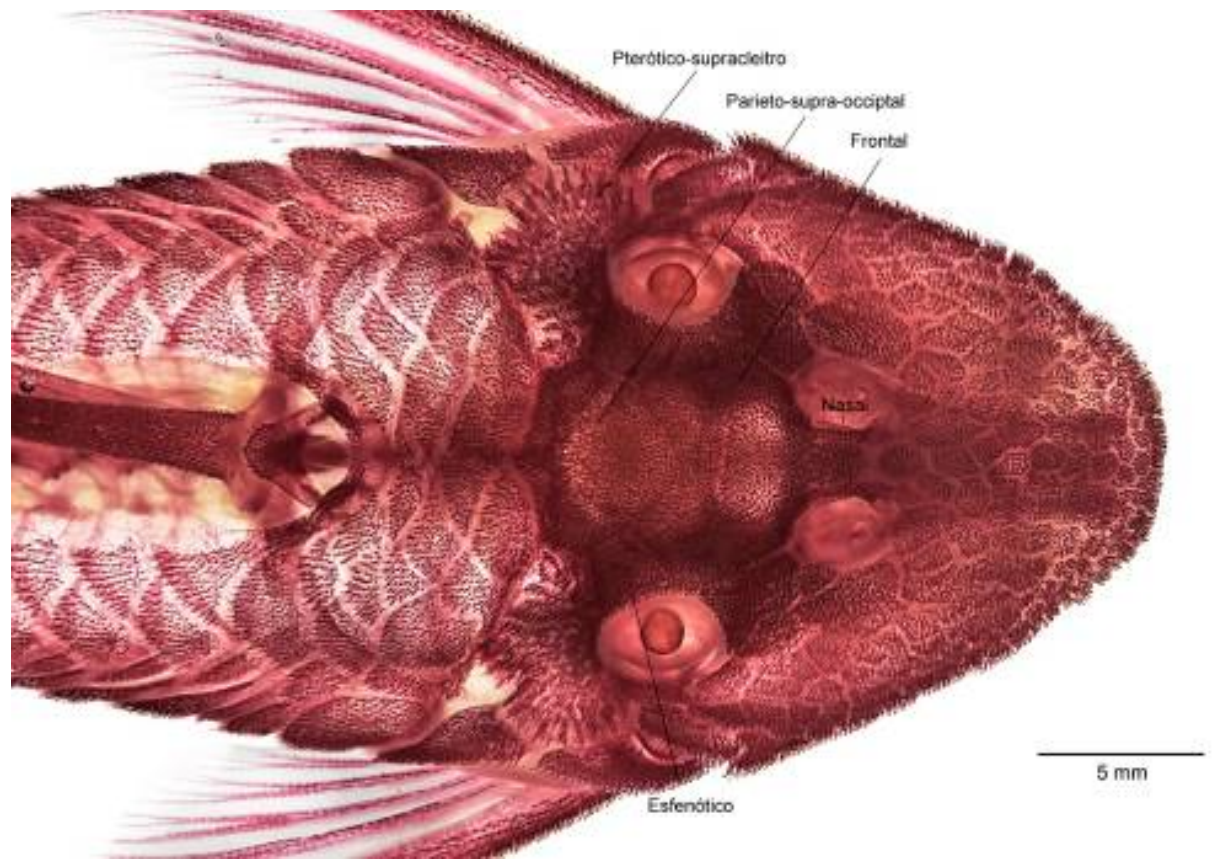

Figura 9. Vista dorsal da cabeça e placas pré-dorsais de Spectracanthicus murinus (MZUSP 24293 - 36,10 mm CP). 


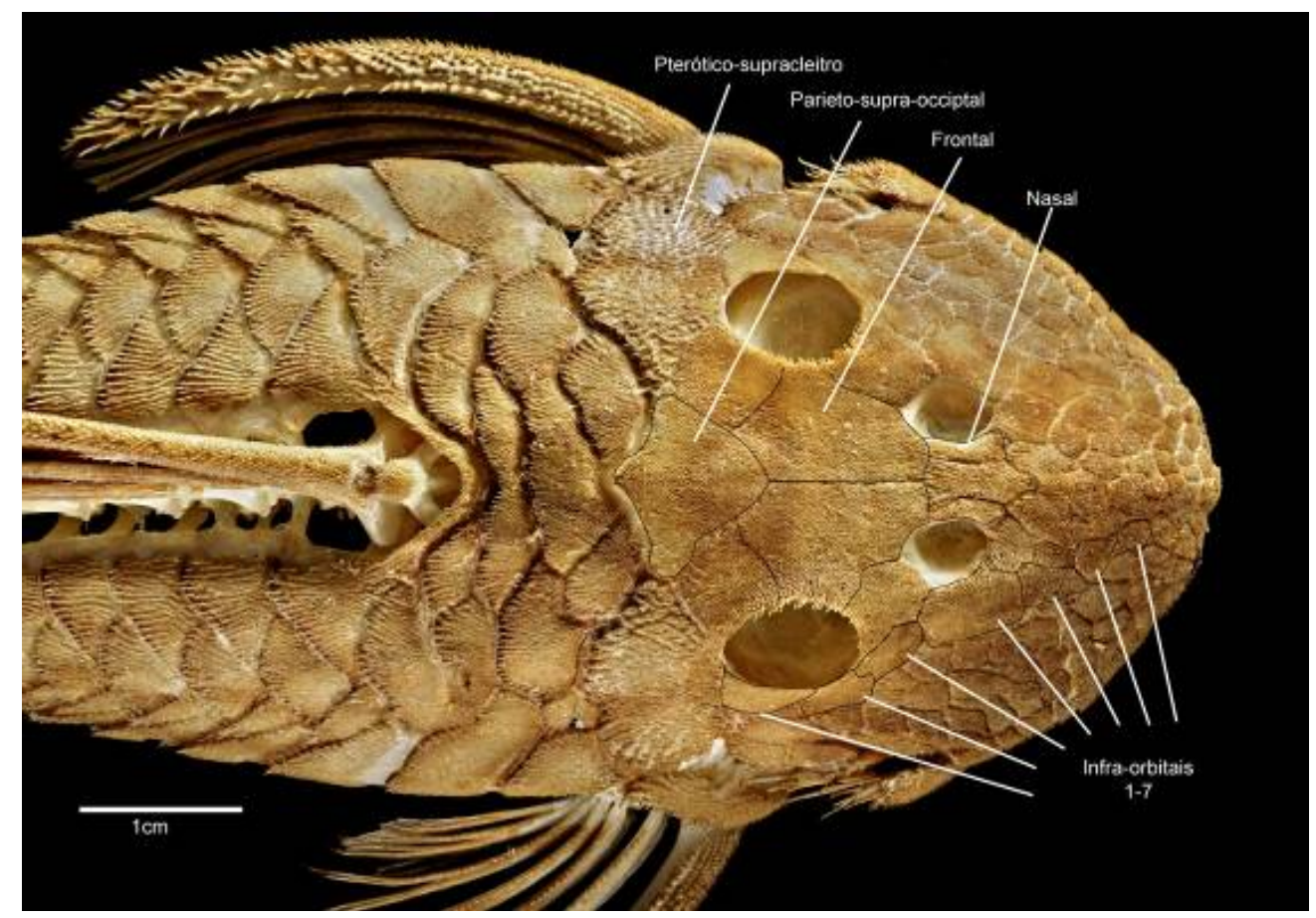

Figura 10. Vista dorsal da cabeça e placas pré-dorsais de Spectracanthicus sp. "bola branca" (MZUSP 108569 - 111,7 mm CP). 


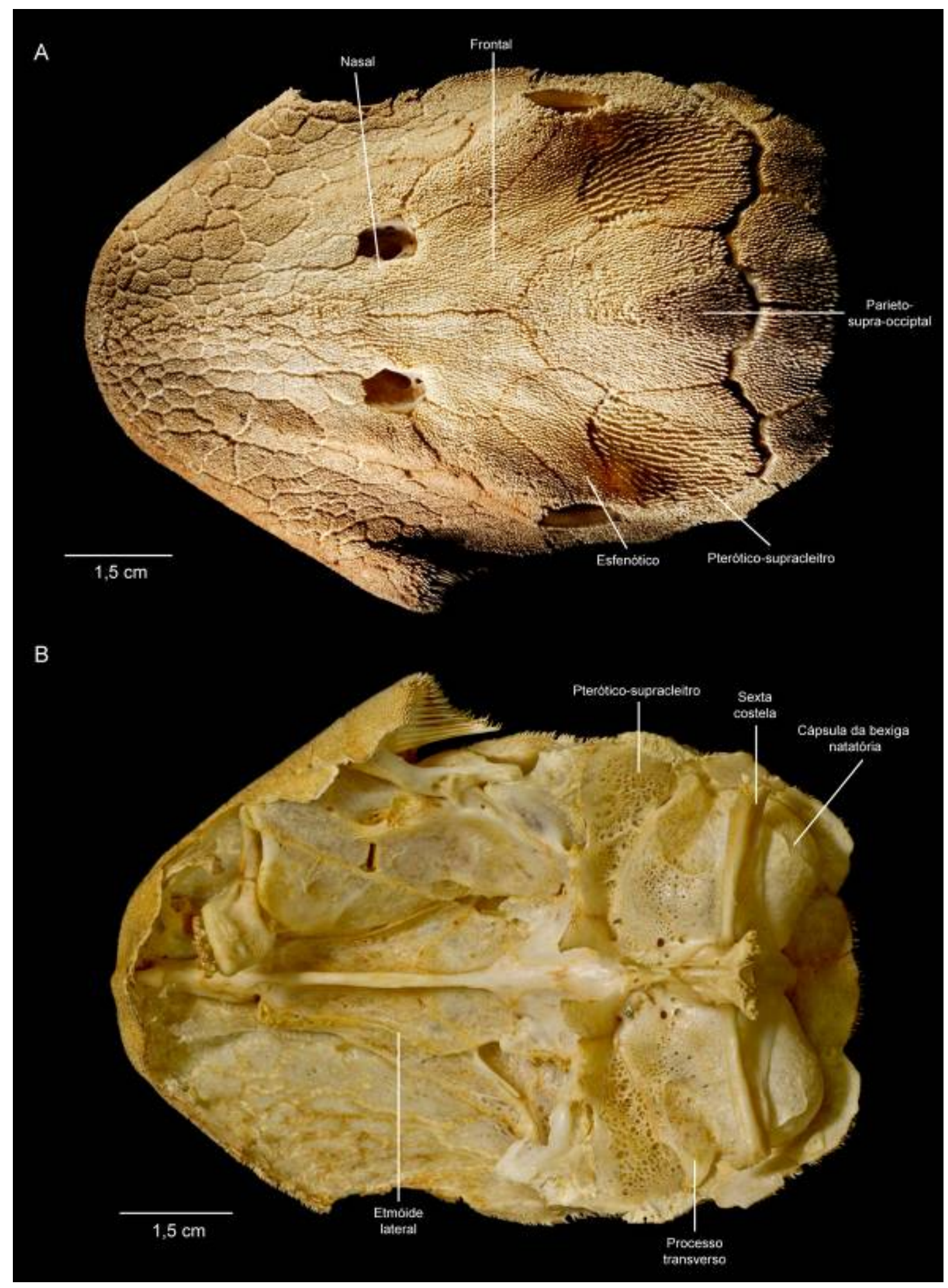

Figura 11. Vista dorsal e ventral do neurocrânio de Panaque gr. nigrolineatus (MZUSP 94453 - 268,1 mm CP). 


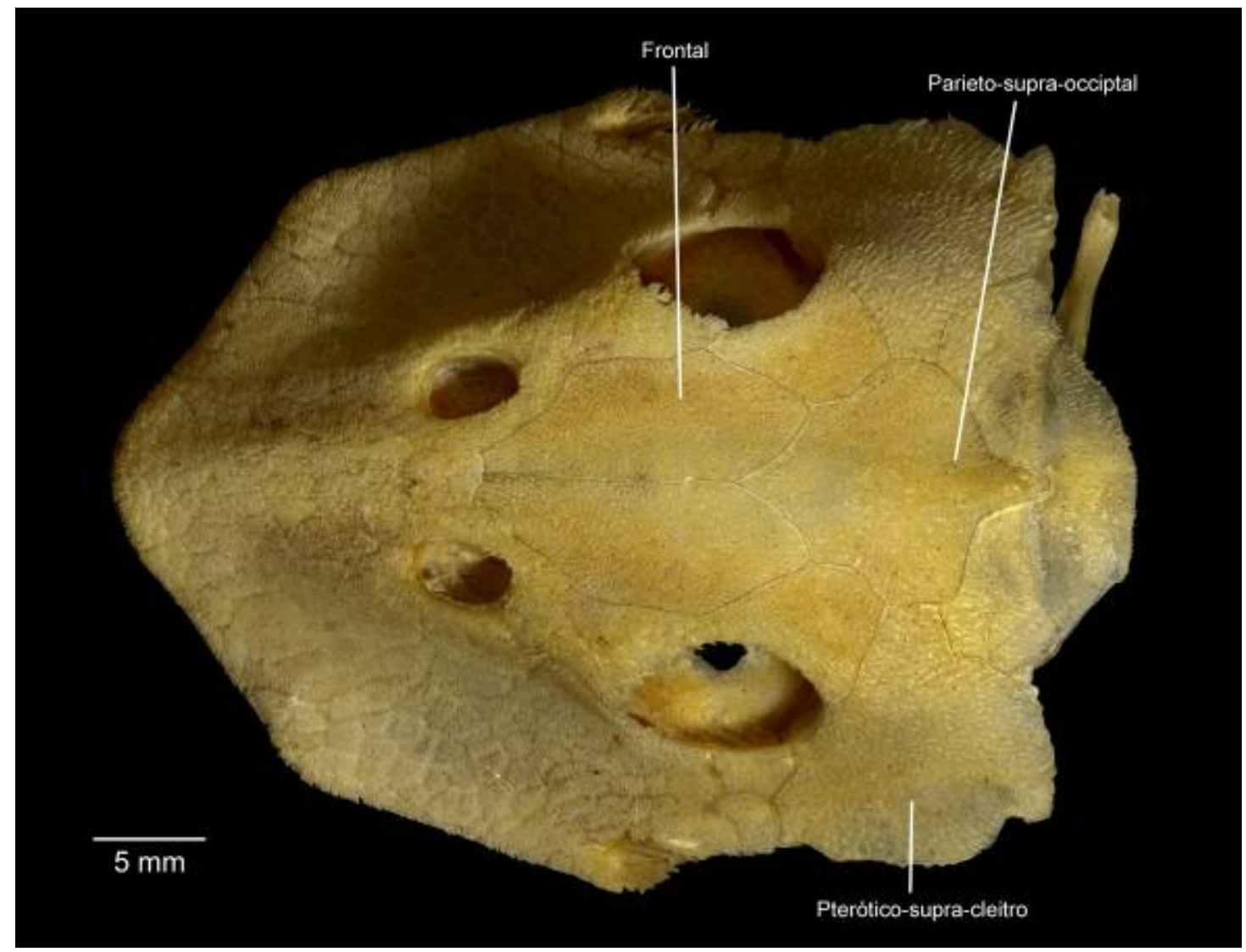

Figura 12. Vista dorsal do neurocrânio de Scobinancistrus aureatus INPA 25858 - 130,11 mm $\mathrm{CP})$. 


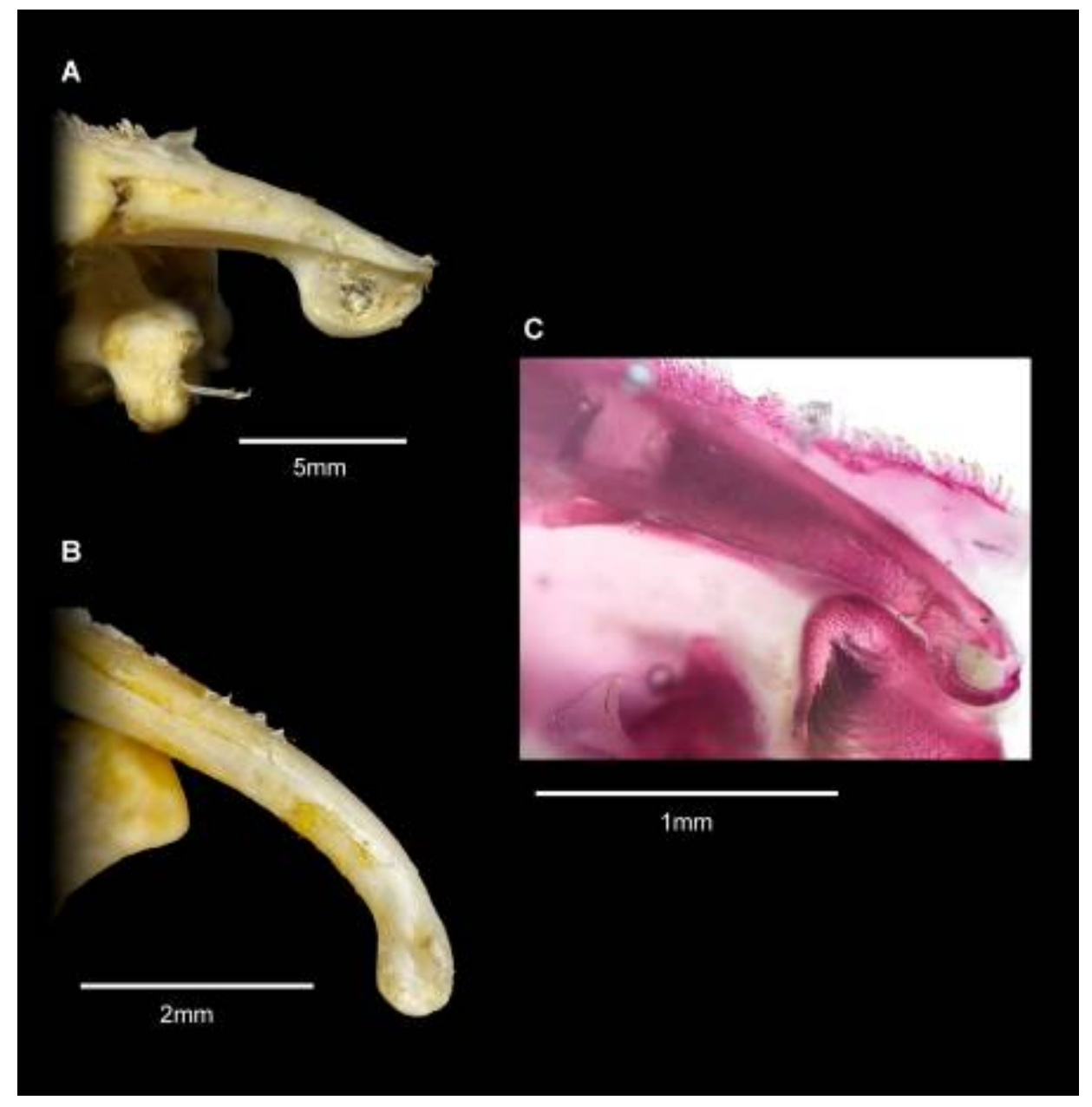

Figura 13. Vista lateral do mesetmóide de (A) Acanthicus adonis, (B) Megalancistrus barrae e (C) Pseudacanthicus leopardus. 


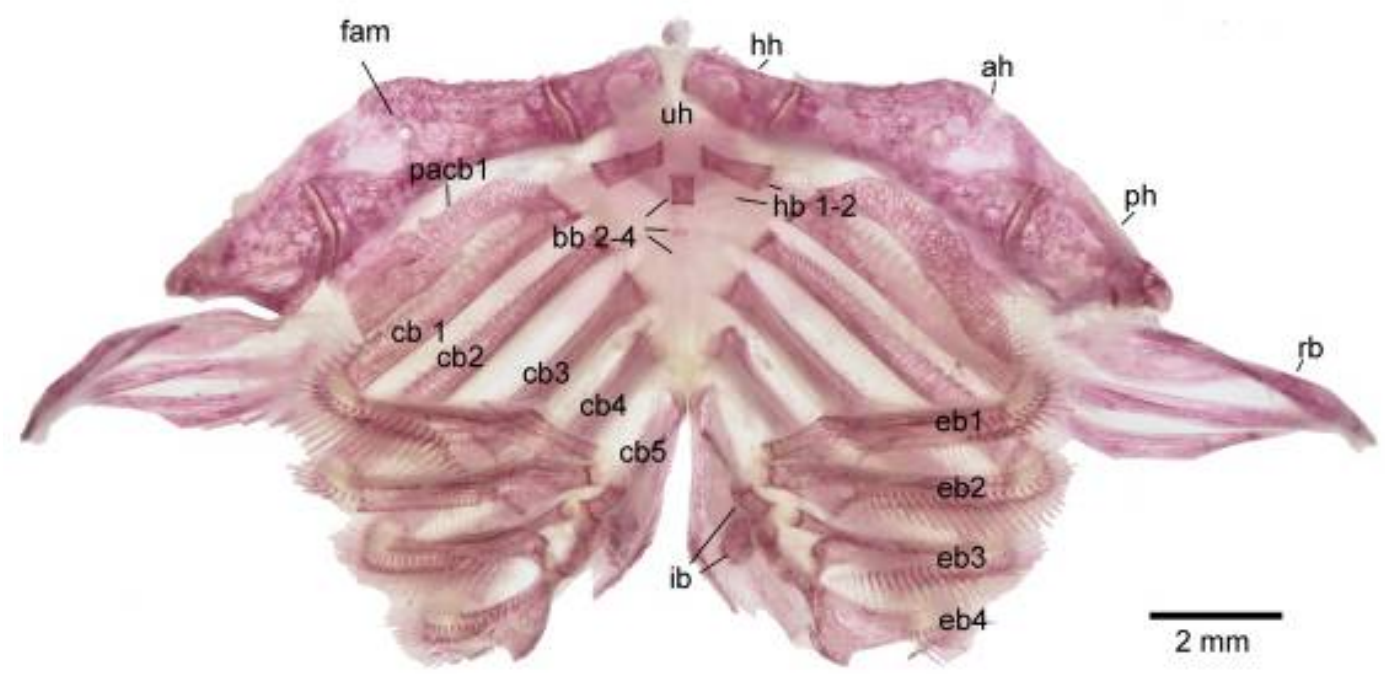

Figura 14. Arcos hióide e branquiais de Acanthicus hystrix; hh=hipo-hial, ah=ântero-hial, ph=póstero-hial, uh=urohial, hb=hipo-branquial, $\mathrm{BB}=$ basibranquial, cb=cerato-hial, eb=epibranquial, IB=infra-faringo-branquial, pacb1=processo acessório do cb1, fam=forame da artéria mandibular aferente e $\mathrm{rb}=$ raios branquiostégios. 

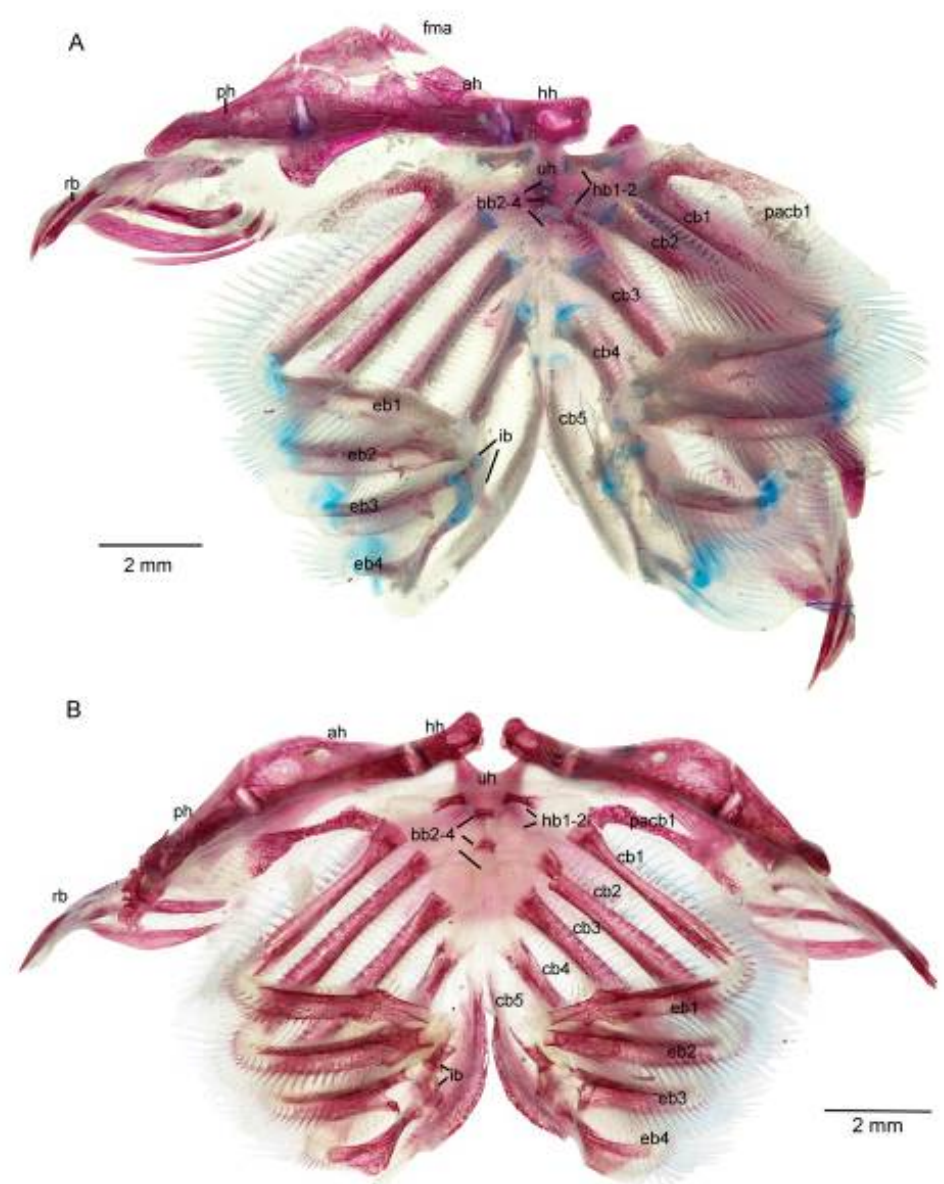

C

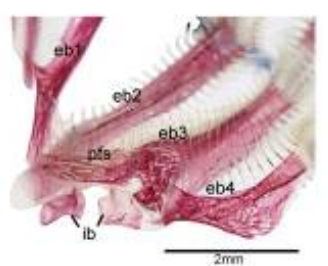

Figura 15. Arcos hióide e branquiais em Pseudacanthicus leopardus (A) e P. spinosus (B e C); hh=hipo-hial, ah=ântero-hial, $\quad \mathrm{ph}=$ =óstero-hial, $\mathrm{uh}=$ urohial, $\mathrm{hb}=$ =hipo-branquial, $\mathrm{BB}=$ basibranquial, $\quad \mathrm{cb}=$ cerato-hial, $\quad \mathrm{eb}=$ epi-branquial, $\quad \mathrm{IB}=$ infra-faringo-branquial, pacb1=processo acessório do $\mathrm{cb} 1$, fam=forame da artéria mandibular aferente e $\mathrm{rb}=\mathrm{raios}$ branquiostégios. 

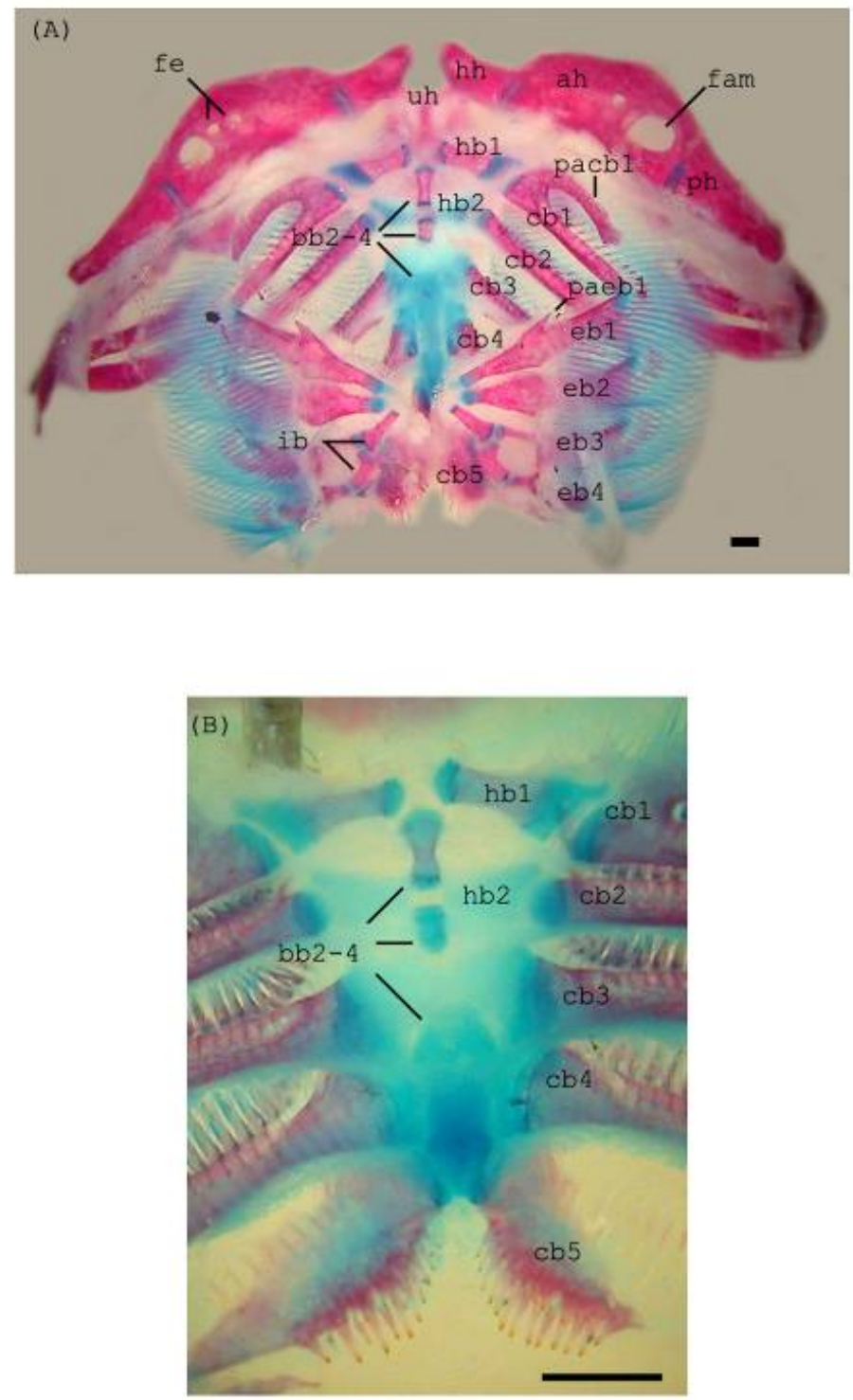

Figura 16. Arcos hióide e branquiais de Leporacanthicus galaxias (A) e L. triactis (B); hh=hipo-hial, ah=ântero-hial, $\quad \mathrm{ph}=$ póstero-hial, uh=urohial, $\mathrm{hb}=$ hipo-branquial, $\mathrm{BB}=$ basibranquial, $\quad \mathrm{cb}=$ cerato-hial, $\quad \mathrm{eb}=$ epi-branquial, $\quad \mathrm{IB}=$ infra-faringo-branquial, pacb1=processo acessório do $\mathrm{cb} 1$, fam=forame da artéria mandibular aferente e $\mathrm{rb}=\mathrm{raios}$ branquiostégios. 

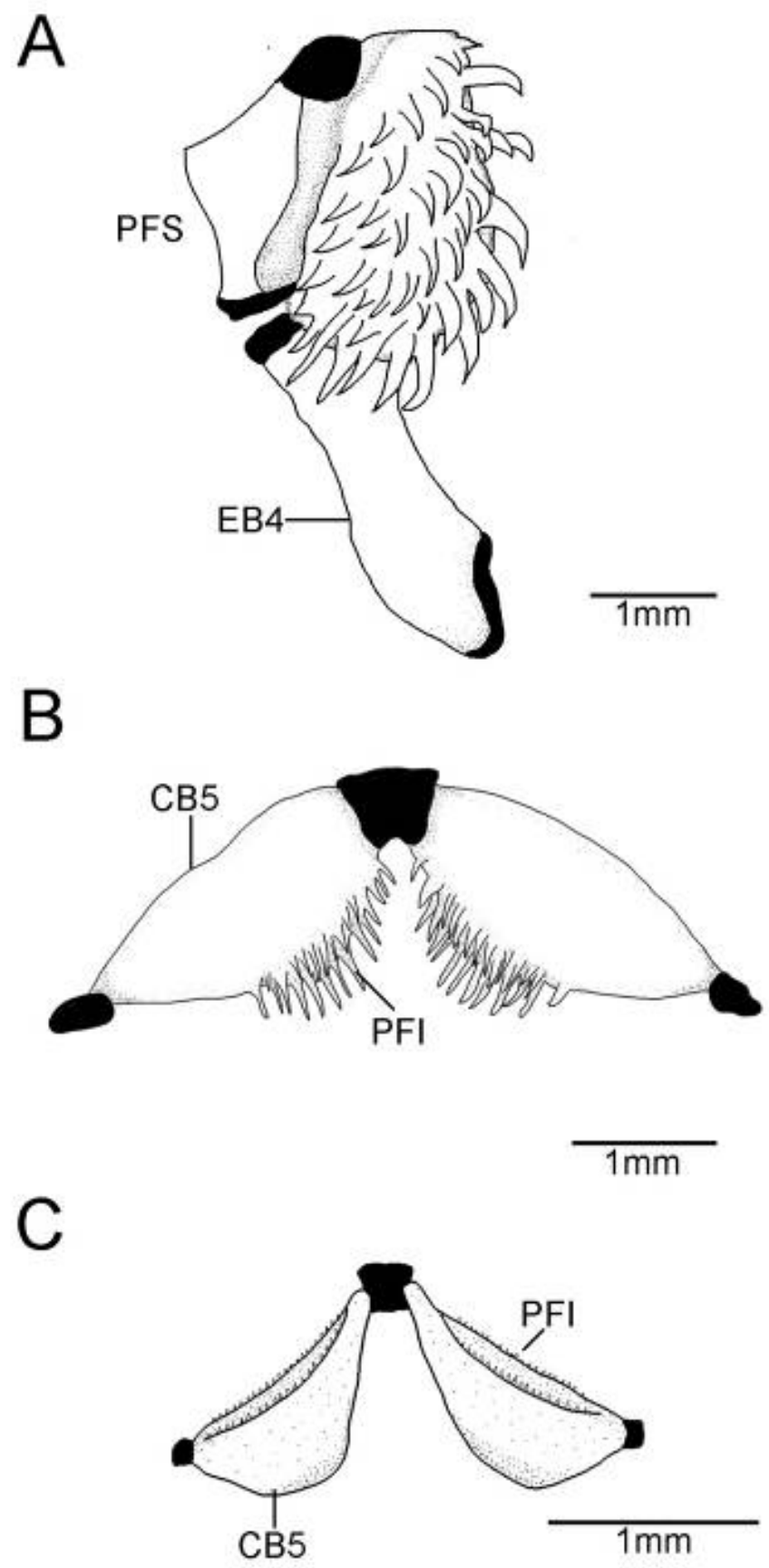

Figura 17. Placa faríngea superior (A) de Leporacanthicus galaxias, placa faríngea inferior (B e C) de L. galaxias e Spectracanthicus sp. "bola branca", respectivamente. 


\section{A}

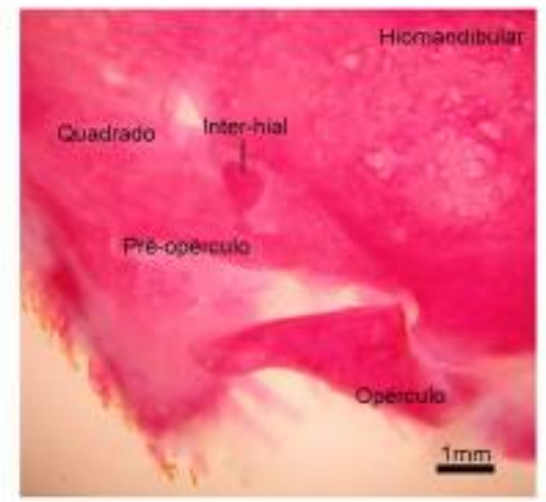

B

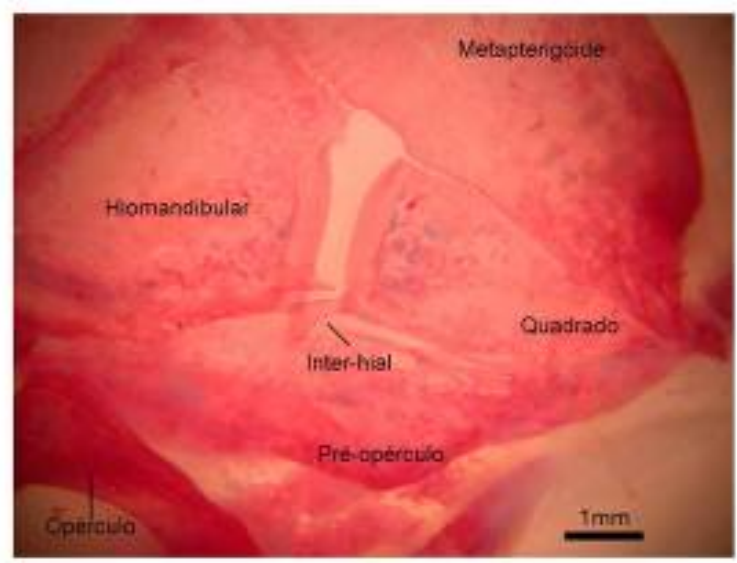

Figura 18. Vista ventral do suspensório, destacando o inter-hial de (A) Leporacanthicus galaxias e (B) Spectracanthicus punctatissimus. 


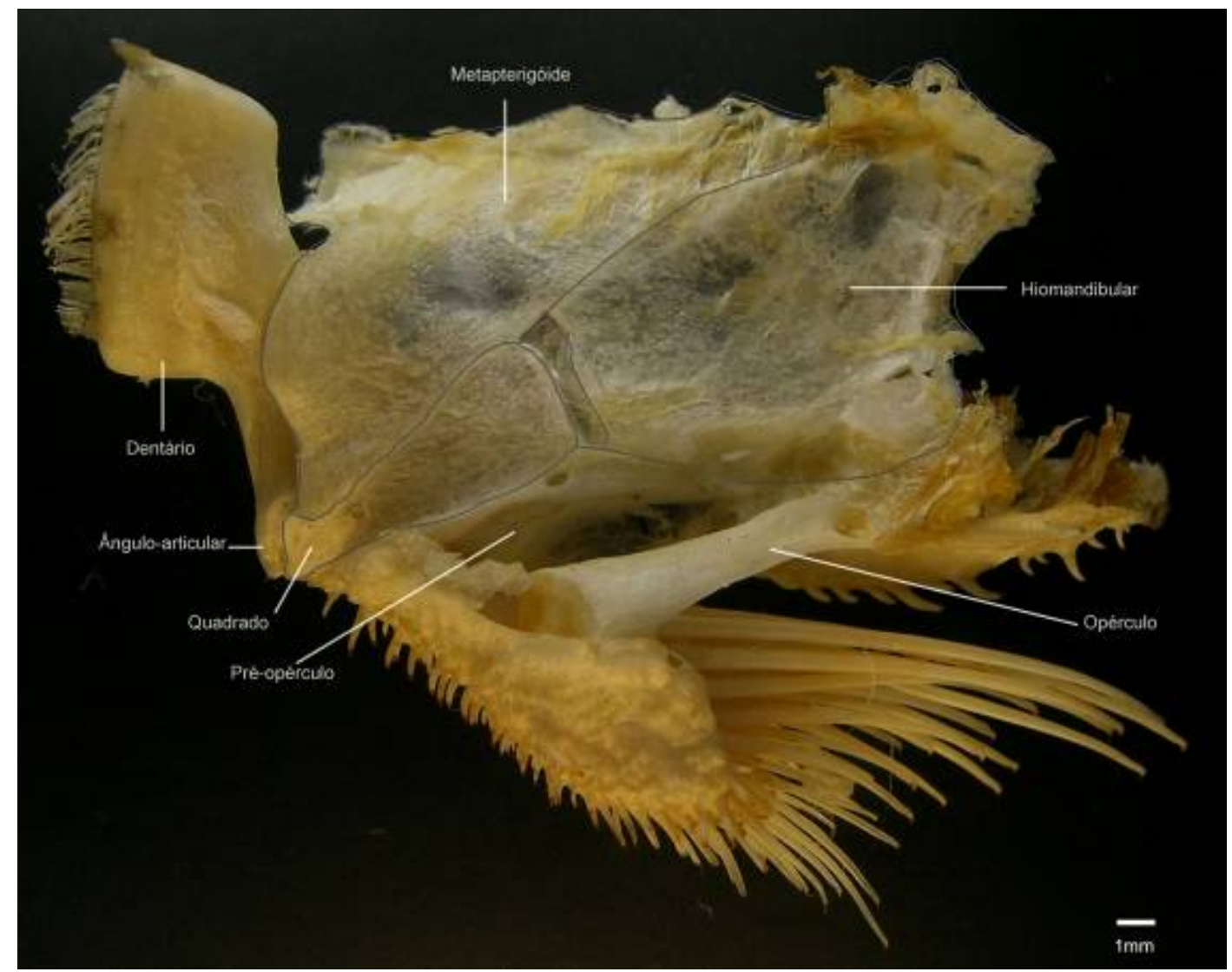

Figura 19. Vista ventral do suspensório de Acanthicus hystrix. 


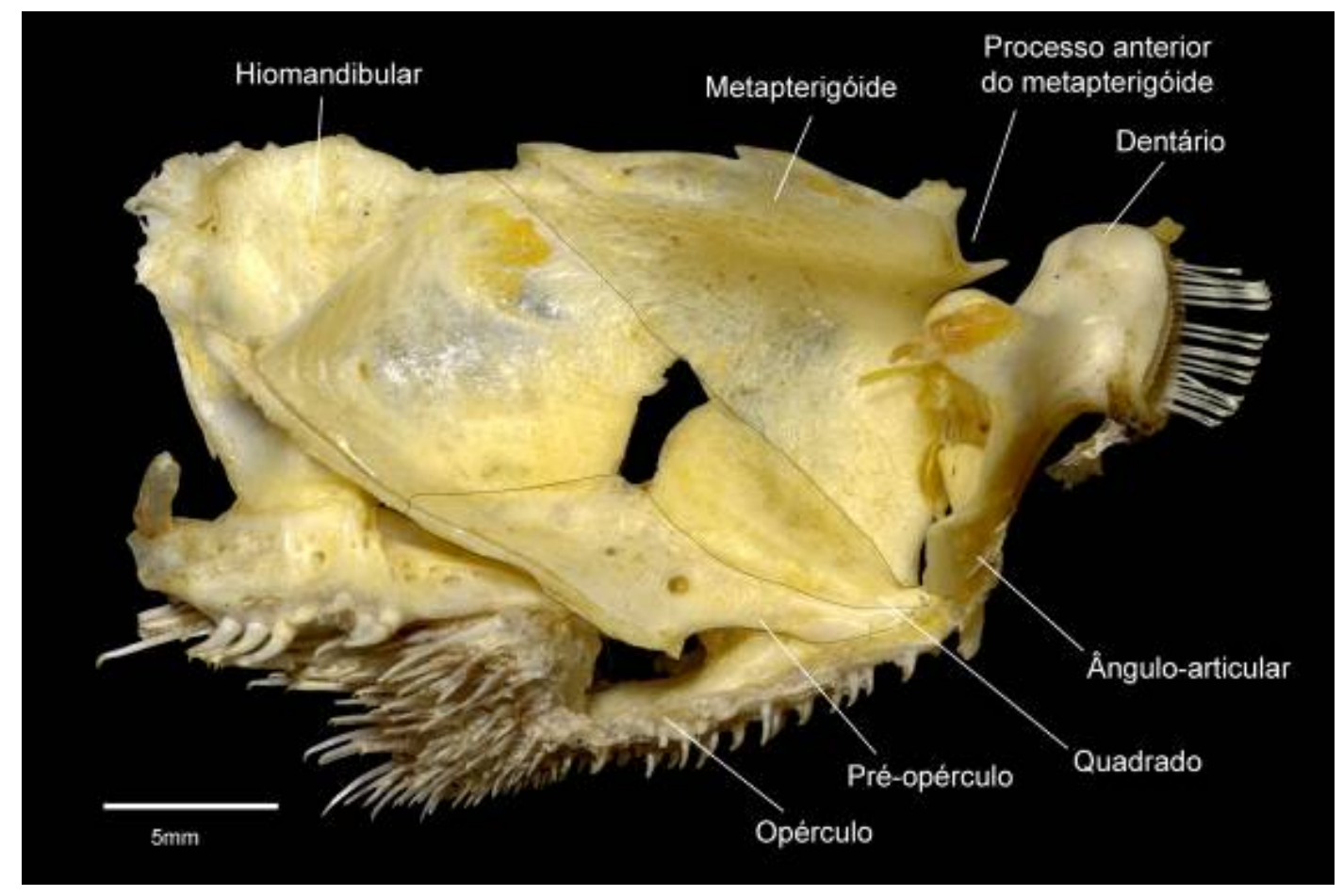

Figura 20. Vista ventral do suspensório de Acanthicus adonis.

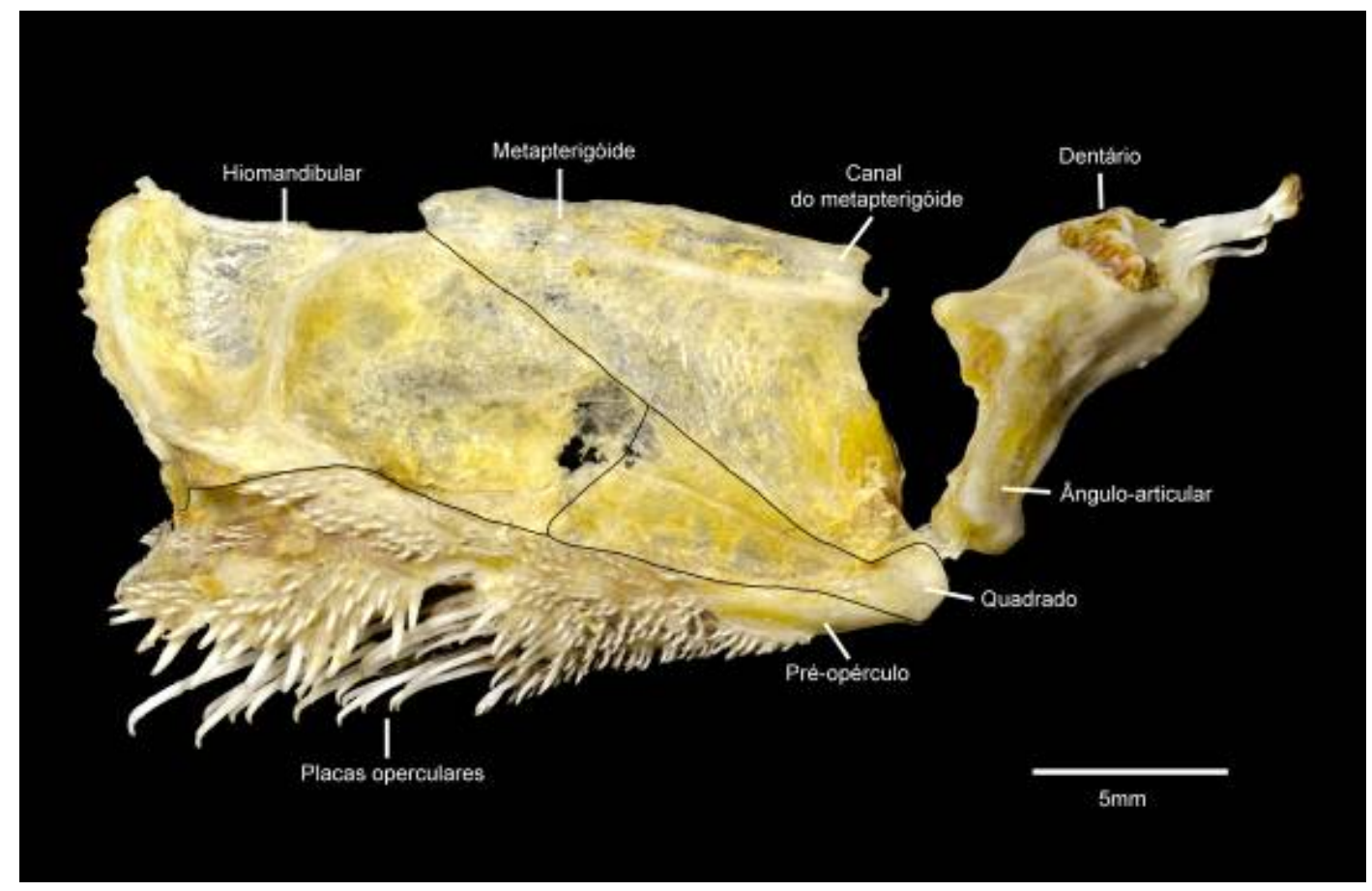

Figura 21. Vista lateral do suspensório de Megalancistrus barrae. 

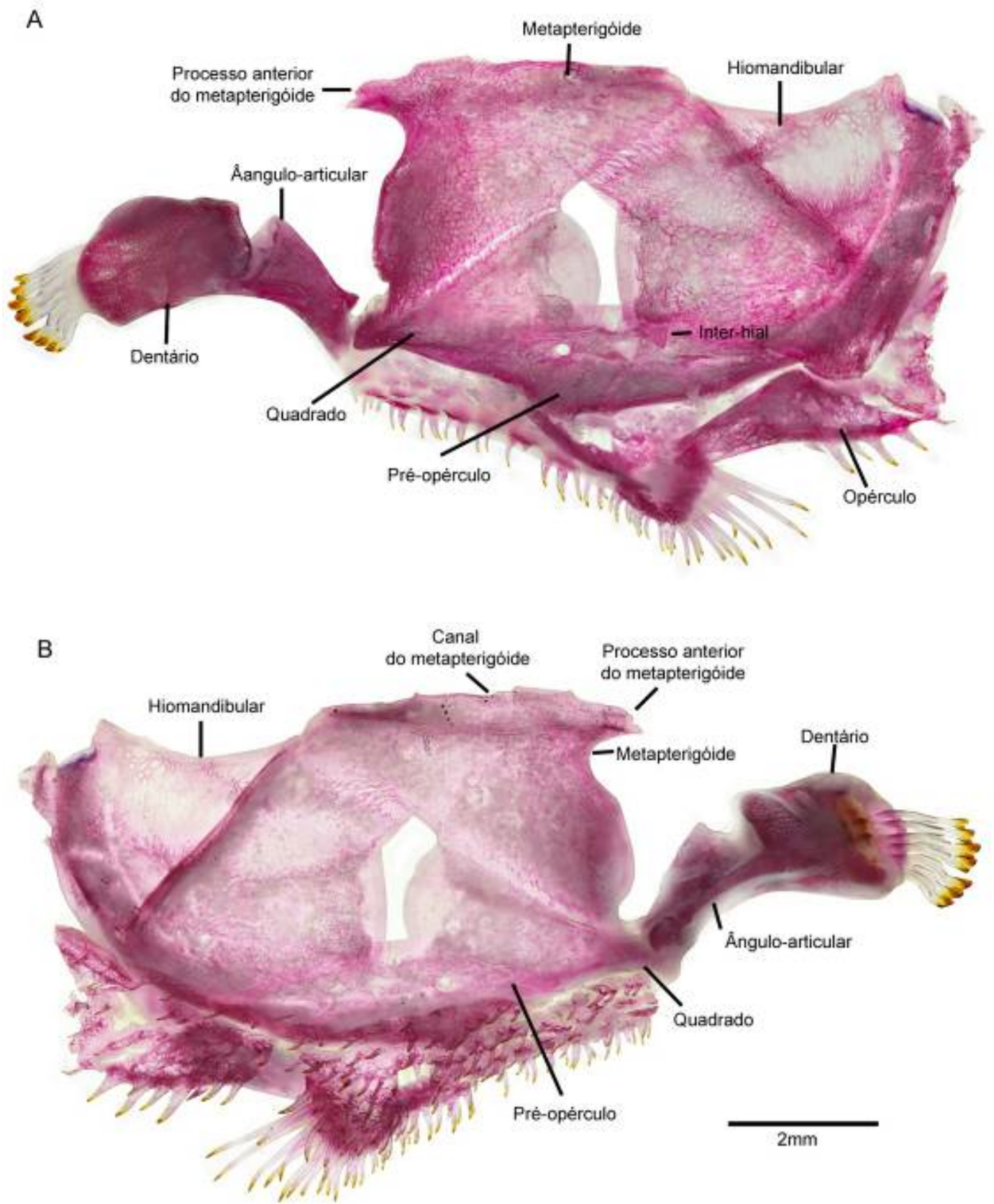

Figura 22. Supensório de Pseudacanthicus leopardus; (A) vista ventral e (B) vista lateral. 
A
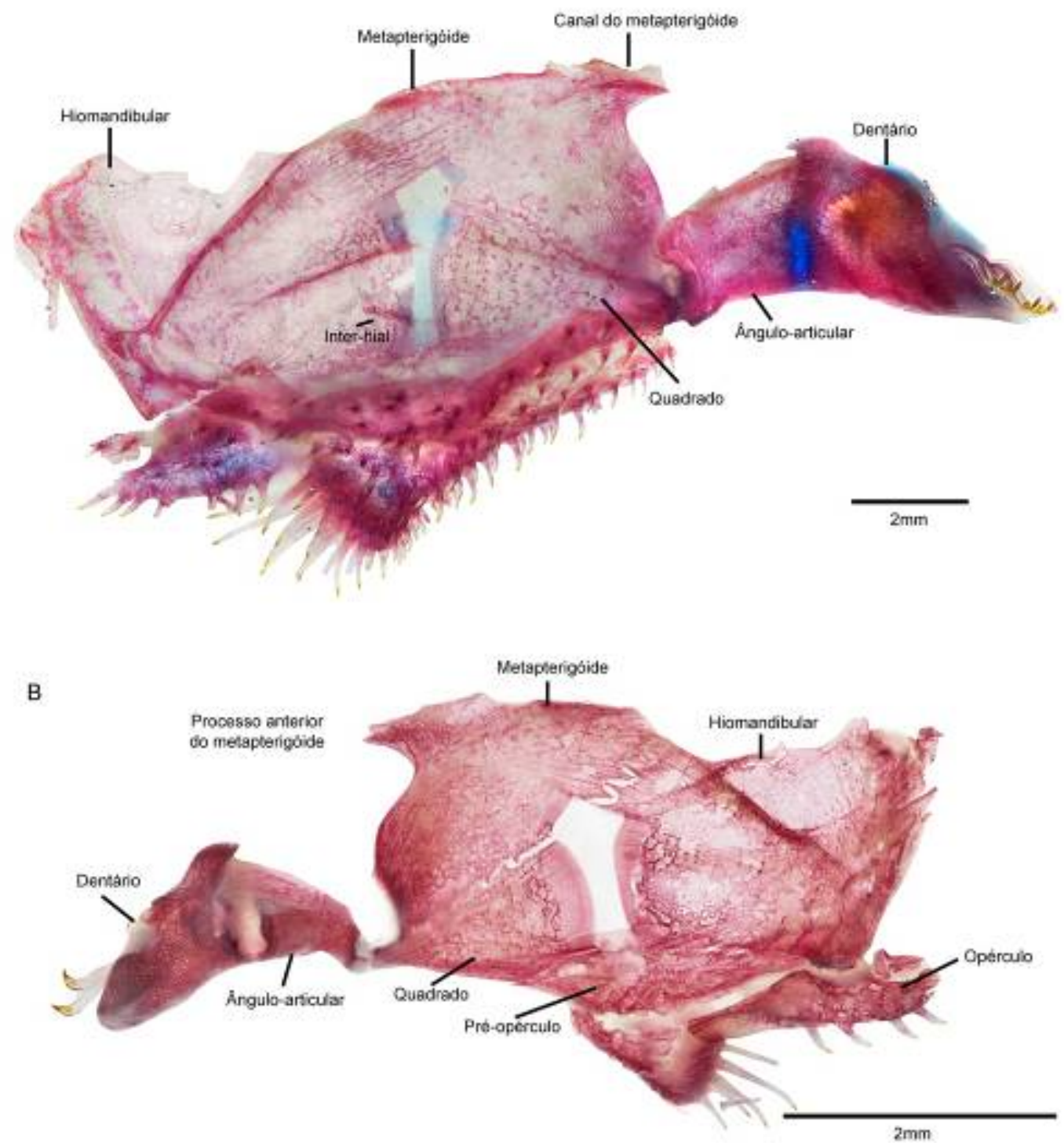

Figura 23. Suspensório de (A) Pseudacanthicus sp. "açacu preto" em vista ventral e (B) $P$. spinosus em vista lateral. 


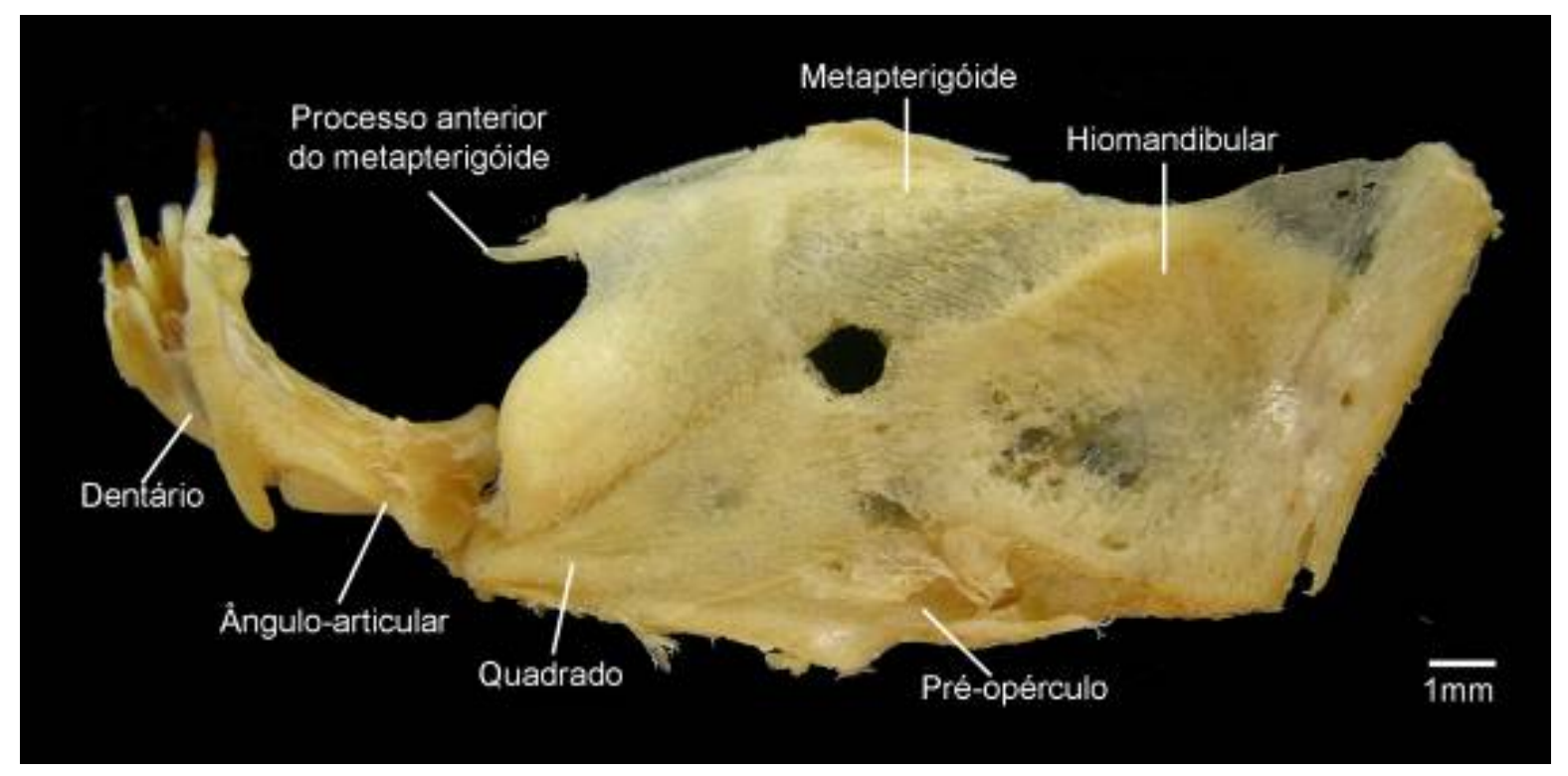

Figura 24. Suspensório em vista ventral de Leporacanthicus galaxias. 

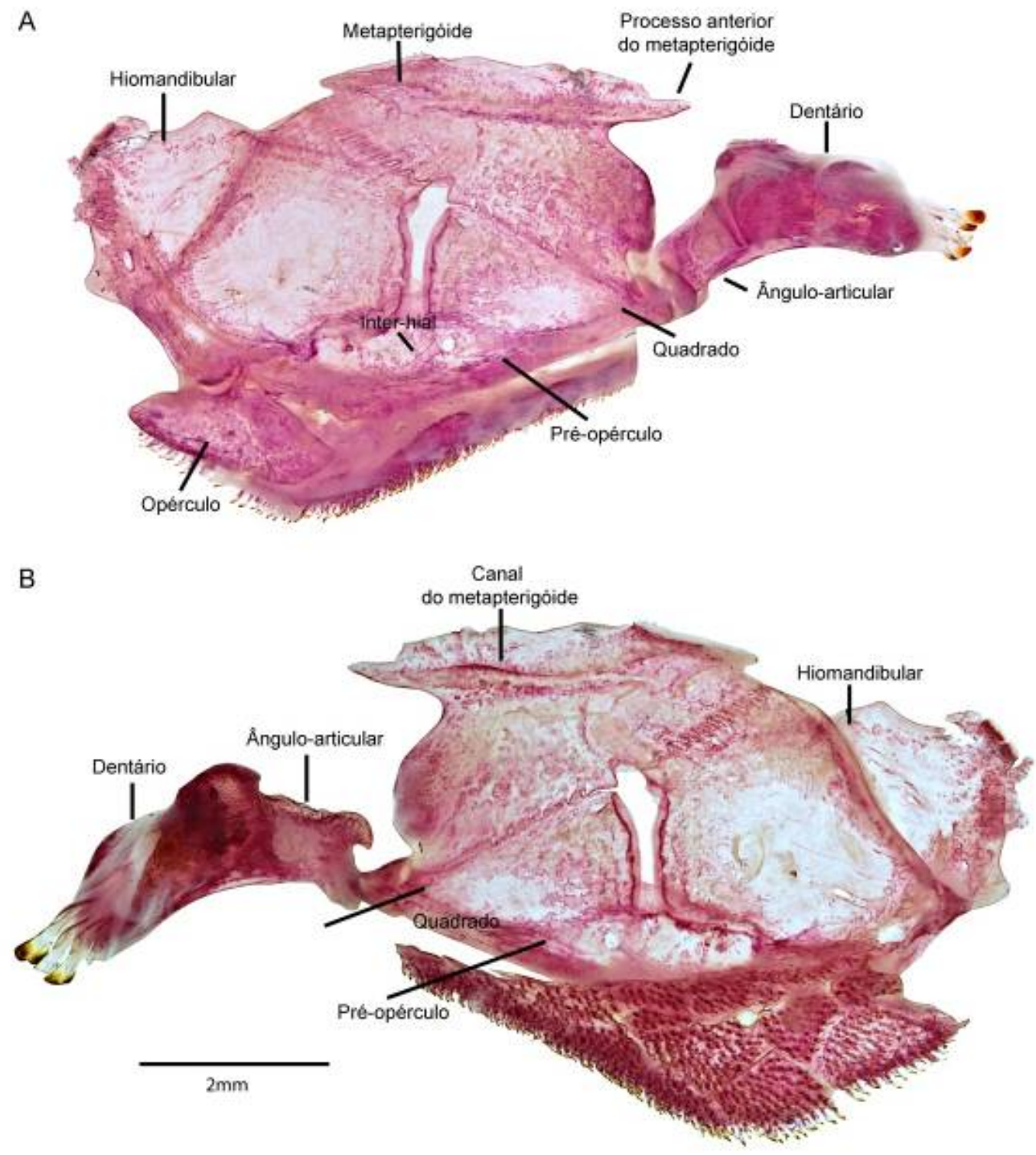

Figura 25. Suspensório de Spectracanthicus murinus; (A) vista ventral e (B) vista lateral. 


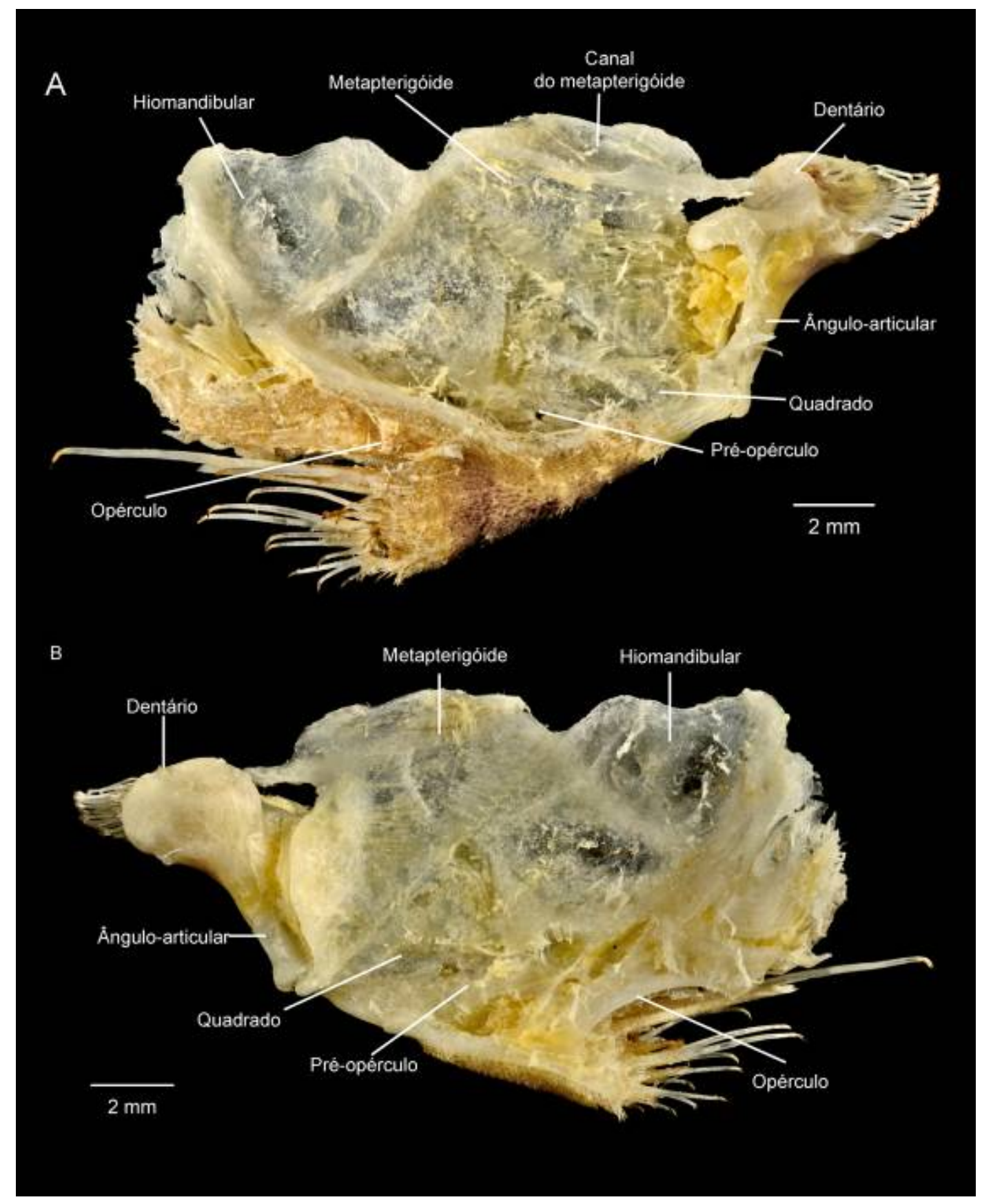

Figura 26. Suspensório de S. punctatissimus, (A) vista lateral e (B) vista ventral. 


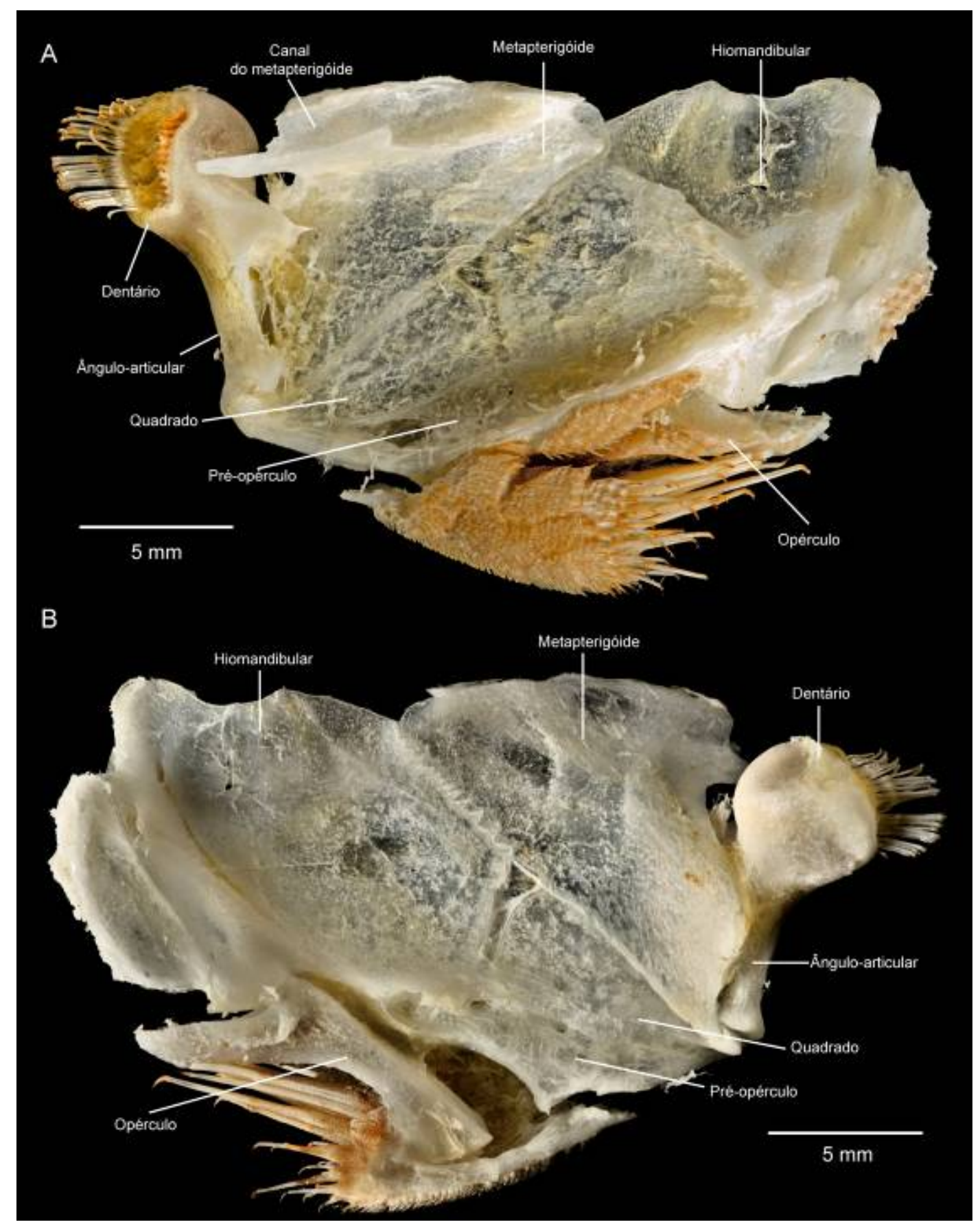

Figura 27. Suspensório de Spectracanthicus sp. "bola branca", (A) vista lateral e (B) vista dorsal. 


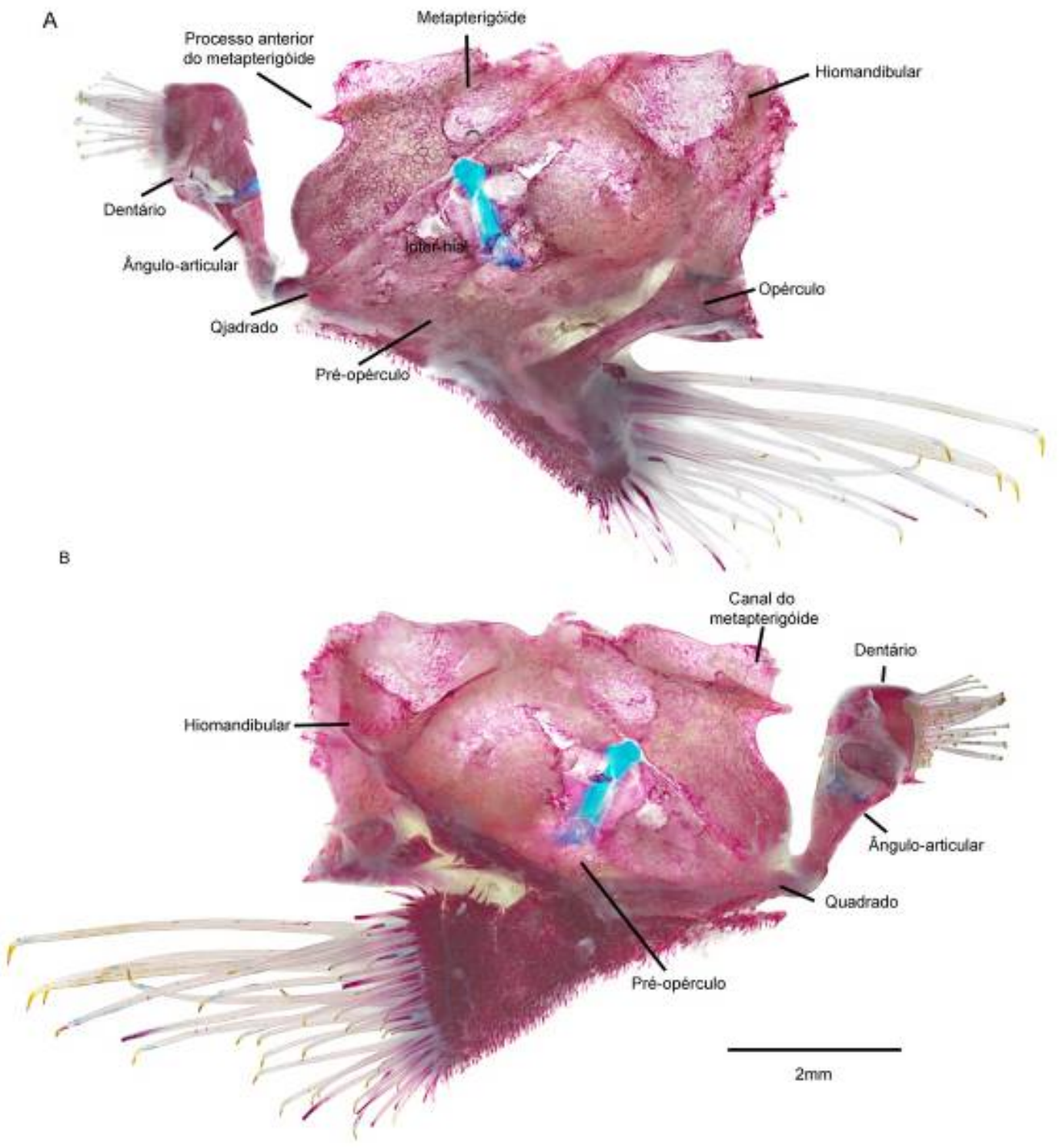

Figura 28. Suspensório de Spectracanthicus sp. “Tapajós”, (A) vista lateral e (B) vista ventral. 


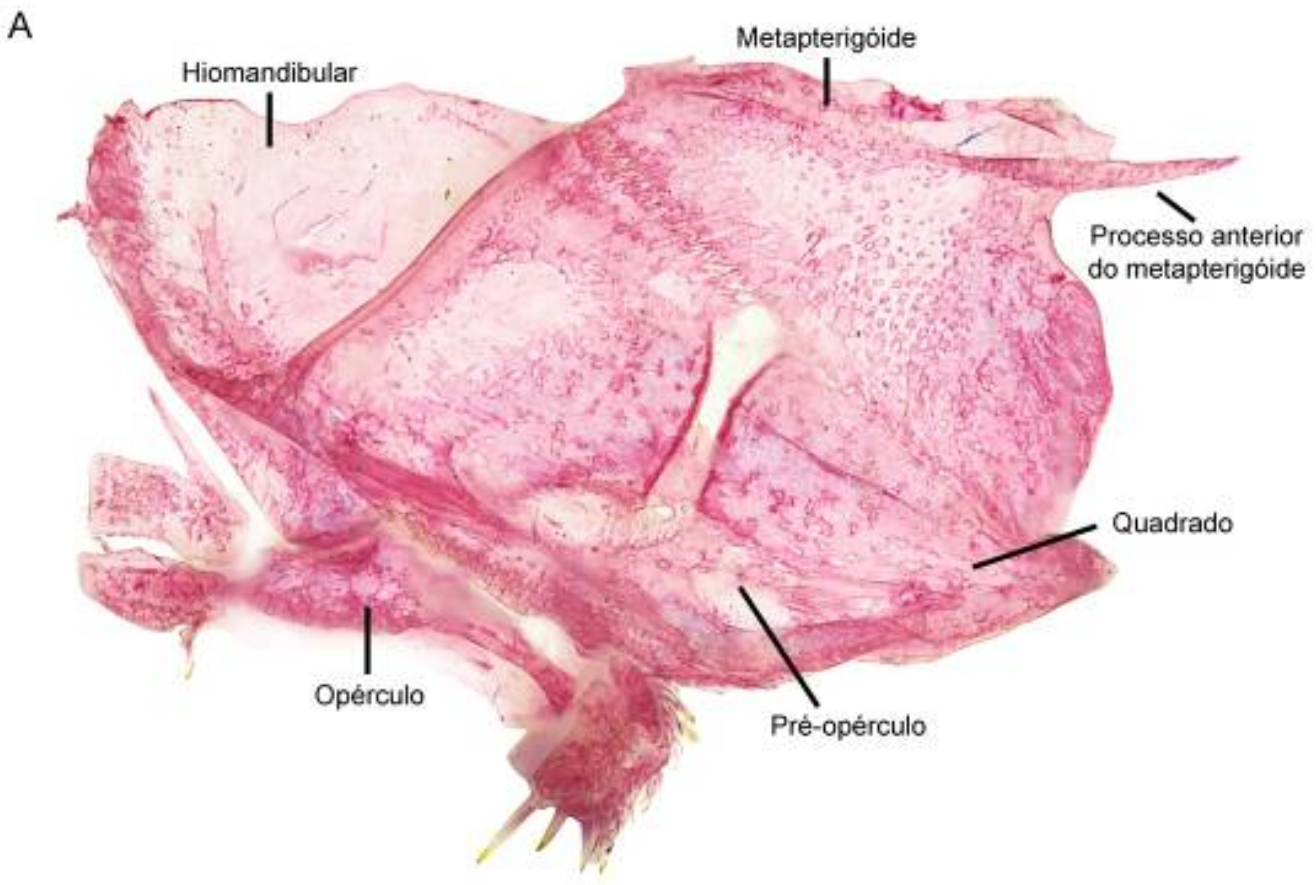

B

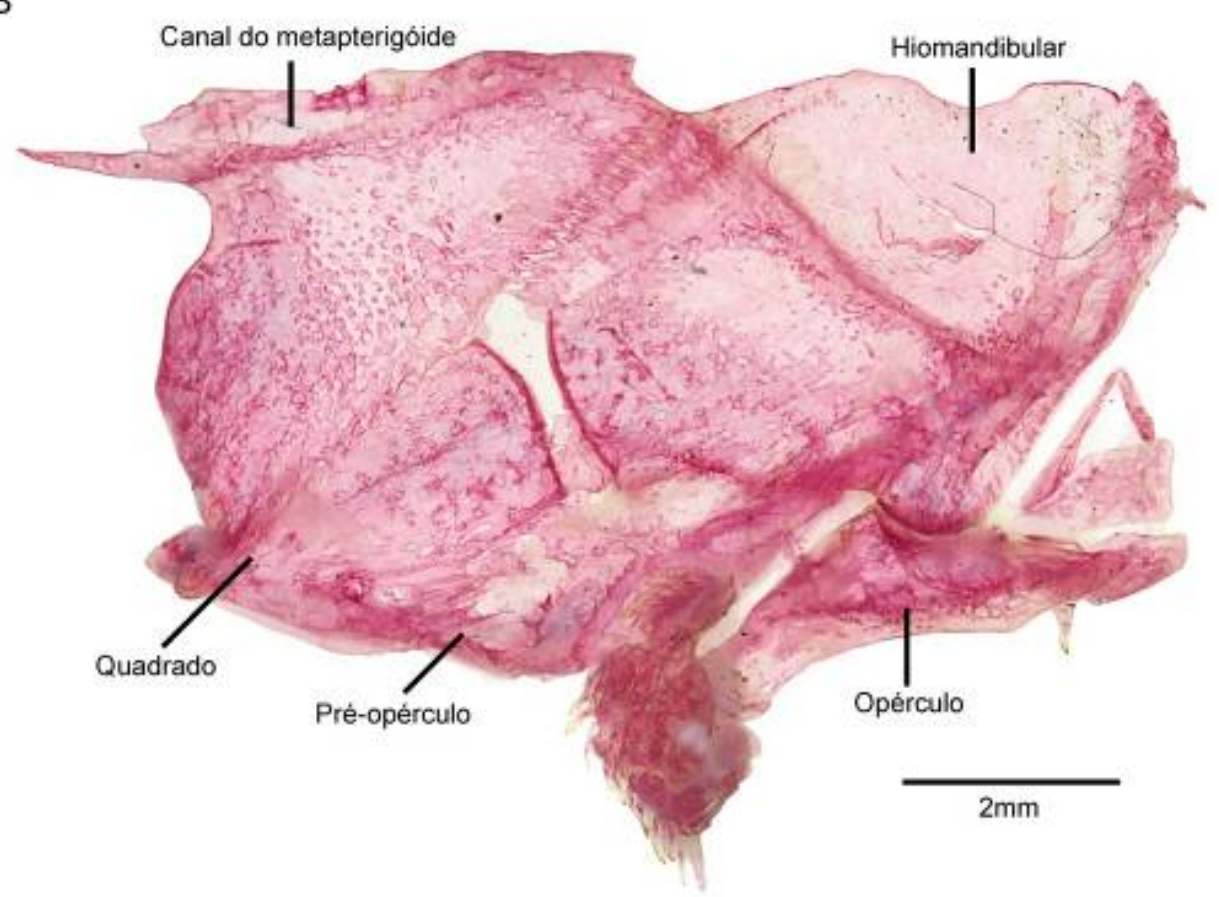

Figura 29. Suspensório de Spectracanthicus sp. "Tocantins", (A) vista lateral e (B) vista dorsal. 


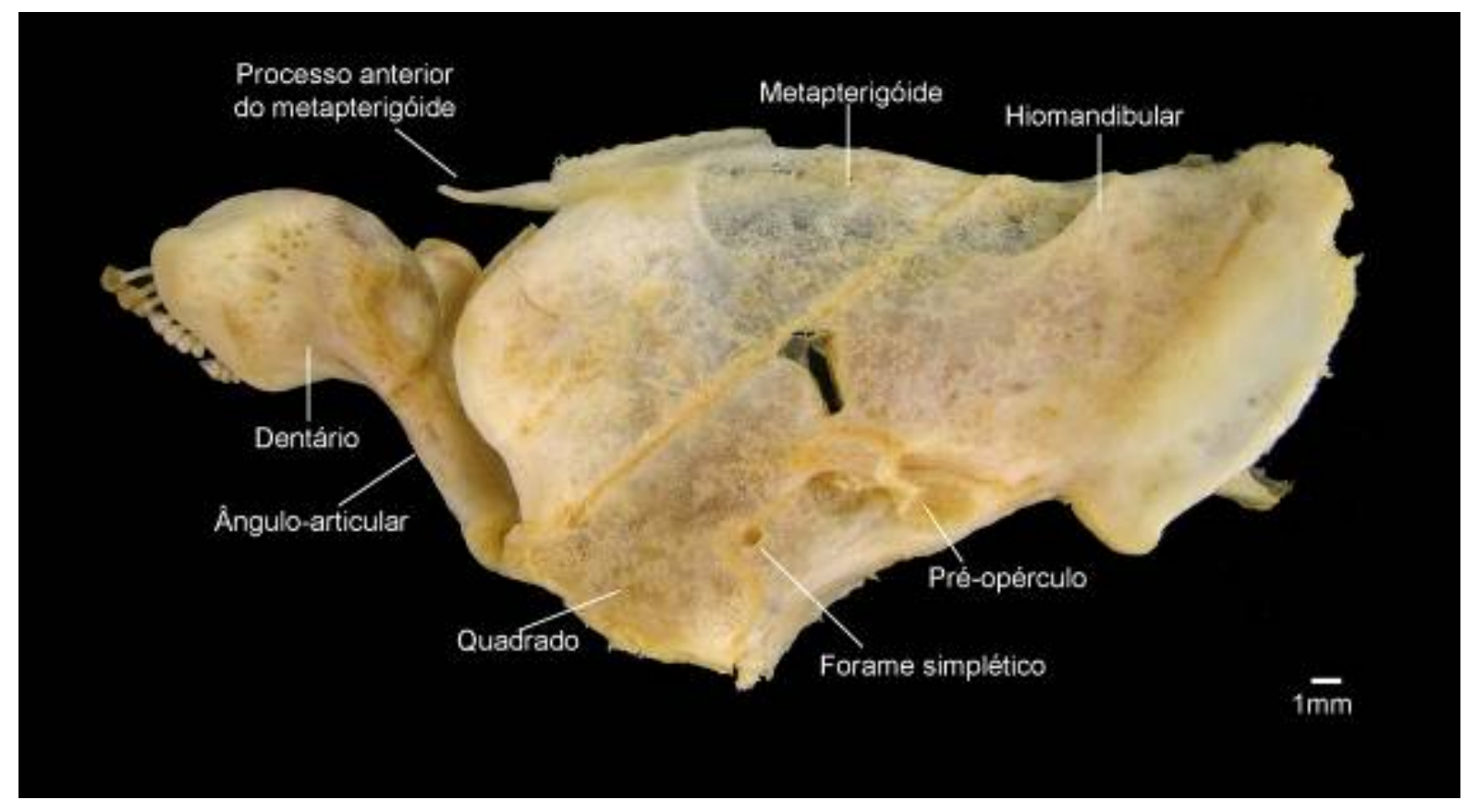

Figura 30. Suspensório de Panaque gr. nigrolineatus, vista ventral. 


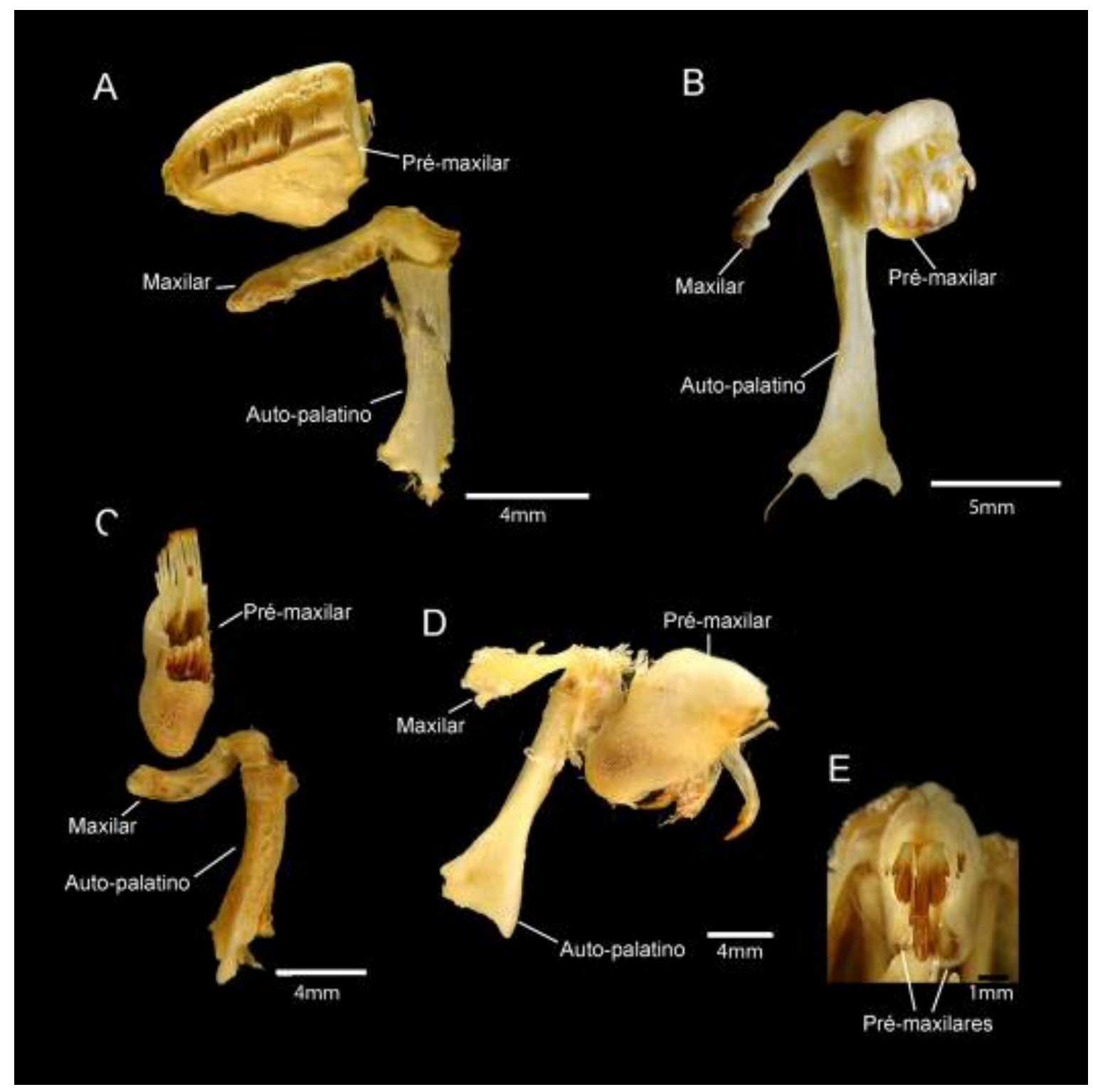

Figura 31. Auto-palatino, maxilar e pré maxilar de (A) Acanthicus hystrix, (B) Megalancistrus barrae, (C) Pseudacanthicus sp. "aba laranja", (D) e (E) Leporacanthicus galaxias. 


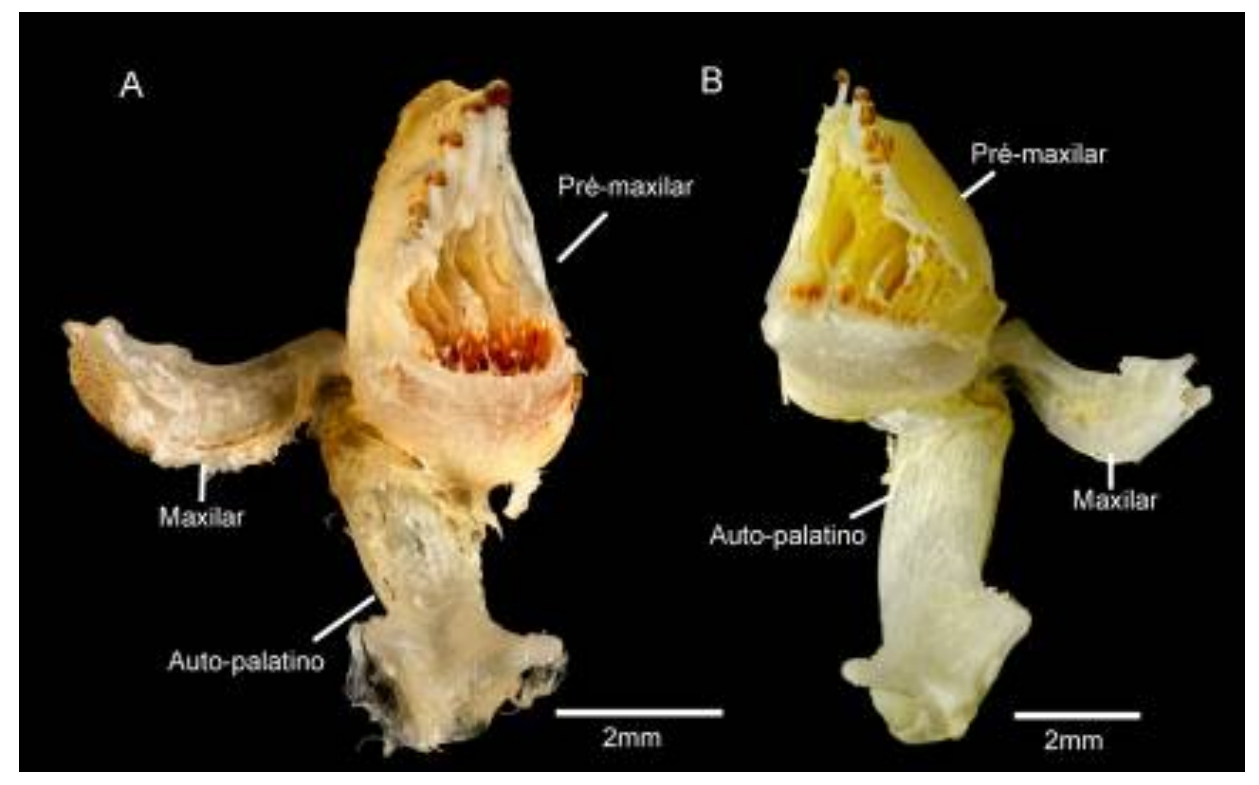

Figura 32. Auto-palatino, maxilar e pré maxilar de (A) Spectracanthicus punctatissimus e (B) Spectracanthicus sp "bola branca". 


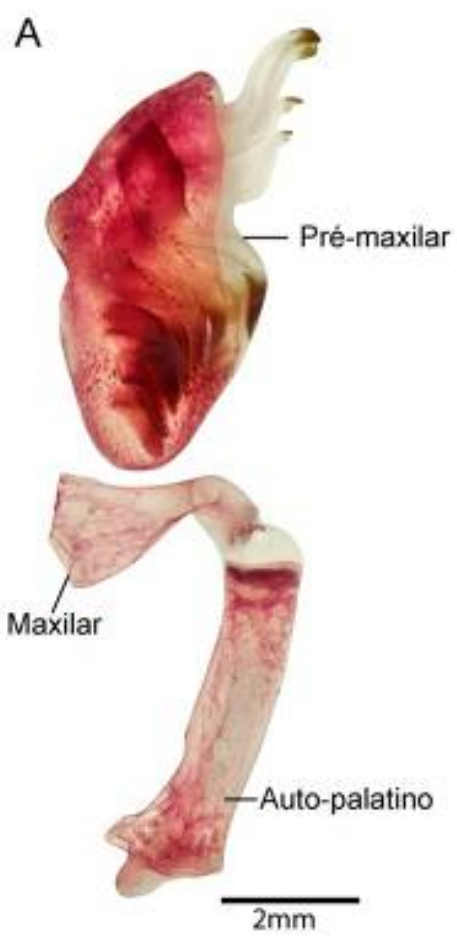

C

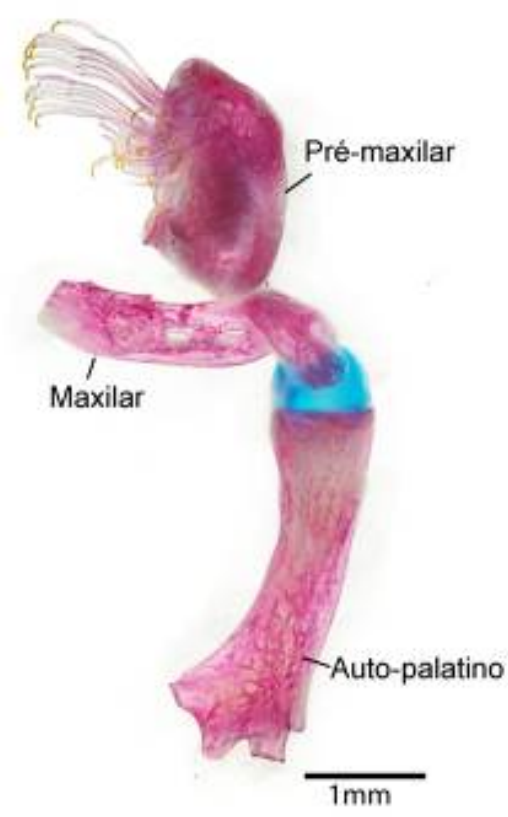

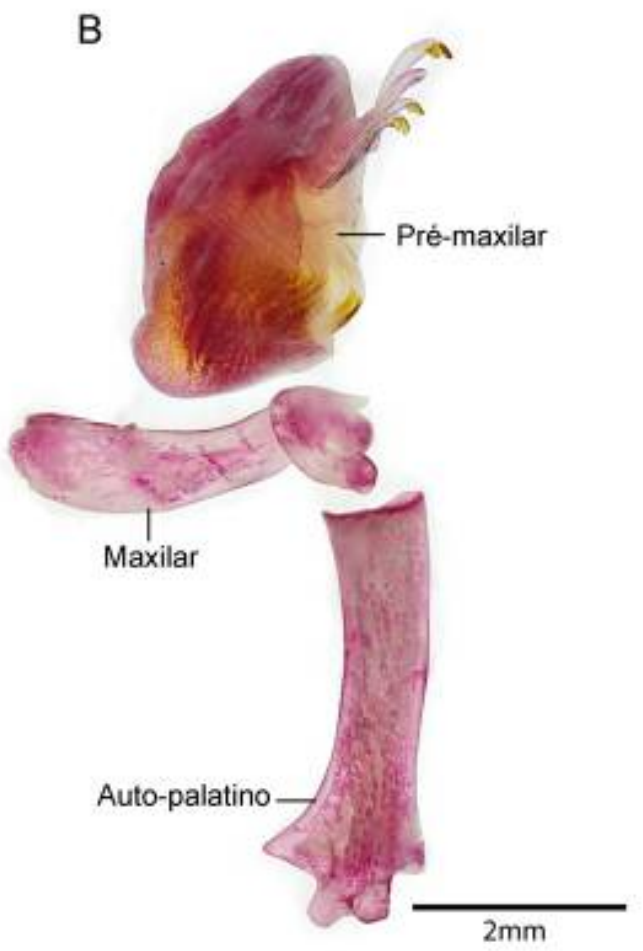

D

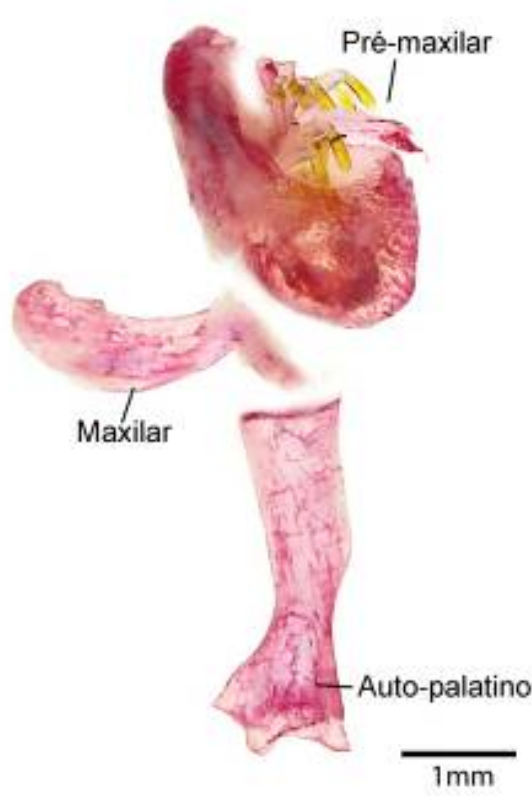

Figura 33. Auto-palatino, maxilar e pré maxilar de (A) S. murinus, (B) Spectracanthicus sp. "bola branca", (C) Spectracanthicus sp. "Tapajós" e (D) Spectracanthicus sp. "Tocantins". 


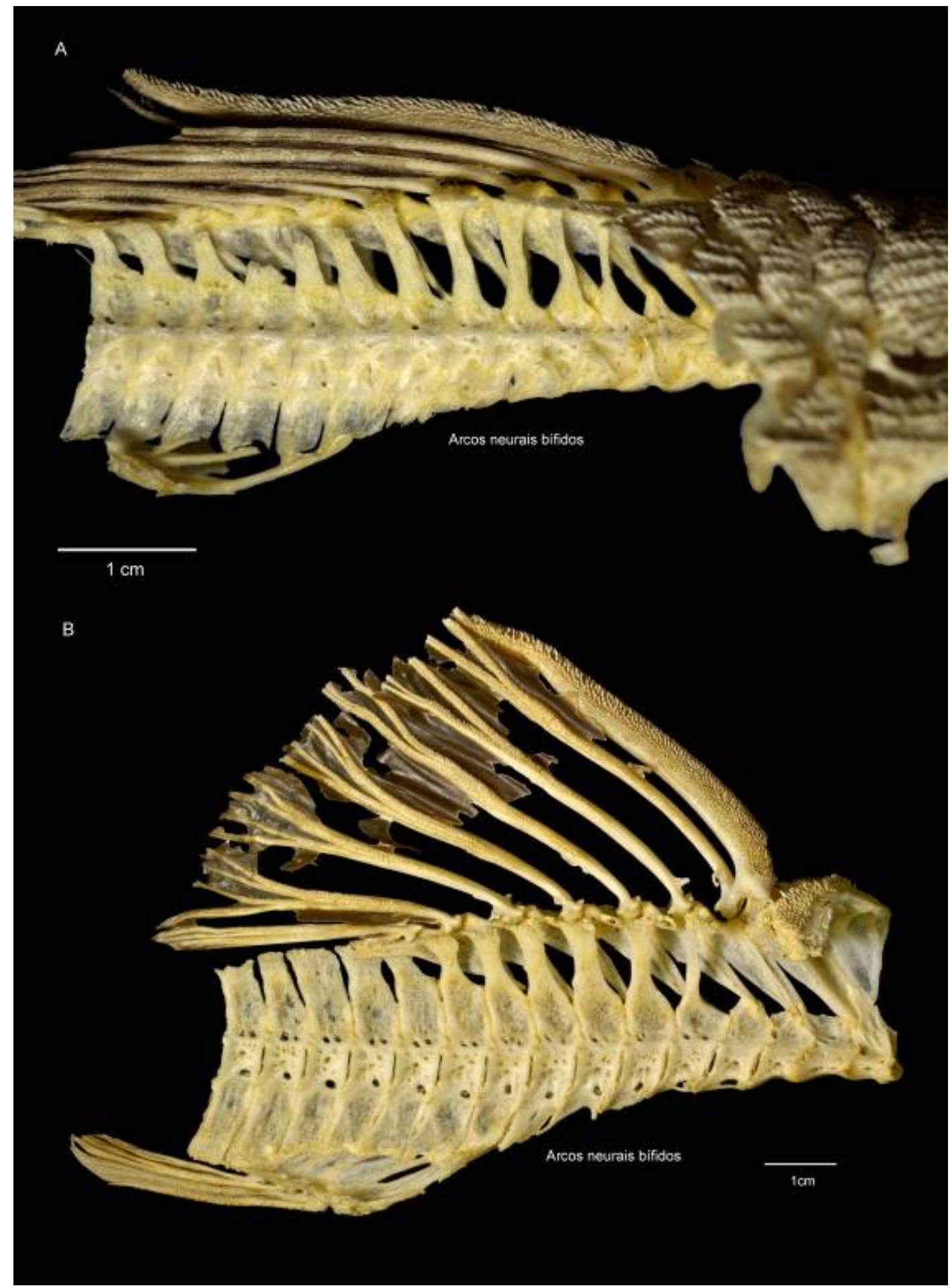

Figura 34. Esqueleto axial de (A) Megalancistrus barrae e (B) Panaque gr. nigrolineatus. 


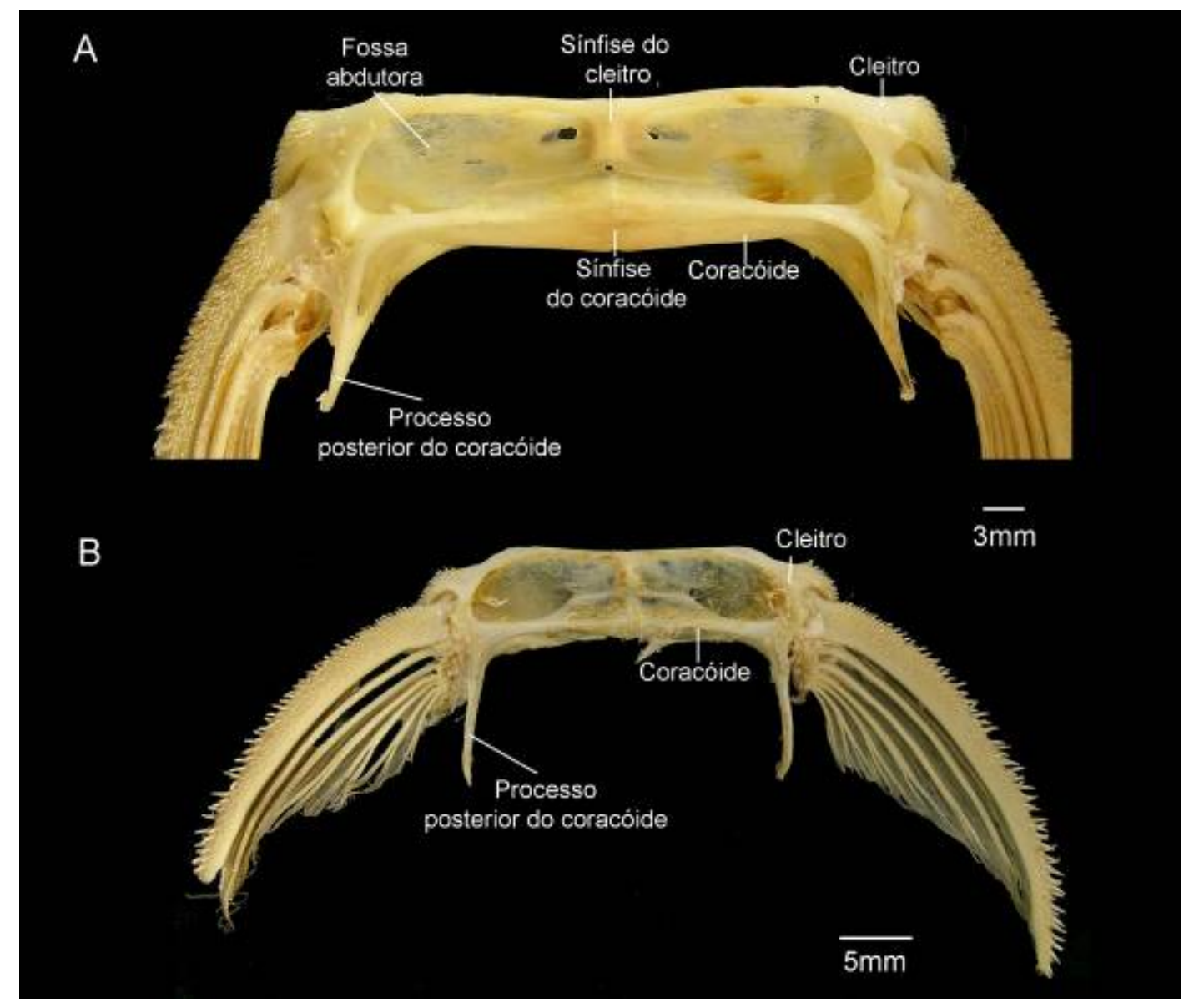

Figura 35. Cintura peitoral de (A) Leporacanthicus galaxias e (B) Acanthicus hystrix. 


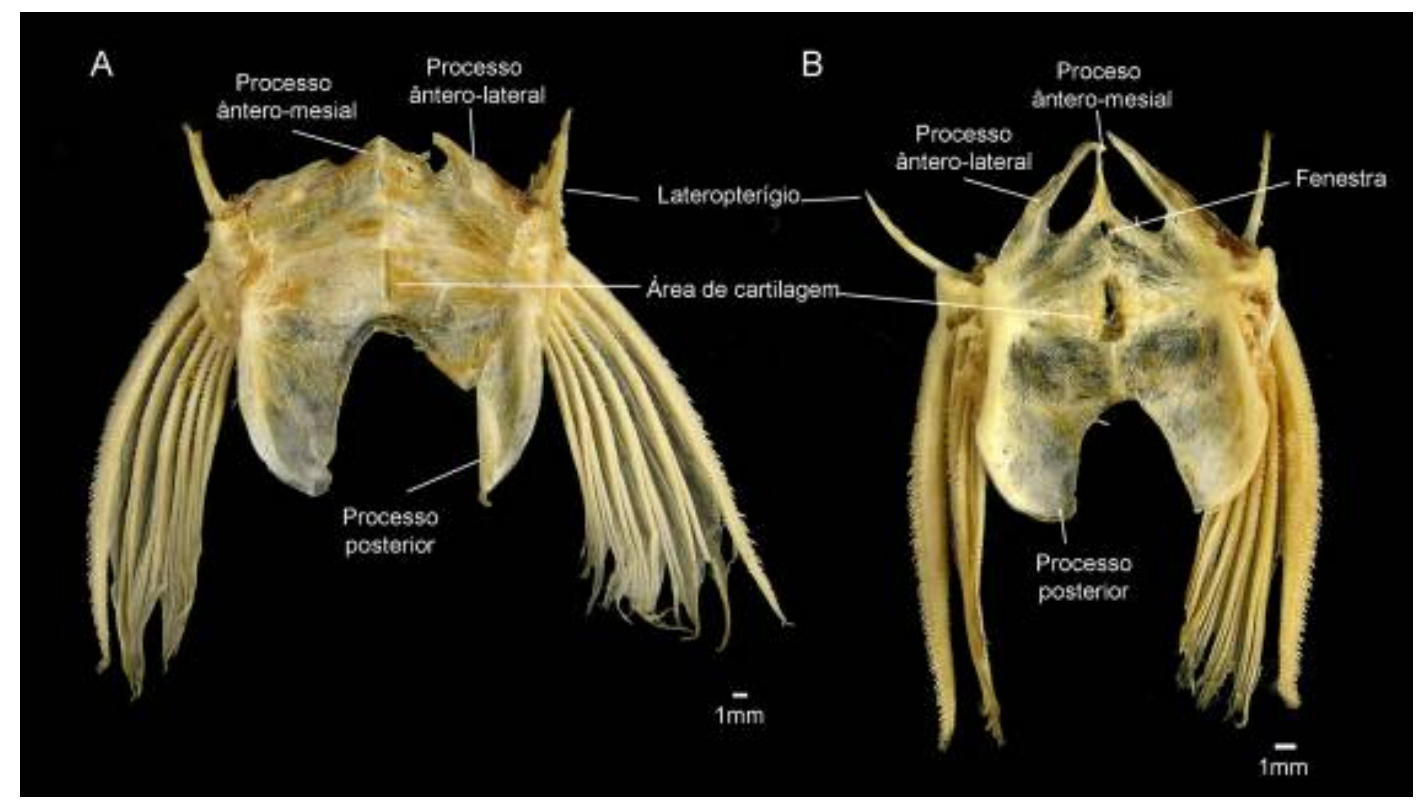

Figura 36. Cintura pélvica em (A) Acanthicus hystrix e (B) Leporacanthicus galaxias. 

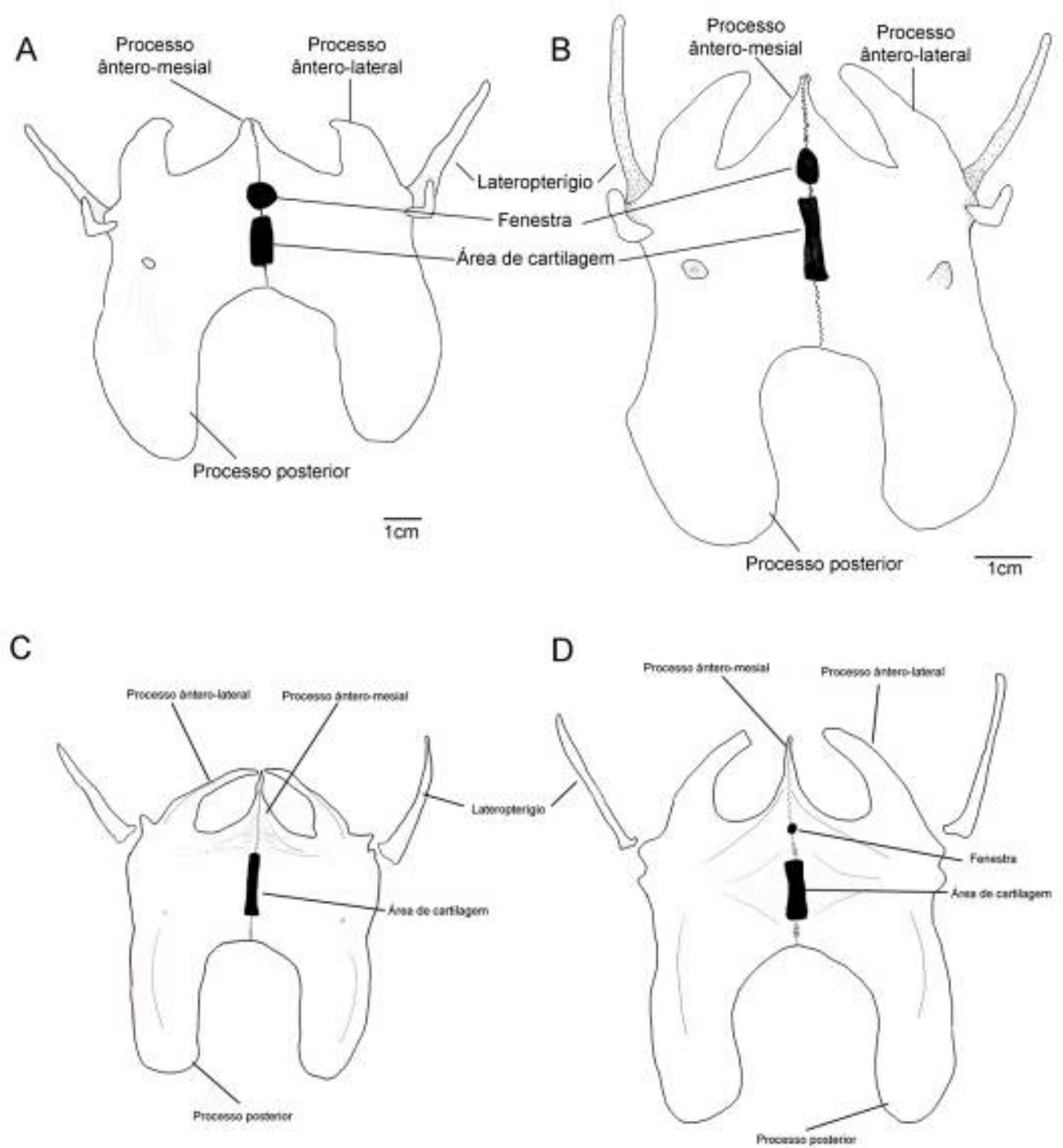

Figura 37. Cintura pélvica de (A) Megalancistrus parananus, (B) Pseudacanthicus sp. "aba laranja", (C) P. leopardus e (D) P. spinosus. 

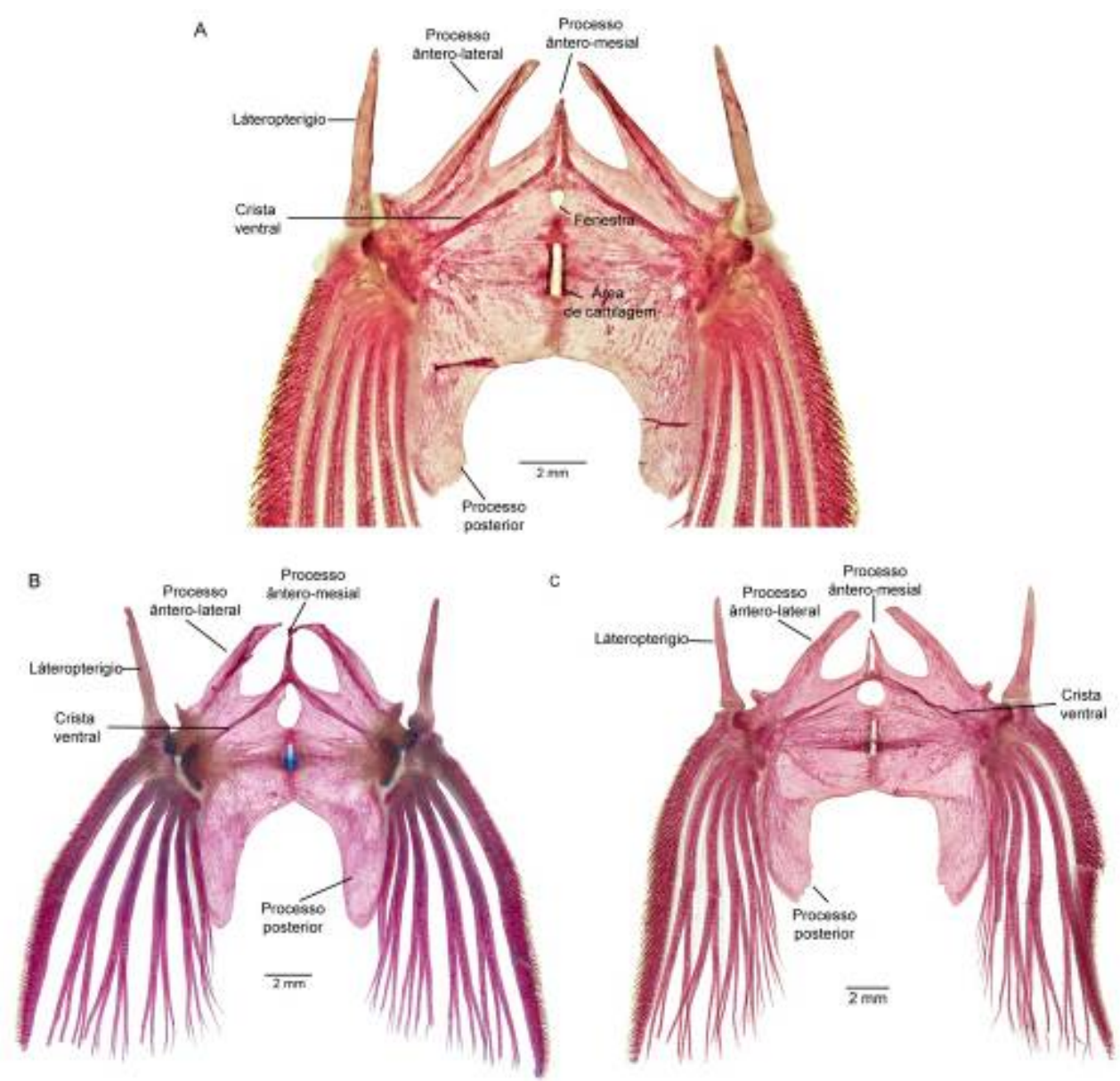

Figura 38. Cintura pélvica de (A) S. murinus, (B) Spectracanthicus sp. "Tapajós" e (C) Spectracanthicus sp. "Tocantins". 


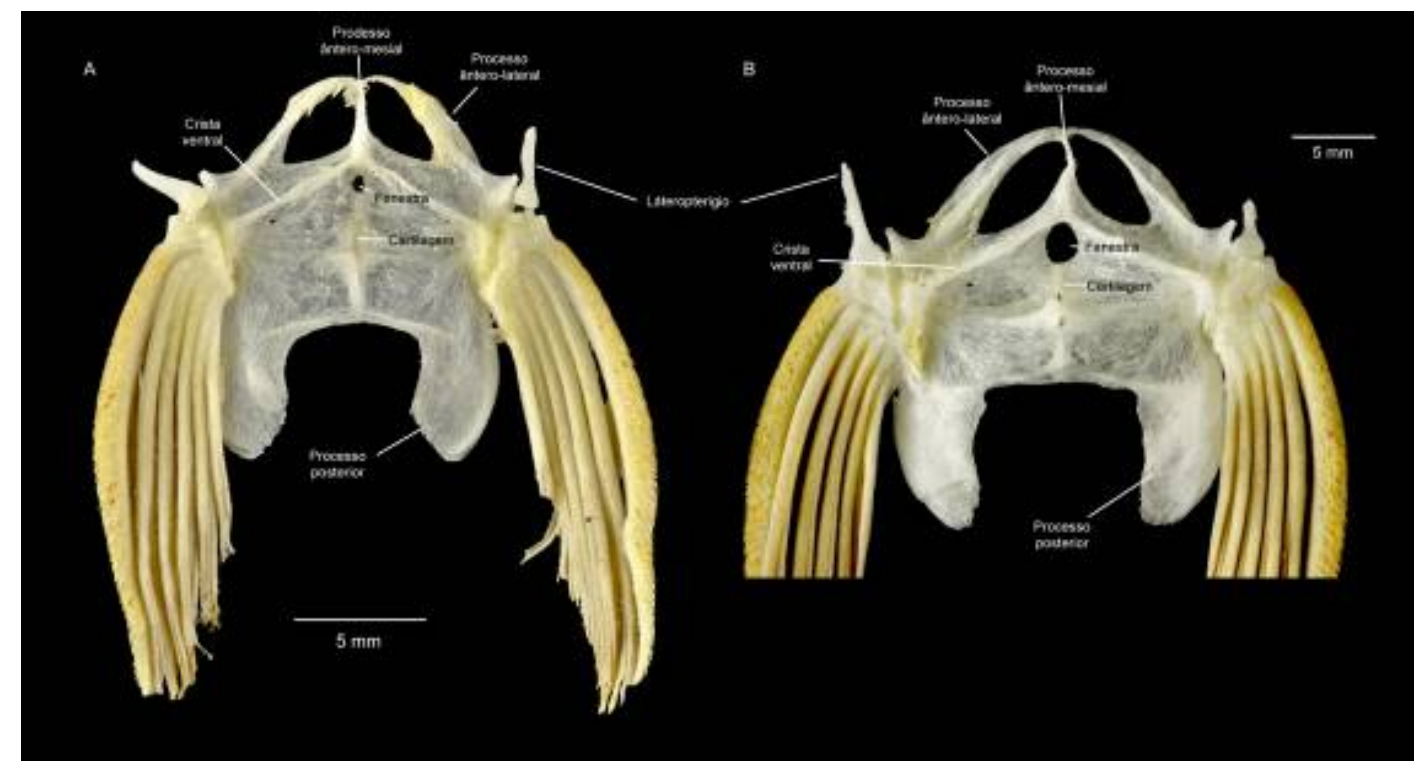

Figura 39. Cintura pélvica de (A) S. punctatissimus, (B) Spectracanthicus sp. “Tocantins”.

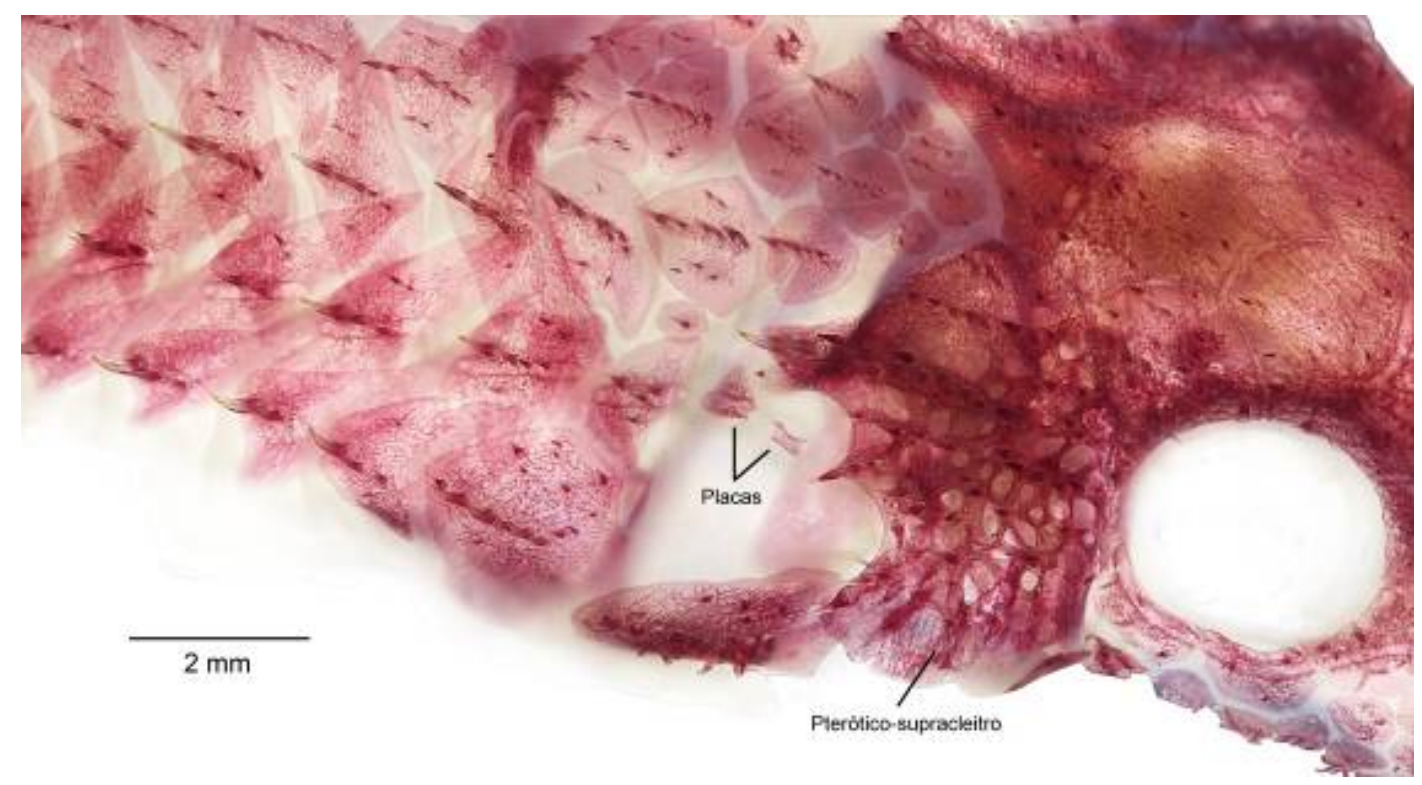

Figura 40. Vista lateral posterior ao pterótico-supracleitro de Pseudacanthicus spinosus. 


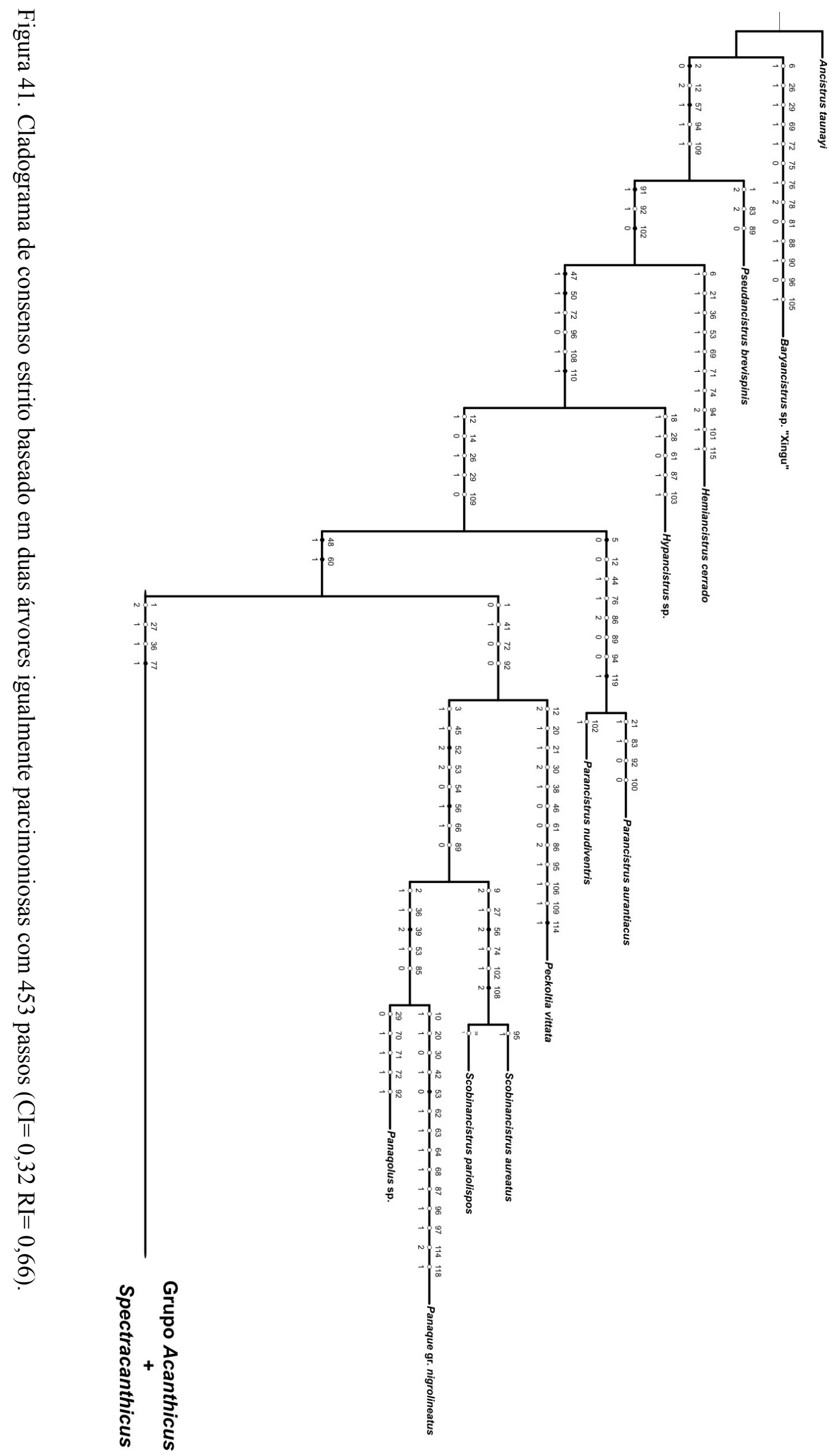




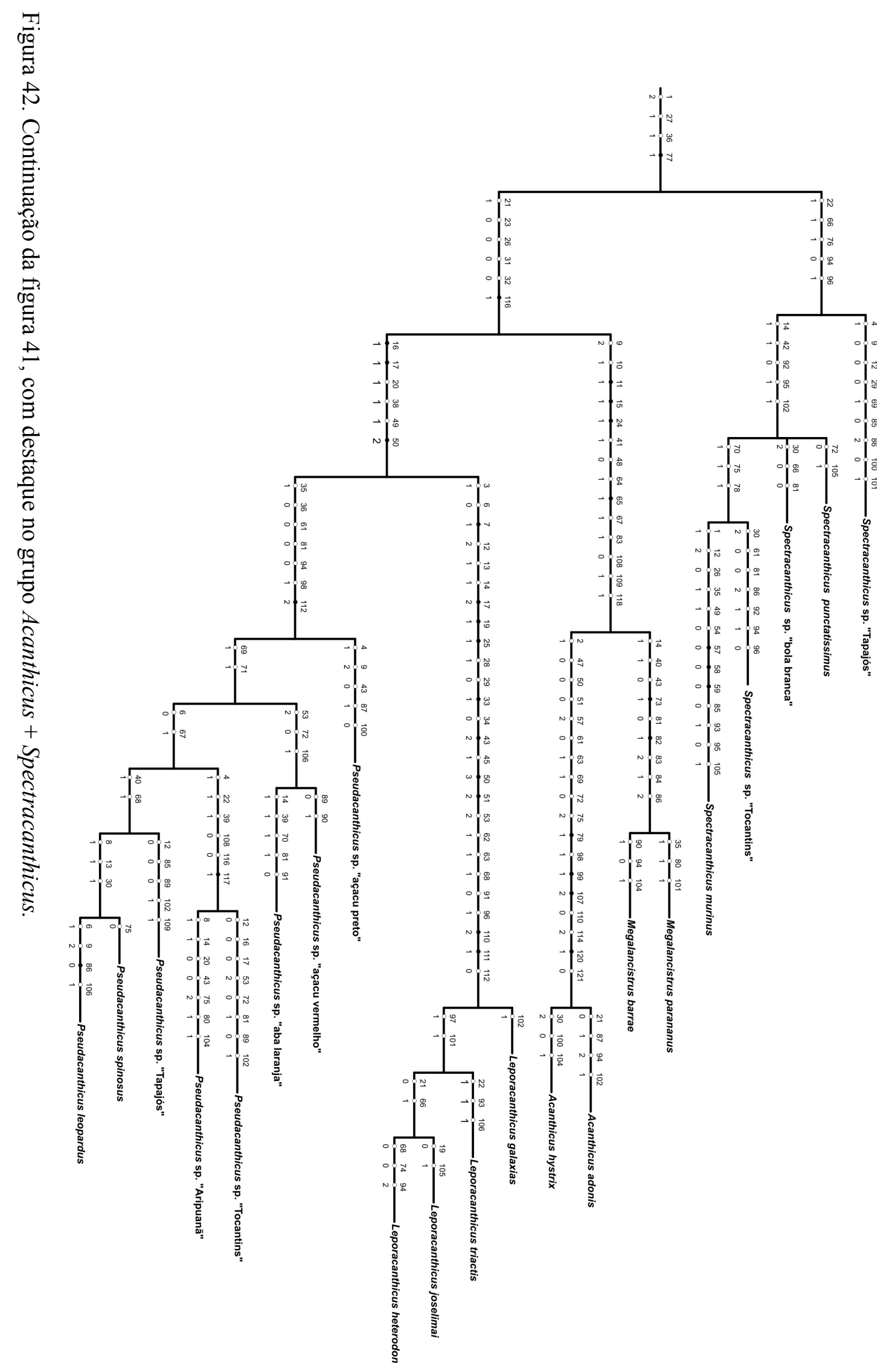




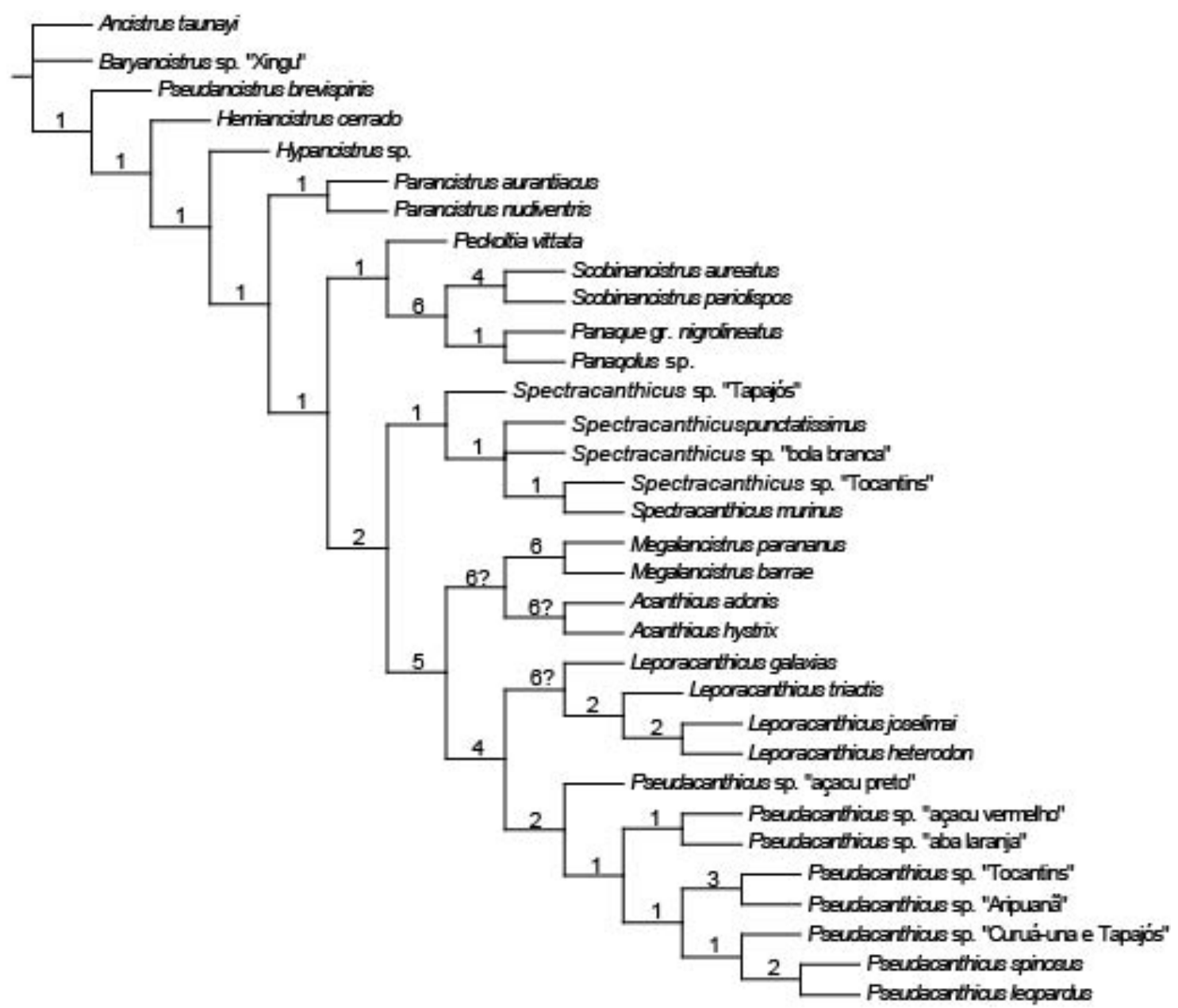

Figura 43. Árvore com suporte de Bremer. 


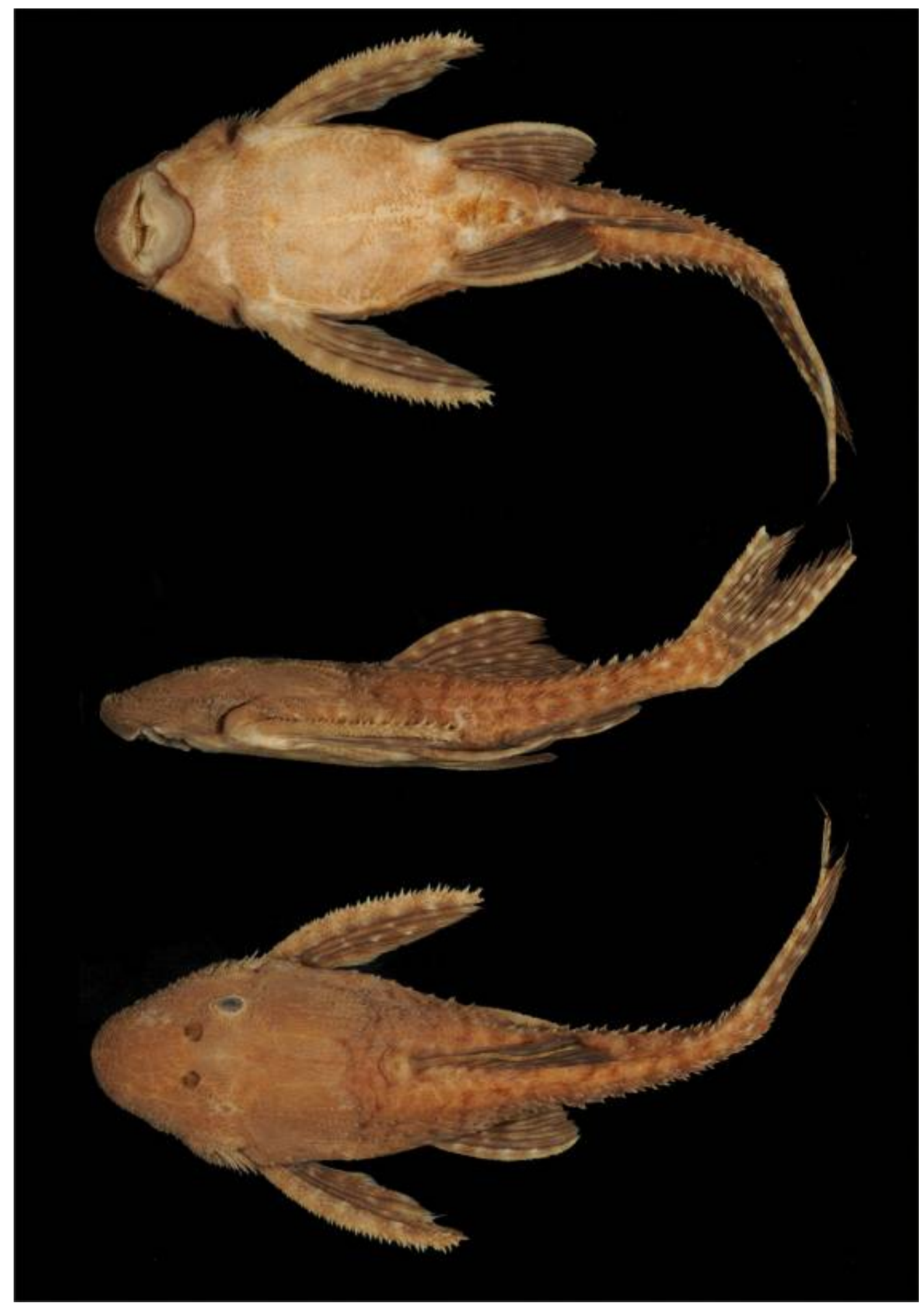

Figura 44. Holótipo de Acanthicus adonis, MZUSP 38580 - 134,6 mm CP. 


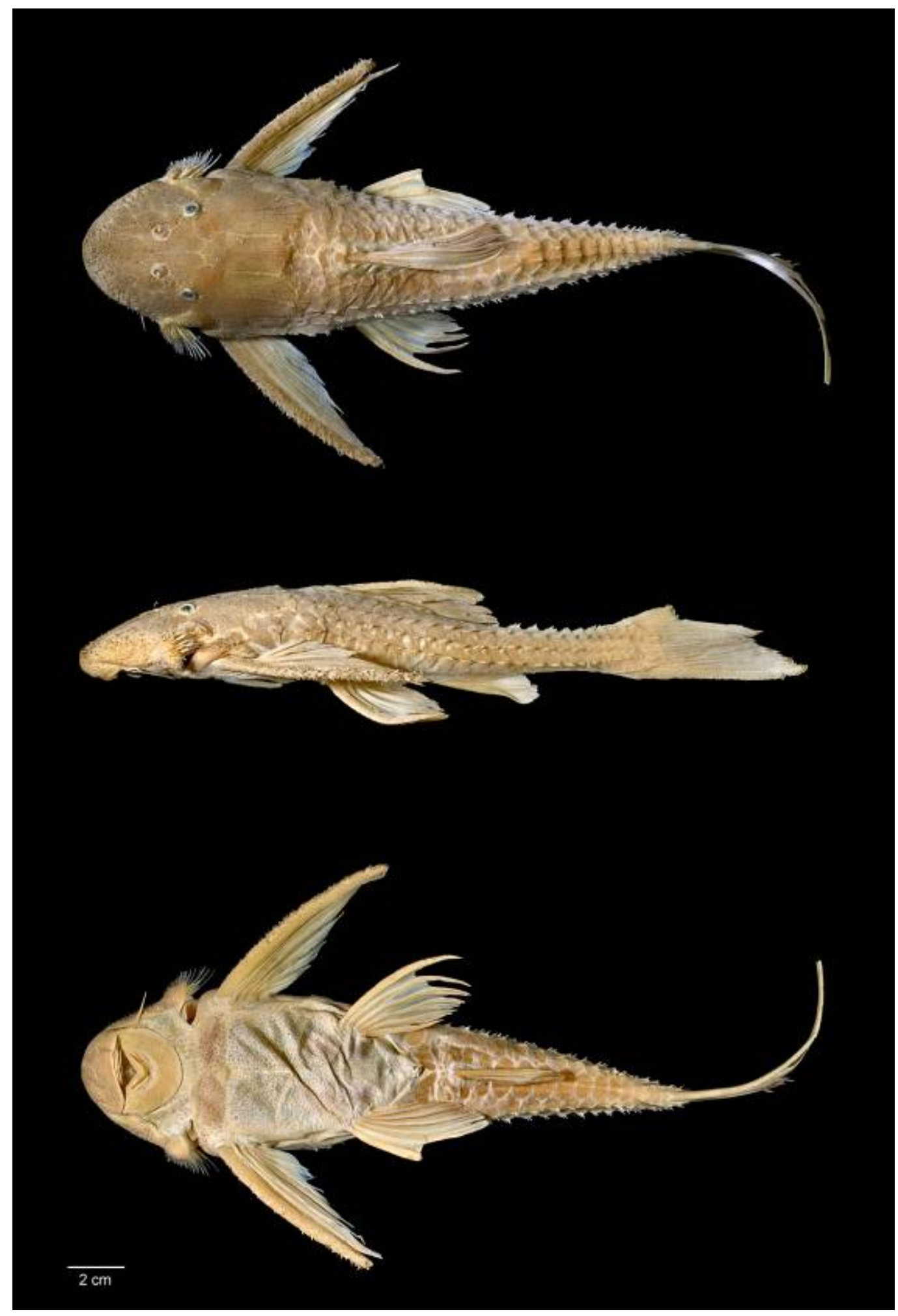

Figura 45. Neótipo de Acanthicus hystrix, MZUSP 103858 - 182,6 mm CP. 


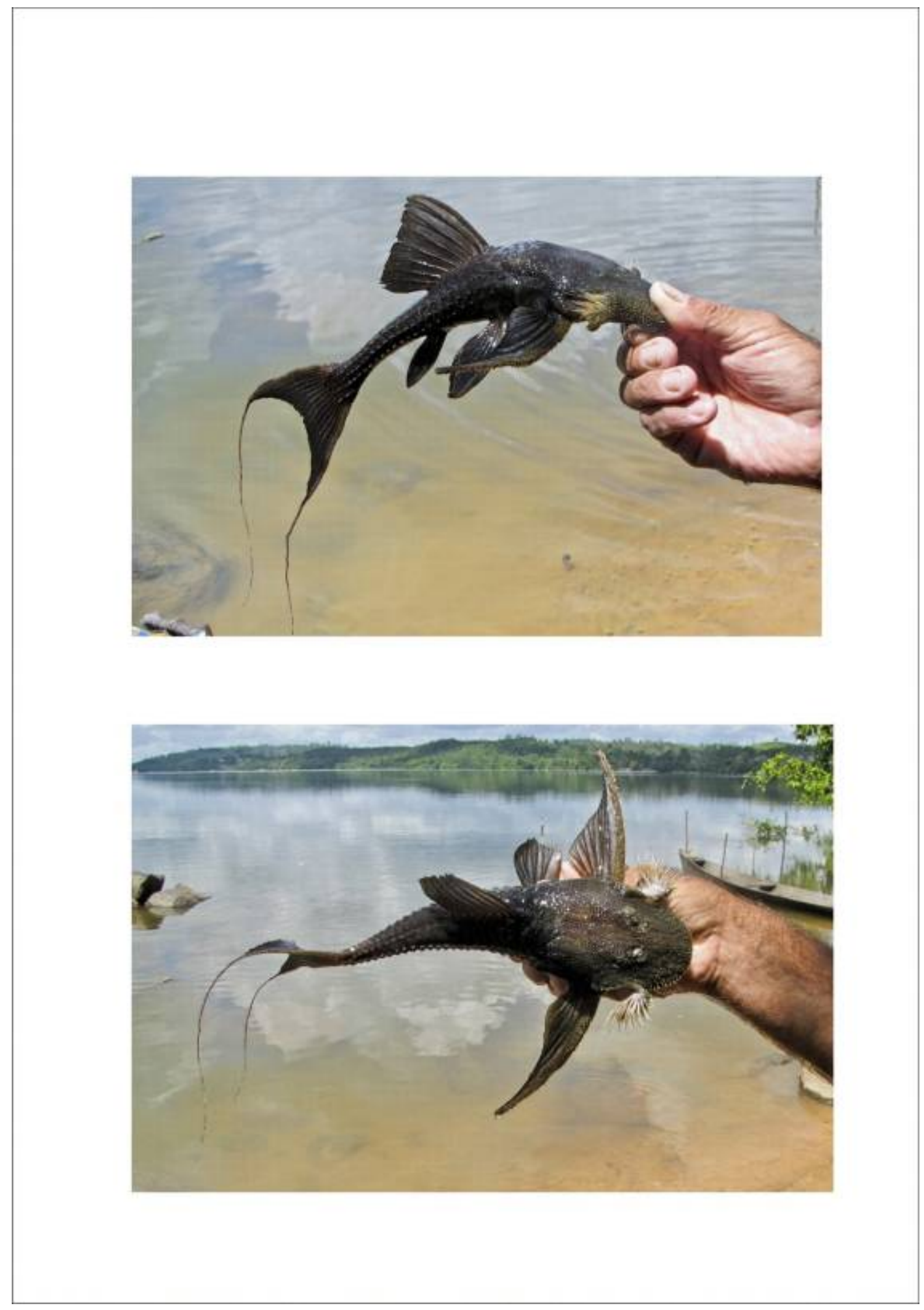

Figura 46. Acanthicus hystrix vivo, rio Xingu. 


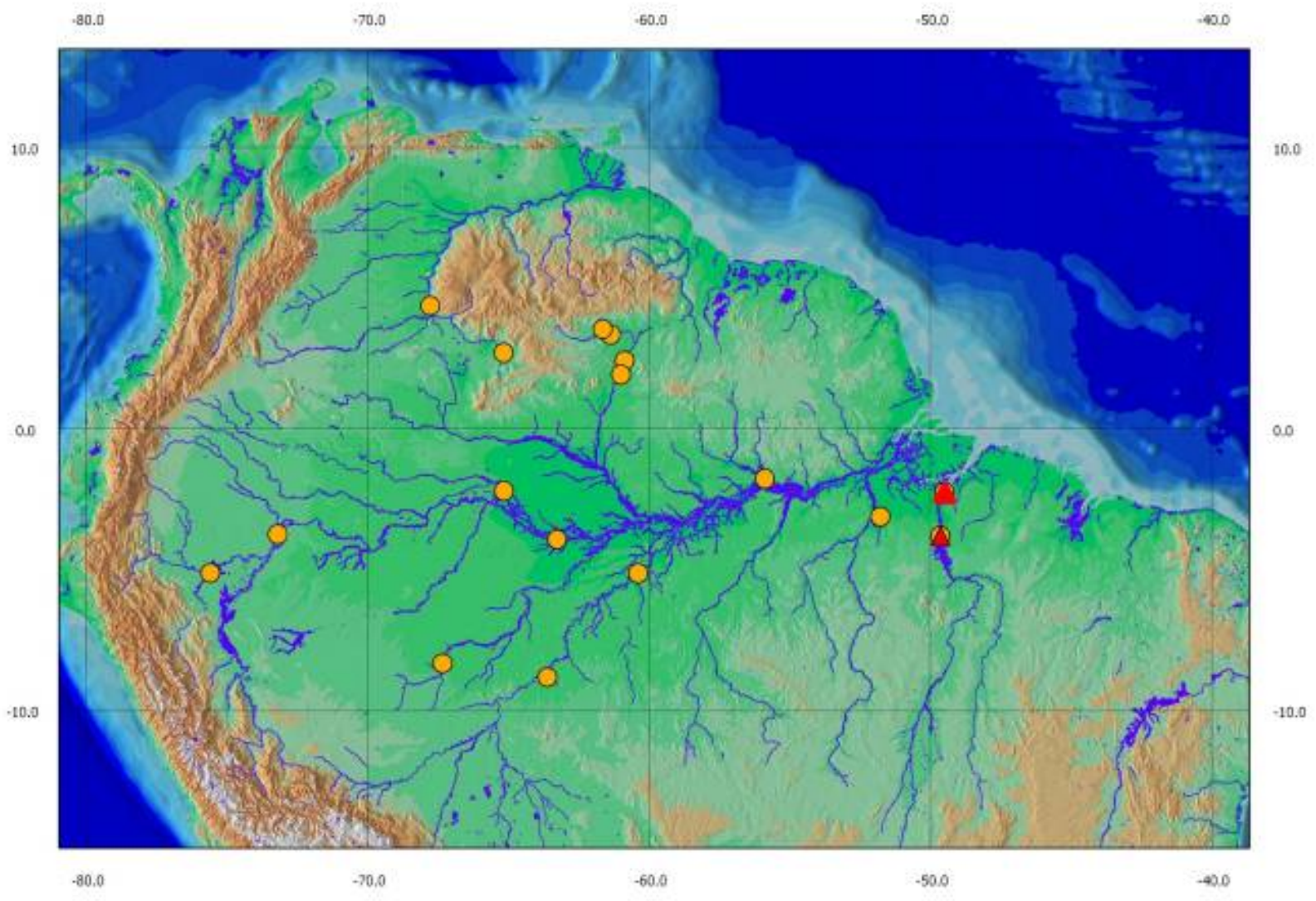

Figura 47. Mapa de distribuição de Acanthicus adonis (triângulo vermelho) e A. hystrix (círculo laranja). Símbolo aberto representa a localidade tipo. 

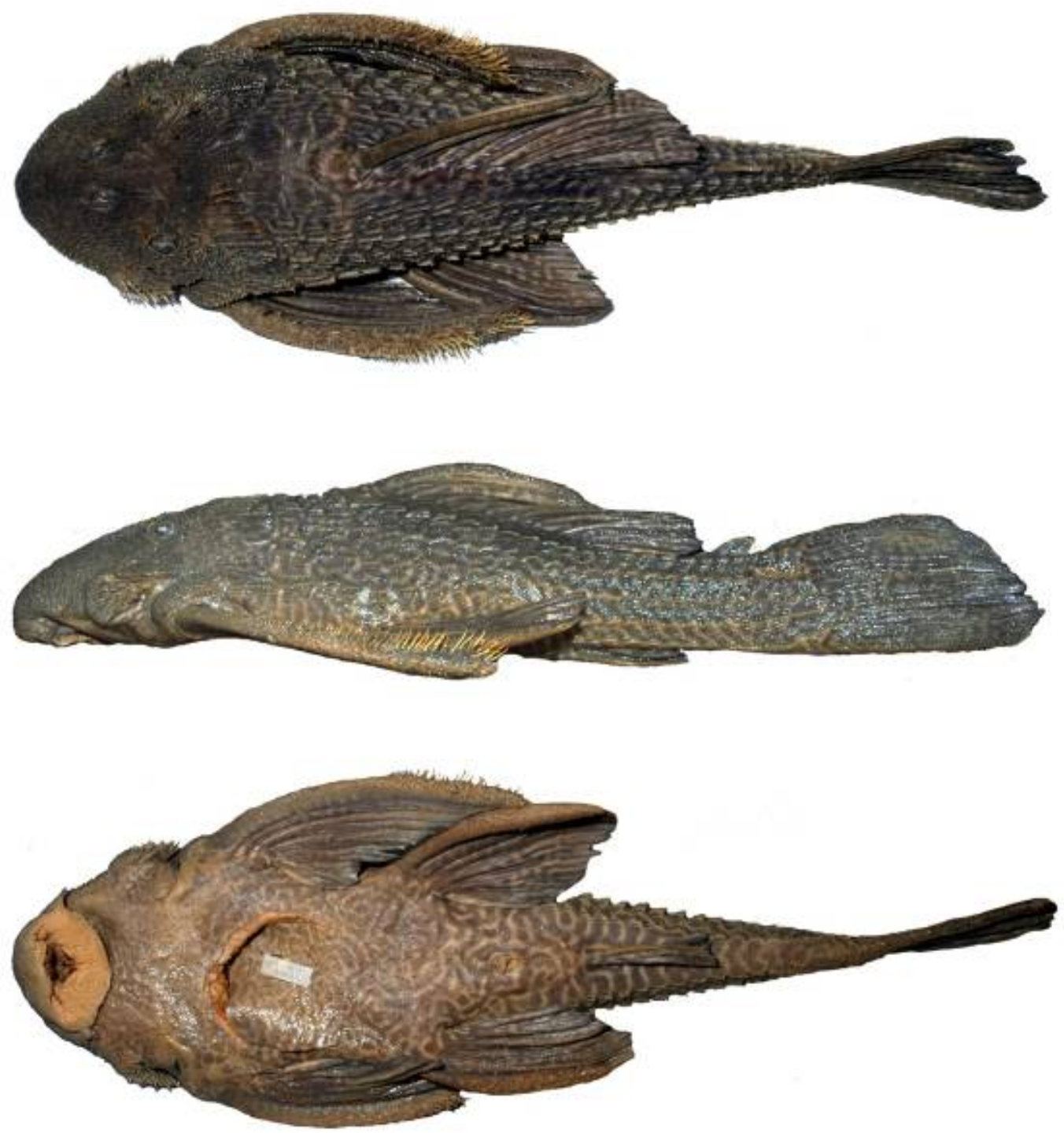

Figura 48. Síntipo de Megalancistrus barrae, NMW 48019 - 399,4 mm CP. 


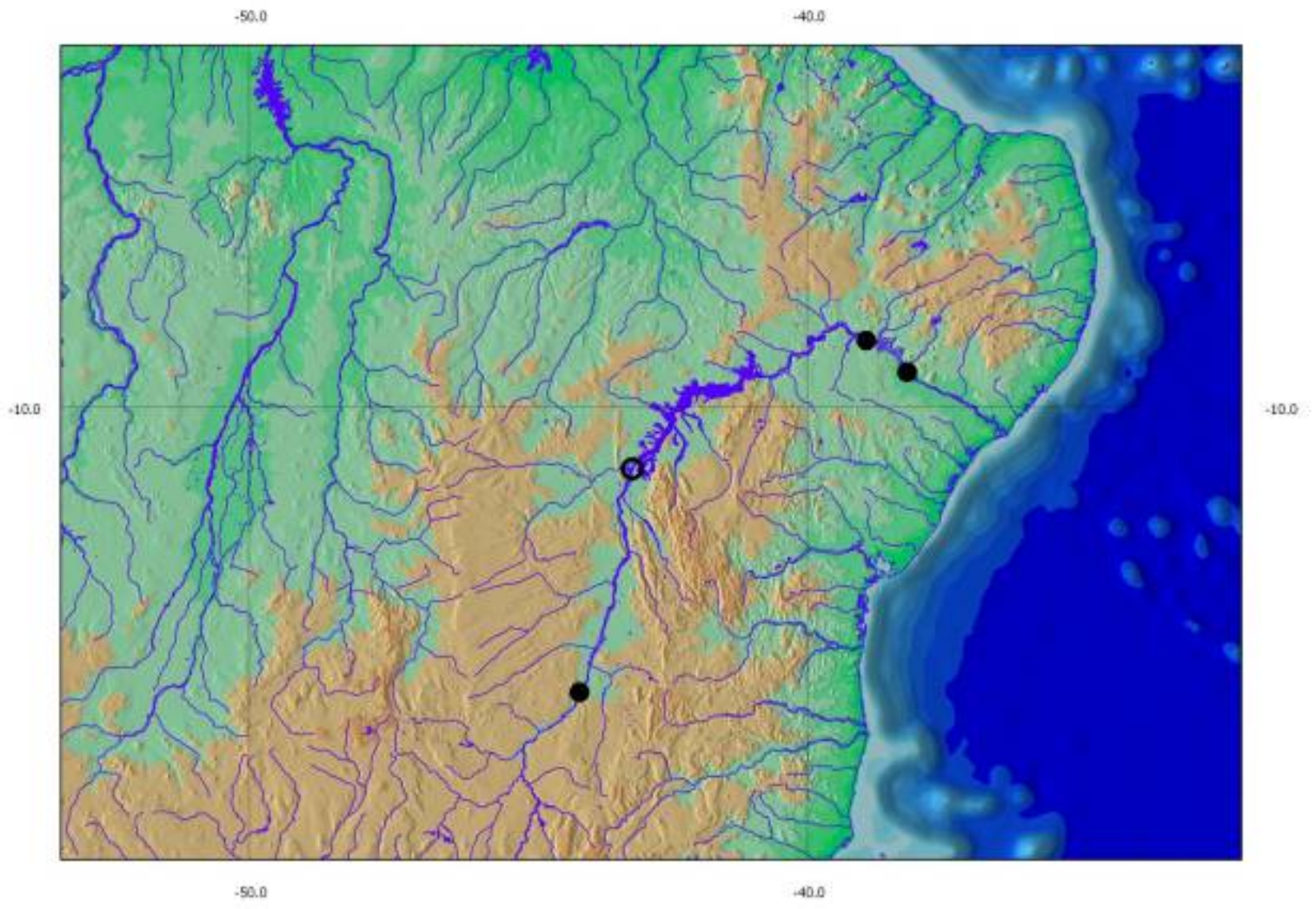

Figura 49. Mapa de distribuição de Megalancistrus barrae, símbolo aberto representa a localidade tipo. 


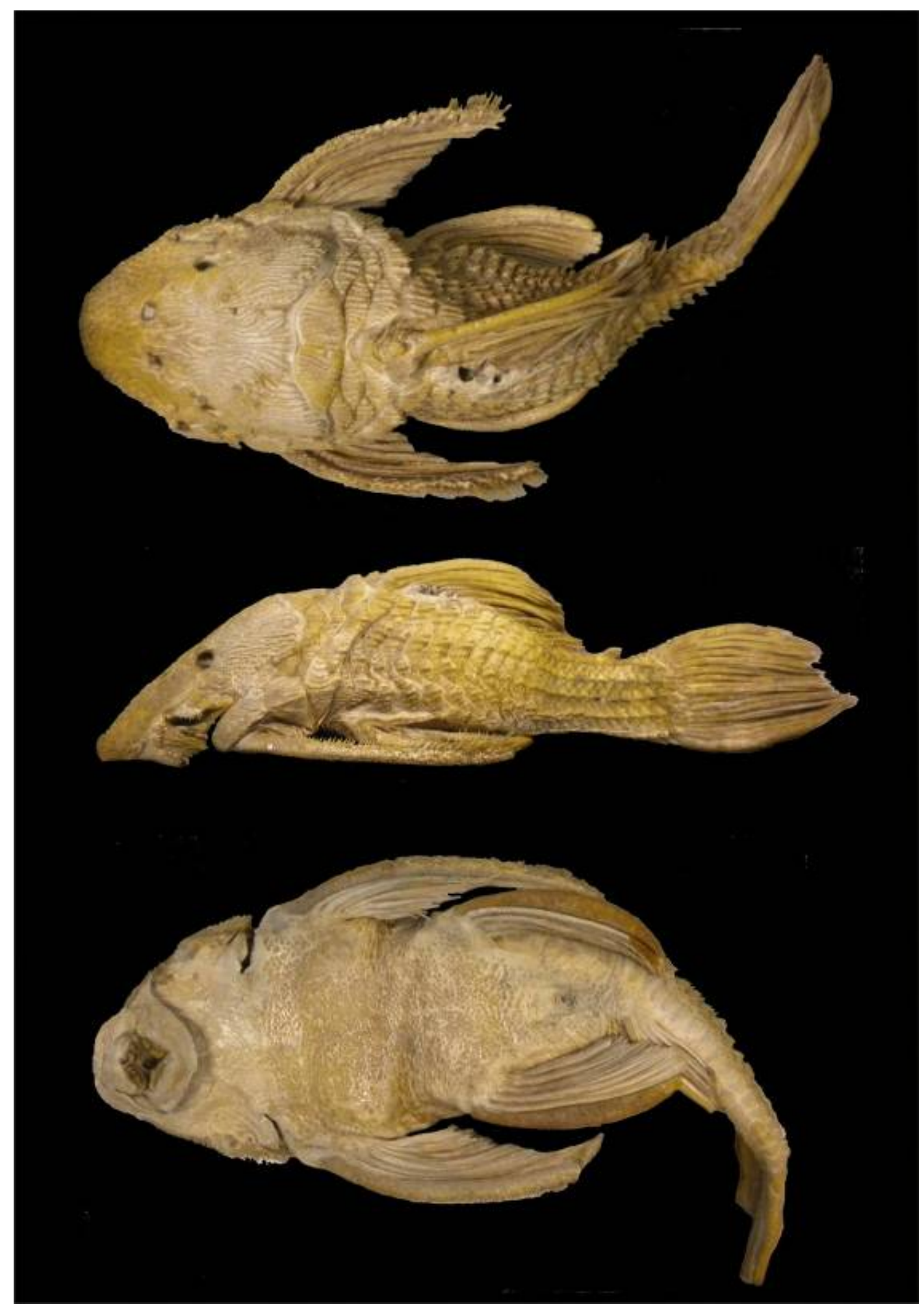

Figura 50. Holótipo de Megalancistrus parananus, ZMB 11328 - 462,5 mm CP. 


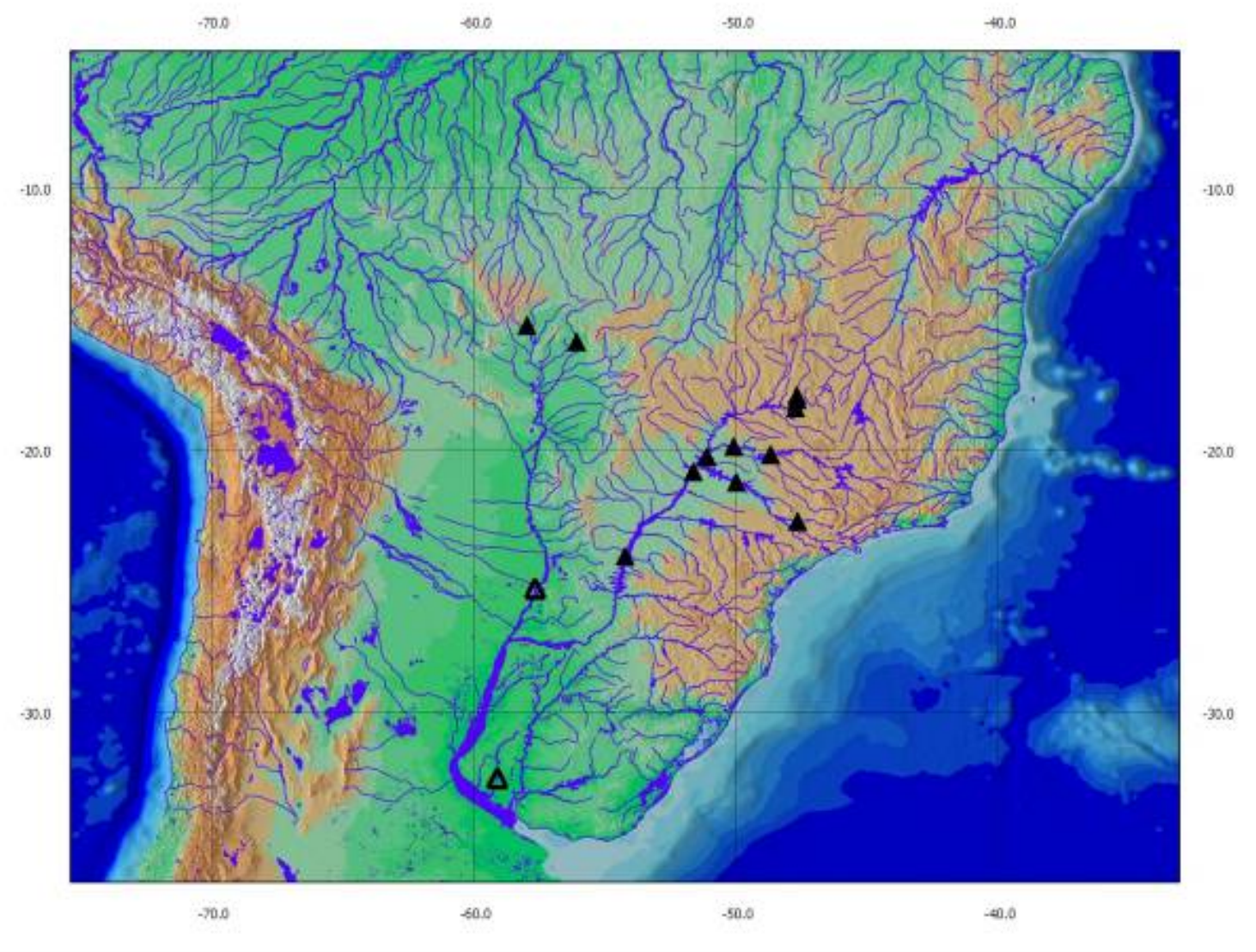

Figura 51. Mapa de distribuição de Megalancistrus parananus, símbolo aberto representa a localidade tipo. 


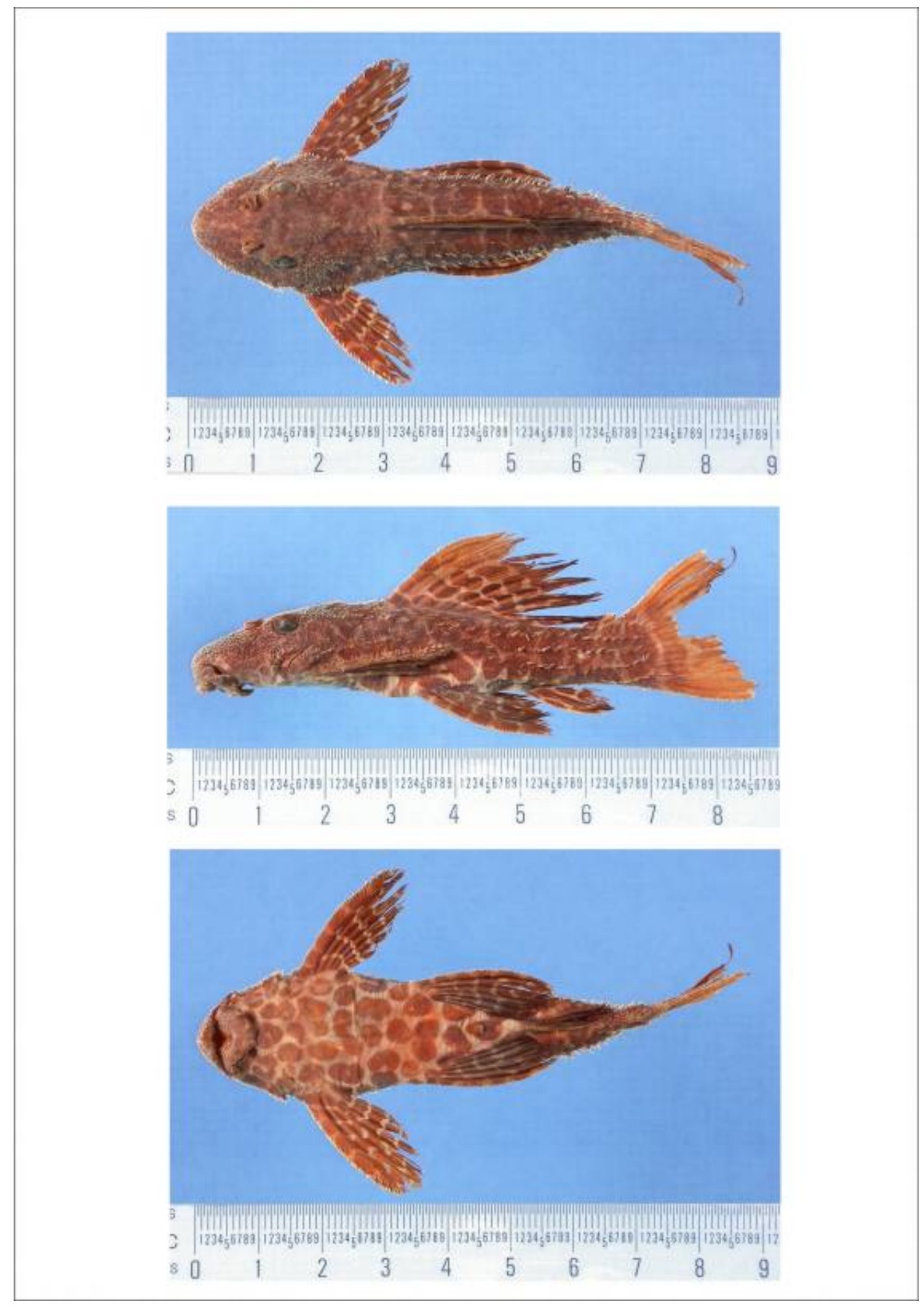

Figura 52. Holótipo de Pseudacanthicus leopardus, ANSP 39345 - 71,7 mm CP. 


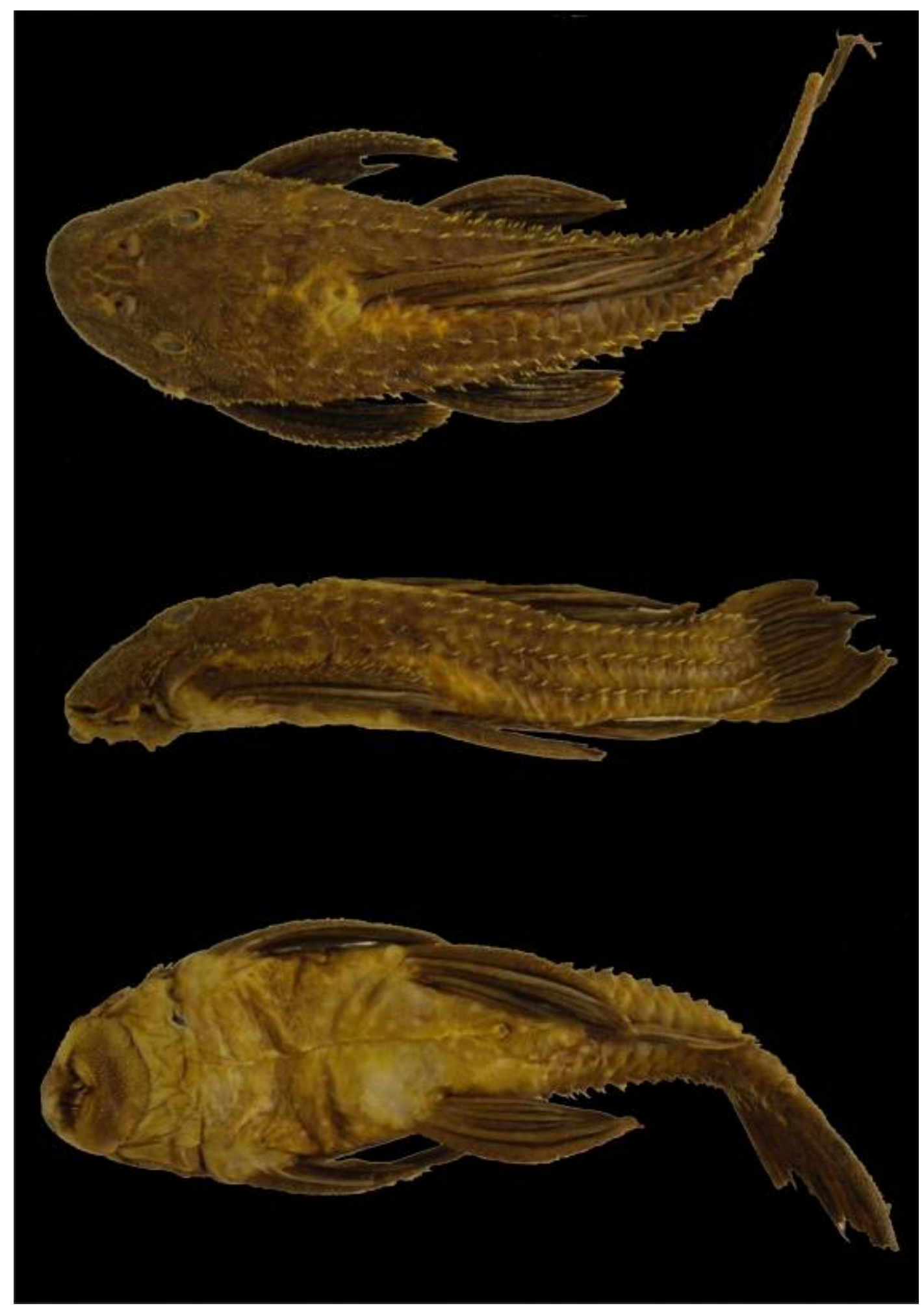

Figura 53. Holótipo de Pseudacanthicus serratus, RMNH 3125 - 148,7 mm CP. 
$-60.0$

.50 .0

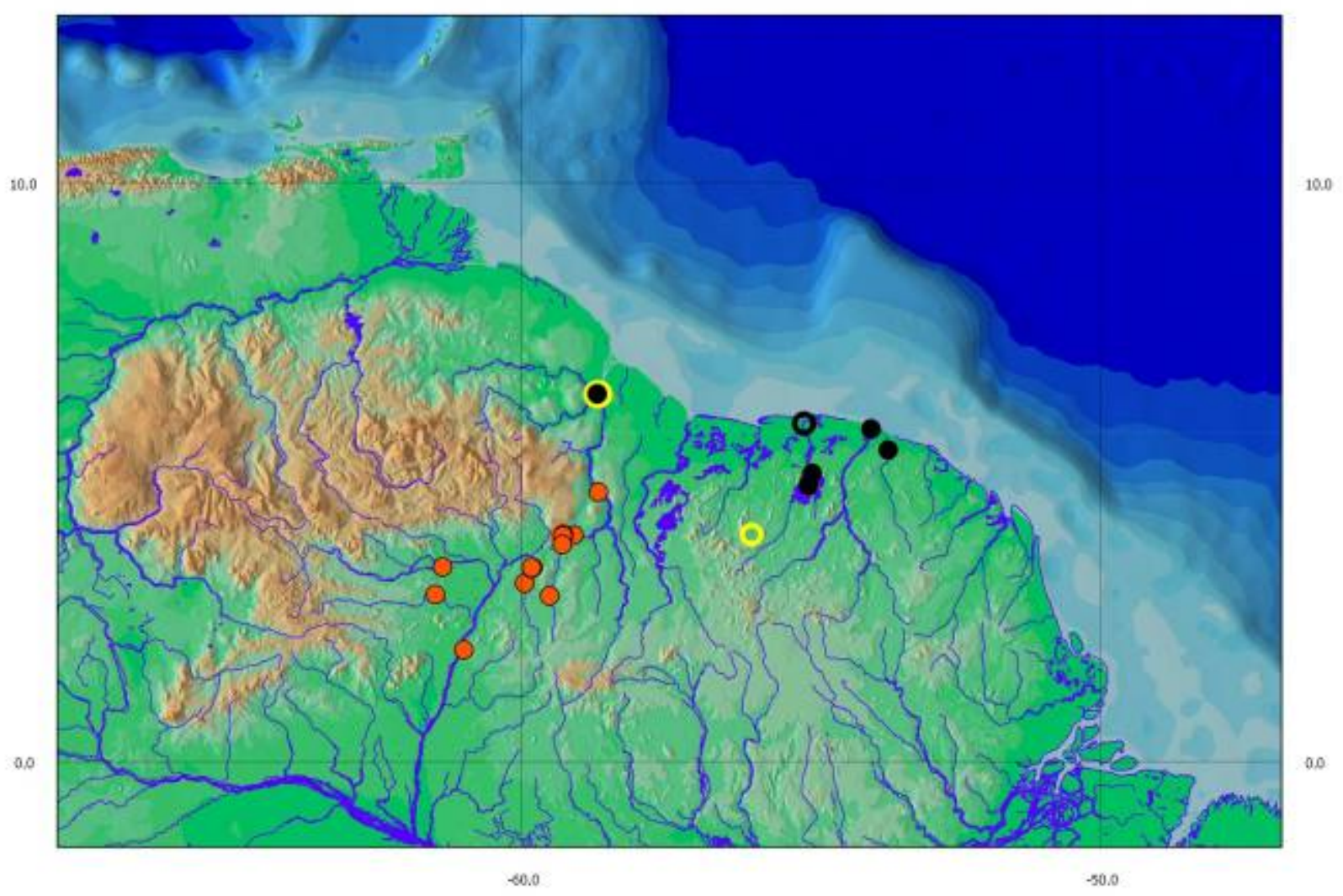

Figura 54. Mapa de distribuição de Pseudacanthicus leopardus (círculo vermelho) e $P$. serratus (círculo preto). Círculo amarelo representa localidade tipo dos sintipos de $P$. fordii proposto como sinônimo de $P$. serratus neste estudo. Símbolos abertos representam as localidades tipo. 

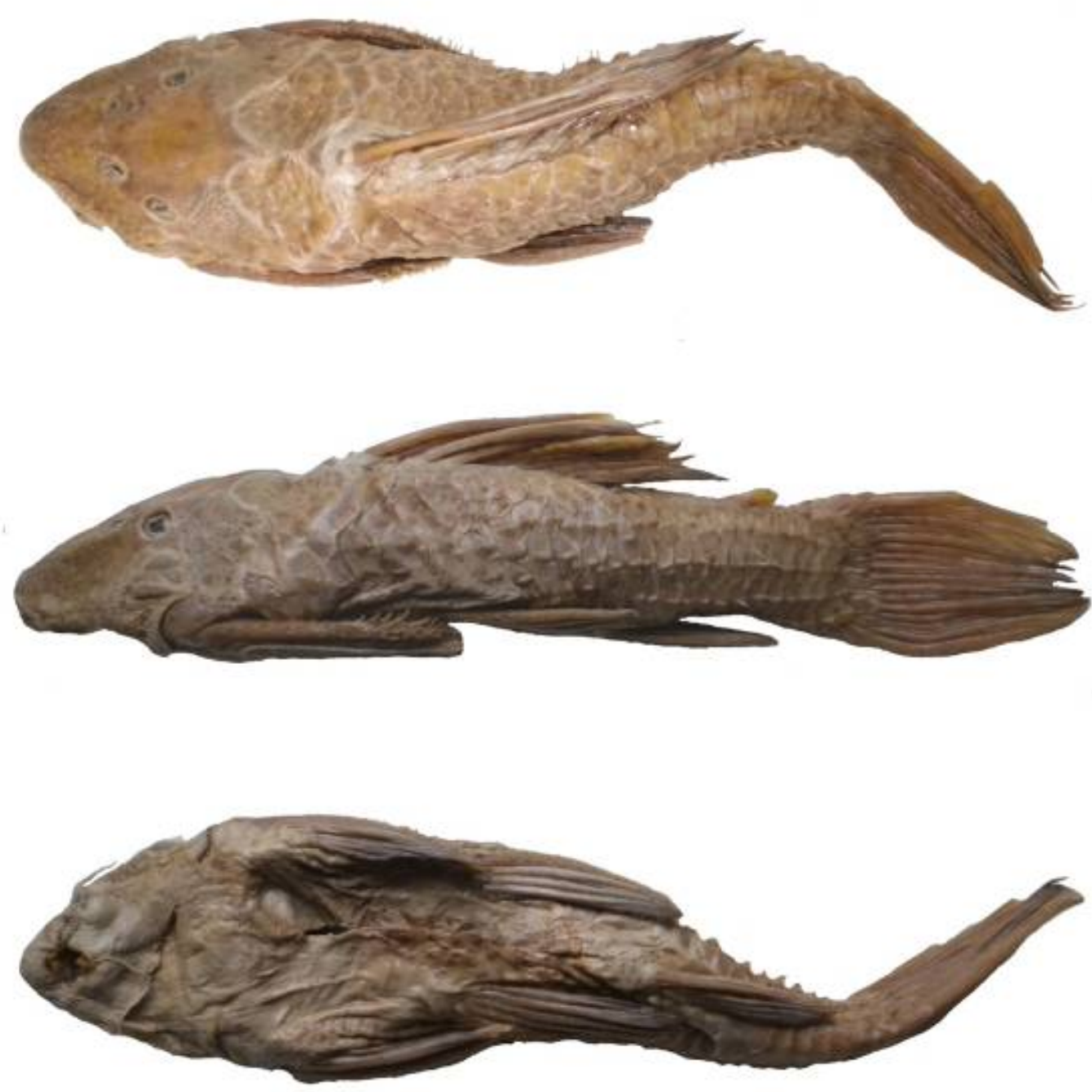

Figura 55. Holótipo de Pseudacanthicus spinosus, MNHN A-9577 - 262,6 mm CP. 


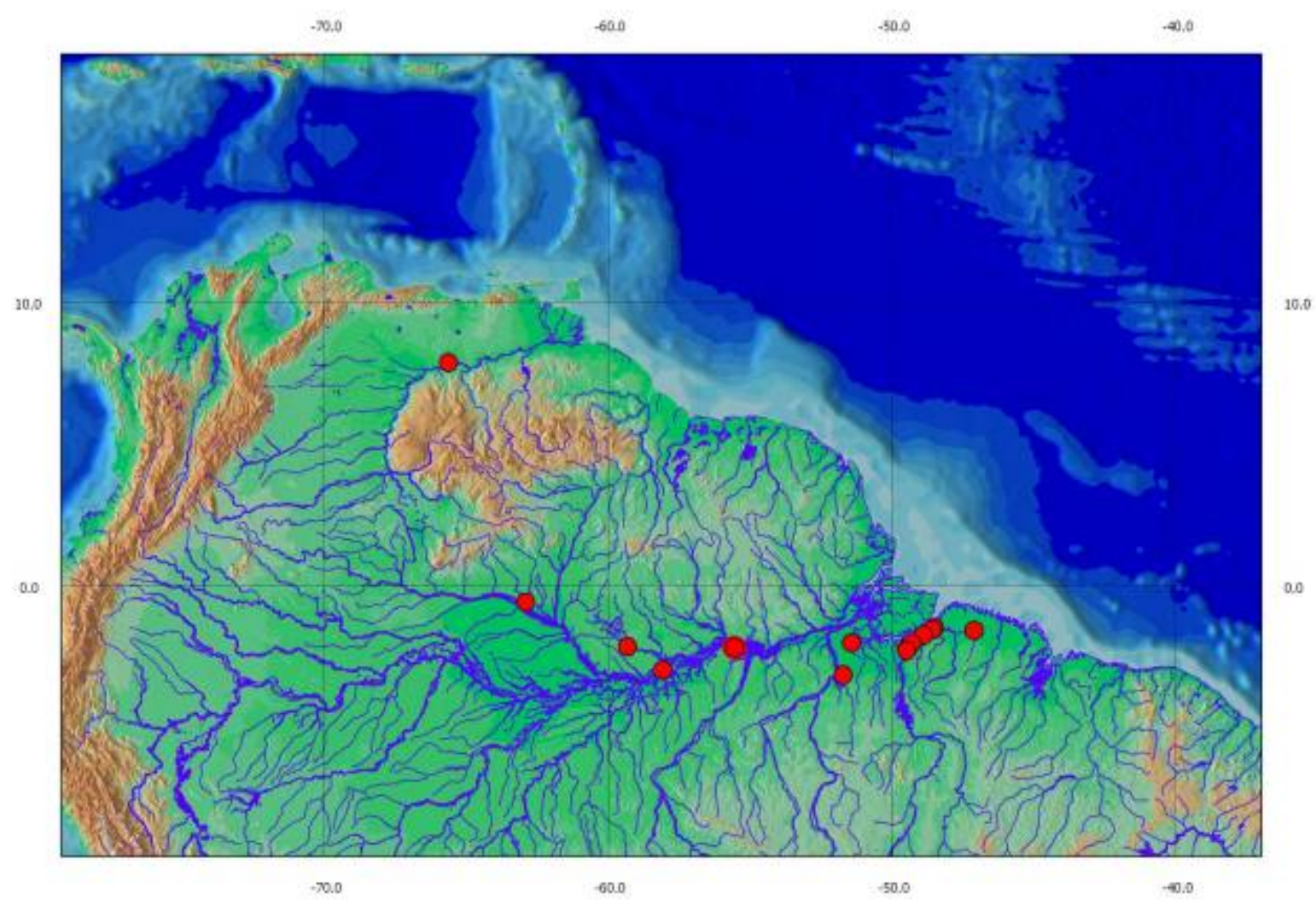

Figura 56. Mapa de distribuição de Pseudacanthicus spinosus; símbolo aberto representa a localidade tipo. 


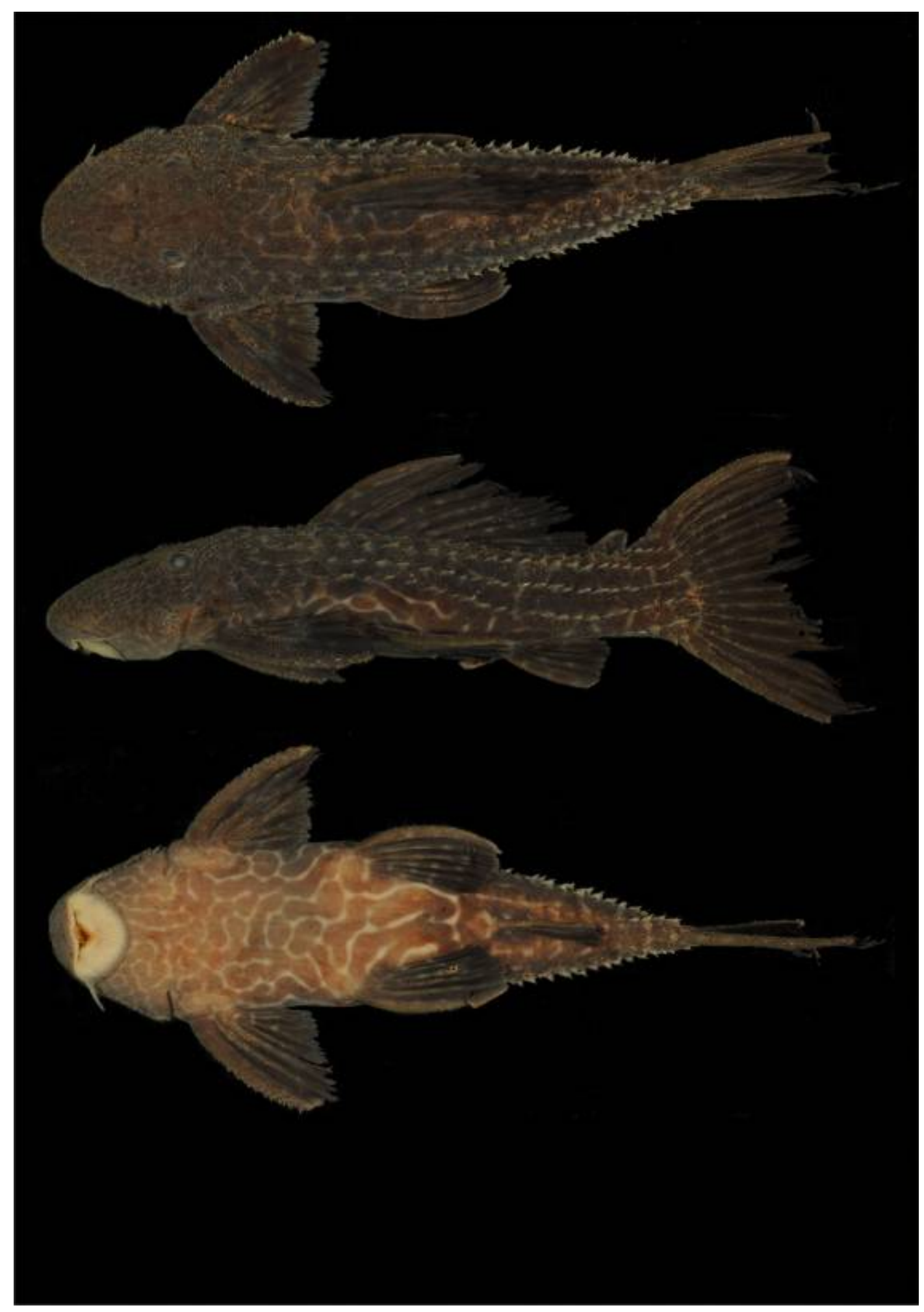

Figura 57. Pseudacanthicus sp. “Aripuanã”, MZUSP (s/ número) - 105, 6 mm CP. 


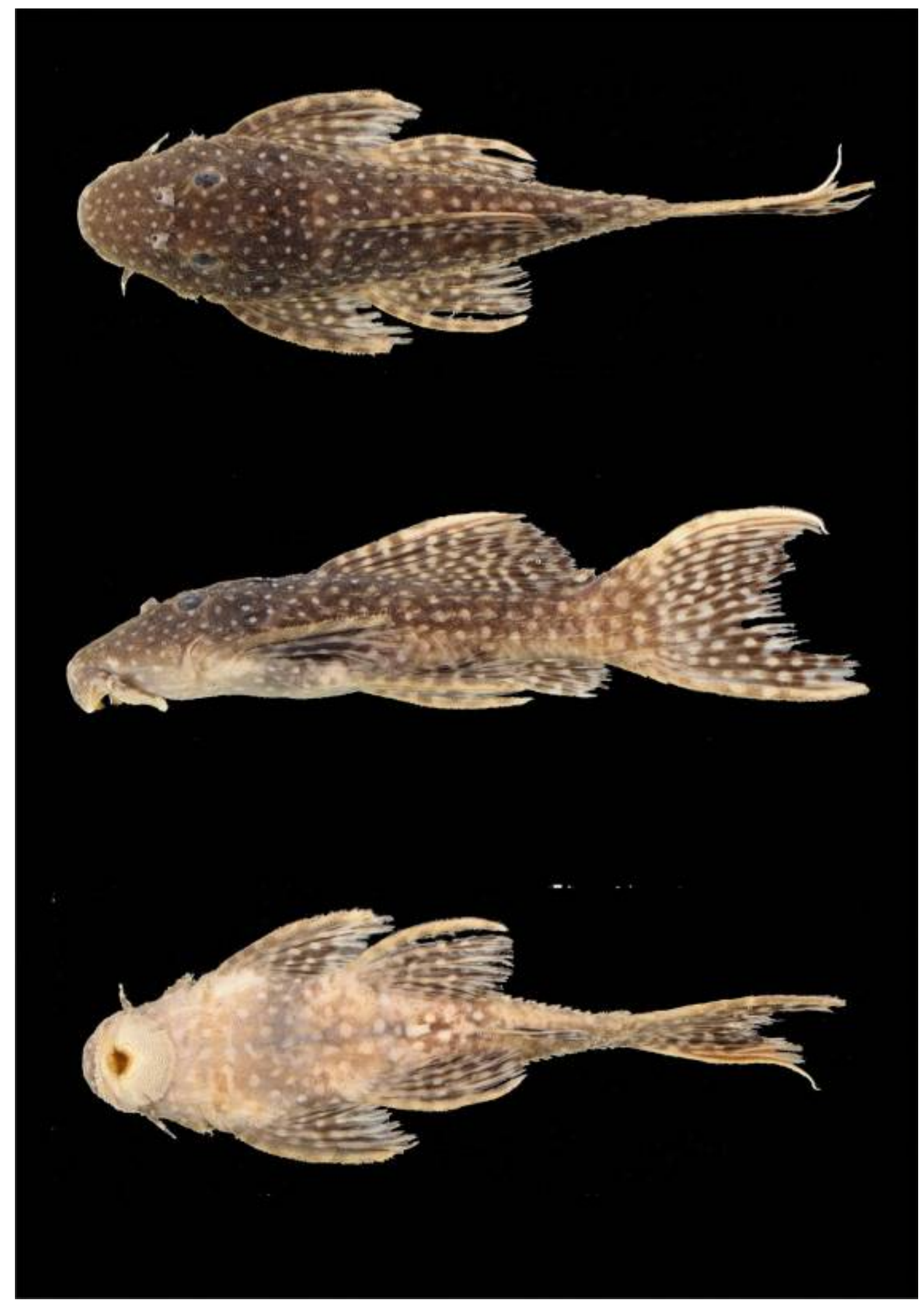

Figura 58. Pseudacanthicus sp. “Tapajós”, MZUSP 108195 - 121,7 mm CP. 


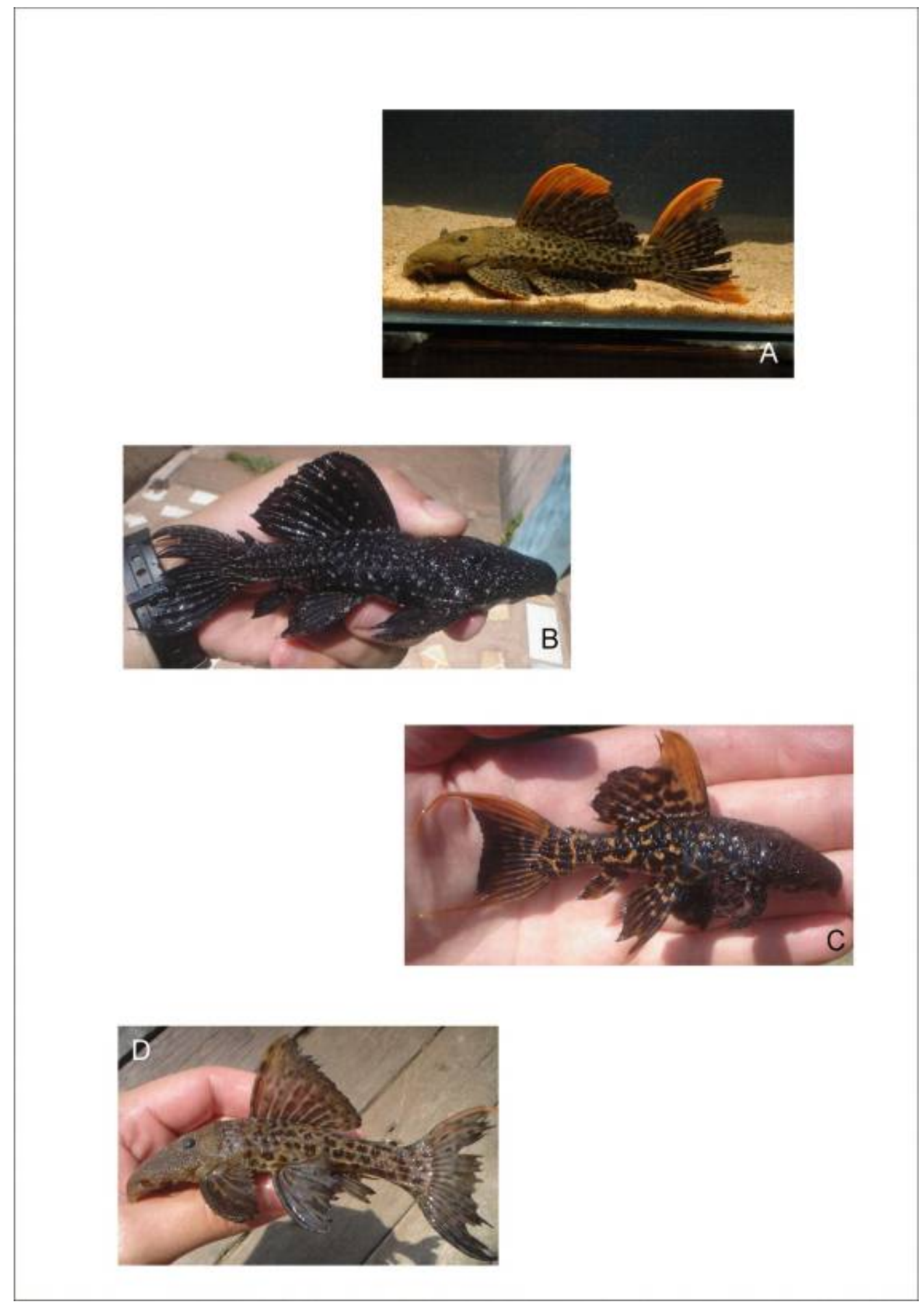

Figura 59. Colorido de (A) Pseudacanthicus leopardus, (B) Pseudacanthicus sp. "Tapajós", (C) e (D) juvenis de P. spinosus. Fotos: J. Zuanon e J. Binrindelli. 


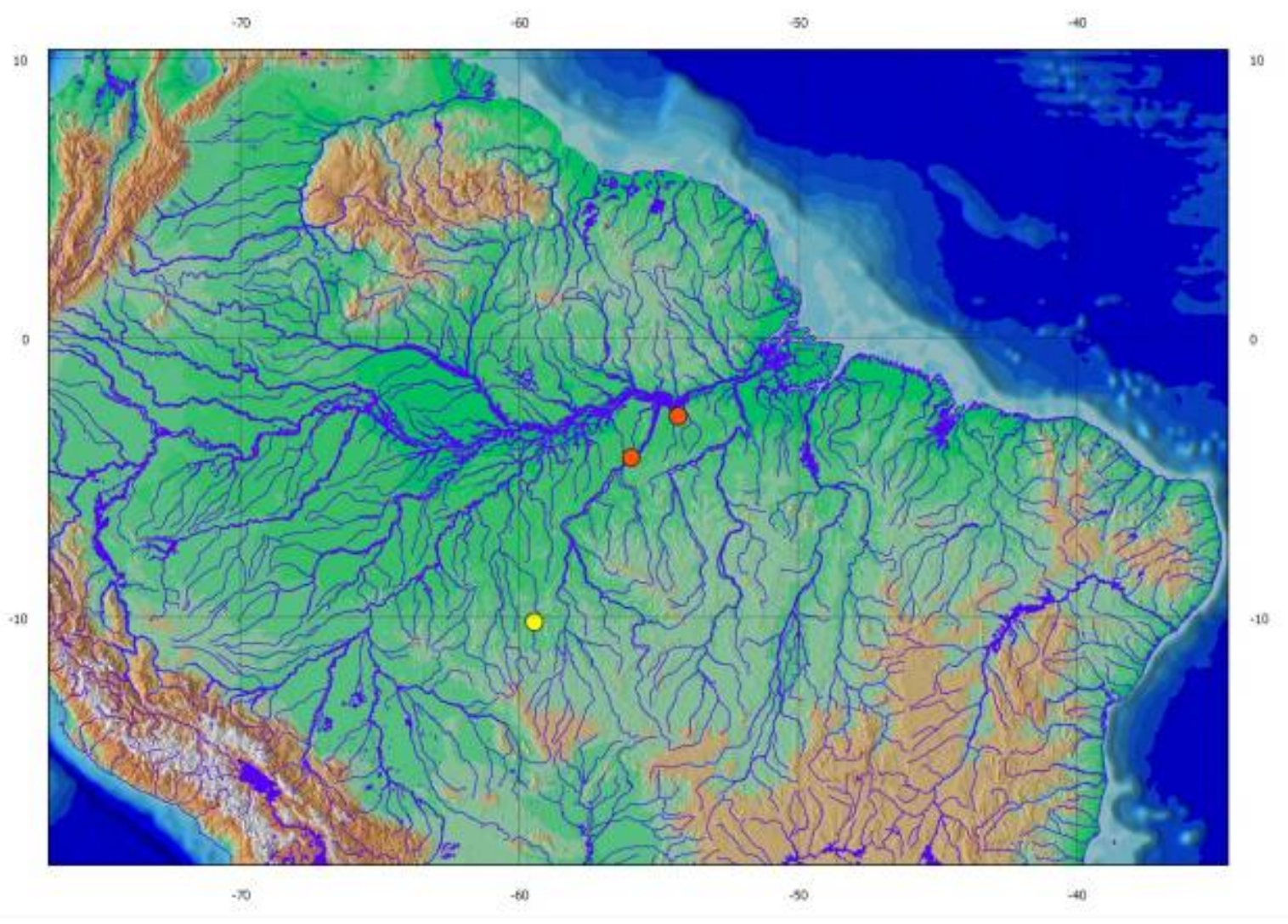

Figura 60. Mapa de distribuição de Pseudacanthicus sp. "Aripuanã" (círculo amarelo) e Pseudacanthicus sp. "Tapajós" (círculo vermelho). 


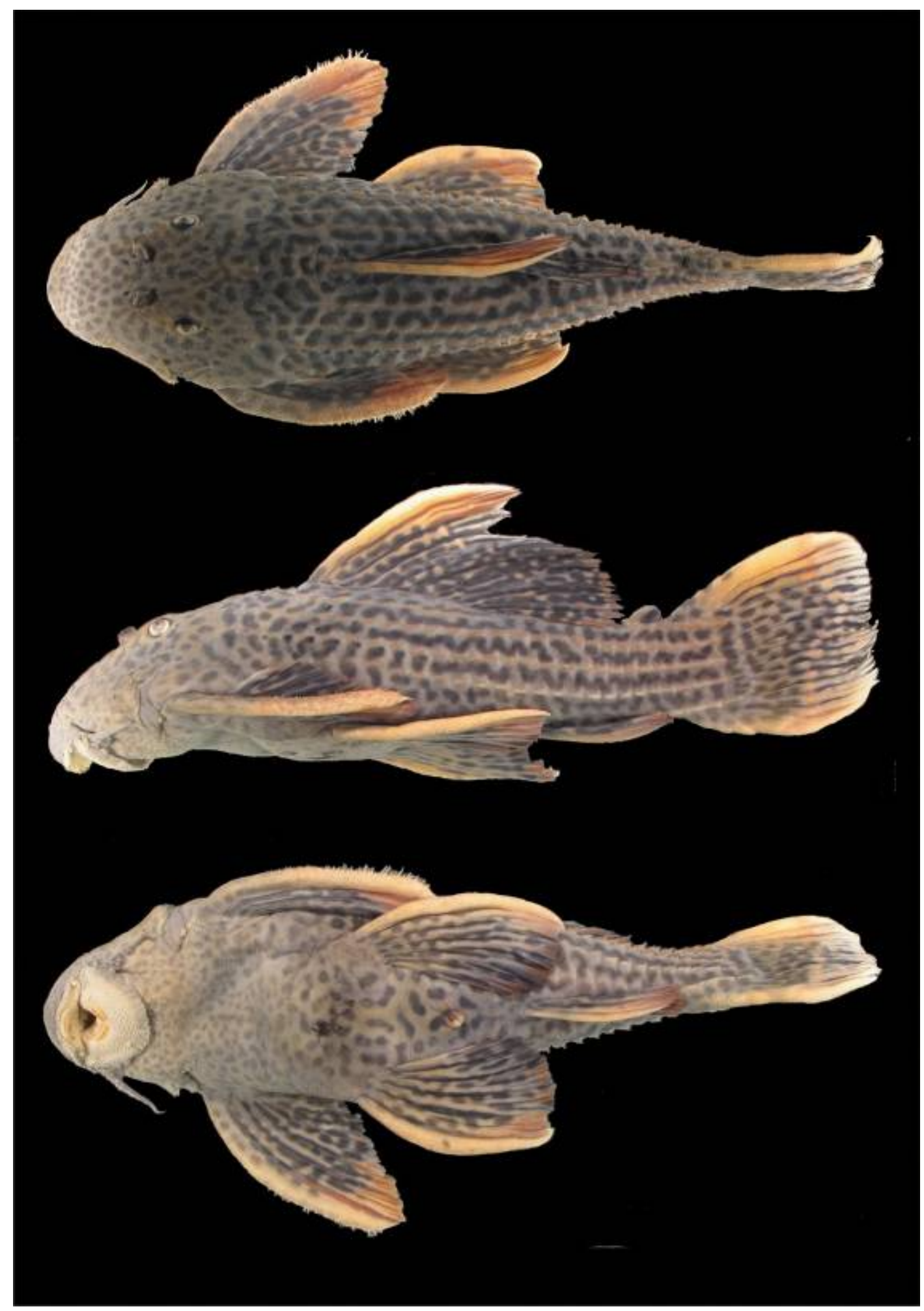

Figura 61. Pseudacanthicus sp. “açacu vermelho”, MZUSP (ECIX2010070802) - 246,5 mm CP. 


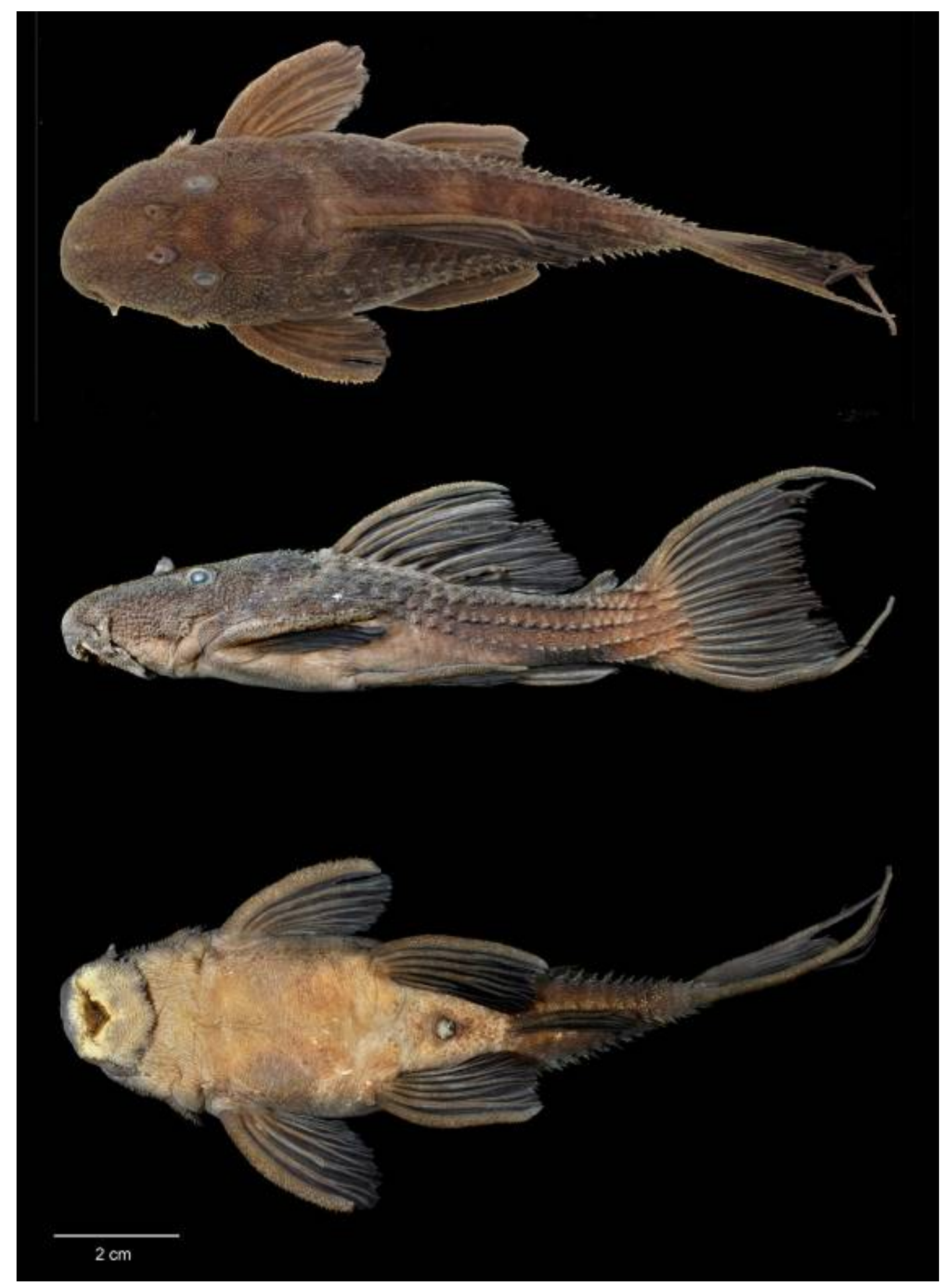

Figura 62. Pseudacanthicus sp. "açacu preto", MZUSP (ECIX2010071201\#2) - 113,6 mm CP. 

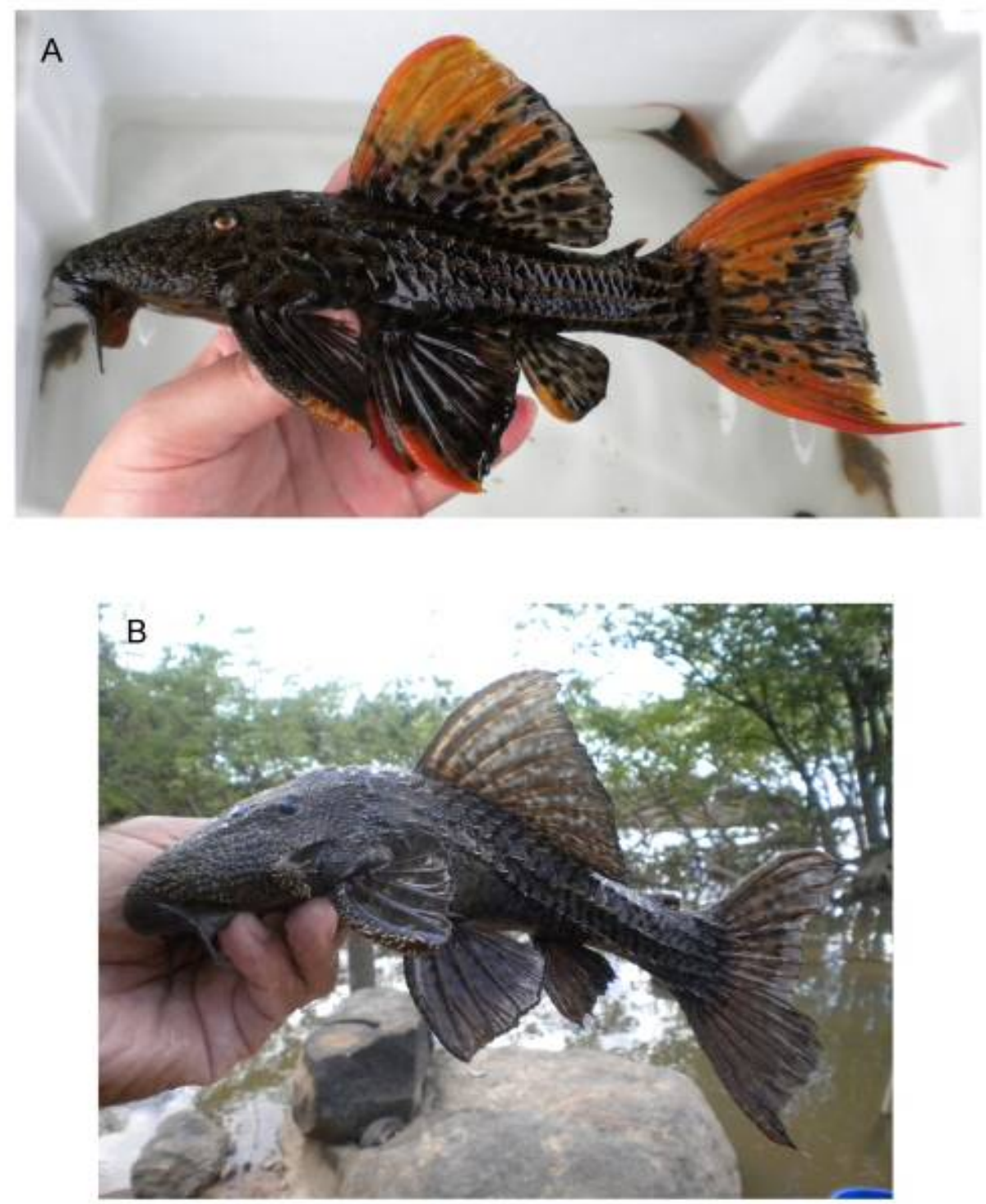

Figura 63. Colorido em vida de Pseudacanthicus sp "açacu vermelho"(A) e Pseudacanthicus sp. "açacu preto" (B). 
.50 .0

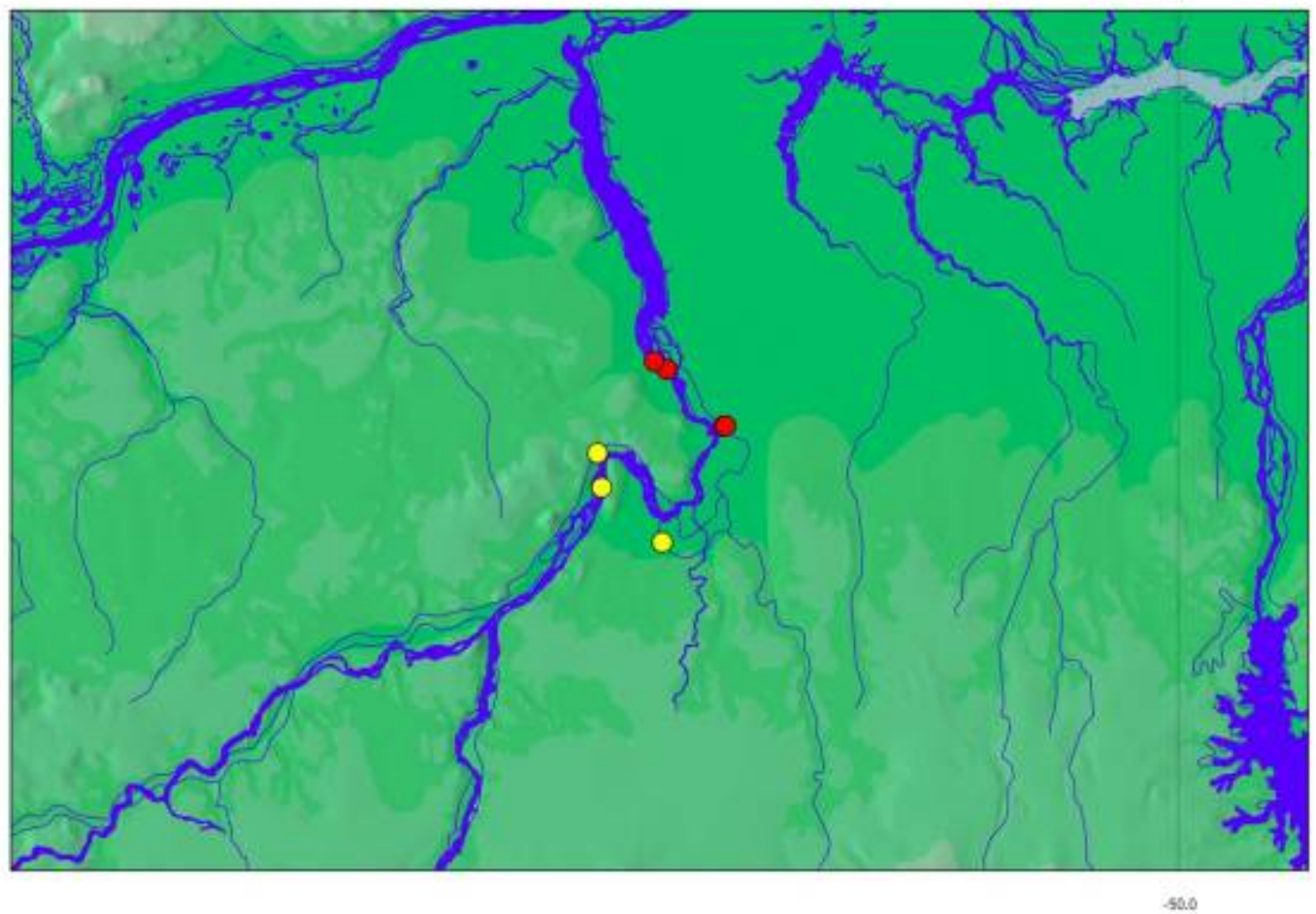

Figura 64. Mapa de distribuição de Pseudacanthicus sp "açacu vermelho"(círculo amarelo) e Pseudacanthicus sp. "açacu preto" (círculo vermelho). 


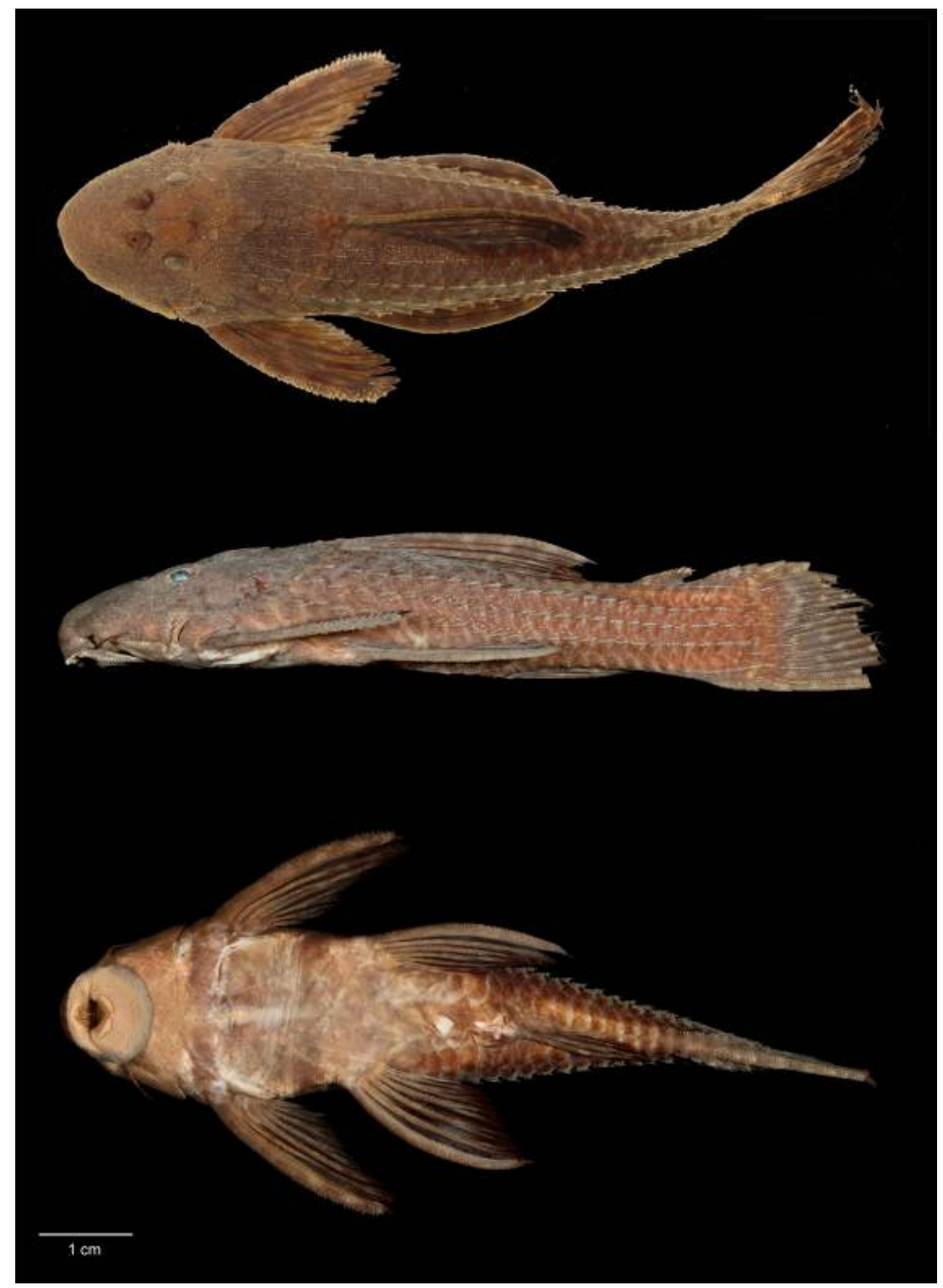

Figura 65. Pseudacanthicus sp. "Tocantins", INPA 32234 - 115,1 mm CP. 


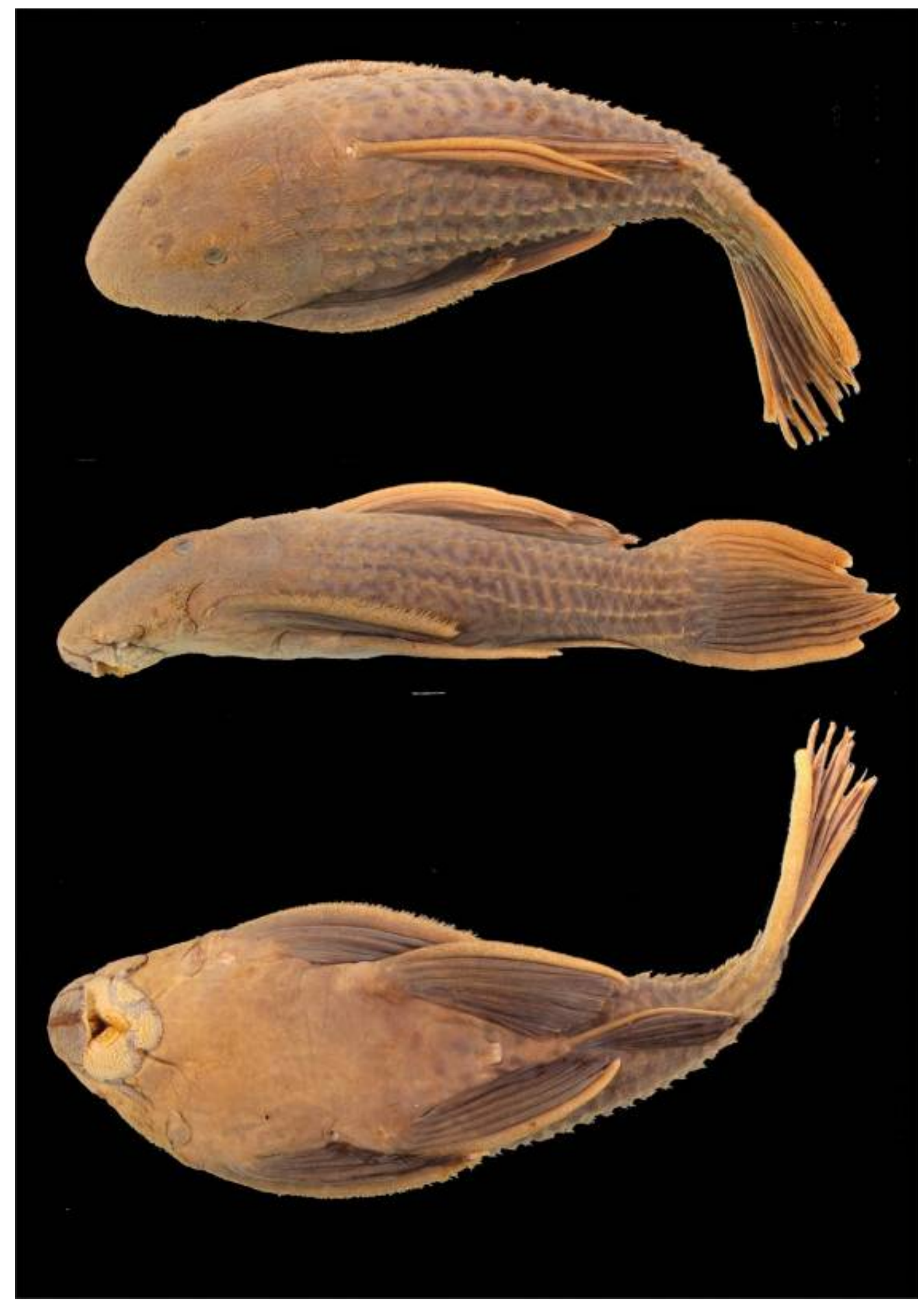

Figura 66. Pseudacanthicus sp. “aba laranja”, MZUSP 34296 - 220,7 mm CP. 


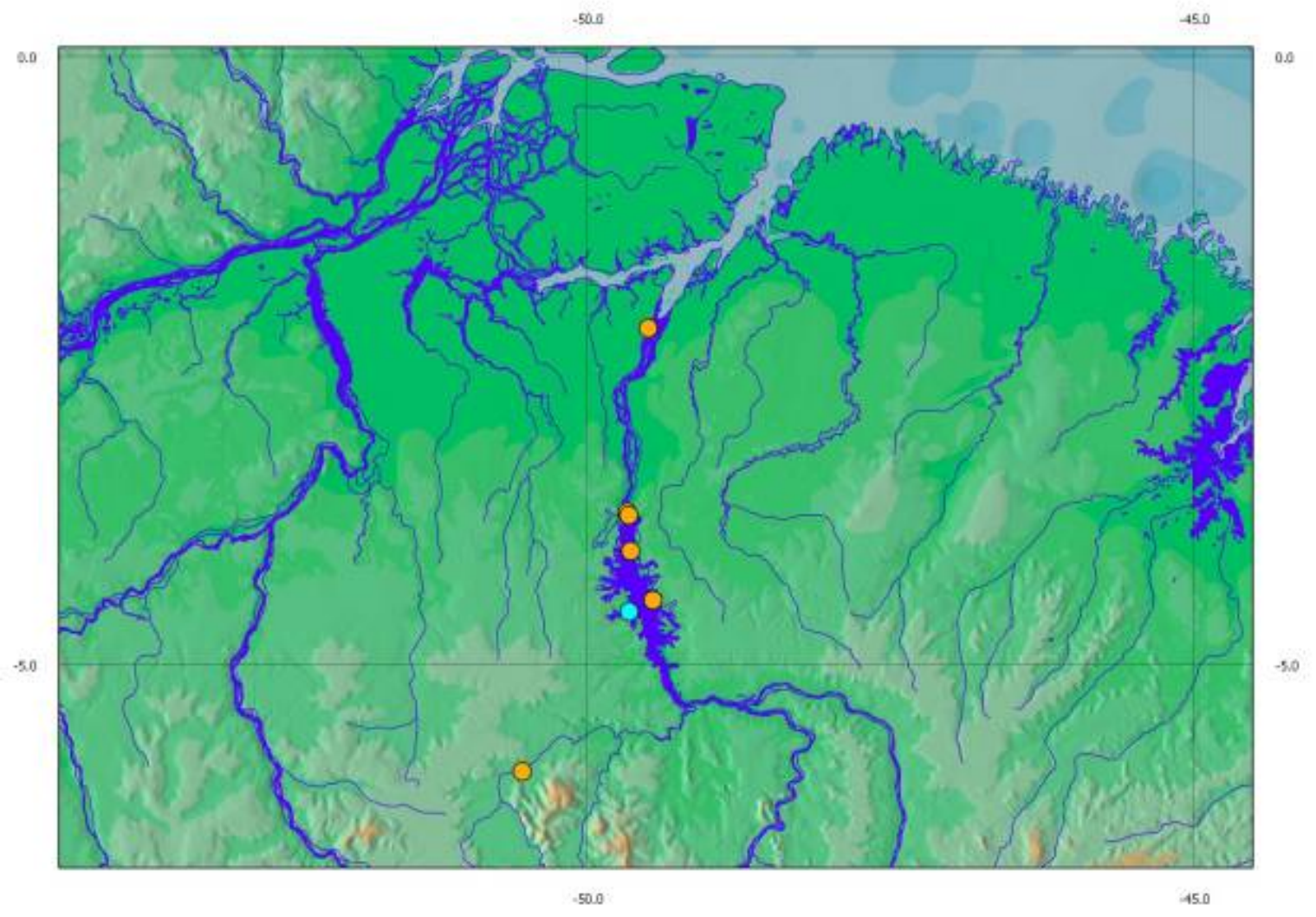

Figura 67. Mapa de distribuição de Pseudacanthicus sp. "aba laranja" (círculo laranja) e Pseudacanthicus sp. "Tocantins" (círculo azul). 


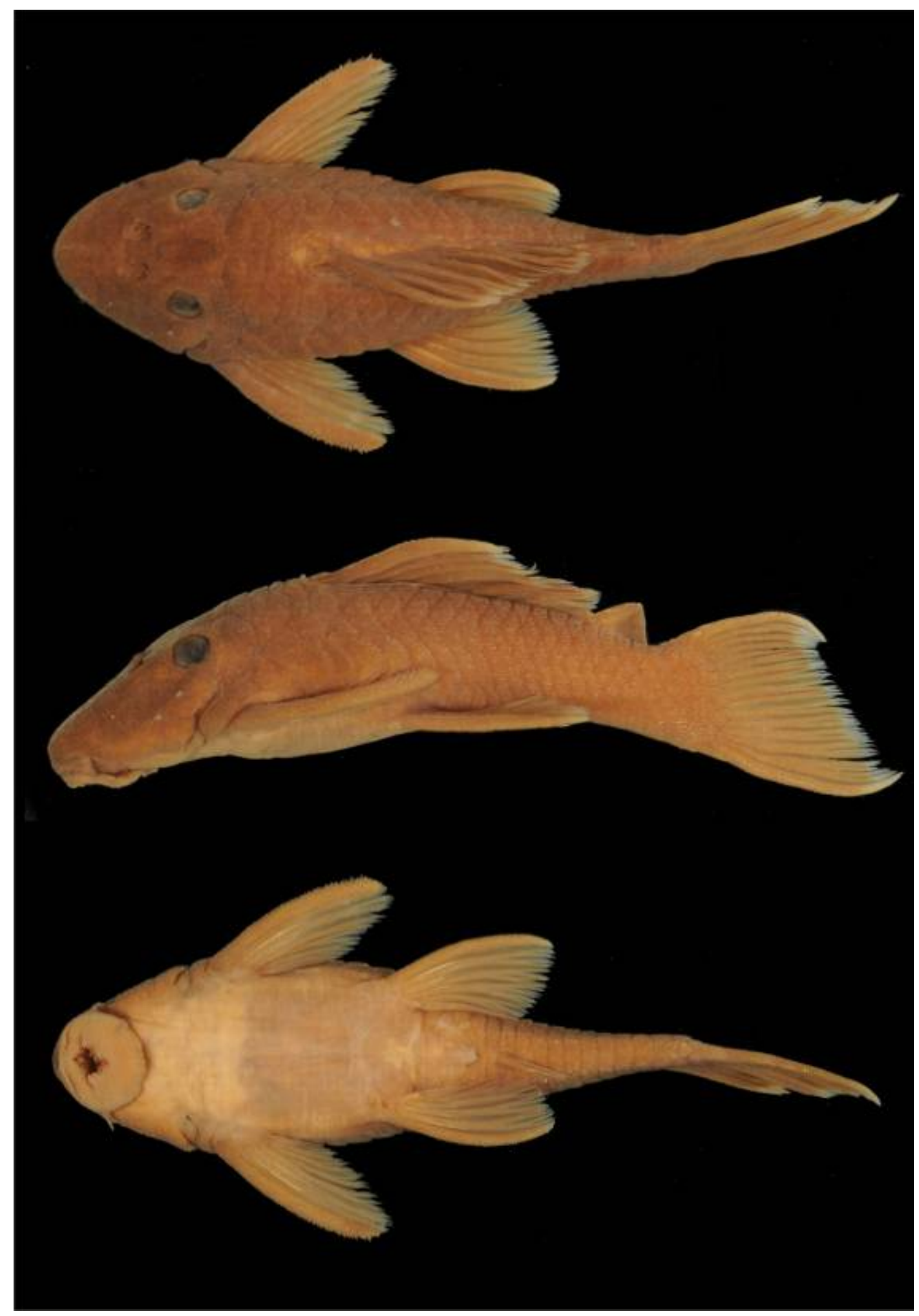

Figura 68. Holótipo de Spectracanthicus murinus, MZUSP 22011 - 59,7 mm CP. 

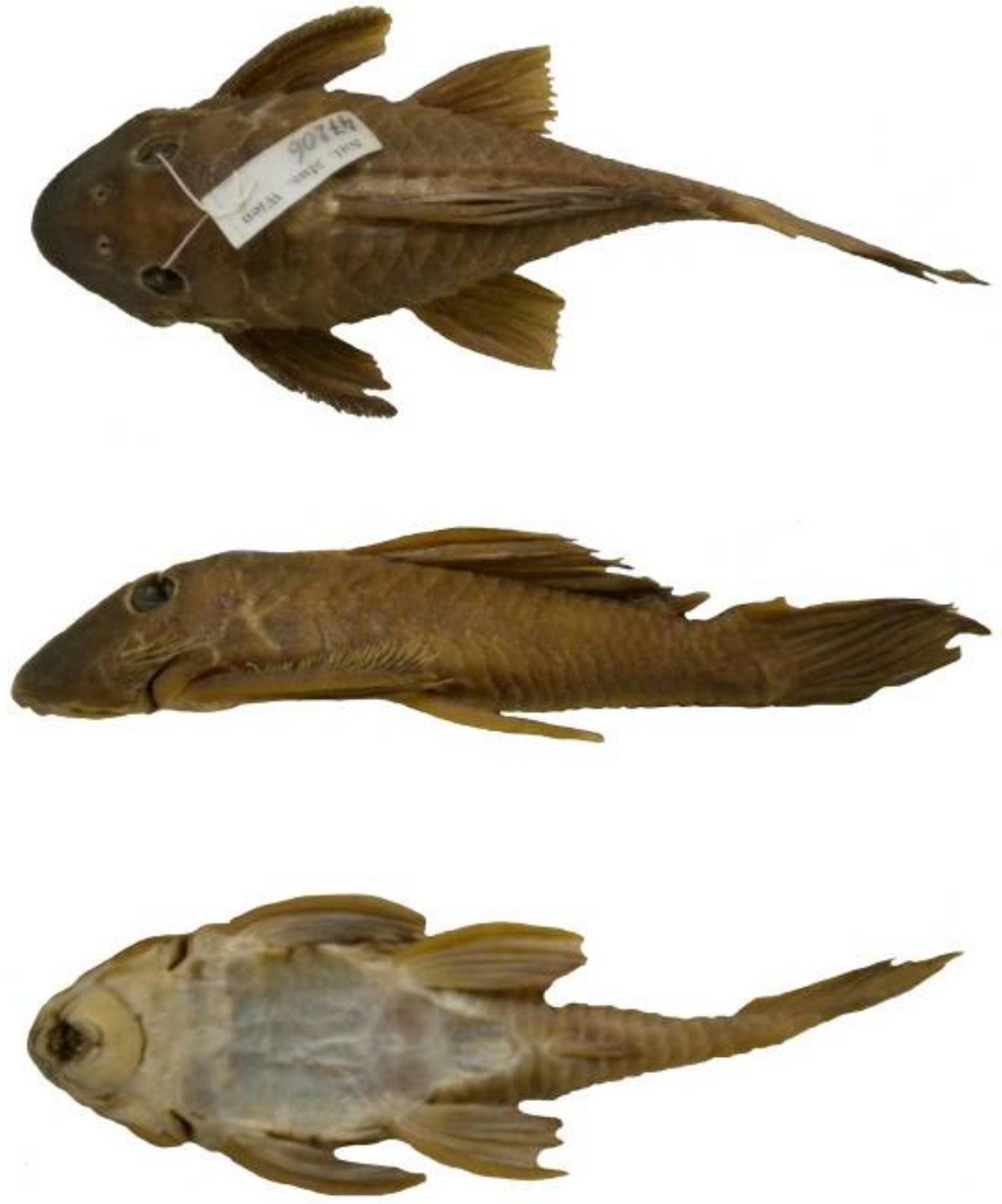

Figura 69. Holótipo de Spectracanthicus punctatissimus, NMW 47206 - 104,0 mm CP. 


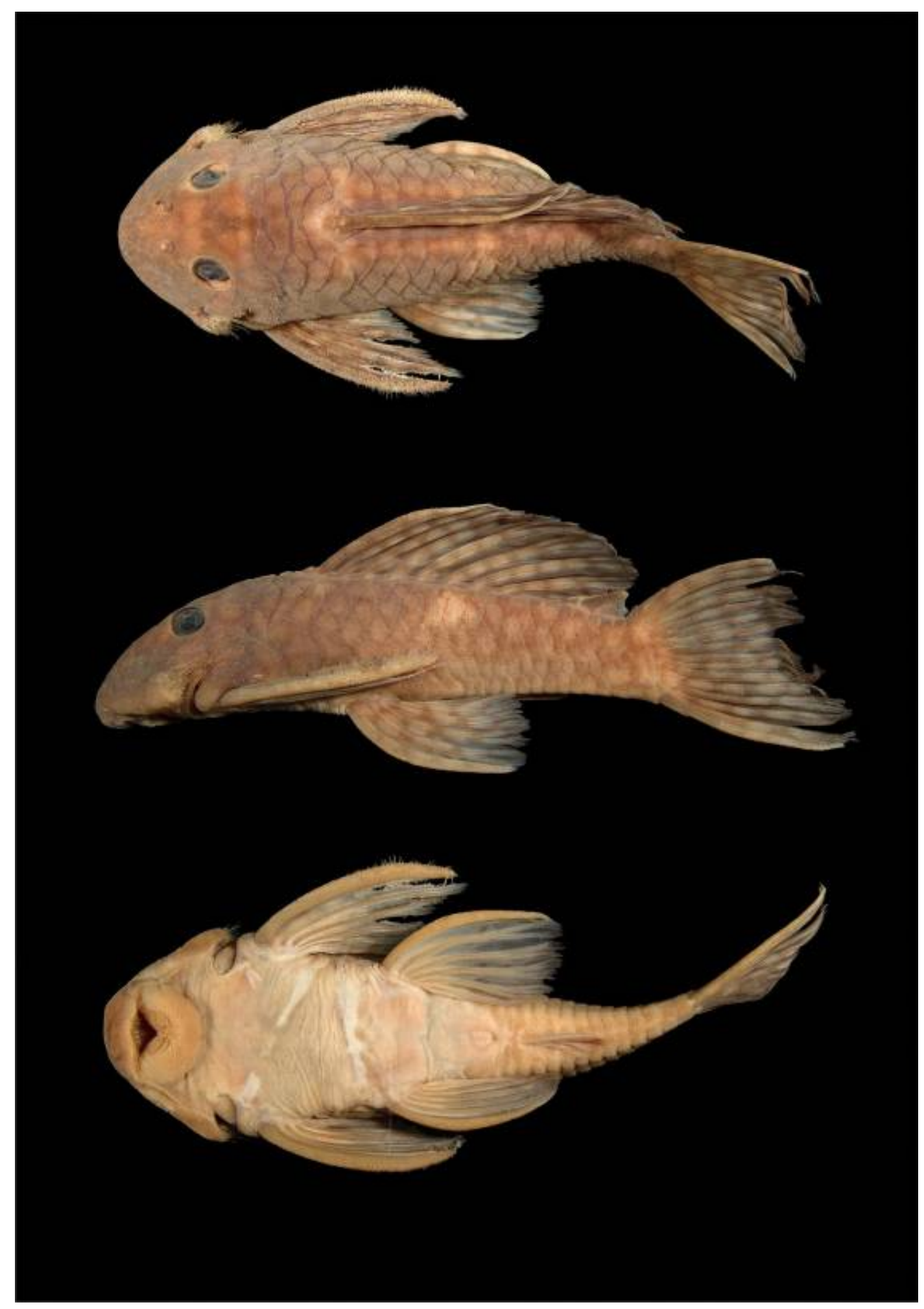

Figura 70. Spectracanthicus sp. "bola branca”, INPA 3957 - 80,6 mm CP. 


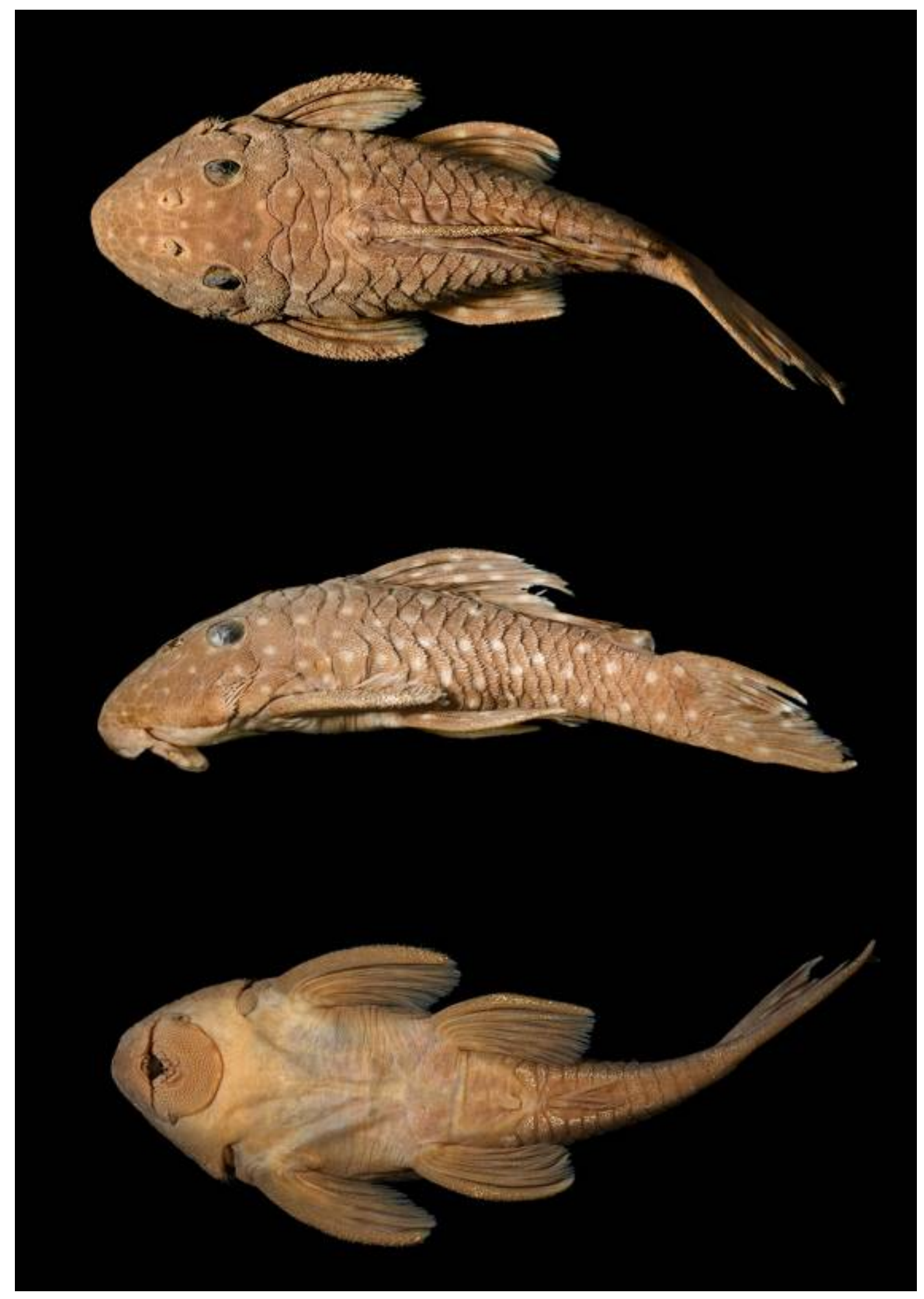

Figura 71. Spectracanthicus sp. “Tocantins”, MZUSP 34265 - 49,5 mm CP. 


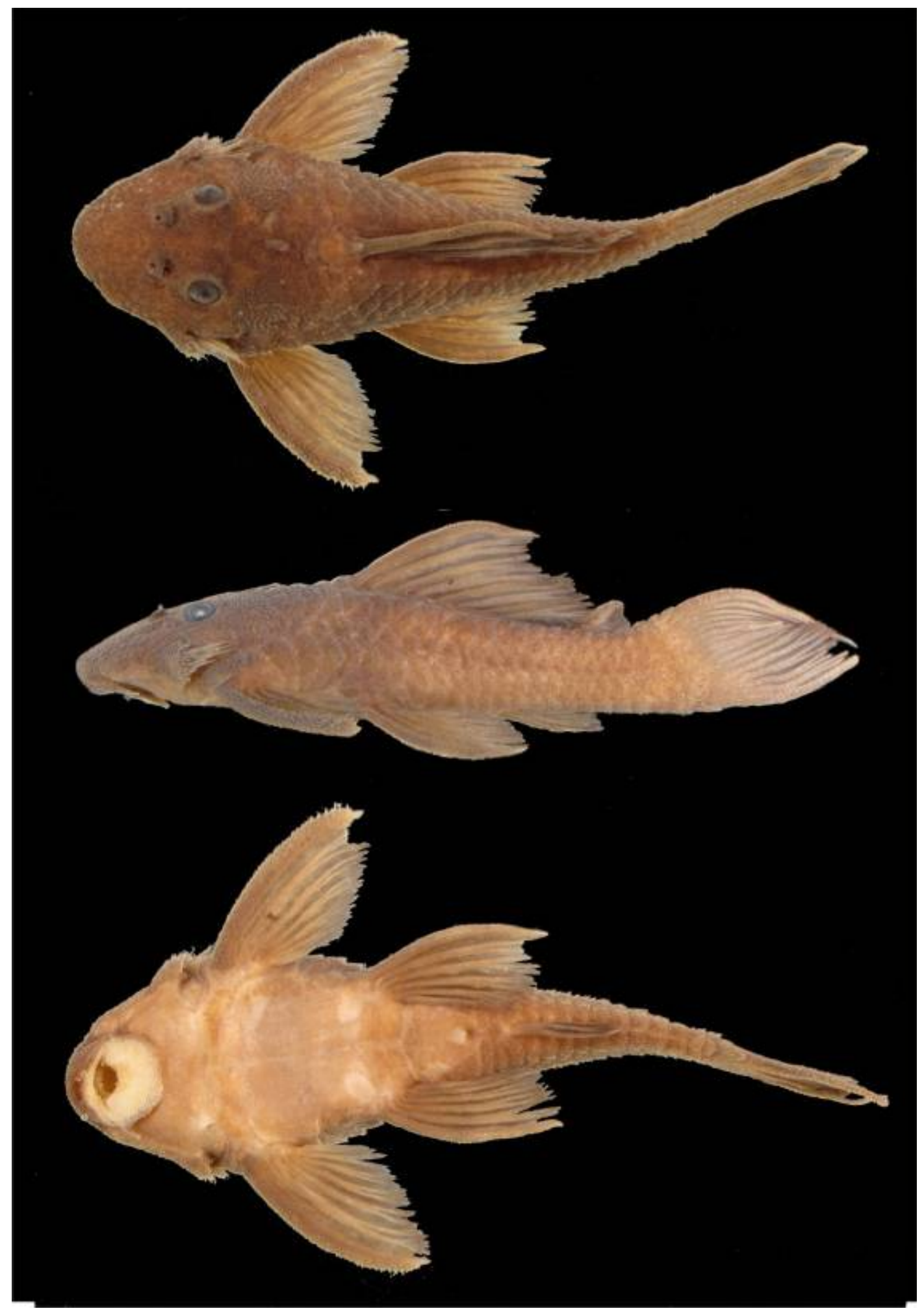

Figura 72. Spectracanthicus sp. “Tapajós”, MZUSP 92797 - 64,6 mm CP. 


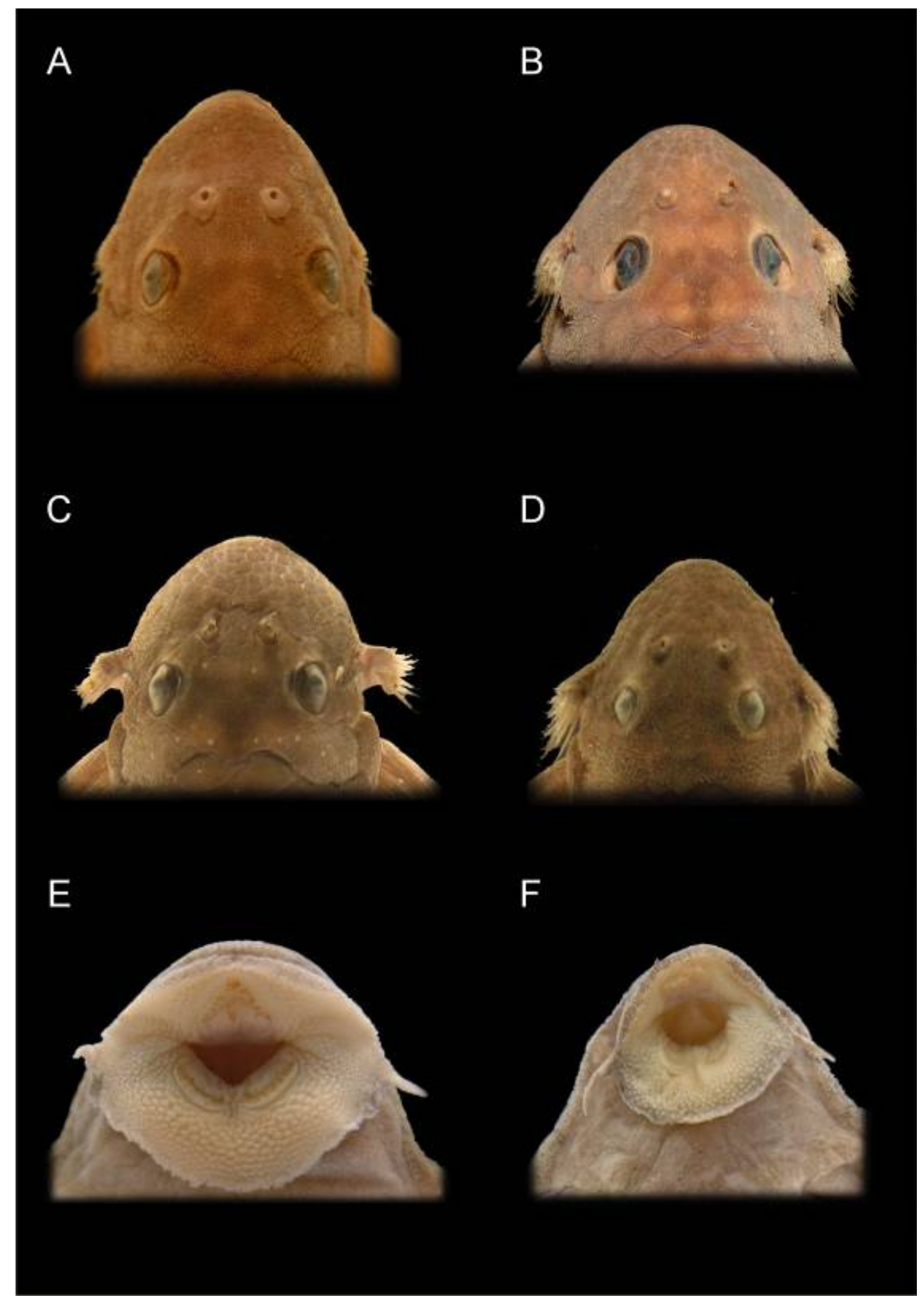

Figura 73. Perfil dorsal do focinho de Spectracanthicus sp. "Tocantins" (A), Spectracanthicus sp . "bola branca" (B), S. punctatissimus (C) e Spectracanthicus sp. "Tapajós" (D). Forma da boca em Spectracanthicus sp . "bola branca" (E) e Spectracanthicus sp. "Tapajós” (F). 

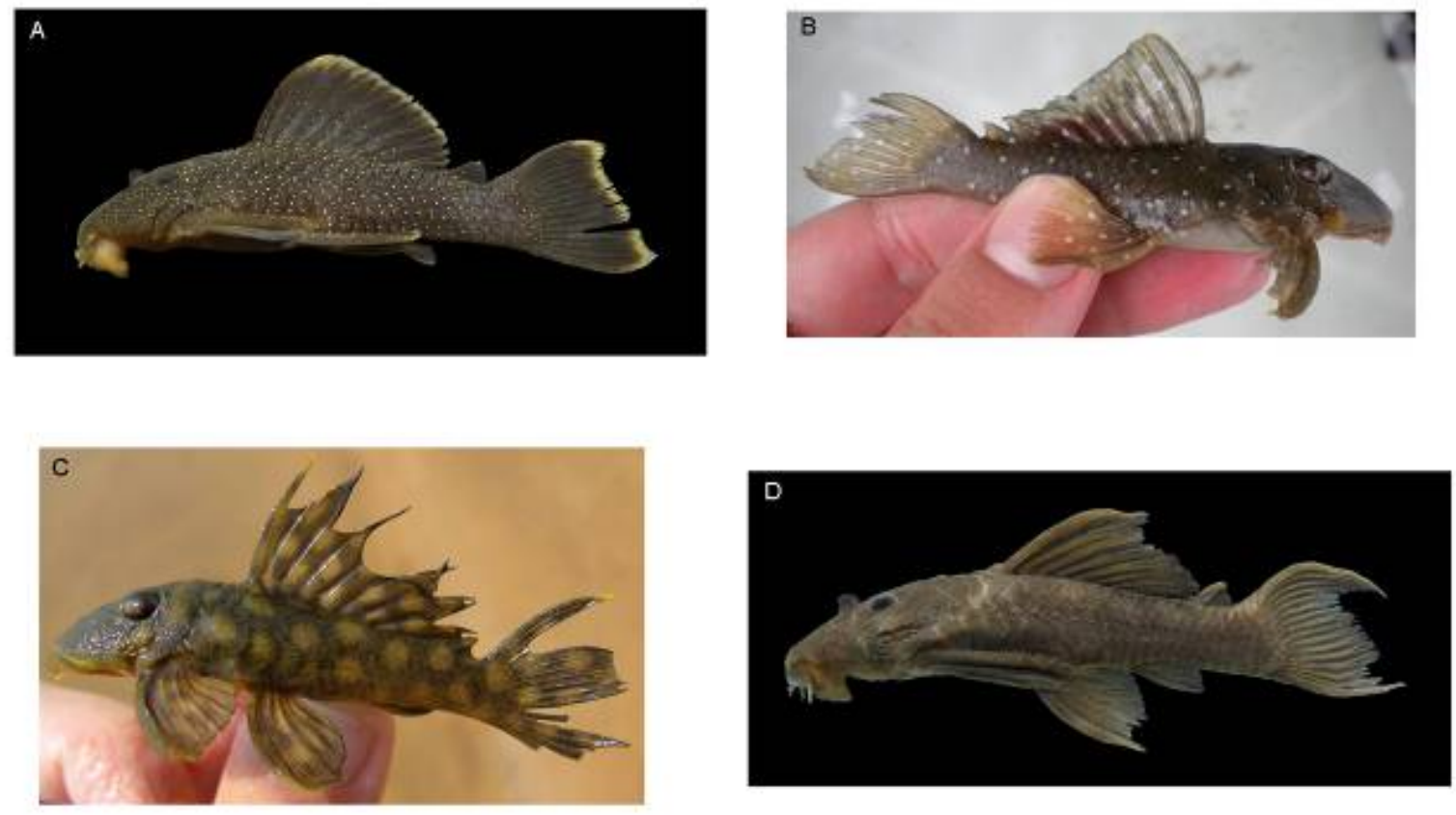

Figura 74. Colorido em vida de (A) S. murinus, (B) S. punctatissimus, (C) Spectracanthicus sp. "bola branca" e (D) Spectracanthicus sp. "Tapajós". 


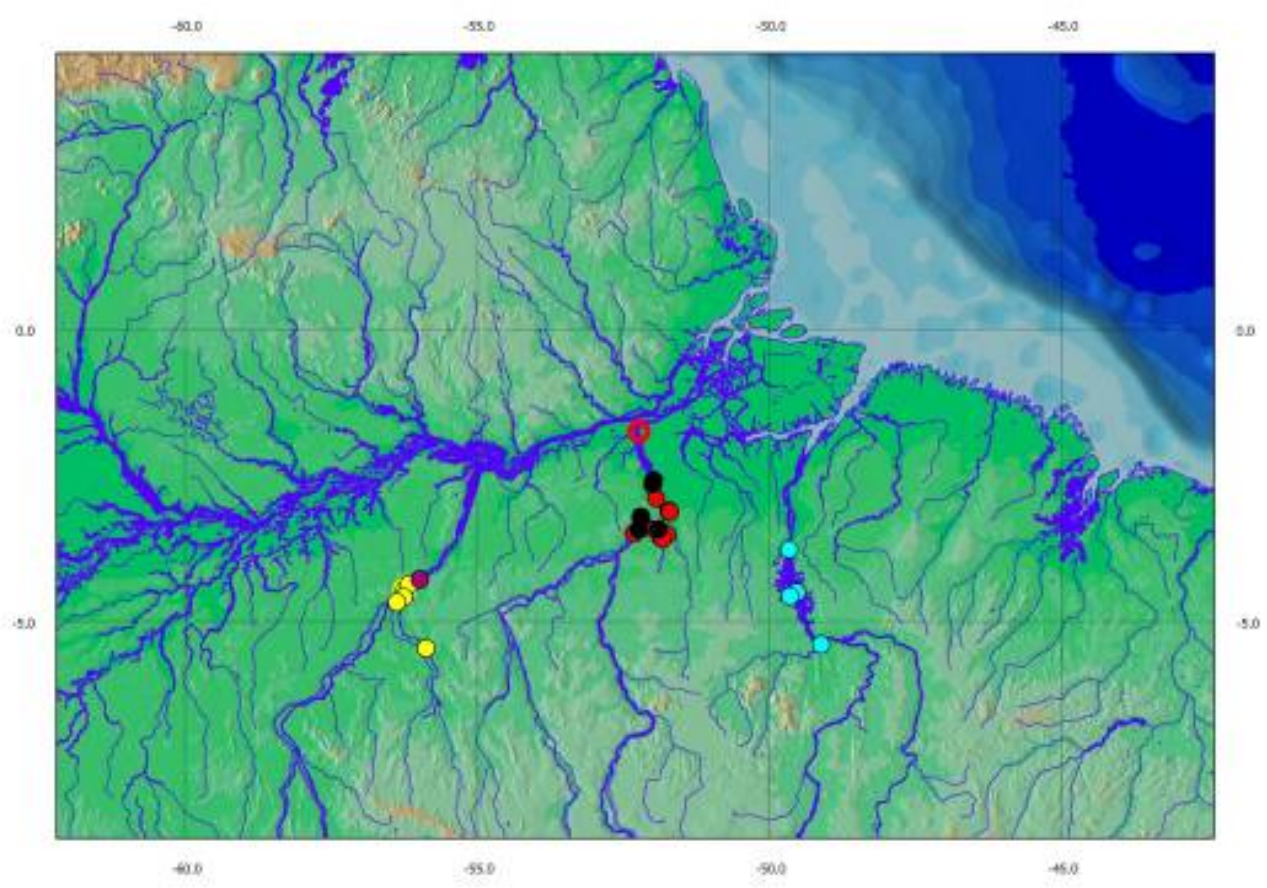

Figura 75. Mapa de distribuição de S. murinus (círculo amarelo), S. punctatissimus (círculo vermelho), Spectracanthicus sp. "bola branca" (círculo preto), Spectracanthicus sp. "Tocantins" (círculo azul) e Spectracanthicus sp. "Tapajós" (círculo roxo). Símbolos abertos representam as localidades tipo. 


\section{TABELAS}

Tabela 1. Dados morfométricos e merístico de Acanthicus adonis. N= número de exemplares. $\mathrm{DP}=$ desvio padrão.

\begin{tabular}{|c|c|c|c|c|c|c|}
\hline & $\begin{array}{c}\text { Holótipo } \\
\text { MZUSP } 38580\end{array}$ & $\mathbf{N}$ & Mínimo & Máximo & Média & DP \\
\hline $\begin{array}{r}\text { Comprimento Padrão (CP) } \\
\text { Porcentagens do CP }\end{array}$ & 134,6 & 17 & 89,1 & 304,6 & & \\
\hline Comprimento pré-dorsal & 45,2 & 17 & 41,8 & 48,8 & 45,4 & 1,6 \\
\hline Comprimento da cabeça (CC) & 40,1 & 17 & 37,4 & 41,8 & 39,3 & 1,1 \\
\hline Altura do corpo & 12,9 & 17 & 12,2 & 17,8 & 14,2 & 1,7 \\
\hline Largura cleitral & 31,2 & 17 & 27,1 & 33,2 & 30,4 & 1,2 \\
\hline Comprimento do tronco & 26,3 & 17 & 22,2 & 30,8 & 25,2 & 2,4 \\
\hline Comprimento do espinho peitoral & 33,3 & 17 & 31,2 & 45,2 & 35,6 & 3,0 \\
\hline Comprimento do abdomem & 22,1 & 17 & 18,2 & 23,9 & 20,6 & 1,5 \\
\hline Comprimento do espinho pélvico & 23,6 & 17 & 22,8 & 28,4 & 24,7 & 1,4 \\
\hline Comprimento pós-anal & 36,2 & 17 & 33,3 & 39,4 & 37,5 & 1,7 \\
\hline Comprimento do espinho anal & 19,8 & 17 & 16,7 & 22,8 & 19,1 & 1,5 \\
\hline Comprimento do espinho dorsal & 26,4 & 17 & 0,0 & 30,7 & 25,3 & 6,5 \\
\hline Comprimento da base da dorsal & 19,6 & 17 & 17,2 & 22,4 & 20,1 & 1,4 \\
\hline $\begin{array}{l}\text { Altura do pedúnculo caudal } \\
\text { Porcentagens do CC }\end{array}$ & 8,1 & 17 & 6,6 & 13,4 & 8,5 & 1,4 \\
\hline Diâmetro horizontal da órbita & 10,1 & 17 & 3,2 & 10,2 & 6,8 & 2,2 \\
\hline Comprimento do focinho & 15,5 & 17 & 15,5 & 56,7 & 39,6 & 17,3 \\
\hline Distância entre as narinas & 11,5 & 17 & 4,3 & 15,2 & 9,9 & 4,0 \\
\hline Distância interorbital & 32,0 & 17 & 11,2 & 34,1 & 24,2 & 9,8 \\
\hline Altura da cabeça & 32,8 & 17 & 12,8 & 41,2 & 28,2 & 11,2 \\
\hline Altura da boca & 38,9 & 17 & 13,2 & 43,3 & 29,7 & 12,0 \\
\hline Largura da boca & 38,9 & 17 & 13,3 & 39,8 & 28,7 & 11,2 \\
\hline Comprimento do pré-maxilar & 10,9 & 17 & 2,9 & 13,2 & 8,1 & 3,4 \\
\hline Comprimento do dentário & 10,2 & 17 & 4,4 & 13,9 & 8,6 & 3,3 \\
\hline Merísticos & & & & & Moda & \\
\hline Placas dorsais & 24 & 17 & 22 & 25 & 22 & \\
\hline Placas médio-dorsais & 23 & 17 & 21 & 23 & 23 & \\
\hline Placas medianas & 23 & 17 & 22 & 24 & 23 & \\
\hline Placas médio-ventrais & 24 & 17 & 22 & 25 & 24 & \\
\hline Placas ventrais & 18 & 17 & 12 & 18 & 18 & \\
\hline Placas da base do pedúnculo caudal & 7 & 17 & 5 & 7 & 7 & \\
\hline Dentes do pré-maxilar & 19 & 15 & 15 & 29 & 19 & \\
\hline Dentes do dentário & 20 & 13 & 20 & 32 & 22 & \\
\hline
\end{tabular}


Tabela 2. Dados morfométricos e merísticos de Acanthicus hystrix. N= número de exemplares. $\mathrm{DP}=$ desvio padrão.

\begin{tabular}{|c|c|c|c|c|c|c|}
\hline & $\begin{array}{c}\text { Neótipo } \\
\text { MZUSP } 103858\end{array}$ & $\mathbf{N}$ & Mínimo & Máximo & Média & DP \\
\hline $\begin{array}{c}\text { Comprimento Padrão (CP) } \\
\text { Porcentagens do CP }\end{array}$ & 182,6 & 52 & 26,1 & 628,3 & 242,1 & \\
\hline Comprimento pré-dorsal & 52,0 & 52 & 41,8 & 79,0 & 47,4 & 5,1 \\
\hline Comprimento da cabeça (CC) & 44,3 & 52 & 35,9 & 71,3 & 40,3 & 4,8 \\
\hline Altura do corpo & 18,7 & 52 & 9,6 & 40,7 & 16,5 & 4,4 \\
\hline Largura cleitral & 32,1 & 52 & 19,6 & 54,5 & 31,9 & 4,4 \\
\hline Comprimento do tronco & 25,7 & 52 & 18,3 & 44,1 & 23,1 & 3,6 \\
\hline Comprimento do espinho peitoral & 42,3 & 52 & 22,4 & 60,4 & 38,5 & 7,5 \\
\hline Comprimento do abdomem & 25,3 & 52 & 18,7 & 36,5 & 21,9 & 2,5 \\
\hline Comprimento do espinho pélvico & 27,9 & 52 & 18,7 & 36,1 & 23,9 & 2,8 \\
\hline Comprimento pós-anal & 44,8 & 52 & 27,2 & 62,2 & 36,4 & 4,8 \\
\hline Comprimento do espinho anal & 21,4 & 49 & 12,8 & 23,0 & 18,3 & 2,2 \\
\hline Comprimento do espinho dorsal & 31,0 & 47 & 21,6 & 41,1 & 27,0 & 3,2 \\
\hline Comprimento da base da dorsal & 25,0 & 52 & 16,9 & 37,3 & 22,1 & 2,8 \\
\hline $\begin{array}{l}\text { Altura do pedúnculo caudal } \\
\text { Porcentagens do CC }\end{array}$ & 10,2 & 52 & 5,7 & 14,3 & 7,9 & 1,3 \\
\hline Diâmetro horizontal da órbita & 5,1 & 52 & 4,1 & 13,6 & 8,1 & 2,3 \\
\hline Comprimento do focinho & 128,1 & 52 & 53,3 & 203,3 & 136,5 & 26,2 \\
\hline Distância entre as narinas & 20,4 & 52 & 11,2 & 31,0 & 18,5 & 3,9 \\
\hline Distância interorbital & 54,4 & 52 & 42,1 & 73,1 & 53,4 & 6,1 \\
\hline Altura da cabeça & 45,8 & 52 & 23,8 & 62,2 & 40,4 & 7,1 \\
\hline Altura da boca & 79,7 & 48 & 54,7 & 91,9 & 72,3 & 9,3 \\
\hline Largura da boca & 58,1 & 48 & 52,4 & 106,9 & 71,9 & 11,5 \\
\hline Comprimento do pré-maxilar & 11,5 & 48 & 9,5 & 20,2 & 14,3 & 2,4 \\
\hline Comprimento do dentário & 22,2 & 50 & 16,4 & 42,8 & 26,8 & 6,0 \\
\hline Merísticos & & & & & Moda & \\
\hline Placas dorsais & 24 & 50 & 22 & 27 & 24 & \\
\hline Placas médio-dorsais & 23 & 50 & 22 & 26 & 23 & \\
\hline Placas medianas & 24 & 50 & 22 & 27 & 24 & \\
\hline Placas médio-ventrais & 24 & 50 & 23 & 36 & 24 & \\
\hline Placas ventrais & 20 & 50 & 13 & 23 & 19 & \\
\hline Placas da base do pedúnculo caudal & 6 & 48 & 5 & 7 & 6 & \\
\hline Dentes do pré-maxilar & 52 & 38 & 28 & 79 & 33 & \\
\hline Dentes do dentário & 58 & 39 & 36 & 87 & 36 & \\
\hline
\end{tabular}


Tabela 3. Dados morfométricos e merísticos de Megalancistrus barrae. $\mathrm{N}=$ número de exemplares e $\mathrm{DP}=$ desvio padrão.

\begin{tabular}{|c|c|c|c|c|c|c|c|}
\hline & \multicolumn{2}{|c|}{ Síntipos } & \multirow[t]{2}{*}{$\mathbf{N}$} & \multirow[t]{2}{*}{ Mínimo } & \multirow[t]{2}{*}{ Máximo } & \multirow[t]{2}{*}{ Média } & \multirow[t]{2}{*}{ DP } \\
\hline & NMW 48019 & NMW 48020 & & & & & \\
\hline Comprimento Padrão (CP) & 399,4 & 356,2 & 8 & 174,1 & 342,0 & 221,9 & \\
\hline \multicolumn{8}{|l|}{ Porcentagens do CP } \\
\hline Comprimento pré-dorsal & 42,7 & 44,7 & 8 & 40,6 & 50,3 & 45,7 & 3,1 \\
\hline Comprimento da cabeça (CC) & 33,1 & 35,0 & 8 & 32,1 & 39,1 & 35,5 & 2,1 \\
\hline Altura do corpo & 22,8 & 25,7 & 8 & 18,7 & 27,6 & 22,3 & 3,6 \\
\hline Largura cleitral & 28,5 & 31,7 & 8 & 13,9 & 35,6 & 28,3 & 6,8 \\
\hline Comprimento do tronco & 24,0 & 24,0 & 8 & 19,9 & 29,0 & 25,5 & 3,2 \\
\hline Comprimento do espinho peitoral & 37,0 & 40,2 & 8 & 30,1 & 37,4 & 34,6 & 2,6 \\
\hline Comprimento do abdome & 23,0 & 23,0 & 8 & 22,9 & 25,1 & 24,0 & 0,8 \\
\hline Comprimento do espinho pélvico & 27,5 & 30,4 & 8 & 25,6 & 34,8 & 29,8 & 2,8 \\
\hline Comprimento pós-anal & 32,0 & 32,6 & 8 & 31,3 & 36,0 & 33,7 & 1,8 \\
\hline Comprimento do espinho anal & 16,6 & 17,3 & 8 & 15,4 & 19,4 & 17,5 & 1,6 \\
\hline Comprimento do espinho dorsal & 32,9 & 37,0 & 8 & 27,5 & 37,8 & 33,4 & 3,8 \\
\hline Comprimento da base da dorsal & 30,7 & 32,6 & 8 & 29,6 & 37,1 & 33,9 & 2,4 \\
\hline & 11,4 & \multicolumn{5}{|c|}{ Porcentagens do $\mathrm{CC}$} & 0,4 \\
\hline Diâmetro horizontal da órbita & 10,6 & 10,0 & 8 & 10,8 & 12,6 & 11,5 & 0,7 \\
\hline Comprimento do focinho & 65,8 & 68,0 & 8 & 64,7 & 68,0 & 66,1 & 1,2 \\
\hline Distância entre as narinas & 14,5 & 13,5 & 8 & 13,2 & 15,6 & 14,3 & 0,9 \\
\hline Distância interorbital & 41,9 & 42,8 & 8 & 38,4 & 42,4 & 40,0 & 1,5 \\
\hline Altura da cabeça & 59,7 & 61,9 & 8 & 46,9 & 64,2 & 54,4 & 5,7 \\
\hline Altura da boca & 34,8 & 37,3 & 8 & 32,1 & 42,2 & 36,8 & 3,9 \\
\hline Largura da boca & 35,8 & 35,9 & 8 & 29,0 & 42,3 & 34,9 & 4,3 \\
\hline Comprimento do pré-maxilar & 8,4 & 8,5 & 8 & 6,7 & 11,0 & 8,4 & 1,8 \\
\hline Comprimento do dentário & 6,4 & 7,1 & 8 & 4,8 & 8,3 & 5,8 & 1,2 \\
\hline Merísticos & & & & & & Moda & \\
\hline Placas dorsais & 27 & 26 & 8 & 25 & 27 & 26 & \\
\hline Placas médio-dorsais & 26 & 26 & 8 & 26 & 27 & 26 & \\
\hline Placas medianas & 27 & 27 & 8 & 26 & 27 & 26 & \\
\hline Placas médio-ventrais & 27 & 26 & 8 & 27 & 27 & 27 & \\
\hline Placas ventrais & 20 & 21 & 8 & 20 & 22 & 21 & \\
\hline Placas da base do pedúnculo caudal & 9 & 8 & 8 & 7 & 8 & 8 & \\
\hline Dentes do pré-maxilar & 10 & 8 & 8 & 4 & 8 & 4 & \\
\hline Dentes do dentário & 12 & 12 & 8 & 6 & 11 & 8 & \\
\hline
\end{tabular}


Tabela 4. Dados morfométricos e merísticos de Megalancistrus parananus. N= número de exemplares. $\mathrm{DP}=$ desvio padrão.

\begin{tabular}{|c|c|c|c|c|c|c|}
\hline & $\begin{array}{l}\text { Holótipo } \\
\text { ZMB } 11328\end{array}$ & $\mathbf{N}$ & Mínimo & Máximo & Média & DP \\
\hline $\begin{array}{l}\text { Comprimento Padrão (CP) } \\
\text { Porcentagens do CP }\end{array}$ & 462,5 & 53 & 67,1 & 395,0 & & \\
\hline Comprimento pré-dorsal & 44,4 & 53 & 37,7 & 60,9 & 46,8 & 3,0 \\
\hline Comprimento da cabeça (CC) & 35,1 & 53 & 30,9 & 39,1 & 36,6 & 1,7 \\
\hline Altura do corpo & 22,7 & 53 & 13,1 & 28,1 & 20,8 & 3,2 \\
\hline Largura cleitral & 31,3 & 53 & 29,2 & 34,5 & 31,9 & 1,3 \\
\hline Comprimento do tronco & 20,2 & 53 & 22,7 & 33,5 & 27,1 & 2,4 \\
\hline Comprimento do espinho peitoral & 36,2 & 53 & 26,8 & 40,1 & 32,8 & 3,4 \\
\hline Comprimento do abdomem & 24,9 & 53 & 20,8 & 27,0 & 24,2 & 1,3 \\
\hline Comprimento do espinho pélvico & 25,9 & 40 & 17,1 & 37,8 & 26,9 & 3,1 \\
\hline Comprimento pós-anal & 25,5 & 53 & 23,1 & 32,2 & 28,9 & 2,0 \\
\hline Comprimento do espinho anal & 16,1 & 53 & 9,5 & 20,6 & 16,5 & 1,8 \\
\hline Comprimento do espinho dorsal & 29,6 & 44 & 23,8 & 40,1 & 32,1 & 3,3 \\
\hline Comprimento da base da dorsal & 28,9 & 53 & 29,7 & 37,8 & 33,7 & 2,0 \\
\hline $\begin{array}{l}\text { Altura do pedúnculo caudal } \\
\text { Porcentagens do CC }\end{array}$ & 12,7 & 53 & 11,3 & 14,9 & 12,7 & 0,8 \\
\hline Diâmetro horizontal da órbita & 8,9 & 53 & 9,7 & 18,8 & 13,2 & 2,0 \\
\hline Comprimento do focinho & 66,9 & 53 & 43,5 & 68,7 & 63,7 & 3,7 \\
\hline Distância entre as narinas & 12,5 & 53 & 10,4 & 18,2 & 15,0 & 1,5 \\
\hline Distância inter-orbital & 43,5 & 53 & 32,8 & 45,3 & 40,2 & 3,4 \\
\hline Altura da cabeça & 52,9 & 53 & 37,3 & 71,0 & 53,3 & 7,7 \\
\hline Altura da boca & 36,3 & 53 & 35,0 & 48,0 & 40,3 & 2,7 \\
\hline Largura da boca & 43,3 & 53 & 34,1 & 55,5 & 42,7 & 4,3 \\
\hline Comprimento do pré-maxilar & 9,5 & 53 & 7,5 & 13,7 & 10,8 & 1,4 \\
\hline Comprimento do dentário & 7,8 & 53 & 5,0 & 13,1 & 8,3 & 1,4 \\
\hline Merísticos & & & & & Moda & \\
\hline Placas dorsais & 25 & 53 & 23 & 27 & 24 & \\
\hline Placas médio-dorsais & 25 & 53 & 24 & 26 & 25 & \\
\hline Placas medianas & 25 & 53 & 24 & 27 & 25 & \\
\hline Placas médio-ventrais & 25 & 53 & 23 & 27 & 25 & \\
\hline Placas ventrais & 20 & 53 & 16 & 21 & 17 & \\
\hline Placas da base do pedúnculo caudal & 9 & 53 & 7 & 9 & 7 & \\
\hline Dentes do pré-maxilar & 9 & 44 & 6 & 13 & 7 & \\
\hline Dentes do dentário & 12 & 44 & 7 & 14 & 9 & \\
\hline
\end{tabular}


Tabela 5. Dados morfométricos e merísticos de Pseudacanthicus leopardus. $\mathrm{N}=$ número de exemplares, $\mathrm{DP}=$ desvio padrão.

\begin{tabular}{|c|c|c|c|c|c|c|}
\hline & $\begin{array}{c}\text { Holótipo } \\
\text { ANSP } 39345\end{array}$ & $\mathbf{N}$ & Mínimo & Máximo & Média & DP \\
\hline $\begin{array}{l}\text { Comprimento Padrão (CP) } \\
\text { Porcentagens do CP }\end{array}$ & 71,67 & 36 & 25,09 & 285,00 & & \\
\hline Comprimento pré-dorsal & 42,81 & 36 & 36,68 & 49,70 & 43,63 & 2,61 \\
\hline Comprimento da cabeça (CC) & 35,65 & 36 & 18,48 & 42,36 & 36,98 & 3,81 \\
\hline Altura do corpo & 18,21 & 36 & 11,90 & 28,74 & 17,74 & 3,81 \\
\hline Largura cleitral & 30,36 & 36 & 25,06 & 34,06 & 30,62 & 1,61 \\
\hline Comprimento do tronco & 27,17 & 36 & 19,58 & 32,22 & 26,37 & 2,91 \\
\hline Comprimento do espinho peitoral & 31,73 & 36 & 26,42 & 35,76 & 30,49 & 1,83 \\
\hline Comprimento do abdomem & 24,24 & 36 & 15,98 & 29,95 & 25,15 & 2,82 \\
\hline Comprimento do espinho pélvico & 31,83 & 36 & 23,94 & 33,27 & 29,69 & 2,11 \\
\hline Comprimento pós-anal & 30,14 & 36 & 27,38 & 36,60 & 31,46 & 1,91 \\
\hline Comprimento do espinho anal & 20,13 & 34 & 15,50 & 25,39 & 19,97 & 2,37 \\
\hline Comprimento do espinho dorsal & 31,41 & 32 & 22,79 & 41,31 & 31,96 & 3,50 \\
\hline Comprimento da base da dorsal & 29,40 & 36 & 23,22 & 35,80 & 27,74 & 2,89 \\
\hline $\begin{array}{l}\text { Altura do pedúnculo caudal } \\
\text { Porcentagens do } \mathrm{CC}\end{array}$ & 14,71 & 36 & 4,98 & 17,19 & 14,14 & 2,01 \\
\hline Diâmetro horizontal da órbita & 16,09 & 36 & 10,48 & 37,84 & 16,41 & 4,63 \\
\hline Comprimento do focinho & 60,27 & 36 & 50,20 & 65,68 & 58,24 & 4,58 \\
\hline Distância entre as narinas & 15,85 & 36 & 12,29 & 23,68 & 16,85 & 2,51 \\
\hline Distância interorbital & 32,68 & 36 & 29,80 & 38,9 & 33,1 & 1,95 \\
\hline Altura da cabeça & 44,93 & 36 & 35,04 & 63,90 & 46,14 & 7,22 \\
\hline Altura da boca & 36,24 & 36 & 31,63 & 85,86 & 44,28 & 8,26 \\
\hline Largura da boca & 40,35 & 36 & 34,07 & 77,78 & 45,76 & 7,17 \\
\hline Comprimento do pré-maxilar & 8,65 & 36 & 6,37 & 16,38 & 9,80 & 1,65 \\
\hline Comprimento do dentário & 5,87 & 36 & 3,08 & 8,16 & 5,19 & 1,03 \\
\hline Merísticos & & & & & Moda & \\
\hline Placas dorsais & 24 & 36 & 21 & 26 & 23 & \\
\hline Placas médio-dorsais & 23 & 36 & 19 & 25 & 23 & \\
\hline Placas medianas & 22 & 36 & 21 & 26 & 23 & \\
\hline Placas médio-ventrais & 23 & 36 & 22 & 25 & 23 & \\
\hline Placas ventrais & 11 & 36 & 7 & 18 & 10 & \\
\hline Placas da base do pedúnculo caudal & 6 & 36 & 5 & 8 & 7 & \\
\hline Dentes do pré-maxilar & 4 & 36 & 3 & 7 & 4 & \\
\hline Dentes do dentário & 6 & 36 & 4 & 13 & 5 & \\
\hline
\end{tabular}


Tabela 6. Dados morfométricos e merísticos de Pseudacanthicus serratus. $\mathrm{N}=$ número de exemplares; $\mathrm{DP}=$ desvio padrão.

\begin{tabular}{|c|c|c|c|c|c|c|}
\hline & $\begin{array}{c}\text { Holótipo } \\
\text { RMNH } 3125\end{array}$ & $\mathbf{N}$ & Mínimo & Máximo & Média & DP \\
\hline Comprimento Padrão (CP) & 148,75 & 18 & 100,0 & 337,1 & - & - \\
\hline \multicolumn{7}{|l|}{ Porcentagens do CP } \\
\hline Comprimento pré-dorsal & 45,1 & 18 & 42,4 & 139,4 & 84,2 & 30,1 \\
\hline Comprimento da cabeça (CC) & 35,2 & 18 & 36,5 & 118,1 & 70,6 & 25,4 \\
\hline Altura do corpo & 16,0 & 18 & 15,7 & 73,7 & 39,5 & 19,3 \\
\hline Largura cleitral & 31,9 & 18 & 31,1 & 95,5 & 61,9 & 23,1 \\
\hline Comprimento do tronco & 26,6 & 18 & 25,2 & 80,8 & 49,2 & 15,4 \\
\hline Comprimento do espinho peitoral & 30,2 & 18 & 30,5 & 86,3 & 58,1 & 18,8 \\
\hline Comprimento do abdomem & 24,1 & 18 & 23,5 & 95,3 & 52,7 & 20,4 \\
\hline Comprimento do espinho pélvico & 30,5 & 18 & 32,2 & 75,1 & 55,1 & 15,5 \\
\hline Comprimento pós-anal & 30,9 & 18 & 31,1 & 93,9 & 59,1 & 19,7 \\
\hline Comprimento do espinho anal & 21,7 & 16 & 22,2 & 59,8 & 41,2 & 11,5 \\
\hline Comprimento do espinho dorsal & 36,9 & 15 & 29,0 & 89,9 & 63,6 & 17,5 \\
\hline Comprimento da base da dorsal & 30,3 & 18 & 29,1 & 99,5 & 55,9 & 20,7 \\
\hline \multicolumn{7}{|l|}{ Porcentagens do CC } \\
\hline Diâmetro horizontal da órbita & 12,2 & 18 & 5,4 & 12,3 & 8,3 & 2,1 \\
\hline Comprimento do focinho & 64,9 & 18 & 22,1 & 77,8 & 44,7 & 17,1 \\
\hline Distância entre as narinas & 18,9 & 18 & 5,1 & 20,8 & 11,9 & 4,9 \\
\hline Distância inter-orbital & 35,4 & 18 & 11,2 & 41,5 & 24,8 & 10,3 \\
\hline Altura da cabeça & 51,2 & 18 & 17,3 & 76,3 & 37,8 & 17,1 \\
\hline Altura da boca & 43,7 & 18 & 13,6 & 54,8 & 31,3 & 12,0 \\
\hline Largura da boca & 50,3 & 18 & 13,5 & 56,3 & 34,1 & 12,7 \\
\hline Comprimento do pré-maxilar & 5,1 & 18 & 1,4 & 9,3 & 5,1 & 1,9 \\
\hline Comprimento do dentário & 11,7 & 18 & 3,0 & 14,7 & 7,8 & 3,9 \\
\hline Merísticos & & & & & Moda & \\
\hline Placas dorsais & 25 & 18 & 24 & 26 & 25 & \\
\hline Placas médio-dorsais & 24 & 18 & 23 & 25 & 24 & \\
\hline Placas medianas & 24 & 18 & 22 & 25 & 24 & \\
\hline Placas médio-ventrais & 24 & 18 & 23 & 26 & 24 & \\
\hline Placas ventrais & 11 & 18 & 10 & 18 & 11 & \\
\hline Placas da base do pedúnculo caudal & 7 & 18 & 5 & 8 & 7 & \\
\hline Dentes do pré-maxilar & 4 & 18 & 4 & 10 & 4 & \\
\hline Dentes do dentário & 9 & 18 & 4 & 17 & 15 & \\
\hline
\end{tabular}


Tabela 7. Dados morfométricos e merísticos de Pseudacanthicus spinosus. N= número de exemplares, $\mathrm{DP}=$ desvio padrão.

\begin{tabular}{|c|c|c|c|c|c|c|}
\hline & $\begin{array}{c}\text { Holótipo } \\
\text { MNHN A-9577 }\end{array}$ & $\mathbf{N}$ & Mínimo & Máximo & Média & DP \\
\hline $\begin{array}{c}\text { Comprimento Padrão (CP) } \\
\text { Porcentagens do CP }\end{array}$ & 262,6 & 44 & 37,4 & 590,5 & & \\
\hline Comprimento pré-dorsal & 41,7 & 44 & 39,5 & 49,9 & 44,4 & 2,3 \\
\hline Comprimento da cabeça (CC) & 34,5 & 44 & 26,5 & 42,3 & 36,5 & 2,5 \\
\hline Altura do corpo & 20,7 & 44 & 13,9 & 28,9 & 20,7 & 2,9 \\
\hline Largura cleitral & 29,2 & 44 & 26,1 & 40,6 & 31,1 & 2,1 \\
\hline Comprimento do tronco & 25,6 & 44 & 18,9 & 29,8 & 25,0 & 2,0 \\
\hline Comprimento do espinho peitoral & 27,4 & 44 & 24,3 & 35,1 & 31,0 & 2,1 \\
\hline Comprimento do abdomem & 25,2 & 44 & 19,3 & 30,0 & 24,6 & 2,0 \\
\hline Comprimento do espinho pélvico & 25,2 & 42 & 22,9 & 34,6 & 29,9 & 2,4 \\
\hline Comprimento pós-anal & 32,3 & 44 & 28,9 & 36,2 & 32,6 & 2,1 \\
\hline Comprimento do espinho anal & 20,5 & 42 & 16,5 & 25,3 & 22,0 & 2,1 \\
\hline Comprimento do espinho dorsal & 32,0 & 40 & 26,6 & 41,3 & 35,0 & 3,4 \\
\hline Comprimento da base da dorsal & 30,3 & 44 & 19,2 & 31,9 & 28,0 & 2,7 \\
\hline $\begin{array}{l}\text { Altura do pedúnculo caudal } \\
\text { Porcentagens do CC }\end{array}$ & 14,6 & 44 & 11,5 & 16,8 & 14,2 & 1,1 \\
\hline Diâmetro horizontal da órbita & 11,1 & 44 & 6,8 & 19,8 & 13,0 & 2,8 \\
\hline Comprimento do focinho & 45,9 & 44 & 45,9 & 67,7 & 59,8 & 4,1 \\
\hline Distância entre as narinas & 14,6 & 44 & 10,8 & 19,7 & 14,7 & 2,1 \\
\hline Distância interorbital & 34,4 & 44 & 25,2 & 40,5 & 32,9 & 3,1 \\
\hline Altura da cabeça & 53,9 & 44 & 39,7 & 69,2 & 53,7 & 6,6 \\
\hline Altura da boca & 44,1 & 44 & 27,7 & 65,4 & 42,5 & 5,6 \\
\hline Largura da boca & 44,9 & 44 & 30,1 & 63,7 & 45,4 & 5,8 \\
\hline Comprimento do pré-maxilar & 7,6 & 44 & 7,5 & 13,3 & 10,0 & 1,6 \\
\hline Comprimento do dentário & 3,1 & 44 & 2,7 & 10,1 & 5,0 & 1,5 \\
\hline Merísticos & & & & & Moda & \\
\hline Placas dorsais & 28 & 44 & 22 & 28 & 24 & \\
\hline Placas médio-dorsais & 26 & 44 & 21 & 26 & 24 & \\
\hline Placas medianas & 24 & 44 & 21 & 25 & 24 & \\
\hline Placas médio-ventrais & 23 & 44 & 21 & 25 & 23 & \\
\hline Placas ventrais & 9 & 44 & 9 & 19 & 12 & \\
\hline Placas da base do pedúnculo caudal & 6 & 44 & 6 & 10 & 6 & \\
\hline Dentes do pré-maxilar & 6 & 44 & 3 & 11 & 4 & \\
\hline Dentes do dentário & 8 & 44 & 3 & 15 & 7 & \\
\hline
\end{tabular}


Tabela 8. Dados morfométricos e merísticos de Pseudacanthicus sp. "Aripuanã”. N= número de exemplares, $\mathrm{DP}=$ desvio padrão.

\begin{tabular}{lccccc}
\hline & N & Mínimo & Máximo & Média & DP \\
\hline Comprimento Padrão (CP) & 9 & 58,13 & 105,62 & - & - \\
$\quad$ Porcentagens do CP & & & & & \\
Comprimento pré-dorsal & 9 & 38,97 & 44,40 & 41,26 & 1,46 \\
Comprimento da cabeça (CC) & 9 & 34,17 & 36,80 & 35,29 & 0,76 \\
Altura do corpo & 9 & 13,68 & 18,48 & 16,31 & 1,51 \\
Largura cleitral & 9 & 28,44 & 30,88 & 29,35 & 0,76 \\
Comprimento do tronco & 9 & 25,73 & 29,78 & 28,10 & 1,46 \\
Comprimento do espinho peitoral & 9 & 27,00 & 29,98 & 28,43 & 1,04 \\
Comprimento do abdome & 9 & 22,81 & 26,08 & 24,77 & 1,10 \\
Comprimento do espinho pélvico & 9 & 24,25 & 29,72 & 26,90 & 1,70 \\
Comprimento pós-anal & 9 & 30,03 & 34,42 & 31,68 & 1,22 \\
Comprimento do espinho anal & 9 & 16,09 & 20,09 & 18,23 & 1,33 \\
Comprimento do espinho dorsal & 9 & 25,97 & 35,22 & 31,61 & 3,17 \\
Comprimento da base da dorsal & 9 & 27,55 & 31,61 & 29,73 & 1,39 \\
Altura do pedúnculo caudal & 9 & 12,94 & 17,98 & 14,29 & 1,47 \\
$\quad$ Porcentagens do CC & & & & & \\
Diâmetro horizontal da órbita & 9 & 11,75 & 14,24 & 12,72 & 0,75 \\
Comprimento do focinho & 9 & 52,94 & 61,50 & 58,36 & 2,33 \\
Distância entre as narinas & 9 & 12,88 & 19,90 & 15,98 & 2,40 \\
Distância interorbital & 9 & 30,70 & 34,90 & 33,06 & 1,34 \\
Altura da cabeça & 9 & 40,33 & 50,20 & 45,70 & 2,82 \\
Altura da boca & 9 & 38,62 & 46,95 & 42,61 & 2,52 \\
Largura da boca & 9 & 41,27 & 49,01 & 45,99 & 2,73 \\
Comprimento do pré-maxilar & 9 & 8,36 & 12,42 & 10,11 & 1,34 \\
Comprimento do dentário & 9 & 4,80 & 6,83 & 5,70 & 0,64 \\
& & & & & \\
$\quad$ Merísticos & & & & Moda & \\
Placas dorsais & 9 & 23 & 25 & 24 & - \\
Placas médio-dorsais & 9 & 22 & 25 & 24 & - \\
Placas medianas & 9 & 23 & 25 & 24 & - \\
Placas médio-ventrais & 9 & 23 & 25 & 24 & - \\
Placas ventrais & 9 & 12 & 14 & 12 & - \\
Placas da base do pedúnculo caudal & 9 & 6 & 7 & 7 & - \\
Dentes do pré-maxilar & 9 & 5 & 6 & 5 & - \\
Dentes do dentário & 9 & 8 & 10 & 9 & - \\
\hline & & & & & \\
& & & &
\end{tabular}


Tabela 9. Dados morfométricos e merísticos de Pseudacanthicus sp. "Tapajós”. N= número de exemplares, $\mathrm{DP}=$ desvio padrão

\begin{tabular}{|c|c|c|c|c|c|}
\hline & $\mathbf{N}$ & Mínimo & Máximo & Média & DP \\
\hline Comprimento Padrão (CP) & 23 & 65,9 & 144,8 & 96,5 & \\
\hline \multicolumn{6}{|l|}{ Porcentagens do CP } \\
\hline Comprimento pré-dorsal & 23 & 42,1 & 48,0 & 44,4 & 1,5 \\
\hline Comprimento da cabeça (CC) & 23 & 35,7 & 39,7 & 37,7 & 1,1 \\
\hline Altura do corpo & 23 & 13,5 & 26,4 & 20,2 & 2,9 \\
\hline Largura cleitral & 23 & 28,7 & 34,1 & 31,1 & 1,4 \\
\hline Comprimento do tronco & 23 & 21,8 & 29,4 & 25,0 & 1,5 \\
\hline Comprimento do espinho peitoral & 23 & 27,7 & 33,7 & 30,6 & 1,6 \\
\hline Comprimento do abdomem & 23 & 23,5 & 29,0 & 25,5 & 1,3 \\
\hline Comprimento do espinho pélvico & 23 & 28,8 & 32,8 & 30,5 & 1,0 \\
\hline Comprimento pós-anal & 23 & 22,3 & 35,7 & 26,3 & 3,9 \\
\hline Comprimento do espinho anal & 23 & 18,0 & 25,2 & 22,2 & 1,7 \\
\hline Comprimento do espinho dorsal & 23 & 30,7 & 37,3 & 34,2 & 1,5 \\
\hline Comprimento da base da dorsal & 23 & 24,2 & 32,2 & 28,0 & 1,9 \\
\hline Altura do pedúnculo caudal & 23 & 13,1 & 17,0 & 14,6 & 0,8 \\
\hline \multicolumn{6}{|l|}{ Porcentagens do CC } \\
\hline Diâmetro horizontal da órbita & 23 & 12,5 & 18,4 & 14,5 & 1,7 \\
\hline Comprimento do focinho & 23 & 56,2 & 63,6 & 59,9 & 2,0 \\
\hline Distância entre as narinas & 23 & 12,1 & 18,5 & 15,4 & 1,6 \\
\hline Distância inter-orbital & 23 & 27,7 & 33,1 & 30,5 & 1,4 \\
\hline Altura da cabeça & 23 & 38,7 & 58,0 & 50,4 & 4,8 \\
\hline Altura da boca & 23 & 39,7 & 50,3 & 45,5 & 2,6 \\
\hline Largura da boca & 23 & 39,7 & 55,0 & 48,0 & 3,7 \\
\hline Comprimento do pré-maxilar & 23 & 6,9 & 12,2 & 9,6 & 1,3 \\
\hline Comprimento do dentário & 23 & 3,7 & 8,8 & 5,6 & 1,2 \\
\hline \multicolumn{3}{|l|}{ Merísticos } & \multicolumn{3}{|c|}{ Moda } \\
\hline Placas dorsais & 23 & 22 & 25 & 23 & \\
\hline Placas médio-dorsais & 23 & 20 & 25 & 22 & \\
\hline Placas medianas & 23 & 21 & 25 & 23 & \\
\hline Placas médio-ventrais & 23 & 21 & 25 & 22 & \\
\hline Placas ventrais & 23 & 11 & 16 & 11 & \\
\hline $\begin{array}{l}\text { Placas da base do pedúnculo } \\
\text { caudal }\end{array}$ & 23 & 6 & 8 & 6 & \\
\hline Dentes do pré-maxilar & 23 & 4 & 6 & 5 & \\
\hline Dentes do dentário & 23 & 5 & 10 & 6 & \\
\hline
\end{tabular}


Tabela 10. Dados morfométricos e merísticos de Pseudacanthicus sp. "açacu vermelho". N= número de exemplares, $\mathrm{DP}=$ desvio padrão.

\begin{tabular}{|c|c|c|c|c|c|c|}
\hline & $\begin{array}{c}\text { Holótipo } \\
\text { ECIX2010070802 } \\
\end{array}$ & $\mathbf{N}$ & Mínimo & Máximo & Média & DP \\
\hline $\begin{array}{l}\text { Comprimento Padrão (CP) } \\
\text { Porcentagens do CP }\end{array}$ & 246,5 & 22 & 163,5 & 210,5 & - & - \\
\hline Comprimento pré-dorsal & 104,9 & 22 & 38,8 & 46,0 & 42,7 & 1,6 \\
\hline Comprimento da cabeça (CC) & 86,5 & 22 & 31,3 & 38,8 & 35,5 & 1,7 \\
\hline Altura do corpo & 55,8 & 22 & 14,1 & 26,5 & 21,2 & 3,4 \\
\hline Largura cleitral & 72,1 & 22 & 19,6 & 32,2 & 29,6 & 2,4 \\
\hline Comprimento do tronco & 59,0 & 22 & 19,0 & 29,7 & 25,3 & 2,4 \\
\hline Comprimento do espinho peitoral & 84,9 & 22 & 29,2 & 35,5 & 32,7 & 1,6 \\
\hline Comprimento do abdomem & 66,0 & 22 & 21,4 & 29,5 & 26,0 & 2,0 \\
\hline Comprimento do espinho pélvico & 74,6 & 22 & 25,4 & 32,4 & 29,8 & 1,8 \\
\hline Comprimento pós-anal & 78,2 & 22 & 29,5 & 34,6 & 32,3 & 1,5 \\
\hline Comprimento do espinho anal & 53,4 & 22 & 16,9 & 22,5 & 20,1 & 1,5 \\
\hline Comprimento do espinho dorsal & 80,8 & 22 & 26,6 & 38,1 & 32,8 & 3,0 \\
\hline Comprimento da base da dorsal & 68,0 & 22 & 24,1 & 29,3 & 27,2 & 1,3 \\
\hline $\begin{array}{l}\text { Altura do pedúnculo caudal } \\
\text { Porcentagens do CC }\end{array}$ & 34,4 & 22 & 11,5 & 15,2 & 13,5 & 0,9 \\
\hline Diâmetro horizontal da órbita & 9,8 & 22 & 7,6 & 15,8 & 11,9 & 2,1 \\
\hline Comprimento do focinho & 59,1 & 22 & 56,7 & 68,2 & 63,2 & 2,9 \\
\hline Distância entre as narinas & 11,4 & 22 & 10,9 & 17,0 & 13,9 & 1,5 \\
\hline Distância inter-orbital & 28,0 & 22 & 11,6 & 33,7 & 30,1 & 4,6 \\
\hline Altura da cabeça & 49,4 & 22 & 20,1 & 62,9 & 50,8 & 9,2 \\
\hline Altura da boca & 35,5 & 22 & 15,3 & 50,3 & 41,8 & 6,8 \\
\hline Largura da boca & 41,4 & 22 & 17,2 & 52,8 & 43,0 & 7,3 \\
\hline Comprimento do pré-maxilar & 7,3 & 22 & 3,5 & 12,2 & 8,0 & 2,2 \\
\hline Comprimento do dentário & 2,8 & 22 & 2,1 & 7,4 & 4,6 & 1,4 \\
\hline Merísticos & & & & & Moda & \\
\hline Placas dorsais & 26 & 22 & 24 & 27 & 26 & \\
\hline Placas médio-dorsais & 25 & 22 & 23 & 27 & 25 & \\
\hline Placas medianas & 26 & 22 & 22 & 27 & 26 & \\
\hline Placas médio-ventrais & 25 & 22 & 24 & 26 & 25 & \\
\hline Placas ventrais & 15 & 22 & 11 & 19 & 17 & \\
\hline Placas da base do pedúnculo caudal & 7 & 22 & 7 & 8 & 7 & \\
\hline Dentes do pré-maxilar & 8 & 21 & 4 & 11 & 8 & \\
\hline Dentes do dentário & 18 & 21 & 7 & 21 & 14 & \\
\hline
\end{tabular}


Tabela 11. Dados morfométricos e merísticos de Pseudacanthicus sp. "açacu preto". N= número de exemplares; $\mathrm{DP}=$ desvio padrão.

\begin{tabular}{|c|c|c|c|c|c|c|}
\hline & Holótipo & $\mathbf{N}$ & Mínimo & Máximo & Média & DP \\
\hline & ECIX201007120 & & & & & \\
\hline $\begin{array}{l}\text { Comprimento Padrão (CP) } \\
\text { Porcentagens do CP }\end{array}$ & 113,6 & 19 & 35,4 & 250,2 & & \\
\hline Comprimento pré-dorsal & 47,2 & 19 & 40,0 & 50,8 & 43,2 & 1,7 \\
\hline Comprimento da cabeça (CC) & 42,4 & 19 & 32,8 & 39,0 & 36,4 & 2,0 \\
\hline Altura do corpo & 22,6 & 19 & 12,9 & 24,0 & 17,7 & 1,9 \\
\hline Largura cleitral & 34,3 & 19 & 17,2 & 32,8 & 29,6 & 4,8 \\
\hline Comprimento do tronco & 28,3 & 19 & 20,4 & 29,3 & 25,7 & 1,7 \\
\hline Comprimento do espinho peitoral & 30,8 & 19 & 26,0 & 34,4 & 29,5 & 2,6 \\
\hline Comprimento do abdomem & 28,3 & 19 & 21,6 & 28,1 & 24,0 & 1,2 \\
\hline Comprimento do espinho pélvico & 31,9 & 19 & 25,3 & 32,5 & 29,0 & 2,5 \\
\hline Comprimento pós-anal & 36,5 & 19 & 23,7 & 34,8 & 31,7 & 1,3 \\
\hline Comprimento do espinho anal & 22,9 & 19 & 16,3 & 30,7 & 20,8 & 0,5 \\
\hline Comprimento do espinho dorsal & 37,9 & 19 & 29,3 & 37,3 & 33,3 & 2,5 \\
\hline Comprimento da base da dorsal & 32,5 & 19 & 25,3 & 34,3 & 28,8 & 1,7 \\
\hline $\begin{array}{l}\text { Altura do pedúnculo caudal } \\
\text { Porcentagens do } \mathrm{CC}\end{array}$ & 15,2 & 19 & 11,8 & 16,0 & 13,4 & 0,8 \\
\hline Diâmetro horizontal da órbita & 4,8 & 19 & 10,3 & 16,9 & 13,6 & 2,2 \\
\hline Comprimento do focinho & 25,8 & 19 & 55,8 & 69,1 & 60,1 & 3,9 \\
\hline Distância entre as narinas & 5,7 & 19 & 12,2 & 21,9 & 16,0 & 2,1 \\
\hline Distância inter-orbital & 13,2 & 19 & 29,3 & 36,7 & 32,8 & 2,2 \\
\hline Altura da cabeça & 19,6 & 19 & 36,3 & 63,4 & 46,3 & 5,0 \\
\hline Altura da boca & 19,0 & 19 & 35,6 & 52,1 & 43,2 & 3,4 \\
\hline Largura da boca & 19,4 & 19 & 38,1 & 57,7 & 49,3 & 5,7 \\
\hline Comprimento do pré-maxilar & 4,7 & 19 & 6,6 & 11,6 & 8,9 & 0,9 \\
\hline Comprimento do dentário & 1,8 & 19 & 2,8 & 6,2 & 4,6 & 1,0 \\
\hline Merísticos & & & & & Moda & \\
\hline Placas dorsais & 27 & 19 & 22 & 27 & 24 & \\
\hline Placas médio-dorsais & 24 & 19 & 22 & 24 & 24 & \\
\hline Placas medianas & 26 & 19 & 23 & 26 & 25 & \\
\hline Placas médio-ventrais & 26 & 19 & 22 & 26 & 23 & \\
\hline Placas ventrais & 13 & 19 & 9 & 16 & 11 & \\
\hline $\begin{array}{l}\text { Placas da base do pedúnculo } \\
\text { caudal }\end{array}$ & 6 & 19 & 5 & 7 & 6 & \\
\hline Dentes do pré-maxilar & 3 & 19 & 3 & 5 & 3 & \\
\hline Dentes do dentário & 8 & 19 & 4 & 8 & 6 & \\
\hline
\end{tabular}


Tabela 12. Dados morfométricos e merísticos de Pseudacanthicus sp. "Tocantins". N= número de exemplares; $\mathrm{DP}=$ desvio padrão,

\begin{tabular}{|c|c|c|c|c|c|}
\hline & $\mathbf{N}$ & Mínimo & Máximo & Média & DP \\
\hline Comprimento Padrão (CP) & 15 & 62,28 & 460,00 & - & - \\
\hline \multicolumn{6}{|l|}{ Porcentagens do CP } \\
\hline Comprimento pré-dorsal & 15 & 39,23 & 43,80 & 41,87 & 1,24 \\
\hline Comprimento da cabeça (CC) & 15 & 30,57 & 35,36 & 33,37 & 1,06 \\
\hline Altura do corpo & 15 & 14,76 & 21,01 & 17,88 & 1,63 \\
\hline Largura cleitral & 15 & 26,58 & 29,47 & 27,95 & 0,77 \\
\hline Comprimento do tronco & 15 & 20,96 & 26,40 & 23,54 & 1,62 \\
\hline Comprimento do espinho peitoral & 15 & 28,96 & 32,55 & 30,47 & 1,08 \\
\hline Comprimento do abdomem & 15 & 21,16 & 24,65 & 23,18 & 1,01 \\
\hline Comprimento do espinho pélvico & 15 & 28,19 & 32,48 & 30,53 & 1,15 \\
\hline Comprimento pós-anal & 15 & 30,26 & 39,99 & 37,72 & 2,34 \\
\hline Comprimento do espinho anal & 15 & 18,63 & 24,38 & 22,45 & 1,53 \\
\hline Comprimento do espinho dorsal & 13 & 31,17 & 41,77 & 37,10 & 2,66 \\
\hline Comprimento da base da dorsal & 15 & 20,86 & 26,03 & 23,68 & 1,52 \\
\hline Altura do pedúnculo caudal & 15 & 13,43 & 16,27 & 14,32 & 0,63 \\
\hline Diâmetro horizontal da órbita & 15 & 7,65 & 13,74 & 11,85 & 1,67 \\
\hline Comprimento do focinho & 15 & 51,35 & 57,84 & 55,73 & 1,66 \\
\hline Distância entre as narinas & 15 & 11,62 & 18,22 & 13,14 & 1,59 \\
\hline Distância interorbital & 15 & 25,55 & 29,85 & 27,31 & 1,11 \\
\hline Altura da cabeça & 15 & 44,32 & 63,20 & 48,44 & 4,41 \\
\hline Altura da boca & 14 & 36,14 & 48,34 & 43,33 & 2,93 \\
\hline Largura da boca & 14 & 31,79 & 52,49 & 40,91 & 5,26 \\
\hline Comprimento do pré-maxilar & 15 & 8,63 & 12,33 & 10,72 & 1,08 \\
\hline Comprimento do dentário & 15 & 4,23 & 8,81 & 6,17 & 1,04 \\
\hline Merísticos & & & & Moda & \\
\hline Placas dorsais & 15 & 25 & 28 & 25 & - \\
\hline Placas médio-dorsais & 15 & 23 & 26 & 26 & - \\
\hline Placas medianas & 15 & 24 & 27 & 25 & - \\
\hline Placas médio-ventrais & 15 & 24 & 25 & 25 & - \\
\hline Placas ventrais & 15 & 16 & 20 & 18 & - \\
\hline Placas da base do pedúnculo caudal & 15 & 8 & 10 & 9 & - \\
\hline Dentes do pré-maxilar & 15 & 6 & 13 & 7 & - \\
\hline Dentes do dentário & 15 & 10 & 19 & 12 & - \\
\hline
\end{tabular}


Tabela 13. Dados morfométricos e merísticos de Pseudacanthicus sp. "aba laranja". N= número de exemplares; $\mathrm{DP}=$ desvio padrão,

\begin{tabular}{|c|c|c|c|c|c|}
\hline & $\mathbf{N}$ & Mínimo & Máximo & Média & DP \\
\hline Comprimento Padrão (CP) & 29 & 86,54 & 300,00 & - & - \\
\hline \multicolumn{6}{|l|}{ Porcentagens do CP } \\
\hline Comprimento pré-dorsal & 29 & 39,23 & 48,10 & 44,52 & 2,13 \\
\hline Comprimento da cabeça (CC) & 29 & 33,00 & 39,79 & 36,81 & 1,50 \\
\hline Altura do corpo & 29 & 15,61 & 24,64 & 20,67 & 2,36 \\
\hline Largura cleitral & 29 & 27,61 & 33,25 & 30,34 & 1,41 \\
\hline Comprimento do tronco & 29 & 19,69 & 28,16 & 24,94 & 1,84 \\
\hline Comprimento do espinho peitoral & 29 & 28,29 & 39,38 & 31,93 & 2,66 \\
\hline Comprimento do abdomem & 29 & 22,27 & 29,08 & 25,80 & 1,76 \\
\hline Comprimento do espinho pélvico & 29 & 23,29 & 35,46 & 29,04 & 2,43 \\
\hline Comprimento pós-anal & 29 & 27,72 & 35,24 & 31,39 & 1,66 \\
\hline Comprimento do espinho anal & 29 & 13,41 & 24,28 & 20,28 & 2,53 \\
\hline Comprimento do espinho dorsal & 29 & 21,95 & 41,76 & 33,62 & 4,13 \\
\hline Comprimento da base da dorsal & 29 & 23,18 & 31,87 & 27,92 & 1,74 \\
\hline \multicolumn{5}{|l|}{ Porcentagens do CC } & 1,11 \\
\hline Diâmetro horizontal da órbita & 29 & 9,56 & 16,44 & 13,29 & 1,57 \\
\hline Comprimento do focinho & 29 & 58,07 & 69,15 & 63,50 & 2,71 \\
\hline Distância entre as narinas & 29 & 10,43 & 17,06 & 14,06 & 1,72 \\
\hline Distância interorbital & 29 & 29,63 & 38,46 & 33,84 & 2,50 \\
\hline Altura da cabeça & 29 & 41,41 & 60,38 & 52,25 & 5,46 \\
\hline Altura da boca & 29 & 33,75 & 50,52 & 43,34 & 3,69 \\
\hline Largura da boca & 29 & 14,36 & 48,37 & 40,13 & 6,42 \\
\hline Comprimento do pré-maxilar & 29 & 6,22 & 11,85 & 8,58 & 1,46 \\
\hline Comprimento do dentário & 29 & 2,66 & 9,87 & 4,70 & 1,43 \\
\hline \multicolumn{3}{|l|}{ Merísticos } & \multicolumn{3}{|c|}{ Moda } \\
\hline Placas dorsais & 29 & 23 & 27 & 25 & - \\
\hline Placas médio-dorsais & 29 & 23 & 26 & 24 & - \\
\hline Placas medianas & 29 & 23 & 27 & 25 & - \\
\hline Placas médio-ventrais & 29 & 22 & 25 & 24 & - \\
\hline Placas ventrais & 29 & 11 & 20 & 17 & - \\
\hline Placas da base do pedúnculo caudal & 29 & 6 & 9 & 8 & - \\
\hline Dentes do pré-maxilar & 29 & 4 & 10 & 4 & - \\
\hline Dentes do dentário & 29 & 6 & 16 & 13 & - \\
\hline
\end{tabular}


Tabela 14. Dados morfométricos e merísticos de Spectracanthicus murinus. N= número de exemplares, $\mathrm{DP}=$ desvio padrão,

\begin{tabular}{|c|c|c|c|c|c|c|}
\hline & $\begin{array}{c}\text { Holótipo } \\
\text { MZUSP 22011 }\end{array}$ & $\mathbf{N}$ & Mínimo & Máximo & Média & DP \\
\hline Comprimento Padrão (CP) & 59,7 & 28 & 44,1 & 96,7 & & \\
\hline \multicolumn{7}{|l|}{ Porcentagens do CP } \\
\hline Comprimento da cabeça (CC) & 34,3 & 28 & 33,6 & 41,3 & 35,2 & 1,4 \\
\hline Altura da cabeça & 18,1 & 28 & 16,6 & 22,5 & 19,2 & 1,7 \\
\hline Largura da cabeça & 31,3 & 28 & 26,8 & 31,9 & 29,2 & 1,2 \\
\hline Altura do corpo & 19,4 & 28 & 15,3 & 28,8 & 20,5 & 3,0 \\
\hline Largura do corpo na origem da dorsal & 28,3 & 28 & 25,0 & 31,1 & 27,8 & 1,7 \\
\hline Largura do corpo na origem da anal & 15,1 & 28 & 12,2 & 20,0 & 15,3 & 1,7 \\
\hline Comprimento pré-dorsal & 43,5 & 28 & 40,8 & 45,9 & 43,7 & 1,1 \\
\hline Comprimento pós-dorsal & 24,1 & 28 & 22,0 & 63,7 & 51,6 & 15,7 \\
\hline Comprimento pós-anal & 30,2 & 28 & 28,5 & 38,6 & 32,3 & 2,3 \\
\hline Comprimento do espinho dorsal & 26,2 & 28 & 0,0 & 31,7 & 26,9 & 5,5 \\
\hline Comprimento do espinho peitoral & 29,7 & 28 & 27,5 & 31,6 & 29,6 & 1,1 \\
\hline Comprimento do espinho pélvico & 27,8 & 28 & 25,0 & 30,0 & 27,7 & 1,4 \\
\hline Comprimento da base da dorsal & 30,1 & 28 & 29,6 & 40,0 & 34,5 & 2,7 \\
\hline Altura do pedúnculo caudal & 16,4 & 28 & 11,6 & 16,4 & 13,4 & 1,2 \\
\hline \multicolumn{7}{|l|}{ Porcentagens do CC } \\
\hline Comprimento do focinho & 69,7 & 28 & 58,1 & 74,8 & 69,8 & 3,3 \\
\hline Distância interorbital & 34,7 & 28 & 31,4 & 39,5 & 36,0 & 1,9 \\
\hline Diametro horizontal da órbita & 15,1 & 28 & 14,1 & 33,4 & 18,2 & 3,4 \\
\hline Comprimento do dentário & 9,3 & 28 & 4,3 & 9,6 & 8,0 & 1,4 \\
\hline Merísticos & & & & & Moda & \\
\hline Dentes do pré-maxilar & 3 & 28 & 2 & 3 & 3 & \\
\hline Dentes do dentário & 5 & 28 & 5 & 5 & 5 & \\
\hline Raios da nadadeira dorsal & $\mathrm{i}+7$ & 28 & $1+7$ & $1+7$ & $1+7$ & \\
\hline Raios da nadadeira peitoral & $i+6$ & 28 & $1+6$ & $1+6$ & $1+6$ & \\
\hline Raios da nadadeira pélvica & $i+5$ & 28 & $1+5$ & $1+5$ & $1+5$ & \\
\hline Raios da nadadeira anal & $i+3$ & 28 & $1+3$ & $1+3$ & $1+3$ & \\
\hline Raios da nadadeira caudal & $i+14+i$ & 28 & $|+14+|$ & $|+14+|$ & $|+14+|$ & \\
\hline Placas da linha lateral & 21 & 28 & 21 & 22 & 22 & \\
\hline Placas do pedúnculo caudal & 8 & 28 & 7 & 8 & 7 & \\
\hline
\end{tabular}


Tabela 15. Dados morfométricos e merísticos de Spectracanthicus punctatissimus. N= número de exemplares, $\mathrm{DP}=$ desvio padrão,

\begin{tabular}{|c|c|c|c|c|c|c|}
\hline & $\begin{array}{l}\text { Holótipo } \\
\text { NMW } 47206\end{array}$ & $\mathbf{N}$ & Mínimo & Máximo & Média & DP \\
\hline Comprimento Padrão (CP) & 104,0 & 53 & 33,7 & 119,8 & & \\
\hline \multicolumn{7}{|l|}{ Porcentagens do CP } \\
\hline Comprimento da cabeça (CC) & 34,4 & 53 & 32,8 & 45,3 & 36,5 & 2,1 \\
\hline Altura da cabeça & 19,4 & 53 & 15,9 & 27,9 & 20,4 & 2,5 \\
\hline Largura da cabeça & 29,4 & 53 & 27,2 & 38,0 & 31,1 & 2,3 \\
\hline Altura do corpo & 17,8 & 53 & 15,1 & 29,8 & 20,9 & 3,3 \\
\hline Largura do corpo na origem da dorsal & 31,6 & 53 & 26,0 & 41,6 & 30,2 & 2,4 \\
\hline Largura do corpo na origem da anal & 14,9 & 53 & 12,1 & 21,1 & 15,9 & 1,9 \\
\hline Comprimento pré-dorsal & 42,6 & 53 & 36,4 & 49,1 & 43,7 & 2,1 \\
\hline Comprimento pós-dorsal & 31,0 & 53 & 18,7 & 67,5 & 57,3 & 12,9 \\
\hline Comprimento pós-anal & 32,3 & 53 & 24,9 & 35,8 & 30,6 & 2,4 \\
\hline Comprimento do espinho dorsal & 28,1 & 53 & 21,3 & 39,4 & 31,7 & 3,9 \\
\hline Comprimento do espinho peitoral & 28,3 & 53 & 27,0 & 35,9 & 31,3 & 2,1 \\
\hline Comprimento do espinho pélvico & 28,0 & 53 & 22,9 & 32,4 & 28,7 & 2,1 \\
\hline Comprimento da base da dorsal & 28,8 & 53 & 30,2 & 49,3 & 37,9 & 3,4 \\
\hline $\begin{array}{l}\text { Altura do pedúnculo caudal } \\
\text { Porcentagens do CC }\end{array}$ & 12,4 & 53 & 11,6 & 16,5 & 13,8 & 1,3 \\
\hline Comprimento do focinho & 66,0 & 53 & 53,9 & 76,1 & 62,6 & 4,7 \\
\hline Distância interorbital & 37,1 & 53 & 27,4 & 40,4 & 33,4 & 2,8 \\
\hline Diametro horizontal da órbita & 17,1 & 53 & 14,4 & 25,7 & 20,3 & 2,7 \\
\hline Comprimento do dentário & 13,9 & 53 & 8,0 & 16,8 & 11,4 & 2,1 \\
\hline Merísticos & & & & & Moda & \\
\hline Dentes do pré-maxilar & 14 & 53 & 3 & 25 & 8 & \\
\hline Dentes do dentário & 25 & 53 & 8 & 46 & 25 & \\
\hline Raios da nadadeira dorsal & $1+7$ & 53 & $1+7$ & $1+7$ & $1+7$ & \\
\hline Raios da nadadeira peitoral & $1+6$ & 53 & $1+6$ & $1+6$ & $1+6$ & \\
\hline Raios da nadadeira pélvica & $1+5$ & 53 & $1+5$ & $1+5$ & $1+5$ & \\
\hline Raios da nadadeira anal & $1+4$ & 53 & $1+4$ & $1+4$ & $1+4$ & \\
\hline Raios da nadadeira caudal & $\mid+14+1$ & 53 & $1+14+1$ & I+14+I & $\mid+14+1$ & \\
\hline Placas da linha lateral & 22 & 53 & 20 & 22 & 22 & \\
\hline Placas do pedúnculo caudal & 8 & 53 & 7 & 8 & 8 & \\
\hline
\end{tabular}


Tabela 16. Dados morfométricos e merísticos de Spectracanthicus sp, "bola branca", N=32; $\mathrm{DP}=$ desvio padrão.

\begin{tabular}{lccccc}
\hline & N & Mínimo & Máximo & Média & DP \\
\hline Comprimento Padrão (CP) & 32 & 59,32 & 129,03 & 92,50 & - \\
$\quad$ Porcentagens do CP & 32 & 32,74 & 42,06 & 36,03 & 1,89 \\
Comprimento da cabeça (CC) & 32 & 18,07 & 29,14 & 21,74 & 2,63 \\
Altura da cabeça & 32 & 28,07 & 38,17 & 32,47 & 2,08 \\
Largura da cabeça & 32 & 19,50 & 28,47 & 23,00 & 2,67 \\
Altura do corpo & 32 & 27,37 & 38,11 & 31,35 & 2,32 \\
Largura do corpo na origem da dorsal & 32 & 12,66 & 22,75 & 16,78 & 2,22 \\
Largura do corpo na origem da anal & 32 & 38,67 & 49,35 & 43,45 & 2,32 \\
Comprimento pré-dorsal & 32 & 19,22 & 27,72 & 22,67 & 1,95 \\
Comprimento pós-dorsal & 32 & 29,94 & 35,22 & 32,19 & 1,37 \\
Comprimento pós-anal & 32 & 28,04 & 36,67 & 32,50 & 2,96 \\
Comprimento do espinho dorsal & 32 & 29,21 & 35,85 & 32,61 & 1,87 \\
Comprimento do espinho peitoral & 32 & 23,63 & 33,63 & 29,05 & 2,50 \\
Comprimento do espinho pélvico & 32 & 20,49 & 41,73 & 34,20 & 4,38 \\
Comprimento da base da dorsal & 32 & 14,50 & 20,76 & 16,83 & 1,69 \\
Altura do pedúnculo caudal & & & & & \\
$\quad$ Porcentagens do CC & 32 & 29,61 & 73,90 & 60,88 & 9,24 \\
Comprimento do focinho & 32 & 14,73 & 36,17 & 30,88 & 4,81 \\
Distância interorbital & 32 & 6,32 & 28,78 & 17,33 & 4,46 \\
Diametro horizontal da órbita & 32 & 6,91 & 17,57 & 14,06 & 2,42 \\
Comprimento do dentário & & & & & \\
& & & & Moda & \\
$\quad$ Merísticos & 32 & 6 & 25 & 14 & - \\
Dentes do pré-maxilar & 32 & 19 & 43 & 30 & - \\
Dentes do dentário & 32 & $1+7$ & $1+7$ & $1+7$ & - \\
Raios da nadadeira dorsal & 32 & $1+6$ & $1+6$ & $1+6$ & - \\
Raios da nadadeira peitoral & 32 & $1+5$ & $1+5$ & $1+5$ & - \\
Raios da nadadeira pélvica & 32 & $1+4$ & $1+4$ & $1+4$ & - \\
Raios da nadadeira anal & 32 & $1+14+1$ & $1+14+1$ & $1+14+1$ & - \\
Raios da nadadeira caudal & 32 & 21 & 25 & 22 & - \\
Placas da linha lateral & 32 & 7 & 8 & 7 & - \\
Placas do pedúnculo caudal & & & & &
\end{tabular}


Tabela 17. Dados morfométricos e merísticos de Spectracanthicus sp. "Tocantins". N= número de exemplares, $\mathrm{DP}=$ desvio padrão.

\begin{tabular}{|c|c|c|c|c|c|}
\hline & $\mathbf{N}$ & Mínimo & Máximo & Média & DP \\
\hline Comprimento Padrão (CP) & 31 & 57,65 & 93,25 & 72,51 & - \\
\hline \multicolumn{6}{|l|}{ Porcentagens do CP } \\
\hline Comprimento da cabeça (CC) & 31 & 32,39 & 37,35 & 35,42 & 1,43 \\
\hline Altura da cabeça & 31 & 17,41 & 28,12 & 20,47 & 2,24 \\
\hline Largura da cabeça & 31 & 30,24 & 34,79 & 32,00 & 1,15 \\
\hline Altura do corpo & 31 & 17,27 & 26,38 & 20,58 & 2,31 \\
\hline Largura do corpo na origem da dorsal & 31 & 25,93 & 31,87 & 28,14 & 1,54 \\
\hline Largura do corpo na origem da anal & 31 & 14,63 & 19,13 & 16,08 & 1,26 \\
\hline Comprimento pré-dorsal & 31 & 42,33 & 48,83 & 43,87 & 1,55 \\
\hline Comprimento pós-dorsal & 31 & 16,28 & 28,04 & 22,07 & 2,90 \\
\hline Comprimento pós-anal & 31 & 25,13 & 35,41 & 29,62 & 3,22 \\
\hline Comprimento do espinho dorsal & 31 & 25,48 & 31,76 & 28,75 & 1,72 \\
\hline Comprimento do espinho peitoral & 31 & 27,29 & 31,94 & 29,44 & 1,25 \\
\hline Comprimento do espinho pélvico & 31 & 24,18 & 28,74 & 26,79 & 1,25 \\
\hline Comprimento da base da dorsal & 31 & 30,56 & 36,19 & 33,29 & 1,66 \\
\hline Altura do pedúnculo caudal & 31 & 13,95 & 18,04 & 14,87 & 1,04 \\
\hline \multicolumn{6}{|l|}{ Porcentagens do $\mathrm{CC}$} \\
\hline Comprimento do focinho & 31 & 59,27 & 70,79 & 63,46 & 2,56 \\
\hline Distância interorbital & 31 & 31,68 & 37,69 & 34,80 & 1,36 \\
\hline Diâmetro horizontal da órbita & 31 & 15,44 & 20,30 & 17,94 & 1,23 \\
\hline Comprimento do dentário & 31 & 8,63 & 15,76 & 11,48 & 2,11 \\
\hline Merísticos & & & & Moda & \\
\hline Dentes do pré-maxilar & 31 & 5 & 8 & 6 & - \\
\hline Dentes do dentário & 31 & 8 & 16 & 12 & - \\
\hline Raios da nadadeira dorsal & 31 & $1+7$ & $1+7$ & $1+7$ & - \\
\hline Raios da nadadeira peitoral & 31 & $1+6$ & $1+6$ & $1+6$ & - \\
\hline Raios da nadadeira pélvica & 31 & $1+5$ & $1+5$ & $1+5$ & - \\
\hline Raios da nadadeira anal & 31 & $1+4$ & $1+4$ & $1+4$ & - \\
\hline Raios da nadadeira caudal & 31 & $\mid+14+1$ & $|+14+|$ & $\mid+14+1$ & - \\
\hline Placas da linha lateral & 31 & 20 & 24 & 23 & - \\
\hline Placas do pedúnculo caudal & 31 & 7 & 8 & 7 & - \\
\hline
\end{tabular}


Tabela 18. Dados morfométricos e merísticos de Spectracanthicus sp. "Tapajós”, N= número de exemplares, $\mathrm{DP}=$ desvio padrão.

\begin{tabular}{|c|c|c|c|c|c|}
\hline & $\mathbf{N}$ & Mínimo & Máximo & Média & DP \\
\hline Comprimento Padrão (CP) & 11 & 38,23 & 82,24 & 68,96 & - \\
\hline Porcentagens do CP & 11 & & & & \\
\hline Comprimento da cabeça (CC) & 11 & 34,07 & 36,22 & 35,38 & 0,72 \\
\hline Altura da cabeça & 11 & 16,64 & 29,44 & 20,38 & 3,14 \\
\hline Largura da cabeça & 11 & 18,56 & 33,77 & 31,00 & 4,13 \\
\hline Altura do corpo & 11 & 16,56 & 23,08 & 20,14 & 1,92 \\
\hline Largura do corpo na origem da dorsal & 11 & 24,88 & 31,40 & 28,33 & 2,13 \\
\hline Largura do corpo na origem da anal & 11 & 12,45 & 16,78 & 13,99 & 1,22 \\
\hline Comprimento pré-dorsal & 11 & 39,84 & 44,33 & 42,12 & 1,04 \\
\hline Comprimento pós-dorsal & 11 & 20,18 & 35,98 & 25,67 & 3,80 \\
\hline Comprimento pós-anal & 11 & 24,44 & 32,78 & 28,15 & 2,00 \\
\hline Comprimento do espinho dorsal & 11 & 23,02 & 31,83 & 28,52 & 2,63 \\
\hline Comprimento do espinho peitoral & 11 & 27,76 & 35,05 & 29,28 & 1,95 \\
\hline Comprimento do espinho pélvico & 11 & 24,36 & 27,75 & 26,05 & 0,91 \\
\hline Comprimento da base da dorsal & 11 & 27,54 & 34,06 & 31,34 & 2,30 \\
\hline Altura do pedúnculo caudal & 11 & 12,71 & 14,28 & 13,47 & 0,52 \\
\hline \multicolumn{6}{|l|}{ Porcentagens do CC } \\
\hline Comprimento do focinho & 11 & 55,18 & 63,65 & 60,02 & 2,75 \\
\hline Distância interorbital & 11 & 29,97 & 38,22 & 33,37 & 2,06 \\
\hline Diâmetro horizontal da órbita & 11 & 13,65 & 16,22 & 14,72 & 0,65 \\
\hline Comprimento do dentário & 11 & 8,07 & 12,76 & 10,90 & 1,46 \\
\hline Merísticos & & & & Moda & \\
\hline Dentes do pré-maxilar & 11 & 6 & 22 & 12 & - \\
\hline Dentes do dentário & 11 & 8 & 30 & 18 & - \\
\hline Raios da nadadeira dorsal & 11 & $1+7$ & $1+7$ & $1+7$ & - \\
\hline Raios da nadadeira peitoral & 11 & $1+6$ & $1+6$ & $1+6$ & - \\
\hline Raios da nadadeira pélvica & 11 & $1+5$ & $1+5$ & $1+5$ & - \\
\hline Raios da nadadeira anal & 11 & $1+4$ & $1+4$ & $1+4$ & - \\
\hline Raios da nadadeira caudal & 11 & $|+14+|$ & $|+14+|$ & $1+14+1$ & - \\
\hline Placas da linha lateral & 11 & 21 & 23 & 21 & - \\
\hline Placas do pedúnculo caudal & 11 & 7 & 8 & 7 & - \\
\hline
\end{tabular}




\section{APÊNDICE}

\section{Matriz de dados}

Ancistrus taunayi 0100100000000000000000000000010000010000001000000000210021100000000000000010 010010001200100000010001010100000000000000000

Parancistrus aurantiacus 1000000010000000000010100100112101000010001101100110310011101000000000010001 010010101200001000000000000000110101000000100

Parancistrus nudiventris 1000000010000000000000100100112101000010001101100110310011101000000000010001 010010001200001100000001010000110101000000100

Baryancistrus sp. "Xingu" $110011001001010000000010010011 ? ? 00000000001000000000310021101000000010010001$ 020000010101110000000001010010100001000000000

Hemiancistrus cerrado $100011001002010000001010000000 ? ? 00110000001001000000110011101000000010100110$ 010010000100101102010001100000101001001000000

Pseudancistrus brevispinis

2000100010020100000000100000012101000000001000000010310011101000000000000010 010010211200000001010001010000101001000000000

Hypancistrus sp.

1000100010020100010000100001002101100000001000100110310011100000000000010000 $000010000111101101000001001 ? 00111101000000000$

Peckoltia vittata $00001001000200000001101001001211010001101010001101103100111100000000 ? 0000010$ $000010001201102001100001001 ? 01111101011000000$

Panaque gr. nigrolineatus $01101100010100000001001001001011011100201111111101120001111111110101 ? 0000010$ $000010100111002001011001001 ? 00110101020001001$

Panaqolus sp.

0110110000010000000000100100012101110020101011110112100111111000010011110010 $000010000101001101000001001 ? 00110101000000001$

Scobinancistrus aureatus 
0010110120010000000000100110112101000000101111110112200211111000010000000110 010010101101001001100001010000120101000000001

Scobinancistrus pariolispos

0010110120010000000000100110112101100100101111110112200211111000010000000110 010010101101001001000001010000120101000000001

Leporacanthicus galaxias

2010101110021101211110001011020010011100002011111321211011111110000100010110 120010001101100101010001010000110210101100001

Leporacanthicus joselimai

2010101110021101210100001011020010011100002011111321211011111110010100010110 120010001101100101011001100010110210101100001

Leporacanthicus heterodon

2010101110021101211100001011020010011100002011111321211011111110010000010010 120010001101100102011001100000110210101100001

Leporacanthicus triactis

2010101110021101211111001011020010011100002011111321211011111110000100010110 120010001101100111011001100001110210101100001

Acanthicus adonis

$210011002111001000000 ? 01001011 ? ? 01010000101001000000310021110011101010000020$ 121010101111002102000111010000201001020101010

Acanthicus hystrix

2100110021110010000010010010120001010000101001000000310021110011101010000120 121010101101002101100110000100201001020101010

Megalancistrus parananus

2000110121110110000010010010110001111001100001100111311011111001101000011110 120101211201102101100001100000101101000101001

Megalancistrus barrae

200011002111011000001??????????010110011000011001113110111110011010000111101

20001211201012100100001000100101101000101001

Pseudacanthicus spinosus

2000100110011001110110000010110001101101001001111211311011110000001110110000

120000001101102100000101100000110102101100001

Pseudacanthicus leopardus

2000110120011001110110100010110001101101001001111211311011110000001110110010

$1200000010 ? 1102100000101100001110102101100001$ 
Pseudacanthicus sp. "Tapajós"

2000100010000001100110100010120001101101001001111211311011110000001110110010 120000000101002100000101010000111102101100001

Pseudacanthicus sp. "açacu vermelho"

$2000110010010001110 ? 10100010120001101100001001111211211011110000000010100110$ 120000001101011100000101100001110102101100001

Pseudacanthicus sp. "Tocantins"

2001100010000000000111000010120001101110001001111211211011110000001010100110 110010001101002100000101010000100102101010001

Pseudacanthicus sp."aba laranja" $200011001001010111001 ? 100010 ? 20001101110001001111211211011110000000011100110$ 110010001101100100000101100001110102101100001

Pseudacanthicus sp. "açacu preto"

2001110020010001100110000010110001101100000001111211311011110000000000010010 $110000001111102100000100000 ? 00110102101100001$

Pseudacanthicus sp. "Aripuanã"

2001100110010101110011000010120001101110000001111211311011110000001010110020 110100001101102100000101100100100102101010001

Spectracanthicus murinus

1000110110020100000001100010112101110000011001111111300000011000010001010011 110010000101102010010001010010110101101000001

Spectracanthicus punctatissimus

2000110110010100000001100110112101010010011001110111310011111000010000000001 100010001101101000110001010010100101101000001

Spectracanthicus sp. "bola branca"

2000110110010100000001100110122101010000011001110111310011111000000000010001 100000001101102000110001010000100101101000001

Spectracanthicus sp. "Tocantins"

2000110110010100000001100110122101010000011001110111310011110000010001010011 110000001201102101100001010000110101101000001

Spectracanthicus sp. "Tapajós"

2001110100000000000001100110011101010010001001110110310011111000010010010001

$100010000201101100010000100 ? 00110101101000001$ 


\section{Lista de sinapomorfias}

Leporacanthicus galaxias

102 (1): com manchas ou pontos claros.

Leporacanthicus joselimai

19 (0): fenestras do ante-rohial ausentes ou pequenas e irregulares.

105 (1): nadadeiras com bordas brancas.

Leporacanthicus heterodon

68 (0): processo transverso do CCW não ou moderadamente perfurado distalmente.

74 (0): com 26 a 29 vértebras contando as do CCW e a placa hipural.

94 (2): hipurapófise alta.

Leporacanthicus triactis

22 (1): basibranquial cartilaginoso.

93 (1): três raios ramificados da anal.

106 (1): nadadeiras alaranjadas.

Acanthicus adonis

21 (0): hipo-hial curto.

87 (1): fenestra anterior a seção cartilaginosa do basipterígio alongada, aproximadamente elíptica.

94 (2): hipurapófise alta.

102 (1): com manchas ou pontos claros.

\section{Acanthicus hystrix}

30 (2): hipo-branquial 1 bastante alongado.

100 (0): coloração geral do corpo uniforme.

104 (1): manchas no corpo irregulares e/ou vermiculadas. 


\section{Megalancistrus parananus}

35 (1): hiomandibular com. margem anterior suturada ao metapterigóide ao longo de todo comprimento.

80 (1): área ventral de contato entre o coracóide e o cleitrum grande.

101 (1): com manchas ou pontos escuros.

Megalancistrus barrae

90 (1): crista na base interna do processo posterior do basipterígio bem desenvolvida.

94 (0): hipurapófise baixa.

104 (1): manchas no corpo irregulares e/ou vermiculadas.

Pseudacanthicus spinosus

75 (0): crista lateral à penúltima vértebra ausente.

\section{Pseudacanthicus leopardus}

6 (1): contato do etmóide lateral com o metapterigóide posterior e anterior.

9 (2): nasal retangular, fino e alongado.

86 (0): fenestra anterior à seção cartilaginosa do basipterígio ausente.

106 (1): nadadeiras alaranjadas.

\section{Pseudacanthicus sp. "Curuá Una e Tapajós"}

12 (0): extremidade anterior do pterótico-supracleitro sem contato com a margem posterior da órbita.

85 (0): área cartilaginosa do basipterígio curta.

89 (0): crista ventral do basipterígio reta ou arredondada.

102 (1): com manchas ou pontos claros.

109 (1): papila bucal central bem desenvolvida.

Pseudacanthicus sp. "açacu vermelho"

89 (0): crista ventral do basipterígio reta ou arredondada.

90 (1): crista na base interna do processo posterior do basipterígio bem desenvolvida. 
Pseudacanthicus sp. "Tocantins"

12 (0): processo anterior do pterótico-supracleitro sem contato com a margem posterior da órbita.

16 (0): extremidade posterior do supra-occipital com projeção curta.

17 (0): crista na extremidade posterior do supra-occipital ausente.

53 (2): cúspide lateral pequena.

72 (0): com 12 a 14 vértebras a partir do primeiro espinho neural, não incluindo a placa hipural.

81 (1): área posterior de contato entre o cleitro e o coracóide expandida ventralmente.

89 (0): crista ventral do basipterígio reta ou arredondada.

102 (1): com manchas ou pontos claros.

Pseudacanthicus sp. "aba laranja"

14 (1): contato do esfenótico com o IO6 ausente.

39 (1): face lateral do canal metapterigóide triangular.

70 (1): processo lateral do processo ventral do centro complexo bastante desenvolvido.

81 (1): área posterior de contato entre o cleitro e o coracóide expandida ventralmente

Pseudacanthicus sp. "açacu preto"

4 (1): etmóide lateral retangular, expansão lateral curta ou ausente.

9 (2): nasal retangular, fino e alongado.

43 (0): processo anterior do metapterigóide sem projeção.

87 (1): fenestra anterior a seção cartilaginosa do basipterígio alongada, aproximadamente retangular.

100 (1): com coloração uniforme.

Pseudacanthicus sp. "Aripuanã"

8 (1): disco do mesetmóide se estendendo além do corpo principal.

14 (0): contato do esfenótico com o IO6 ausente.

20 (0): forame da artéria mandibular aferente (fma) pequeno.

43 (0): processo anterior do metapterigóide sem projeção. 
75 (2): crista lateral à penúltima vértebra bastante desenvolvida.

80 (1): área de contato ventral entre o coracóide e o cleitrum grande.

104 (1): padrão de manchas no corpo irregulares e vermiculadas.

\section{Spectracanthicus punctatissimus}

72 (0): com 12 a 14 vétebras a partir do primeiro espinho neural, não incluindo a placa hipural. 105 (1): nadadeiras com bordas brancas.

Spectracanthicus sp. "bola branca"

66 (0): margem distal do processo transverso do centro complexo arredondada

Spectracanthicus sp. "Tocantins"

61 (0): IO4 bastante contato com a órbita através de sua extremidade posterior.

86 (2): fenestra anterior à seção cartilaginosa do basipterígio grande.

94 (1): hipurapófise média.

96 (0): espaço entre o lobo hipural inferior e o último espinho hemal ausente ou pequeno.

Spectracanthicus sp. "Tapajós"

4 (1): etmóide lateral retangular com expansão lateral curta ou ausente.

9 (0): nasal quadrangular, moderadamente alongado.

12 (0): processo anterior do pterótico-supracleitro sem contato com a margem posterior da órbita.

29 (0): expansão laminar posterior do EB4 ausente ou bastante curta.

69 (1): processo ventral do VCW aproximadamente retangular.

85 (0): área cartilaginosa do basipterígio curta.

86 (2): fenestra anterior à seção cartilaginosa grande.

100 (0): coloração geral do corpo uniforme.

101 (1): com manchas ou pontos escuros presentes.

\section{Spectracanthicus murinus}

1 (1): frontal contatando a órbita somente em um pequeno ponto lateral.

12 (2): processo anterior do pterótico-supracleitro com grande contato com a margem posterior da órbita 
26 (0): expansão laminar do EB1 fina e bastante curta.

35 (1): margem anterior do hiomandibular suturada ao metapterigóide ao longo de todo comprimento.

49 (0): maxilar largo e arredondado distalmente.

54 (0): dentes curtos.

57 (0): opérculo triangular.

58 (0): mobilidade das placas operculares ausente.

59 (0): odontódeos desenvolvidos no opérculo ausente.

85 (0): área cartilaginosa do basipterígio curta.

93 (1): três raios ramificados na nadadeira anal.

105 (1): bordas brancas nas nadadeiras presente

\section{Clado 45: Leporacanthicus}

3 (1): etmóide lateral alongado.

6 (0): contato posterior do etmóide lateral com o metapterigóide.

7 (1): mesetmóide bastante alongado.

8 (1): disco do mesetmóide estendido além do corpo principal.

12 (2): processo anterior do pterótico-supracleitro com grande contato com a margem posterior da órbita

13 (1): esfenótico formando uma quilha de odontódeos conspícuos em sua porção lateroposterior.

14 (1): contato do esfenótico com o IO6 ausente.

17 (2): crista na extremidade posterior do parieto-supra-occipital pontuda e arredondada.

19 (1): uma ou duas fenestras grandes no ântero-hial localizadas dentro de uma fossa.

25 (1): odontódeos no CB5 bastante desenvolvidos.

28 (1): processo anterior do EB4 desenvolvido.

29 (0): expansão laminar posterior do EB4 ausente ou bastante curta.

33 (1): placa faríngea superior arredondada com dentes distribuídos por toda a superfície.

34 (0): placa faríngea superior sem invaginação.

43 (2): processo anterior do metapterigóide com duas projeções.

45 (1): côndilo de articulação do quadrado com o angulo-articular grosso, redondo.

50 (2): pré-maxilar bastante estreito e alongado. 
51 (2): no máximo quatro dentes no pré-maxilar.

53 (2): cúspide lateral pequena.

61 (1): IO6 forma toda a borda ventral da órbita.

63 (1): linha lateral ultrapassa a placa hipural.

68 (1):processo transverso perfurado distalmente com forames largos.

91 (0): largura das expansões laminares do processo anterolateral do basipterígio com a porção dorsal mais larga que a ventral.

96 (1): grande espaço entre o lobo hipural inferior e o último espinho hemal.

110 (2): forma do lábio com o comprimento maior que a largura.

111 (1): filamentos labiais em forma de franja.

Clado 46: Leporacanthicus e Pseudacanthicus

16 (1): extremidade posterior do parieto-supra-occipital com projeção alongada e bastante pontuda.

17 (1): crista na extremidade posterior do parieto-supra-occipital em forma de "V".

18 (0): ântero-hial alargado.

20 (1): forame da artéria mandibular aferente grande.

30 (2): hipo-hial bastante alongado.

38 (1): face de articulação do hiomandibular com o pró-ótico alongada.

49 (1): maxilar largo e arredondado distalmente.

50 (1): pré-maxilar estreito e alongado.

Clado 47: grupo Acanthicus.

8 (0): disco do mesetmóide anterior ao corpo principal.

21 (1): hipo-hial alongado.

23 (0): processo acessório do CB1 cerca da mesma largura do CB1.

26 (0): expansão laminar na extremidade distal do EB1 fina e bastante curta.

31 (0): inter-hial no hiomandibular, sem contato com a área de cartilagem com o quadrado.

32 (0): inter-hial pequeno.

37 (1): crista do hiomandibular contínua a do quadrado.

55 (1): extremidade distal dos dentes bastante curvada 
74 (1): 30 a 32 vértebras, incluindo a placa hipural.

78 (2): processo posterior do coracóide com extremidade distal pontiaguda.

116 (1): quilhas bastante desenvolvidas

Clado 48: grupo Acanthicus e Spectracanthicus

1 (2): frontal com grande contato com a órbita lateralmente.

27 (1): superfície medial do EB1 formando quilha.

39 (0): Face lateral do canal metapterigóide arredondada.

36 (1): hiomandibular defletido além da margem posterior

77 (1): i+8 ou mais raios dorsais.

113 (1): 4 ou mais placas pré-dorsais.

Clado 49: Leporacanthicus heterodon e L. joselimai

21 (0): hipo-hial curto.

66 (1): margem distal do processo transverso do centro complexo pontuda.

Clado 50: Leporacanthicus triactis, L. heterodon e L. joselimai.

97 (1): fenestra no lobo hipural inferior presente.

101 (1): coloração com manchas ou pontos escuros.

\section{Clado 51: Acanthicus}

2 (1): margem anterior do frontal alongada, margem anterior ultrapassa a metade do comprimento da narina.

47 (0): anglo dos dentários oblíquo.

50 (0): pré-maxilar largo e curto.

51 (0): dentes numerosos (mais de 25 em cada pré-maxilar).

57 (1): opérculo em forma de barra longitudinal (Ancistrus).

61 (1): IO4 com bastante contato com a órbita através de sua extremidade posterior.

63 (1): linha lateral ultrapassa a placa hipural.

69 (1): processo ventral do CCW aproximadamente retangular.

72 (0): 12 a 14 vértebras a partir do primeiro espinho neural, não incluindo a placa hipural. 
75 (2): crista lateral à penúltima vértebra (contando a placa hipural) bastante desenvolvida.

79 (1): processo posterior do coracóide alongado.

98 (1): filamentos caudais presente.

99 (0): nadadeira adiposa ausente.

107 (2): focinho totalmente coberto por placas.

110 (0): forma do lábio com a largura maior que o comprimento

114 (2): presença de placas abdominais em todo o abdome.

120 (1): espinhos das nadadeiras peitorais quando adpressos alcançam quase o final da extensão do raio indiviso da nadadeira pélvica.

121 (0): canais urogenital e anal com duas saídas separadas.

Clado 52: Acanthicus e Megalancistrus

9 (2): nasal retangular, fino e alongado.

10 (1): pterótico-supracleitro bastante expandido, ultrapassando a inserção da pélvica.

11 (1): perfurações no pterótico-supracleitro grandes.

15 (1): parieto-supra-occipital alongado.

24 (1): CB5 bastante alargado.

41 (1): superfície de articulação entre o etimóde lateral totalmente conectada à parede lateral do metapterigóide por uma ponte reta.

48 (0): maxilar angulado dorsalmente a levemente angulado ventralmente.

64 (1): centro complexo de Weber alongado.

65 (1): margem distal do processo transverso do centro complexo larga, dilatada distalmente.

67 (1): extremidade distal do processo transverso do centro complexo de Weber não conectando o pterótico-supracleitro.

108 (0): prefil dorsal do focinho arredondado.

109 (1): papila bucal central bem desenvolvida

118 (1): bexiga natatória bastante expandida, alcançando ou ultrapassando a sexta vértebra.

Clado 53: Megalancistrus

14 (0): contato do IO6 com o esfenótico ausente.

40 (1): face lateral do canal metapterigóide baixa. 
43 (0): processo anterior do metapterigóide sem projeção.

73 (1): 10-11 espinhos neurais bífidos.

81 (0): área de contato posterior entre o cleitro e o coracóide reta.

82 (1): forma da margem anterior do cleitro arredondada, com proeminência pontuda discreta.

84 (1): processo ântero-lateral do basipterigio largo em toda sua extensão.

86 (2): fenestra anterior à seção cartilaginosa do basipterígio grande.

Clado 54: Pseudacanthicus leopardus e P. spinosus

8 (1): disco do mesetmóide estendido além do corpo principal.

13 (1): esfenótico formando uma quilha de odontódes conspícuos em sua porção láteroposterior.

30 (1): primeiro hipo-branquial moderadamente alongado.

Clado 55: Pseudacanthicus sp. "Curuá-Una", P. leopardus e P. spinosus

40 (1): face lateral do canal metapterigóide baixa.

68 (1): processo transverso perfurado distalmente com forames largos.

78 (2): Extremidade distal do processo posterior do coracóide bem mais fina que a proximal.

Clado 56: Pseudacanthicus sp. "Aripuanã", Pseudacanthicus sp. "Tocantins", Pseudacanthicus sp. "Curuá-Una”, P. leopardus e P. spinosus

6 (0): contato posterior do etmóide lateral com o metapterigóide.

67 (1): extremidade distal do processo transverso do centro complexo de Weber não conectando o pterótico-supracleitro.

Clado 57: Pseudacanthicus sp. "aba laranja", Pseudacanthicus sp. "aba vermelha", Pseudacanthicus sp. “Aripuanã", Pseudacanthicus sp. "Tocantins”, Pseudacanthicus sp. “Curuá-Una”, P. leopardus e P. spinosus

23 (1): processo acessório do CB1 cerca de duas vezes o tamanho do CB1.

69 (1): processo ventral do CCW aproximadamente retangular.

71 (1): processo dorsal e corpo principal do pvcc alongados.

101 (1): coloração com manchas ou pontos pretos. 
Clado 58: Pseudacanthicus

35 (1): margem anterior do hiomandibular suturada ao metapterigóide ao longo de todo comprimento.

36 (0): hiomandibular não defletido além da margem posterior.

61 (0): grande contato do IO4 com a órbita através de sua extremidade posterior.

74 (0): 26-29 vértebras, incluindo a placa hipural.

81 (0): área de contato posterior entre o cleitro e o coracóide reta.

94 (0): hipurapófise baixa.

98 (1): filamentos caudais presentes.

112 (2): área posterior ao pterótico-supracleitro com uma ou duas placas pequenas

Clado 59: Pseudacanthicus "aba laranja" e Pseudacanthicus "açacu vermelho".

20 (0): forame da artéria mandibular aferente pequeno.

53 (2): cúspide lateral pequena.

72 (0): 12 a 14 vértebras a partir do primeiro espinho neural, não incluindo a placa hipural.

74 (1): 30-32 vértebras incluindo as do CCW e a placa hipural.

91 (1): Largura das expansões laminares do processo ântero-lateral simétricas.

106 (1): nadadeiras alaranjadas.

Clado 60: Pseudacanthicus sp. "Aripuanã" e Pseudacanthicus sp. "Tocantins"

4 (1): etmóide lateral retangular com expansão lateral curta ou ausente.

22 (1): segundo basibranquial cartilaginoso.

23 (0) Processo acessório do primeiro cerato-branquial cerca da mesma largura que CB1.

39 (1): face lateral do canal metapterigóide triangular.

108 (0): perfil dorsal do focinho arredondado.

116 (0): quilhas ausentes ou moderadas.

117 (1): perfil pós-dorsal do corpo robusto.

Clado 61: Spectracanthicus (exceto Spectracanthicus sp.”Tapajós”) 
14 (1): contato do esfenótico com o IO6 ausente.

31 (2) inter-hial em contato com o hiomandibular e o quadrado (ambígua).

42 (1): processo anterior do metapterigóide alongado.

92 (0): látero-pterígio grande, ultrapassando o (pal) (ambígua).

95 (1): hipurapófise aproximadamente quadrada (ambígua).

102 (1): coloração com manchas ou pontos claros

108 (0): perfil dorsal do focinho arredondado (ambígua).

\section{Clado 62: Spectracanthicus}

22 (1): segundo basibranquial cartilaginoso.

66 (1): margem distal do processo transverso do centro complexo pontuda.

75 (0): crista lateral à penúltima vértebra, incluindo a placa hipural, ausente.

76 (1): membrana da nadadeira dorsal expandida e conectada à adiposa.

94 (0): hipurapófise baixa.

96 (1): espaço entre o lobo hipural inferior e o último espinho hemal grande.

Clado 63: Spectracanthicus murinus e Spectracanthicus sp. "Tocantins"

70 (1): processo lateral do processo ventral do centro complexo bastante desenvolvido

75 (1): crista lateral à penúltima vértebra, incluindo a placa hipural pouco desenvolvida (ambígua)

78 (1): processo posterior do coracóide com as extremidades distal e proximal com mais ou menos a mesma largura.

108 (1): perfil dorsal do focinho pontudo (ambígua). 